Aus dem Institut für Neuro- und Sinnesphysiologie

(Prof. Dr. rer. nat. S. O. Rizzoli)

im Zentrum Physiologie und Pathophysiologie

der Medizinischen Fakultät der Universität Göttingen

\title{
Einfluss der Rett-Syndrom-assoziierten MeCP2-Defizienz auf die DNA-Oxidation, strukturelle und inflammatorische Marker in zerebralem Gewebe
}

\author{
INAUGURAL-DISSERTATION \\ zur Erlangung des Doktorgrades \\ für Zahnmedizin \\ der Medizinischen Fakultät der \\ Georg-August-Universität zu Göttingen
}

vorgelegt von

Ann-Kathrin Schuster

aus

Lüneburg

Göttingen 2021 
Dekan:

\section{Betreuungsausschuss}

Betreuer/in

Ko-Betreuer/in:

\section{Prüfungskommission}

Referent/in

Ko-Referent/in:

Drittreferent/in:

Datum der mündlichen Prüfung:
Prof. Dr. med. W. Brück

Prof. Dr. rer. nat. M. Müller

Prof. Dr. med. I. Bogeski

Prof. Dr. rer. nat. M. Müller 
Hiermit erkläre ich, die Dissertation mit dem Titel "Einfluss der Rett-Syndrom-assoziierten MeCP2-Defizienz auf die DNAOxidation, strukturelle und inflammatorische Marker in zerebralem Gewebe" eigenständig angefertigt und keine anderen als die von mir angegebenen Quellen und Hilfsmittel verwendet zu haben.

Göttingen, den 


\section{Inhaltsverzeichnis}

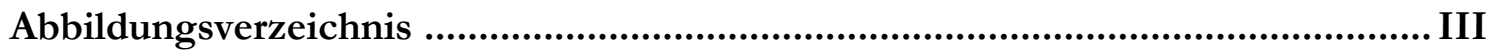

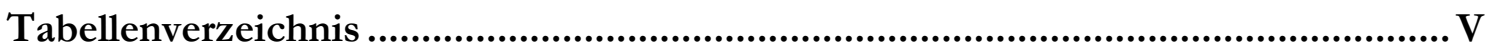

Abkürzungsverzeichnis............................................................................................

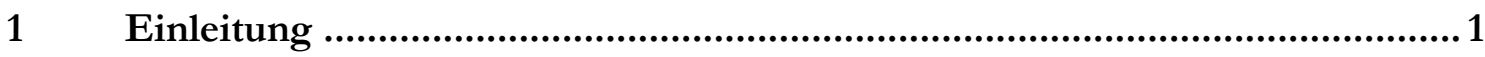

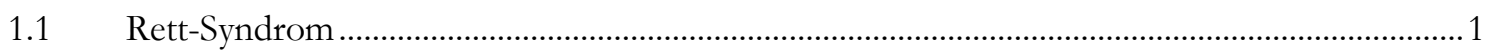

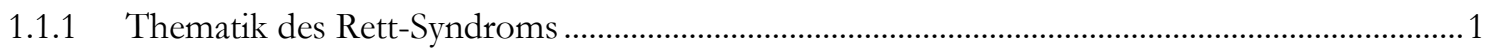

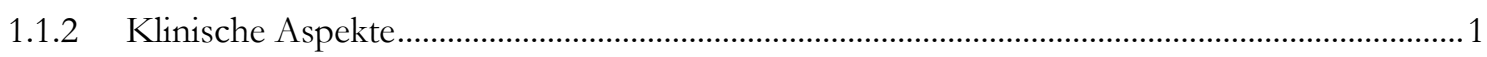

1.1.3 Genetische Ursachen und Diversität der Phänotypen ............................................................... 3

1.1.4 Neuronale und gliale Zellen im Rett-Syndrom.......................................................................

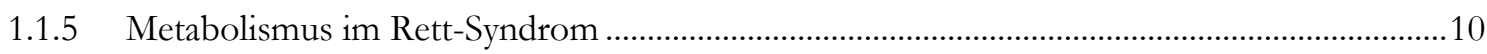

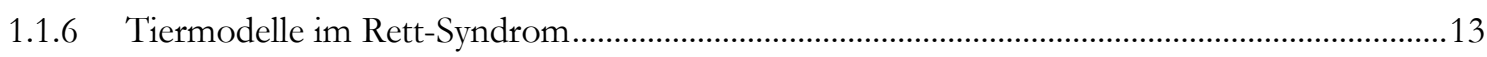

1.1.7 Therapieansätze und Prognose ............................................................................................

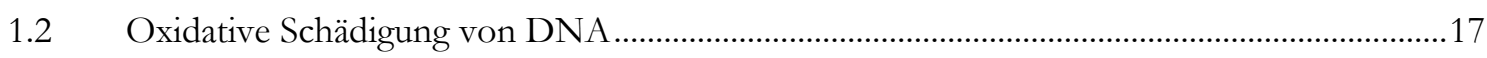

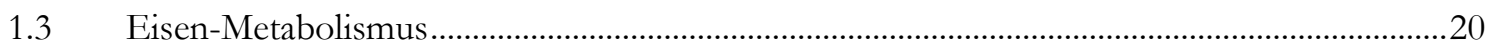

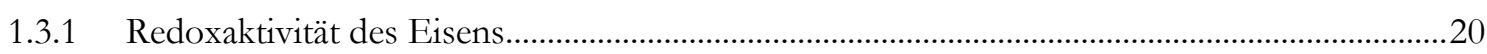

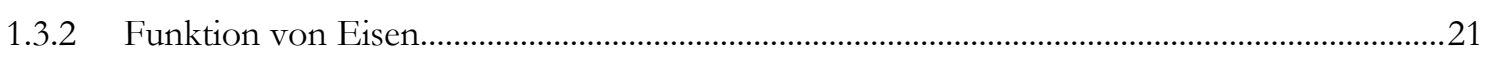

1.3.3 Transport und Speicherung von Eisen im Gehirn...................................................................

1.3.4 Eisen im Zusammenhang mit neuronalen Erkrankungen...................................................23

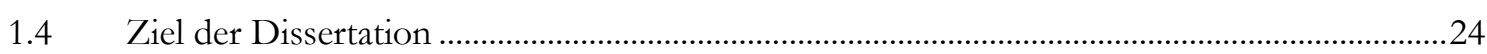

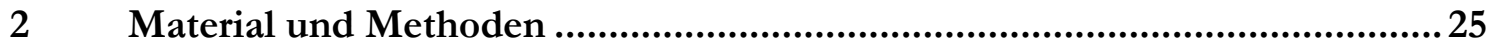

$2.1 \quad$ Die Mecp2-Knockout-Maus als Modell für das Rett-Syndrom...................................................27

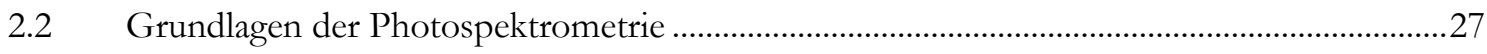

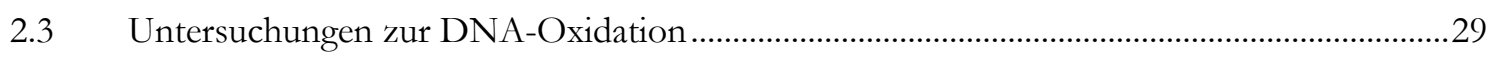

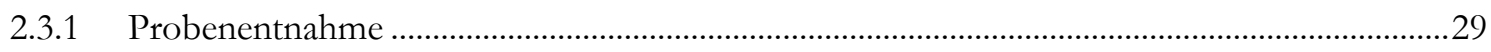

2.3.2 Regionsspezifische Bewertung der Analyse der mitochondrialen $\mathrm{H}_{2} \mathrm{O}_{2}$-Freisetzung ............29

2.3.3 Gewebelysierung zur Quantifizierung der DNA-Oxidation .....................................................30

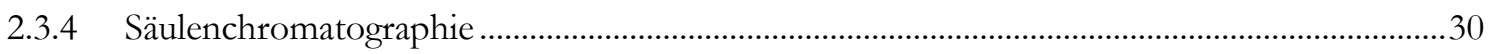

2.3.5 Spektralphotometrische Bestimmung der DNA-Konzentration ..............................................31

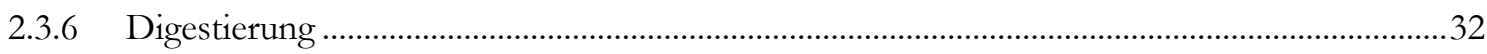

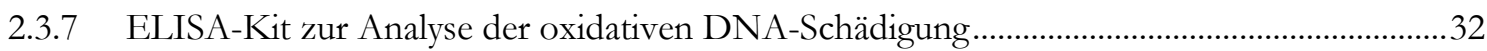

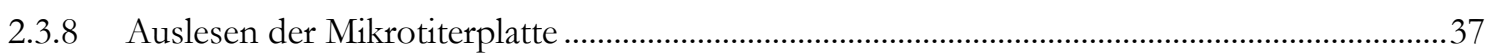

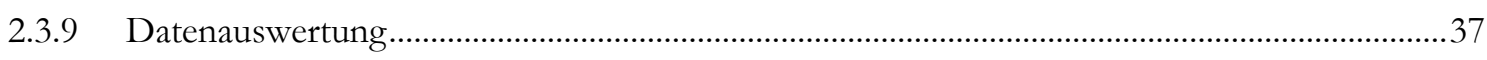

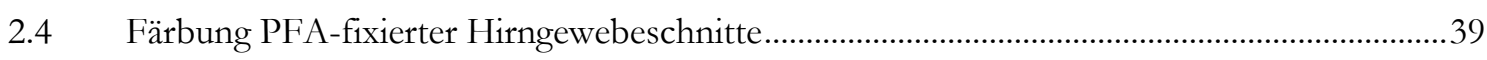

2.4.1 Herstellung von Hirnschnitten mit immunhistochemischer Färbung......................................39

2.4.2 Herstellung von Hirnschnitten mit histochemischer Färbung....................................................40

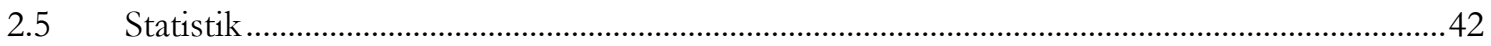




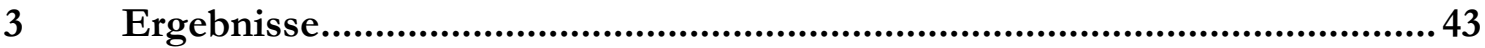

3.1 Auswahl des Hirngewebes anhand der $\mathrm{H}_{2} \mathrm{O}_{2}$-Freisetzung .....................................................43

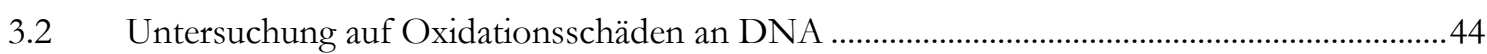

3.2.1 Ergebnisse der DNAox-Bestimmung bei normal gefütterten Wildtyp-Tieren .........................45

3.2.2 Datenübersicht der oxidativen DNA-Schädigung bei normal gefütterten Rett-Mäusen........46

3.2.3 Übersicht der ermittelten oxG-Anteile bei antioxidativ gefütterten Wildtypen........................48

3.2.4 Analyse der oxidativen DNA-Schädigung bei Rett-Tieren nach Fütterung von mit Antioxidantien angereichertem Futter .........................................................................................4

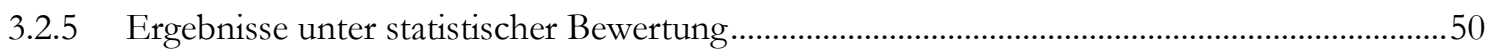

3.3 Auswertung verschiedener Färbungen an PFA-fixierten Hirnschnitten ...................................54

3.3.1 Analyse der Hämatoxylin-Eosin-gefärbten Präparate (HE) .....................................................56

3.3.2 Bestimmung der Verteilung dreiwertigen Eisens über die Färbung von Berliner Blau ..........59

3.3.3 Verteilungsanalyse von zweiwertigem Eisen durch die Färbung von Turnbulls Blau ...........62

3.3.4 Analyse der immunhistochemischen Färbung für das Amyloid-Precursor-Protein APP..............65

3.3.5 Bewertung der histochemischen Färbung von Myelin und Kohlenhydraten in der

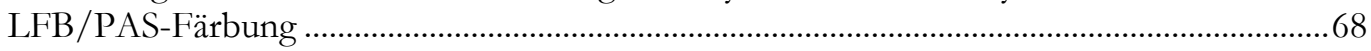

3.3.6 Analyse der immunhistochemischen Färbung von astrozytärem saurem Gliafaserprotein GFAP ……………………………………………………………….....

3.3.7 Verteilungsbestimmung von makrophagenspezifischem aktiviertem Antigen 3 durch immunhistochemische Färbung (Mac 3) ...............................................................................76

3.3.8 Bewertung der immunhistochemisch gegen Synaptophysin gefärbten Hirnschnitte..............79

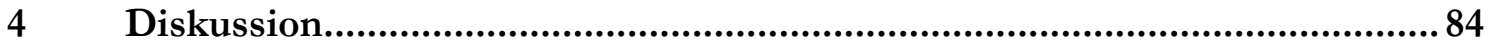

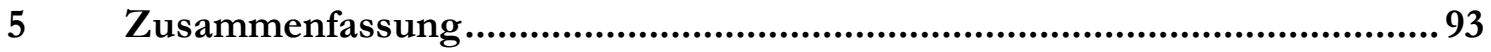

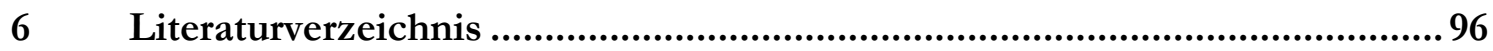




\section{Abbildungsverzeichnis}

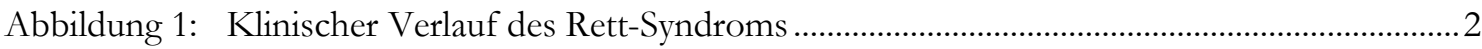

Abbildung 2: DNA-Inaktivierung durch MeCP2 und dessen Zielgene..............................................

Abbildung 3: Kontakte neuronaler und nichtneuronaler Zellen. ..........................................................

Abbildung 4: Schematische Gegenüberstellung der Atmungskette bei (A) normaler Mitochondrienfunktion und (B) Entkopplung im Rett-Syndrom. ...............................12

Abbildung 5: Möglicher Einfluss der intermittierenden Hypoxie auf die Progression des Rett-

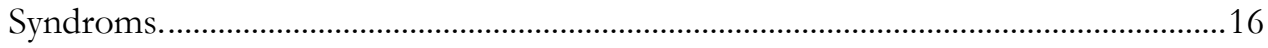

Abbildung 6: Keto-Enol-Tautomerie von am C8 oxidiertem Guanosin............................................18

Abbildung 7: Schematische Darstellung von Transport, Speicherung und Reaktivität von

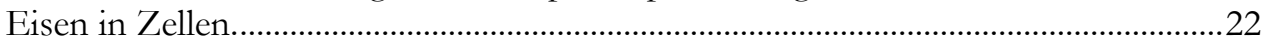

Abbildung 8: Physikalischer Mechanismus von Absorption und Emission.........................................28

Abbildung 9: Funktionsweise des ELISA-Kits zur Quantifizierung der oxidativen DNASchädigung.

Abbildung 10: Chemische Reaktionen im Rahmen der Probenentwicklung............................................34

Abbildung 11: Probenaufteilung auf der Mikrotiterplatte. .......................................................................

Abbildung 12: Mitochondriale Produktion von Wasserstoffperoxid in verschiedenen Hirngeweben.

Abbildung 13: Ausmaß der DNA-Oxidation bei männlichen und weiblichen Wildtyp-Tieren, welche normales Futter erhielten.

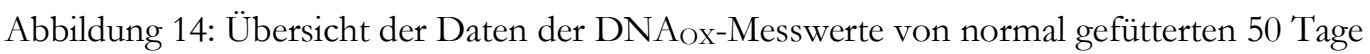
alten Rett-Männchen und Rett-Weibchen im Alter von 50 und 400 Tagen. ...............47

Abbildung 15: Gegenüberstellung der ermittelten Werte der oxidativen DNA-Schädigung bei antioxidativ gefütterten Wildtyp-Tieren beider Geschlechter.

Abbildung 16: DNA-Oxidation von antioxidativ gefütterten, männlichen und weiblichen RettMäusen

Abbildung 17: DNA-Oxidation im Vergleich unter Normierung auf die entsprechende Kontrollgruppe mit dem Genotyp "Wildtyp".

Abbildung 18: Vergleich der oxidativen DNA-Schädigung unter Normierung auf die entsprechende Kontrollgruppe mit männlichem Geschlecht.

Abbildung 19: Ausmaß DNA-Oxidation unter Normierung auf die entsprechende Kontrollgruppe unter Normalfutter.

Abbildung 20: Gruppenvergleich der Oxidation in DNA unter Normierung auf die entsprechende Kontrollgruppe im Alter von 50 Tagen..................................................54

Abbildung 21: Einteilung der Hirnareale im transversalen Schnitt.......................................................55

Abbildung 22: Präparat eines heterozygoten Weibchens in der HE-Färbung. .......................................56

Abbildung 23: Präparate in der HE-Färbung von heterozygoten und Wildtyp-Weibchen aus den Bereichen des auditiven Cortex (A) und des Gyrus dentatus des Hippocampus (B)

Abbildung 24: Übersichtsaufnahme eines Präparates eines Mecp2+/+-Weibchens in der Färbung Berliner Blau.

Abbildung 25: Exemplarische Ausschnitte aus den Präparaten in der Färbung Berliner Blau aus den Bereichen des visuellen Cortex (A) und des Gyrus dentatus des Hippocampus (B).

Abbildung 26: Aufnahme eines exemplarischen Präparates in der Färbung Turnbulls Blau aus dem Gehirn eines Wildtyp-Weibchens.

Abbildung 27: Exemplarische Ausschnitte aus dem visuellen Cortex (A) und dem Gyrus dentatus des Hippocampus (B) in der Färbung Turnbulls Blau...

Abbildung 28: Gegen APP gefärbtes Präparat eines heterozygoten Weibchens. 
Abbildung 29: Präparatausschnitte aus dem visuellen Cortex (A) und dem Gyrus dentatus des Hippocampus (B) mit immunhistochemischer Färbung von APP.

Abbildung 30: LFB/PAS-gefärbtes, exemplarisches Präparat aus dem Gehirn eines heterozygoten Weibchens.

Abbildung 31: Ausschnitte aus Präparaten in der LFB/PAS-Färbung aus dem auditiven Cortex (A) und dem Gyrus dentatus des Hippocampus (B). . .70

Abbildung 32: Präparat aus dem Gehirn eines Wildtyp-Weibchens mit immunhistochemischer Markierung von GFAP.

Abbildung 33: Ausschnitte aus den Bereichen des retrosplenialen Cortex (A) und aus dem visuellen Cortex (B) in GFAP-Färbung.

Abbildung 34: Ausschnitte aus den Bereichen des auditiven Cortex (A) und aus den Cortexregionen TeA, Ect und PRh (B) in GFAP-Färbung.

Abbildung 35: Präparate aus den Bereichen des lateralen entorhinalen Cortex (A) und aus dem Gyrus dentatus des Hippocampus (B) in GFAP-Färbung..

Abbildung 36: Gegen Mac3-gefärbte Übersichtsaufnahme eines Präparates eines heterozygoten Weibchens.

Abbildung 37: Präparate in Mac3-Färbung im Bereich des retrosplenialen Cortex (A) und des Gyrus dentatus des Hippocampus (B) mit markierten aktivierten Makrophagen (Pfeil).

Abbildung 38: Exemplarisches, gegen Synaptophysin gefärbtes Präparat eines Mecp2 +/+_ Weibchens.

Abbildung 39: Präparate in Synaptophysin-Färbung im Bereich des retrosplenialen Cortex (A) und des visuellen Cortex (B).

Abbildung 40: Ausschnitte in Synaptophysin-Färbung im Bereich des auditiven Cortex (A) und der Regionen TeA, Ect und PRh (B).

Abbildung 41: Präparatausschnitte in Synaptophysin-Färbung im Bereich lateraler entorhinaler Cortex (A) und des Gyrus dentatus des Hippocampus (B). 


\section{Tabellenverzeichnis}

Tabelle 1: Übersicht der verwendeten Chemikalien zur Bestimmung der mitochondrialen

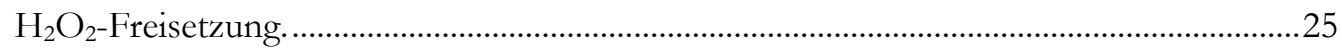

Tabelle 2: Zur experimentellen Umsetzung verwendeten Geräte.......................................................25

Tabelle 3: Benötigte Chemikalien zur Quantifizierung der oxidativen DNA-Schädigung...................26

Tabelle 4: Konzentrationen von oxidiertem Guanin der Standardlösungen. .........................................35

Tabelle 5: Pipettierschema des ELISA-Kits zur Quantifizierung der DNA-Oxidation. ........................37

Tabelle 6: Zusammenfassung der immunhistochemisch gefärbten Proteine............................................40

Tabelle 7: Zusammenfassung der histochemisch gefärbten Strukturen................................................ 41

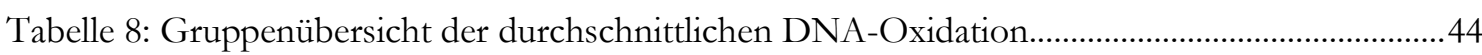




\section{Abkürzungsverzeichnis}

$\begin{array}{ll}\text { 8-OHdG } & \text { 8-Hydroxy-2'-Desoxyguanosin } \\ \text { 8-oxodG } & \text { 8-Oxo-2'-Desoxyguanosin } \\ \text { AChE } & \text { Acetylcholinesterase } \\ \text { AK } & \text { Antikörper } \\ \text { APE1 } & \text { Apurinische- bzw. Apyrimidinische Endonuklease 1 } \\ \text { APP } & \text { Amyloid-Precursor-Protein } \\ \text { ATP } & \text { Adenosintriphosphat } \\ \text { B } & \text { Maximale Absorption } \\ \text { BDNF } & \text { Brain derived neurotrophic factor } \\ \text { BER } & \text { Basenexzisionsreparatur } \\ \text { CDKL5 } & \text { Cyclin dependent kinase like 5 } \\ \text { CPG } & \text { Cytosin-Guanin-Dinukleotid } \\ \text { CSF } & \text { Cerebrospinal fluid } \\ \text { DAB } & \text { Diaminobenzidin } \\ \text { DMT1 } & \text { Divalenter Metallionentransporter 1 } \\ \text { DNA } & \text { Desoxyribonukleinsäure } \\ \text { DNAox } & \text { Anteil der oxidierten Guaninspezies an der Gesamt-DNA } \\ \text { EDTA } & \text { Ethylendiamintetraacetat } \\ \text { ELISA } & \text { Ensyme-linked immunosorbent assay } \\ \text { FAD } & \text { Flavin-Adenin-Dinukleotid } \\ \text { FEN1 } & \text { Flap-Endonuklease 1 } \\ \text { GABA } & \text { Gamma-Aminobutyric acid } \\ \text { GFAP } & \text { Glial fibrillary acid protein } \\ \text { HE } & \text { Hämatoxylin-Eosin } \\ \text { HO• } & \text { Hydroxylradikal } \\ \text { HRP } & \text { Horseradish peroxidase } \\ \text { LFB } & \text { Luxol-fast-blue }\end{array}$

$\mathrm{Mac} 3$

Makrophagenspezifisches aktiviertes Antigen 3

$\mathrm{MBD}$

Methyl-CpG-bindende Domäne

$\mathrm{MeCP} 2$

Methyl-CpG-bindendes Protein 2

Mecp2

Methyl-CpG-bindendes Protein 2, kodierendes Gen Maus

MECP2

Methyl-CpG-bindendes Protein 2, kodierendes Gen Mensch

mRNA

Messenger ribonucleic acid

MTP1

Metalltransportprotein 1

NPBI

Non-protein bound iron

NSB

Non-specific binding

OGG1

Oxoguaninglykosylase 1

oxG

Oxidierte Guaninspezies

PAS

Periodic acid Schiff

PFA Paraformaldehyd

PBS Phosphatgepufferte Salzlösung

POB DNA-Polymerase $\beta$ 
POD

RNA

RNS

ROS

RT'T

SOD

$\mathrm{Tf}$

TfR

TRD

W'T
DNA-Polymerase $\delta$

Ribonukleinsäure

Reaktive Stickstoffspezies

Reaktive Sauerstoffspezies

Genotyp „Rett“ (Mecp2+/- und Mecp2-/y)

Superoxiddismutase

Transferrin

Transferrin-Rezeptor

Transkriptionsrepressionsdomäne

Genotyp „Wildtyp“ (Mecp2+/+ und Mecp2+/y) 


\section{$1 \quad$ Einleitung}

\section{$1.1 \quad$ Rett-Syndrom}

\subsubsection{Thematik des Rett-Syndroms}

Die Grundlage dieser Arbeit stellt das Rett-Syndrom dar, welches erstmals 1966 vom Wiener Pädiater Dr. Andreas Rett charakterisiert wurde (Rett 1966). Dieser stellte klinische Gemeinsamkeiten an 22 jungen Patientinnen fest, darunter auch die für das Rett-Syndrom typischen Händewasch-Bewegungen. Erst einige Jahre später wurde der Erkrankung auch in der Öffentlichkeit mehr Beachtung geschenkt, nachdem der schwedische Neurologe Dr. Bengt Hagberg 1983 ebenfalls einer Gruppe Patientinnen die von Dr. Rett beschriebenen Symptomen zuordnen konnte (Hagberg et al. 1983). In den folgenden Abschnitten sollen alle relevanten Aspekte des Rett-Syndroms erläutert werden.

\subsubsection{Klinische Aspekte}

Es handelt sich beim Rett-Syndrom um eine neuronale Entwicklungsstörung, die zu schwerwiegenden kognitiven und motorischen Behinderungen führt. Der Krankheitsverlauf erfolgt in vier Stadien, die sich einer zunächst scheinbar normalen postnatalen Entwicklung anschließen (Chahrour und Zoghbi 2007) (Abb. 1).

Nachdem betroffene Kinder bereits einige Fähigkeiten, darunter meist Laufen und in manchen Fällen das Sprechen einiger Worte, erlernt haben, beginnt zwischen dem 6. und 18. Lebensmonat die Etablierung erster Symptome. Dieses Stadium I ist gekennzeichnet von der Stagnation des Lernfortschrittes sowie von verzögertem Wachstum, Hypertonie der Extremitäten und Mikrozephalie und dauert bis zum 2. oder 3. Lebensjahr an (Rett 1966; Hagberg et al. 1983).

Daran schließt sich Stadium II bis ungefähr zum 4. Lebensjahr an, in welchem es zur Regression des Zustandes kommt. Patienten mit dem Rett-Syndrom verlernen zuvor bereits erlernte Fähigkeiten, wie das Sprechen oder das Laufen (Rett 1966). Auffällig sind auch einige autistische Merkmale, darunter Emotionslosigkeit oder selbstverletzendes Verhalten, weshalb Autismus mitunter die häufigste Differentialdiagnose darstellt (Nomura 2005). Außerdem beobachtet man bei den Patienten stereotypische Handbewegungen in Form von Händewaschen (Rett 1966). Zudem entwickeln sie motorische Störungen, darunter Ataxie, und diverse Atemdysfunktionen. Diese Atemunregelmäßigkeiten führen zu einer intermittierenden Hypoxie (Julu et al. 2001; Stettner et al. 2008). Häufig leiden Rett-Patienten auch unter epileptischen Anfällen und Angstzuständen (Jian et al. 2006). 
Das darauffolgende Stadium III wird als stationäre Phase bezeichnet. Zwischen dem 4. und 10. Lebensjahr verschlechtern sich die bestehenden Symptome zwar nicht signifikant, jedoch treten in dieser Periode zusätzliche Probleme wie Skoliose oder Bruxismus auf (Mount et al. 2001).

In der letzten Phase der Erkrankung, dem Stadium IV, erfolgt die späte motorische Verschlechterung, welche sich bis zum Lebensende erstreckt. Betroffene verlieren dann meist ihre Mobilität und sind auf einen Rollstuhl angewiesen (Hagberg et al. 1983). Die bestehenden Symptome verschlechtern sich weiterhin, sodass die Patienten kognitiv und motorisch schwerbehindert sind. Hinzu kommen kardiale Probleme, zum Beispiel Tachykardie (Hagberg 2005). Die Lebenserwartung variiert stark, da die Ausprägung der Symptome bei vielen Patienten unterschiedlich ausfällt. Häufig tritt der plötzliche Tod durch kardiale Dysregulation, Apnoe oder epileptische Anfälle ein (Kerr et al. 1997; Julu et al. 2001; Steffenburg et al. 2001). Es gibt aber es auch Patienten, die trotz der schweren geistigen und motorischen Behinderung, über 50 Jahre alt werden (Hagberg et al. 2001).

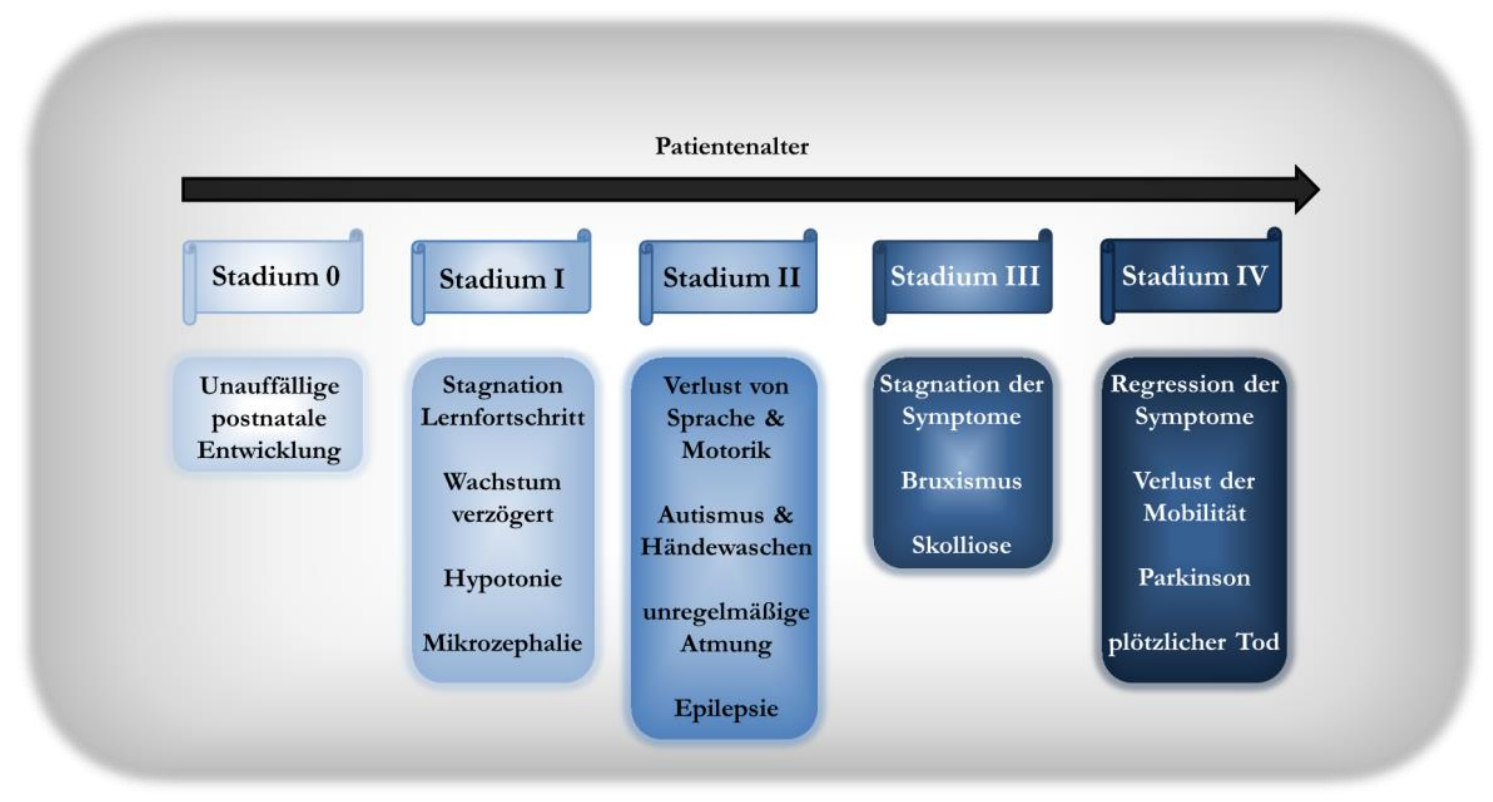

Abbildung 1: Klinischer Verlauf des Rett-Syndroms

Das Fortschreiten des Phänotyps im Rett-Syndrom erfolgt nach einer scheinbar normalen postnatalen Entwicklung bis zu einem Alter von sechs bis 18 Monaten in vier Stadien. Dabei kommt es im ersten Stadium zunächst nur zu einer Stagnation von Wachstum und Lernfortschritt sowie zur Hypotonie und Mikrozephalie. Dem schließt sich im zweiten Stadium der Verlust motorischer und kognitiver Fähigkeiten, darunter Sprechen und Laufen, sowie das Einsetzen autistischer Symptome, epileptischer Anfälle und unregelmäßiger Atmung an. Im darauffolgenden dritten Stadium stagnieren die meisten kognitiven und motorischen Symptome bis es im vierten und letzten Stadium zu einer Regression des Phänotyps bis hin zum Verlust der Mobilität kommt. In allen Stadien, aber besonders im letzten Stadium, ist mit dem Eintreten eines plötzlichen Todes zu rechnen. 
Klinisch sind somatosensorische evozierte Potentiale sowie des Elektroenzephalogramms verändert, besonders wenn es im Rahmen epileptischer Krämpfe zu fokalen, multifokalen oder generalisierten Anfällen kommt (Moser et al. 2007). Außerdem ist das Elektrokardiogramm häufig auffällig, da dort die QT-Intervalle besonders lang ausfallen. Dies könnte auf Störungen im Nervensystem hinweisen (Glaze 2005). Weiterhin lässt sich eine abnorme synaptische Langzeitpotenzierung, allgemein reduzierte kortikale Aktivität und synaptische Plastizität feststellen (Dani et al. 2005; Asaka et al. 2006; Moretti et al. 2006). Dazu passen die für das Rett-Syndrom typischen Symptome, darunter Verzögerungen beim Lernvorgang und generelle kognitive Beeinträchtigungen.

\subsubsection{Genetische Ursachen und Diversität der Phänotypen}

Die Entstehung des Rett-Syndroms konnte auf verschiedene Mutationen in einem Gen zurückgeführt werden, welches sich auf dem X-Chromosom befindet. Obwohl in fast allen Fällen nur dieses Gen betroffen ist, variiert der Phänotyp der Erkrankung stark zwischen verschiedenen Patienten. Im Folgenden werden unterschiedliche Aspekte des Genes und der festgestellten Mutationen sowie des dazugehörigen Proteins und der starken Varianz des Phänotyps erörtert werden.

Beim betroffenen Gen handelt es sich um das MECP2-Gen, welches für das MeCP2-Protein kodiert (Quaderi et al. 1994; Amir et al. 1999). Mutationen in diesem Gen führen zu einer reduzierten MeCP2-Konzentration im Körper des Patienten; bei schweren Fällen, darunter hauptsächlich männliche Patienten, kann sogar ein absoluter MeCP2-Mangel auftreten. Dieses Protein fungiert als Transkriptionsmodulator, der die Expression verschiedener Gene reguliert (Nan et al. 1997). Dabei steht MeCP2 für methyl-CpG-binding protein 2 und bindet dementsprechend an methylierte CpG-Dinukleotide (Cytosin-Guanin-Dinukleotide) in der DNA (Lewis et al. 1992). Eine Strukturanalyse des MECP2-Genes ergab einen Aufbau aus vier Exons, welche für zwei Isoformen des MeCP2-Proteins kodieren, die durch alternatives Spleißen am zweiten Exon entstehen (Kriaucionis und Bird 2004; Mnatzakanian et al. 2004; Dragich et al. 2007). Die Existenz der zwei Isoformen könnte eine Ursache für die phänotypischen Abweichungen sein.

Beide Isoformen des Proteins bestehen aus drei Domänen sowie zwei Kernlokalisierungssequenzen. Die Methyl-CpG-bindende Domäne (MBD) bindet spezifisch an methylierte CpG-Dinukleotide, wohingegen die Transkriptionsrepressionsdomäne (TRD) Korepressoren und weitere Chromatin-modulierende Komplexe rekrutiert (Hendrich und Bird 1998). Die C-terminale Domäne erlaubt die Bindung des Proteins direkt an Nukleosomen. Zur Transkriptionsinhibition eines Genes bindet MeCP2 also über die MBD an zuvor methylierte CPG-Dinukleotide und rekrutiert verschiedene Korepressoren, darunter der Transkriptionsregulator Sin3A, sowie weitere Proteine, zum Beispiel Histonacetylasen 1 und 2. Zusammen mit der C-terminalen Domäne bewirken die Histonacetylasen die Clusterbildung der Nukleosomen und erreichen über diese dicht 
gepackte räumliche Struktur die Inaktivierung der DNA für die Transkription. Über diesen Mechanismus kann also methylierte DNA durch MeCP2 inaktiviert werden (Jones et al. 1998; Nan et al. 1998) (Abb. 2).

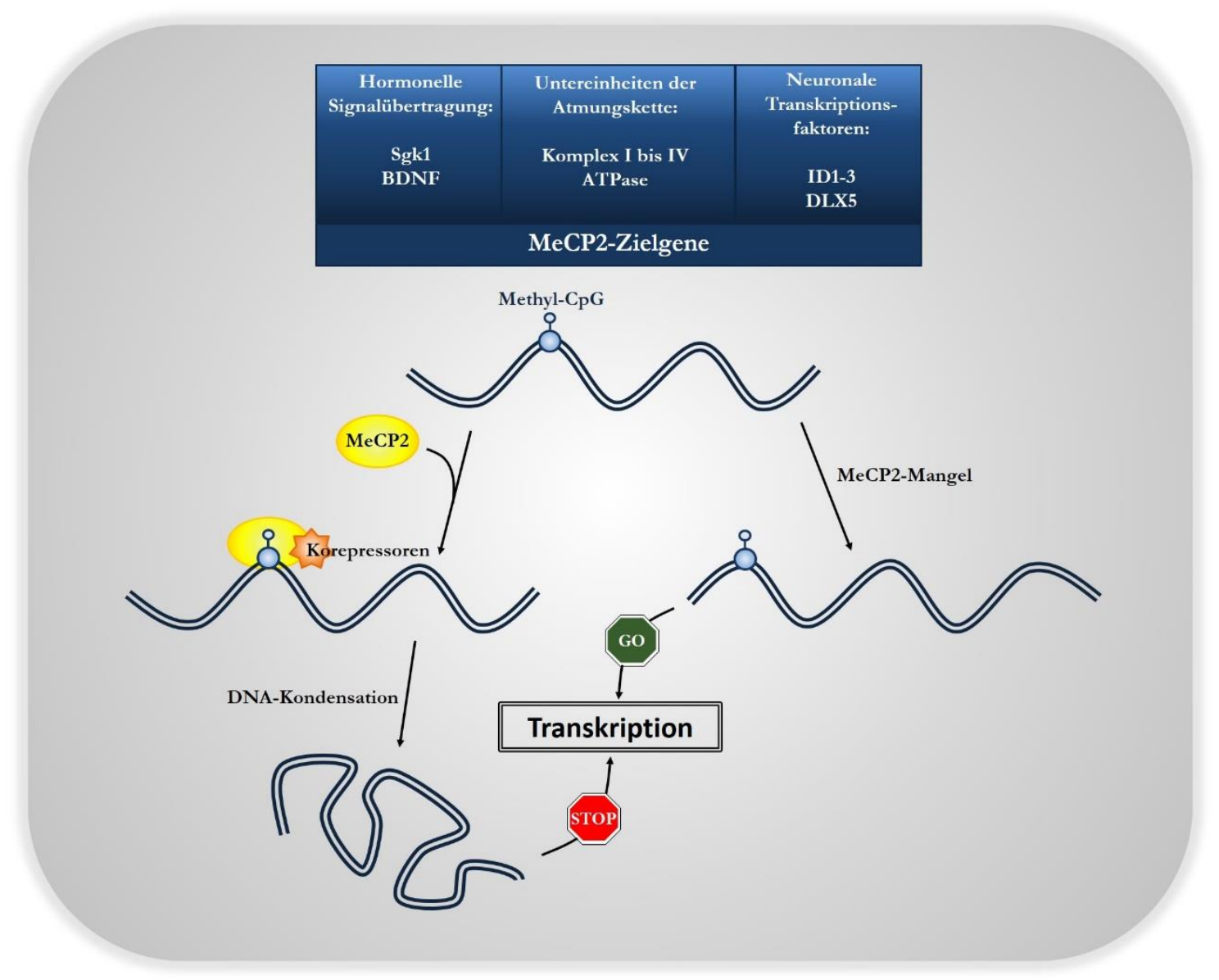

Abbildung 2: DNA-Inaktivierung durch MeCP2 und dessen Zielgene.

Transkribierbare DNA wird inaktiviert, indem MeCP2 an methylierte CpG-Motive bindet und Korepressoren rekrutiert, welche eine Kondensation der DNA-Struktur bewirken. Liegt ein MeCP2Mangel vor, entfällt diese Inaktivierung und die eigentlichen Zielgene von MeCP2 werden weiter unkontrolliert transkribiert. Die Zielgene für MeCP2 sind vielfältig; darunter fallen Gene aus dem Bereich der hormonellen Signalübermittlung, der Atmungskette und ATP-Synthese und weiterer Transkriptionsfaktoren aus dem neuronalen Bereich (Nuber et al. 2005; Kriaucionis et al. 2006; Peddada et al. 2006; Itoh et al. 2007).

Das MeCP2-Protein agiert zwar weniger als globaler, sondern eher als lokaler Transkriptionsmodulator, trotzdem wird die Expression diverser Gene durch dieses Protein reguliert (Tudor et al. 2002). Eines dieser Zielgene ist das BDNF-Gen, welches für den Wachstumsfaktor BDNF (brain derived neurotrophic factor) kodiert (Martinowich et al. 2003; Chen et al. 2003b). Die Expression dieses Proteins steht unter der Kontrolle mehrerer Promotorregionen, wobei einer dieser Promotoren durch eine Depolarisation über spannungsabhängige Calciumkanäle bei einem Aktionspotential aktiviert wird (Tao et al. 1998). Bei fehlender neuronaler Aktivität wird dieser Promotor durch die Bindung von MeCP2 inaktiviert, wodurch eine Stimulierung der Expression durch den Promotor entfällt 
(Chen et al. 2003b). Bei Auftreten einer Depolarisation wird die Bindung zwischen MeCP2 und der Promotorregion durch Phosphorolyse wieder zerstört und der Promotor reaktiviert (Chang et al. 2006). Somit ist die Expression von BDNF proportional zur neuronalen Zellaktivität. Obwohl aufgrund des MeCP2-Mangels im Rett-Syndrom und der damit einhergehenden reduzierten Transkriptionsinhibition eine erhöhte BDNF-Konzentration vermutet werden würde, liegt die BDNF-Konzentration tatsächlich im Normalbereich (Chang et al. 2006). Dadurch, dass im Rett-Syndrom die neuronale Aktivität herabgesetzt ist, werden die Neuronen weniger häufig depolarisiert. Folglich bleibt das vorhandene MeCP2 auch länger am BDNF-Gen gebunden und reduziert dessen Transkription. Dementsprechend liegt bei Rett-Patienten auch eine reduzierte BDNF-mRNAKonzentration vor. Die Normalisierung der BDNF-Konzentration erfolgt trotz der reduzierten Genexpression durch eine erhöhte Speicherung des BDNF-Proteins (Chang et al. 2006). Weitere Zielgene des MeCP2 finden sich in den Bereichen der hormonellen Signalkaskade, der mitochondrialen Atmungskette, der GABA-Rezeptoren sowie weiterer neuronaler Transkriptionsfaktoren (Horike et al. 2005; Nuber et al. 2005; Samaco et al. 2005; Kriaucionis et al. 2006).

Die Funktion von MeCP2 liegt folglich in der Modulation der Expression von Genen, die unter anderem eine wichtige Rolle bei der physiologischen Antwort des Körpers auf eine divergente Redoxbalance spielen. Neben der Transkriptionsrepression bestimmter Zielgene reagiert MeCP2 außerdem mit dem Protein YB1 (Y-Box-bindendes Protein 1), welches an RNA bindet und deren Spleißen moduliert (Jeffery und Nakielny 2004). Daher konnten auch bei Patienten mit Rett-Syndrom abnorme Splicing-Muster festgestellt werden (Young et al. 2005). Das methyl-CpG-bindende Protein MeCP2 spielt demnach eine Schlüsselrolle bei der Erforschung des Rett-Syndroms, da es die Inaktivierung von Nukleosomen verschiedener Gene im Rahmen der Transkription sowie die Ausprägung von Splicing-Muster beeinflusst.

Bisher sind über 300 verschiedene Mutationen bekannt, die das Rett-Syndrom auslösen können, darunter Punktmutationen (missense und nonsense) und Mutationen, die zur Verschiebung des Leserasters führen (frameshift) (Christodoulou et al. 2003). Zu 99\% tritt das Rett-Syndrom spontan und de novo durch Mutationen in der Keimbahn des Vaters auf (Wan et al. 1999; Trappe et al. 2001). Es sind nur sehr wenige Fälle bekannt, in denen die Erkrankung durch ein erkranktes Elternteil vererbt wurde. Die Art und Lokalisation der Mutation korreliert mit dem Schweregrad der Erkrankung, weshalb neben dem klassischen Rett-Syndrom auch atypische milde oder besonders schwerwiegende Formen bekannt sind. So bewirken zum Beispiel Mutationen, die die Kernlokalisierungssequenz von MECP2 verändern, einen schwerer betroffenen Phänotyp als Veränderungen in der C-terminalen Domäne (Smeets et al. 2005). 
Der Phänotyp der Erkrankung ist nicht nur von der Art der Mutation, sondern auch vom Geschlecht des Patienten abhängig. Frauen, die unter dem Rett-Syndrom leiden, weisen eine besonders starke Varianz im Phänotyp auf. Grund hierfür ist die Mosaik-Struktur der XChromosomen. Da Frauen zwei X-Chromosomen besitzen und das Rett-Syndrom fast immer über eine Mutation auf dem vom Vater vererbten X-Chromosom entsteht, besitzen Rett-Patientinnen ein intaktes und ein defektes X-Chromosom. An einem frühen Punkt in der embryonalen Entwicklung wird eines der beiden Chromosomen inaktiviert, wobei diese Inaktivierung bestimmten Mustern unterliegt, die je nach Art der Mutation im MECP2-Gen unterschiedlich sind. So ergibt es sich, dass in verschiedenen Zellen in einem Gewebe nicht das gleiche X-Chromosom inaktiviert wird und dass in verschiedenen Geweben auch nicht die Inaktivierung des gleichen X-Chromosoms überwiegt. Entsprechend dieser unterschiedlichen Inaktivierung in verschiedenen Geweben des Körpers unterliegen der Phänotyp und damit auch der Schweregrad der Erkrankungen sehr großen Schwankungen.

Neben Frauen können auch Männer vom Rett-Syndrom betroffen sein (Jan et al. 1999). Da diese aber nur ein X-Chromosom besitzen, welches im Rett-Syndrom auch das mutierte MECP2-Gen enthält, sind die Symptome bei Männern in der Regel deutlich schwerwiegender als bei Frauen. Daher führen Rett-assoziierte Mutationen bei neugeborenen Jungen zu schweren, neonatalen Enzephalopathien und meist im ersten Lebensjahr zum Tod. Es gibt auch Mutationen im MECP2-Gen, die bei Frauen nicht das Rett-Syndrom auslösen, aber bei Männern schwere kognitive Behinderungen herbeiführen.

Nicht nur ein Mangel, sondern auch ein Überschuss von MeCP2 führt zu Symptomen, die dem Rett-Syndrom zuzuordnen sind. Dieser Überschuss entsteht bei der MECP2Duplikationserkrankung, bei der nur das MECP2-Gen dupliziert ist, und beim KlinefelterSyndrom, bei dem das gesamte X-Chromosom zweifach vorliegt, sodass das Genom betroffener Patienten mit XXY charakterisiert werden kann (Schwartzman et al. 2001; Collins et al. 2004).

Zusätzlich zur klassischen Form des Rett-Syndroms existieren auch seltene und untypische Formen der Erkrankung, die durch Mutationen auf anderen Genen als dem MECP2-Gen entstehen. Erkrankungen, die durch Mutationen auf dem X-chromosomalen CDKL-5-Gen entstehen, galten früher aufgrund des ähnlichen Phänotyps als eine atypische Unterform des Rett-Syndroms, werden heute aber als eigenständige Erkrankung eingestuft (Fehr et al. 2013). Dabei ähneln sich nicht nur die klinischen Anzeichen beider Erkrankungen in Form von Spasmen und epileptischen Anfällen, auch ähnliche Veränderungen im Stoffwechsel, darunter eine Redoximbalance, können bei beiden Erkrankungen festgestellt werden (Tao et al. 2004; Weaving et al. 2004; Grosso et al. 2007). Dieses Gen kodiert für das cyclin dependent kinase like 5 Protein, welches durch Phosphorylierung sich selbst, aber auch MeCP2 aktiviert und damit ebenfalls die Genexpression reguliert (Bertani et al. 2006). Außerdem können Mutationen auf dem FOXG1-Gen ebenfalls Auslöser für eine seltene Variante des RettSyndroms sein (Ariani et al. 2008). Dieses Gen kodiert für das forkhead box protein $G$, welches 
wie MeCP2 als Transkriptionsmodulator fungiert und Einfluss auf die neuronale Entwicklung ausübt (Ariani et al. 2008). Das klinische Bild beider Erkrankungen unterscheidet sich vom klassischen Rett-Syndrom darin, dass es keine klar abgegrenzten Phasen der Regression gibt (Neul et al. 2010).

\subsubsection{Neuronale und gliale Zellen im Rett-Syndrom}

Unter den verschiedenen Zellarten, die im Hirngewebe lokalisiert sind, waren vor allem Neurone bereits häufig Gegenstand der Erforschung des Rett-Syndroms. Dagegen ist über die Morphologie und Funktionalität anderer Zellen im Rett-Syndrom wenig bekannt, obwohl die Population glialer Zellen in Gehirnen von Ratten etwa vier Mal größer ist als die neuronaler Zellen; bei Menschen ist die Anzahl glialer Zellen noch deutlich größer (Friede 1954; Bass et al. 1971). Ihr Zusammenwirken ist schematisch in Abbildung 3 dargestellt.

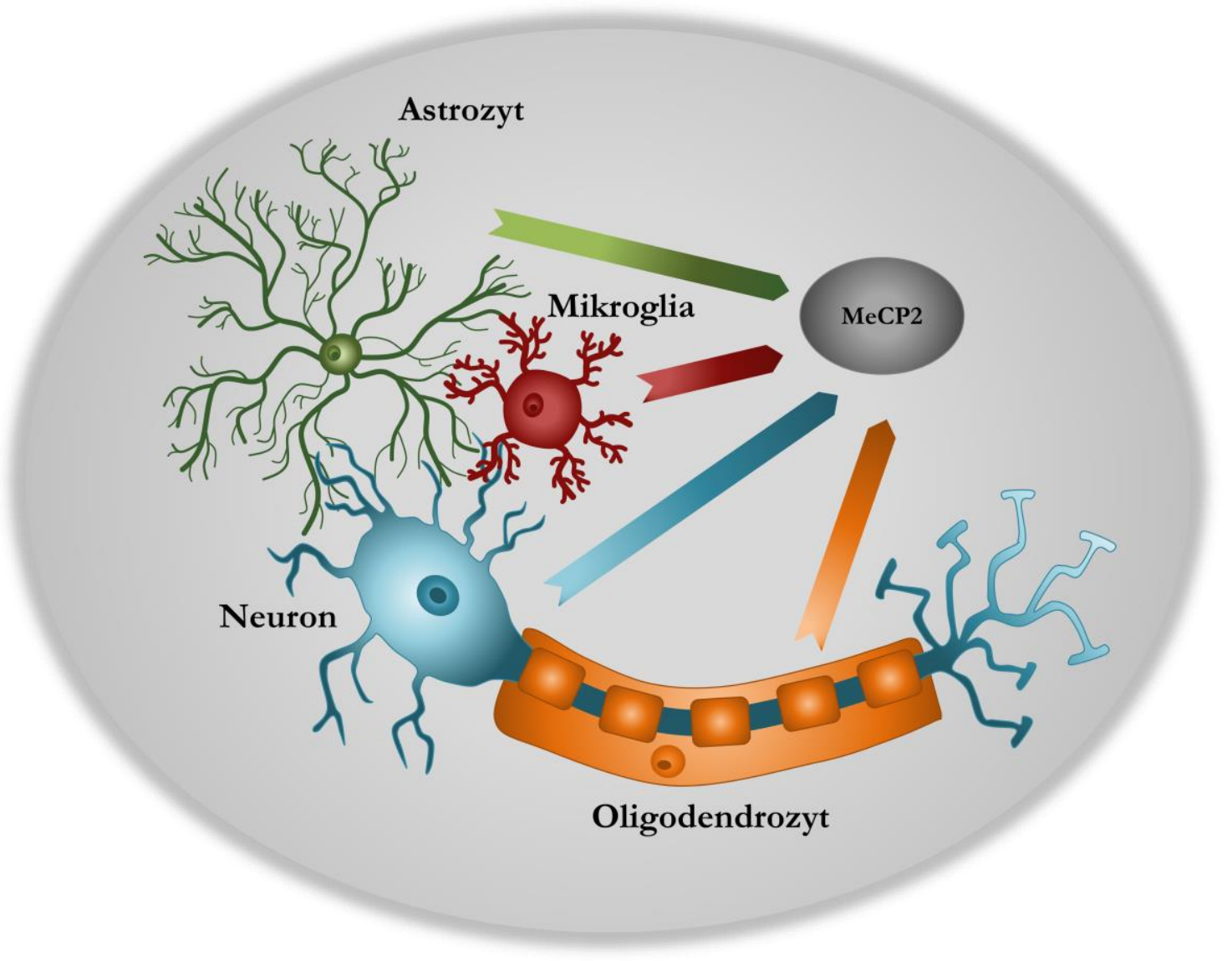

Abbildung 3: Kontakte neuronaler und nichtneuronaler Zellen.

Sowohl Neurone als auch Gliazellen exprimieren MeCP2 und leiden im Rett-Syndrom unter dessen Mangel. Neurone werden in ihrer Funktion der Weitergabe von Aktionspotentialen von glialen Zellen unterstützt, indem Oligodendrozyten im ZNS eine Myelinscheide um Axone bilden und so die Weiterleitungsgeschwindigkeit erhöhten. Astrozyten führen eine formgebende Funktion über die Expression von GFAP aus und stabilisieren Dendriten, Synapsen und Axone. Dagegen fungieren Mikroglia als zerebraler Teil des Immunsystems und treten dauerhaft mit den umgebenden Zellen in Verbindung, wodurch sie die synaptische Plastizität beeinflussen. 


\subsubsection{Neurone}

Obwohl die Phänotypen der Patienten stark divergieren, können einige gemeinsame neuronale Veränderungen bei allen Rett-Patienten diagnostiziert werden. Das Gehirn sowie die Neurone sind hinsichtlich ihrer Größe reduziert, wobei die Neurone dabei dichter gepackt als üblich im Gewebe vorliegen (Kaufmann und Moser 2000; Armstrong 2005). In der Großhirnrinde sind außerdem die säulenförmigen Verarbeitungseinheiten verkleinert und dendritische Verzweigungen reduziert (Belichenko et al. 1994; Casanova et al. 2003).

Während der embryonalen Entwicklung wird MeCP2 kaum synthetisiert, die Bildung steigt während der postnatalen neuronalen Reifung aber rapide an (Shahbazian et al. 2002a; Balmer et al. 2003; Cohen et al. 2003; Kishi und Macklis 2004; Mullaney et al. 2004; Pelka et al. 2005). Dieses Protein ist also weniger für die Entwicklung der einzelnen Neurone, sondern mehr für ihre Verknüpfung untereinander und für die Erstellung eines neuronalen Netzwerkes verantwortlich, indem es die Synaptogenese, die Aktivität sowie die Plastizität der Neurone erhöht (Fukuda et al. 2005). Bei Patienten, die am Rett-Syndrom leiden, sind diese Funktionen aufgrund des MeCP2-Mangels daher eingeschränkt, wodurch es zu einer Erkrankung der aberranten Plastizität und Verknüpfung der Zellen des zentralen Nervensystems und somit zu einer Synaptopathie wird. Diesen neuronalen Veränderungen liegt aber kein offensichtlicher neurodegenerativer Prozess zugrunde, da ursprünglich weder eine Degeneration, noch signifikante Atrophien oder Entzündungen des neuronalen Gewebes festgestellt werden können (Jellinger et al. 1988; Reiss et al. 1993).

Allerdings wurden in einer späteren Studie Hinweise auf entzündliche Vorgänge gefunden. Eine Untersuchung von positiven und negativen Akute-Phase-Proteinen im Stadium II an Rett-Patienten ergab, dass zwar die Konzentration des C-reaktiven Proteins unverändert war, andere Akute-Phase-Proteine aber signifikant erhöht beziehungsweise erniedrigt waren und damit auf einen pro-inflammatorischen Prozess hindeuten (Cortelazzo et al. 2014). Eine Veränderung dieser Proteinkonzentrationen steht im Zusammenhang mit autistischen Erkrankungen (Croonenberghs et al. 2002). Außerdem wurde in derselben Studie gezeigt, dass die Erythrozyten-Sedimentationsrate bei Rett-Patienten erhöht war (Cortelazzo et al. 2014). Dies indiziert ebenfalls eine Zunahme von Akute-Phase-Proteinen im Rett-Syndrom, da diese aufgrund ihrer Ladung die Erythrozyten-Sedimentationsrate steigern.

Um eine mögliche Schädigung der Neurone trotzdem auszuschließen, können verschiedene neuronale Marker in histochemischen Färbungen dargestellt werden. Dazu gehört zum einen das Amyloid-Precursor-Protein APP, welches in Neuronen synthetisiert wird. Intrazellulär erfolgt eine Spaltung des APP durch $\alpha$-Sekretasen, wodurch zwei Segmente entstehen, denen eine neuroprotektive Wirkung zugeschrieben werden (Schubert et al. 1989; Weidemann et al. 1989). Dagegen entsteht bei der pathologischen Spaltung von APP durch $\beta$ - und $\gamma$ Sekretasen als Fragment das $\beta$-Amyloid, welches neurotoxisch wirkt und bei der AlzheimerErkrankung akkumuliert in Plaques vorliegt (Hardy und Higgins 1992). Eine axonale Akkumulation von APP in Neuronen erfolgt nur pathologisch und gilt als Zeichen einer 
akuten axonalen Schädigung (Bramlett et al. 1997). Eine weitere Möglichkeit zur Darstellung möglicher neuronaler Schädigungen ist die histochemische Färbung mit LFB/PAS. Dabei wird mit Luxol-fast-blue (LFB) Myelin in den Markscheiden der Neurone dargestellt, wohingegen mit periodsaurem Schiff-Reagenz (PAS) eine Anfärbung von Kohlenhydraten in entmyelinisierten Bereichen ermöglicht wird.

\subsubsection{Astrozyten}

Ebenso wie andere Gliazellen stehen auch Astrozyten im engen Kontakt mit Neuronen. Sie stabilisieren über das Protein GFAP (glial fibrillary acid protein; saures Gliafaserprotein) die extrazelluläre Matrix des Hirngewebes und modulieren die synaptische und dendritische Plastizität, da sie durch schnelle Aufnahme von Neurotransmittern durch entsprechende Transporter eine toxische Wirkung dieser Stoffe bei Exzitation verhindern (Maragakis und Rothstein 2001; Ullian et al. 2001). Es konnte gezeigt werden, dass nicht nur Neurone $\mathrm{MeCP} 2$ exprimieren und im Rett-Syndrom unter dessen Verlust leiden, sondern dass selbiges auch für alle Gliazellen gilt (Ballas et al. 2009). Außerdem legten sie die Vermutung nahe, dass Astrozyten durch einen autonomen Effekt Neurone beeinflussen, da MeCP2-defiziente Astrozyten sowohl an Wildtyp-Neuronen als auch an Rett-Neuronen daran scheiterten, die dendritische Morphologie aufrecht zu erhalten. Eine Untersuchung der GFAP-Verteilung in verschiedenen Hirngeweben ergab keine sichtbaren Unterschiede zwischen Wildtyp- und Rett-Mäusen, was vermuten lässt, dass die Astrozyten nicht in ihrer Anzahl reduziert sind. Es wurde auch festgestellt, dass keine Astrozytose vorliegt, nur gelegentlich tritt eine milde Hyperplasie der Astrozyten auf, wobei die GFAP-Expression unverändert bleibt (Jellinger et al. 1988). Bei morphometrischen Untersuchungen konnten an glialen Zellen keine Abnormalitäten festgestellt werden. Ihrem Einfluss auf das Rett-Syndrom liegt wohl eher eine funktionelle Störung zugrunde (Ballas et al. 2009). Auch eine mögliche neurotoxische Wirkung exozytierter Stoffe aus Astrozyten konnte ausgeschlossen werden (Maezawa und Jin 2010).

\subsubsection{Mikroglia}

Ursprünglich galten Mikroglia-Zellen als irrelevant für die Rett-Forschung, da diesen keine MeCP2-Exprimierung zugeschrieben wurde (Shahbazian et al. 2002a). Dies konnte allerdings widerlegt werden (Ballas et al. 2009). Die Zellen dieser Untergruppe von Gliazellen fungieren als lokale Gewebsmakrophagen, welche nicht der hämatopoetischen Entwicklungsreihe entspringen. Sie modulieren die synaptische Plastizität durch deren Abbau und Aufbau und sind als Teil des Immunsystems unter anderem an inflammatorischen Vorgängen beteiligt (Wake et al. 2009). Während sie dauerhaft mit Neuronen in Kontakt stehen, exprimieren sie Wachstumsfaktoren, darunter BDNF1, um ihre Umgebung zu beeinflussen (Elkabes et al. 1996; Levitt und Campbell 2009). Obwohl eine gewisse toxische Wirkung von Mikroglia durch ROS-Ausschüttung beim oxidative burst erwünscht ist, zeigen diese Zellen im Rett-Syndrom eine übermäßige Glutamat-Abgabe, 
welche neurotoxisch auf die umgebenden Neurone wirkt. Die Morphologie von Mikroglia ist ebenso wie die von Astrozyten im Rett-Syndrom unverändert (Maezawa und Jin 2010). Aktivierte Mikroglia-Zellen lassen sich histologisch durch eine Färbung spezifischer Proteine von Neuronen und Astrozyten unterscheiden. Eine Möglichkeit ist die Anfärbung des Antigens Mac3 (Makrophagenspezifisches aktiviertes Antigen 3) durch entsprechende Antikörper, welches in aktivierten Makrophagen und Mikroglia vorkommt (Giulian und Baker 1986).

\subsubsection{Metabolismus im Rett-Syndrom}

\subsubsection{Hypoxie}

Ein wichtiger Ansatzpunkt der Forschung bezüglich des Rett-Syndroms ist die besondere Stoffwechselsituation der Patienten. Aufgrund einer gestörten kardiorespiratorischen Kontrolle leiden diese unter Atemproblemen, wie zum Beispiel Apnoen, welche in ungefähr einem Viertel aller Fälle irgendwann zum spontanen Versterben führen (Kerr et al. 1997; Julu et al. 2001). Da während dieser Apnoe-Phasen die arterielle Sauerstoffsättigung stark fällt, kommt es zu einer intermittierenden Hypoxie (Julu et al. 2001; Stettner et al. 2008; Katz et al. 2009). Trotz solcher repetitiven hypoxischen Stimuli erfolgt keine ausreichende Adaptation des neuronalen Gewebes an die verschlechterte Sauerstoffversorgung; es bleibt hypersensitiv gegenüber hypoxischen Zuständen (Fischer et al. 2009; Mironov et al. 2009; Kron und Müller 2010; Kron et al. 2011).

\subsubsection{Morphologische und funktionelle Veränderungen in Mitochondrien}

Neben der gestörten Atemsituation sind auch Veränderungen an den Mitochondrien in neuronalem und Muskelgewebe festzustellen (Belichenko et al. 2009). Dabei sind die Mitochondrien angeschwollen und vergrößert, ihre Cristae sind unregelmäßig und es finden sich vermehrte Einschlüsse von Lipofuszin-Granula (Ruch et al. 1989; Eeg-Olofsson et al. 1990; Cornford et al. 1994). Diese morphologischen Veränderungen treten bereits zu einem frühen postnatalen Zeitpunkt vor dem Eintritt der ersten Symptome auf und verschlechtern sich progressiv mit dem Fortschreiten der Erkrankung. Diese Alterationen sind also keine Folge der intermittierenden Hypoxie, sondern sie entstehen primär aus bisher nicht gänzlich geklärten Gründen und stellen damit eher einen kausalen als einen sekundären Defekt im Rett-Syndrom dar (Großer et al. 2012).

Die Mitochondrien sind aber nicht nur morphologisch, sondern auch funktionell abnorm. Diese Organellen sind der Hauptverbraucher der Zellen für Sauerstoff, welcher in der Atmungskette für die Erstellung des Protonengradienten benötigt wird. Im Rett-Syndrom ist die Rate der Atmungskette an diesen Mitochondrien um bis zu 30\% erhöht, da einerseits die Genexpression für Proteine der Komplexe I und III gesteigert ist, andererseits auch deren Enzymaktivität stimuliert ist. Die Steigerung der Genexpression für die Proteine dieser Untereinheiten korreliert dabei mit dem Schweregrad der Erkrankung (Kriaucionis et al. 
2006). Neben den Untereinheiten der Komplexe I und III sind auch Proteine der Komplexe II, IV und der ATP-Synthase selbst von einer intensivierten Genexpression betroffen, über die ein Zuwachs der basalen Atmung generiert werden kann (Pecorelli et al. 2013). Die erhöhte Umsatzrate der Atmungskette lässt sich am erhöhten $\mathrm{FAD} / \mathrm{FADH}_{2}$-Verhältnis feststellen, da das Koenzym FAD (Flavin-Adenin-Dinukleotid) vermehrt in seiner oxidierten Form vorliegt (Kriaucionis et al. 2006). Ursache hierfür muss ein vermehrter Ablauf der oxidativen Phosphorylierung sein. Trotz der verstärkten mitochondrialen Aktivität ist im Hirngewebe aber eine reduzierte ATP-Konzentration festzustellen (Formichi et al. 1998; Saywell et al. 2006). Dieser Widerspruch legt die Vermutung nahe, dass die Atmungskette entkoppelt sein muss, wodurch weniger ATP synthetisiert wird, oder der ATP-Verbrauch der Zellen muss signifikant erhöht sein. Somit wäre die Effizienz der Mitochondrien reduziert (Kriaucionis et al. 2006). Dort wird vermutet, dass ein „Leck“ über der Mitochondrienmembran existiert, welches den Protonengradienten abbaut. Dafür spricht außerdem, dass das Membranpotential der Mitochondrien weniger negativ ist, welches durch Fluoreszenzmessungen mit Rhodamin (Rh 123) festgestellt wurde (Großer et al. 2012). Das würde bedeuten, dass die Aktivität der Atmungskette bereits unter Ruhebedingungen erhöht ist, wodurch der Sauerstoffverbrauch der Zelle steigt, wenngleich die Sauerstoffversorgung aufgrund der Hypoxie beschränkt ist.

Während der oxidativen Phosphorylierung entstehen bei sauerstoffabhängigen Reaktionen vor allem an den Komplexen I und III neben Wasser auch reaktive Sauerstoffspezies (ROS) (Kushnareva et al. 2002; Chen et al. 2003a). Die dabei gebildete Menge an ROS ist an die mitochondriale Aktivität geknüpft (Boveris und Chance 1973). Das führt dazu, dass bei der erhöhten mitochondrialen Aktivität im Rett-Syndrom auch die ROS-Freisetzung zunimmt (Can et al. 2019). Reaktive Sauerstoffspezies sind radikalische und nicht-radikalische Sauerstoffverbindungen, zum Beispiel Wasserstoffperoxid $\left(\mathrm{H}_{2} \mathrm{O}_{2}\right)$, Superoxidanionen $\left({ }^{\circ} \mathrm{O}_{2}{ }^{-}\right)$ oder Hydroxylradikale $\left(\mathrm{HO}^{\circ}\right)$. Neben ROS gibt es außerdem reaktive Stickstoffspezies (RNS), die aus der Reaktion von Superoxiden mit Stickstoffmonoxid (NO) resultieren. Die Hauptentstehungsquelle für ROS ist die Atmungskette, außerdem werden sie aber auch unter anderem beim oxidative burst als Teil der Immunreaktion gebildet (Thrasher et al. 1994). Die problematische Stoffwechselsituation der Mitochondrien ist in Abbildung 4 schematisch dargestellt. In ihrer Funktion als sehr reaktives Oxidationsmittel führen ROS zur Oxidation verschiedener Stoffe. Innerhalb von Zellen bedeutet dies eine potenzielle Oxidation von allen Zellbestandteilen wie Proteinen, Lipiden oder DNA und folglich zur Zellschädigung. Aufgrund ihrer erhöhten Konzentration ist das Redox-Gleichgewicht in der Zelle gestört; die Vorgänge der Reduktion und Oxidation stehen nicht mehr im physiologischen Gleichgewicht (Harman 1956). Aufgrund der erhöhten ROS-Konzentration ist das zelluläre Redox-Gleichgewicht besonders vulnerabel; die Zellen sprechen sehr intensiv auf oxidative Reize an. Dieses Ungleichgewicht stellt einen möglichen pharmakotherapeutischen Ansatz bei der Therapie des Rett-Syndroms dar (De Felice et al. 2012; Großer et al. 2012; Janc und Müller 2014). 


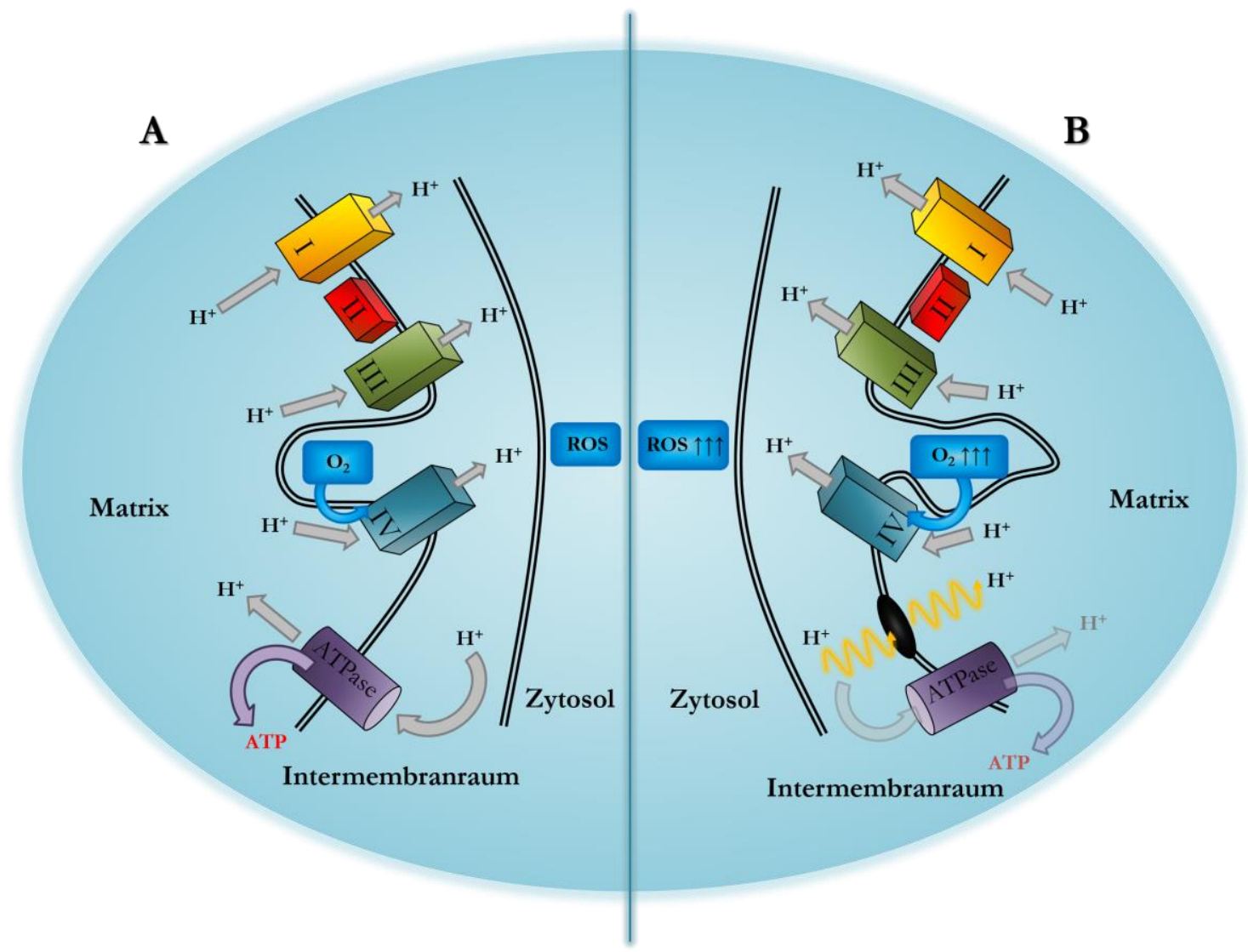

Abbildung 4: Schematische Gegenüberstellung der Atmungskette bei (A) normaler Mitochondrienfunktion und (B) Entkopplung im Rett-Syndrom.

Bei der in (A) schematisch dargestellten Funktionsweise der Atmungskette werden über die Komplexe I, III und IV Protonen in den Intermembranraum der Mitochondrien gepumpt, wobei der Verbrauch von Sauerstoff an Komplex IV stattfindet und physiologische Mengen an ROS als Nebenprodukt entstehen. Dieser Protonengradient wird von der ATP-Synthase wieder abgebaut und für die ATP-Biosynthese genutzt. Da im Rett-Syndrom (B) ein Leck in der Mitochondrienmembran vermutet wird, ist die Atmungskette partiell entkoppelt. Der Protonengradient wird über das Leck abgebaut, ohne von der ATP-Synthase zur Generierung von ATP genutzt werden zu können. Da sowohl die Expression als auch die Aktivität der Komplexe erhöht sind, entstehen dabei auch deutlich höhere Mengen an ROS als in (A).

Da ROS ohne Vorliegen einer Erkrankung bei der oxidativen Phosphorylierung entstehen, existieren auch körpereigene Mechanismen, um diese unschädlich zu machen (Boveris und Chance 1973). Dies geschieht, indem Superoxiddismutasen (SOD) die Reaktion von Superoxidanionen $\mathrm{zu}$ Wasserstoffperoxid katalysieren, welches anschließend über Peroxidasen, zum Beispiel Katalase, zu Sauerstoff und Wasser reagiert und somit abgebaut wird. Die Aktivität dieser Enzyme ist im Rahmen des Rett-Syndroms reduziert, wodurch der erhöhten ROS-Synthese weniger Abbau entgegensteht und sich das Redox-Gleichgewicht weiter zur Seite der Oxidation hin verschiebt. Allerdings konnte eine erhöhte Expression der SOD1 in Hippocampi von Mecp2-Knockout-Mäusen festgestellt werden, wohingegen die Aktivität der SOD1 in Erythrozyten deutlich reduziert ist (Sierra et al. 2001; Großer et al. 2012). 


\subsubsection{Redox-abhängige Ionenkanäle und Rezeptoren}

Die Redox-Veränderungen modulieren die Aktivität spannungsabhängiger Natrium- und Kaliumkanäle (Hammarström und Gage 2000) sowie der NMDA Glutamat-Rezeptoren (Aizenman et al. 1989) und $\mathrm{GABA}_{\mathrm{A}}$-Rezeptoren (Sah et al. 2002). Diese veränderte Modulation könnte Ursache für eine reduzierte synaptische Plastizität und Einschränkungen beim Lernvorgang der Patienten mit Rett-Syndrom sein. Außerdem ist die gesamte Kalziumhomöostase abhängig von der Redox-Situation der Zelle. Das betrifft spannungsabhängige Kalziumkanäle (Todorovic et al. 2001), Ryanodin- und Inositoltriphosphatrezeptoren (Hidalgo et al. 2004; Gerich et al. 2009) und die sarkoplasmatische Kalziumpumpe SERCA sowie den Natrium-Kalzium-Austauscher (Kuster et al. 2010).

$\mathrm{Zu}$ der gestörten Kalziumhomöostase trägt zusätzlich die Herabregulation der Genexpression einer Untereinheit des spannungsabhängigen Kalziumkanals vom T-Typ Cacna1g bei (Großer et al. 2012). Diese steht in Verbindung mit der Hypererregbarkeit und der synaptischen Plastizität der Neurone, aufgrund dessen Auslenkungen aus diesem Gleichgewicht mit den Symptomen des Rett-Syndroms korrelieren, die Fehler in der neuronalen Vernetzung indizieren (Guy et al. 2001; Asaka et al. 2006; Moretti et al. 2006; Fischer et al. 2009).

Weiterhin ist die Expression des Glukosetransporters Slc2a4 erhöht (Großer et al. 2012). Diesem Vorgang könnte eine kompensatorische Funktion zugrunde liegen, da die Blutglukosekonzentration von Patienten häufig signifikant reduziert ist. Zusätzlich zum offenbar veränderten Glukosemetabolismus sind auch Fluktuationen von Laktat- und Pyruvat-Konzentrationen im Blut zu verzeichnen (Haas et al. 1986). Somit leiden Betroffene nicht nur unter neurologischen und motorischen Problemen, sondern auch unter diversen Störungen des Metabolismus.

Zusammenfassend lässt sich folglich sagen, dass Mitochondrien die neuronale Plastizität und die Signalfortpflanzung von Aktionspotentialen über die ROS-Freigabe, die basale Atmung und die Kalziumhomöostase sowie über die Aktivitätsmodulation diverser Kanäle beeinflussen und damit eine Schlüsselrolle im Zusammenhang mit dem Rett-Syndrom einnehmen.

\subsubsection{Tiermodelle im Rett-Syndrom}

Zur Erforschung der Pathogenese sowie weiterer Aspekte des Rett-Syndroms existieren verschiedene Tiermodelle, die Genotyp und wesentliche Aspekte des Phänotyps der Erkrankung wiederspiegeln. Am häufigsten finden Maus-Modelle Verwendung, bei denen das Mecp2-Gen inaktiviert wurde (Mecp2-Knockout, Mecp2 $2^{\text {tm1.1Bird }}$ ) oder bei denen große Teile des Mecp2-Genes fehlen (Mecp2-Keimbahndeletion, Mecp2 ${ }^{\text {tm1.1Jae }}$ ) (Chen et al. 2001; Guy et al. 2001). Bei einem weiteren, häufig verwendeten Mausmodell (Mecp $\left.2^{308}\right)$ existiert ein vorzeitiges Stopp-Codon, welches zur Synthese verkürzter und weniger aktiver Mecp2- 
Transkripte führt. Dabei endet die Proteinbiosynthese nach der 308. Aminosäure, weshalb bei diesem Transkript die C-terminale Domäne fehlt (Shahbazian et al. 2002). Trotz der unterschiedlichen genetischen Veränderungen in diesen Modellen, ist ihnen ein Funktionsverlust des MeCP2-Proteins gemeinsam, der zu Phänotypen mit unterschiedlichen Schweregraden führt. Ihr Schweregrad ist neben der Art der Mutation auch vom Geschlecht der Maus abhängig, wobei hemizygote Männchen einen schwereren und schnelleren Krankheitsverlauf erleiden als die heterozygoten Weibchen. Wie bei humanen Patientinnen variiert auch bei weiblichen Rett-Mäusen der Phänotyp stark (Villard et al. 2001).

In verschiedenen Studien konnten eine große Bandbreite an Symptomen der Mausmodelle festgestellt werden (Calfa et al. 2011; Katz et al. 2012; Li und Pozzo-Miller 2012). Dazu gehört der verzögerte, postnatale Einsatz der Symptome, der Verlust der motorischen Fähigkeiten, ein steifer, unkoordinierter Gang sowie Schwierigkeiten beim Lernen und Gedächtnisprobleme. Zusätzlich konnten in den verschiedenen Modellen eine allgemeine Hypoaktivität, epileptische Anfälle und spinale Deformationen festgestellt werden. Auch die soziale Interaktion der Mäuse untereinander ist eingeschränkt. Wie auch bei humanen RettPatienten leiden auch die Mäuse unter respiratorischen und kardialen Unregelmäßigkeiten, wie zum Beispiel Apnoe oder langen QT-Intervallen (Stettner et al. 2008). Weiterhin sind sowohl ihre Schädel als auch ihre Gehirne sowie die einzelnen Neurone verkleinert. Dabei nimmt der Schweregrad des Phänotyps mit fortschreitendem Krankheitsverlauf zu. All dies führt schließlich dazu, dass männliche Rett-Mäuse eine eingeschränkte Lebenserwartung von ungefähr 50 Tagen haben, nachdem ab dem zehnten Lebenstag mit dem Einsetzen erster Symptome zu rechnen ist. Die Weibchen erreichen dagegen eine normale Lebenserwartung von ca. 400 Tagen nach dem Einsatz der Symptome ungefähr ab dem 50. Tag (Guy et al. 2001; Shahbazian et al. 2002; Lawson-Yuen et al. 2007; Jentarra et al. 2010; Goffin et al. 2011; Wegener et al. 2014; Pitcher et al. 2015).

Neben dem oben genannten Knockout-Modell Mecp $2^{\text {tm1.1Bird }}$ existieren noch weitere Knockout-Modelle, die häufigen humanen Mutationen entsprechen, die dem Rett-Syndrom zuzuordnen sind, aber seltener verwendet werden. Dazu gehören $M e c p 2^{\text {R168x }}, M e c 2^{\text {R255X }}$ und Mecp2 ${ }^{\mathrm{T} 158 \mathrm{~A}}$ (Lawson-Yuen et al. 2007; Jentarra et al. 2010; Goffin et al. 2011; Wegener et al. 2014; Pitcher et al. 2015).

Auch für die bereits beschriebene Rett-Variante durch MeCP2-Überexpression konnten verschiedene Mausmodelle (Mecp $2^{\mathrm{Tg} 1}$ und $M e c p 2^{\mathrm{WT}{ }^{\mathrm{T}} \mathrm{EGFP}}$ ) entwickelt werden (Collins et al. 2004; Bodda et al. 2013). Dabei korreliert die Ausprägung des Phänotyps besonders mit der Abweichung von der normalen MeCP2-Funktion und MeCP2-Konzentrationen. Indem also sowohl die Überexpression als auch die Unterexpression von MeCP2 in verschiedenen Mausmodellen diesen Zusammenhang bestätigt, wird die Wichtigkeit einer optimalen MeCP2-Balance hervor gehoben (Chao und Zoghbi 2012).

Dass auch bei Mäusen der Ursprung des Rett-Syndroms ausschließlich auf dem XChromosom liegt, wurde von (Pelka et al. 2006) nachgewiesen, indem männliche $M e c p 2^{-/ y_{-}}$ 
und Mecp $2^{-/ 0}$-Knockoutmäuse, bei denen das Y-Chromosom fehlt, verglichen wurden und ein sehr ähnlicher Phänotyp festgestellt wurde.

Neben den unterschiedlichen Mausmodellen wurden auch Modelle mit anderen Spezies entwickelt, darunter ein Mecp2-Knockout-Rattenmodell (Engineer et al. 2015) und das erste nicht-humane Primatenmodell für das Rett-Syndrom in China (Liu et al. 2014) und Japan (Kishi et al. 2014). Trotzdem bieten Mausmodelle die vermutlich besten Bedingungen zur Durchführung verschiedener Untersuchungen zum Rett-Syndrom, da sie einen kurzen Reproduktionszyklus aufweisen und mit kostengünstigeren und einfacheren Mitteln artgerecht auf wenig Raum gehalten und gezüchtet werden können als andere Spezies.

\subsubsection{Therapieansätze und Prognose}

Für das Rett-Syndrom liegen verschiedene Therapieformen vor, die symptomatischer Natur sind (Hanks 1986; De Felice et al. 2012; Katz et al. 2016). Eine Therapie, die direkt auf die genetisch bedingte Ursache der Erkrankung abzielt, konnte bisher nicht etabliert werden, obwohl erfolgversprechende Ansätze vorhanden sind.

Ein verbreiteter Therapieansatz liegt in der Verabreichung von Antioxidantien und Radikalfängern, die die schädliche Wirkung von ROS reduzieren sollen (Abb. 5). So konnten bei männlichen Mecp2-Knockoutmäusen durch eine Behandlung in-vivo und in-vitro mit dem Vitamin-E-Derivat Trolox das Redoxgleichgewicht, die synaptische Plastizität sowie die Toleranz gegenüber Hypoxie verbessert und die Lipidperoxidation gesenkt werden (Janc et al. 2016). Die Gabe dieses Derivates könnte die verringerten Vitamin-E-Konzentrationen bei Rett-Patienten kompensieren (Formichi et al. 1998). Durch eine orale Verabreichung von Polyphenol-Curcumin konnten bei weiblichen $M e c p 2^{308}$-Mäusen Gefäßfunktionen wiederhergestellt und die intravasale ROS-Synthese in Mesenterialarterien reduziert werden (Panighini et al. 2013). Bei Patienten führt eine orale Einnahme von mehrfach ungesättigten Omega-3-Fettsäuren zu reduzierten Blutkonzentrationen von pro-oxidativen Faktoren und von Markern der Lipidperoxidation. Außerdem ist bei diesen Patienten eine Verbesserung der Atmung und der Herzfunktion sowie der nicht-verbalen Kommunikationsfähigkeiten und der Motorik zu beobachten (De Felice et al. 2012; Maffei et al. 2014). Bei Patienten, die an der CDKL5-Defizienz leiden, welche ursprünglich als eine Form des Rett-Syndroms angesehen wurde, heute aber als eigenständige Krankheit gilt, bewirkt die Therapie mit diesen Fettsäuren ebenfalls eine Verbesserung der Symptome (Leoncini et al. 2015). 


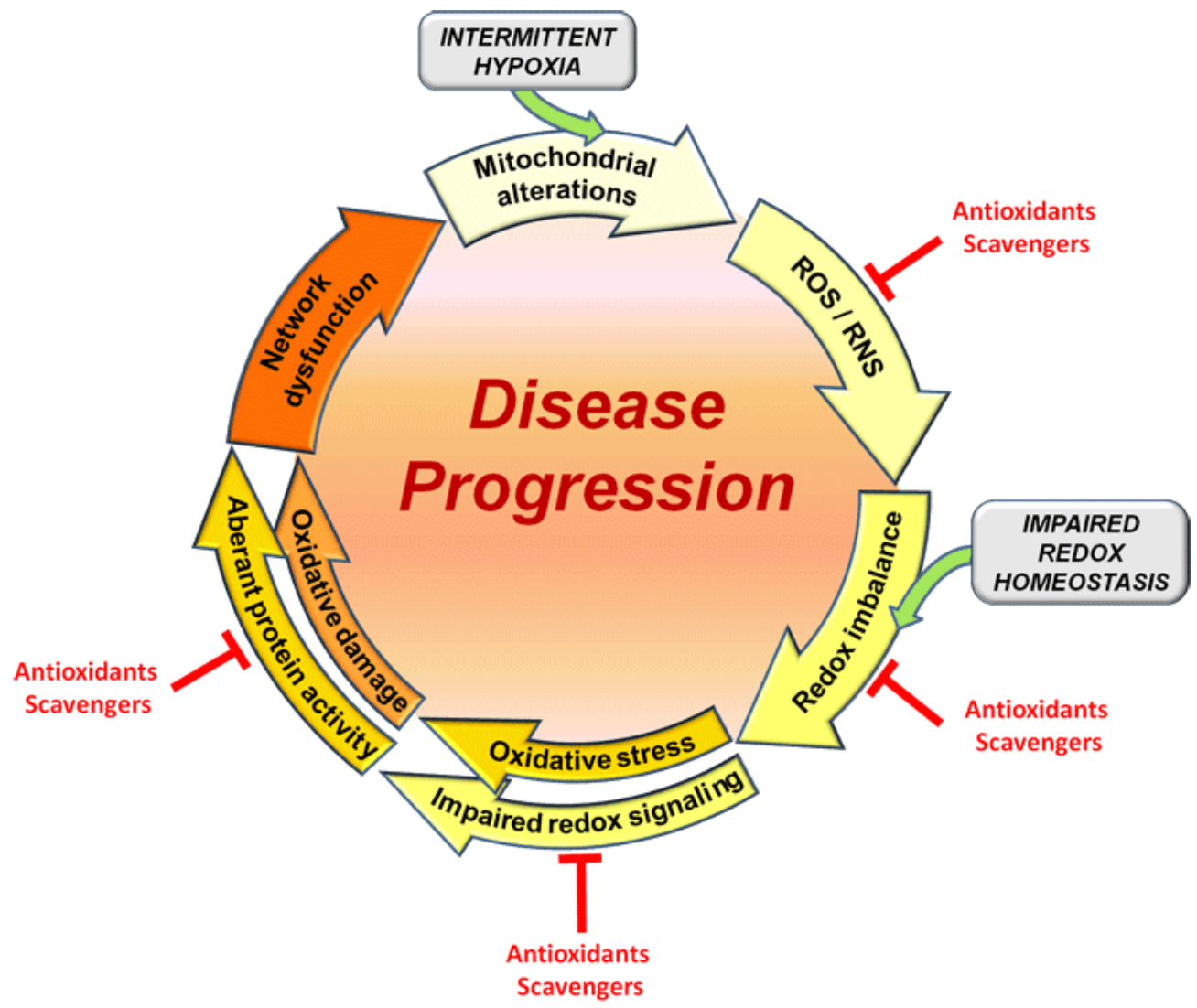

\section{Abbildung 5: Möglicher Einfluss der intermittierenden Hypoxie auf die Progression des Rett-Syndroms.}

Aufgrund der im Rett-Syndrom festgestellten Veränderungen an Mitochondrien, sind diese gegenüber einer intermittierenden Hypoxie deutlich anfälliger für eine erhöhte Synthese an reaktiven Sauerstoffspezies (ROS) und Stickstoffspezies (RNS). Die daraus folgende Redoximbalance wird durch eine eingeschränkte Redoxhomöostase weiter verstärkt. Aus dieser gestörten Redox-Situation der Zellen resultiert oxidativer Stress, welcher die Schädigung von Zellbestandteilen und somit zu einer Veränderung deren Funktionen zur Folge haben. All dies führt schließlich zu Dysfunktionen im gesamten Zellnetzwerk, welche eine Kompensation der Hypoxie reduzieren. Eine Therapiemöglichkeit mit der Behandlung durch Radikalfänger setzt an der ROS-Synthese und den daraus resultierenden Redox-Veränderungen an und könnte die Kompensation hypoxischer Reize verbessern. Abbildung entnommen aus (Müller und Can 2014) mit freundlicher Genehmigung des Verlages Portland Press.

Eine Behandlung mit dem bakteriellen zytotoxischen Nekrosefaktor 1 (CNF1) konnte eine Verbesserung des Phänotyps von weiblichen $M e c p 2^{308}$-Mäusen bewirken, indem die Produktion von Wasserstoffperoxid beschränkt wurde und sich die Atemfunktion normalisieren konnte (De Filippis et al. 2015).

Die Verbesserung des gestörten neuronalen Netzwerkes stellt einen weiteren Therapieansatz dar. Dabei führt die Stimulierung der Serotoninrezeptoren 5-HT7 durch den Serotoninagonisten LP-211 zu einer ähnlichen Verbesserung des Phänotyps wie die Behandlung mit Antioxidantien (Valenti et al. 2017). 
Die Behandlung mit Antioxidantien und Radikalfängern und deren bisherige Erfolge im Mausmodell und an Patienten bestätigen die enge Korrelation zwischen dem gestörten Redoxgleichgewicht, der Pathogenese und der Ausprägung des Phänotyps. Trotzdem müssen diese Behandlungskonzepte weiter verbessert werden, um eine Therapieform zu entwickeln, die lebenslänglich eine Verzögerung oder Unterdrückung der Symptome ermöglicht.

Neben der symptomatischen Therapie des Rett-Syndroms konnten auch Erfolge in der kausalen Behandlung verzeichnet werden. So gelang es das Mecp2-Gen in Mäusen zu reaktivieren (Giacometti et al. 2007; Guy et al. 2007). Dies führte entweder zum Tod der Maus oder zur Umkehrung des Phänotyps. Aufgrund der enormen Schwankung der Ergebnisse, stellt dies zwar keine aktuell verfügbare Therapieform dar, beweist aber, dass eine Heilung des Rett-Syndroms in Zukunft nicht unmöglich wäre.

Da es sich bei dieser Erkrankung nicht um einen neurodegenerativen Prozess handelt, bleibt die Mecp2-Reaktivierung eine mögliche Therapieform, deren Mechanismen genauer untersucht werden müssen, um ein sichereres Ergebnis zu erzielen. Zum jetzigen Zeitpunkt stellt dies aber keine wirksame Therapieform dar, da sowohl ein MeCP2-Mangel sowie ein MeCP2-Überschuss den Phänotyp verschlechtern und zu einem vorzeitigen Tod führen. Bis dahin versprechen die verschiedenen symptomatischen Behandlungen mit Antioxidantien bei Patienten zumindest eine Linderung der Symptome und eine Verbesserung der Lebensqualität.

\subsection{Oxidative Schädigung von DNA}

Aufgrund des gestörten Redox-Equilibriums kommt es zur oxidativen Schädigung von Zellbestandteilen, welche bezüglich Proteinen und Lipiden im Rett-Syndrom bereits bewiesen werden konnte (Sierra et al. 2001; De Felice et al. 2009; Janc et al. 2016). Diese oxidativen Schäden an Lipiden und Proteinen führen zu deren Dysfunktion, was wiederum zu Fehlfunktionen im zellulären Stoffwechselablauf führt und die bestehenden mitochondrialen Veränderungen fördert, da unter anderem die Aktivität diverser Ionenkanäle vom Redox-Gleichgewicht abhängig ist. Auch eine oxidative Schädigung von DNA im Rett-Syndrom ist folglich nicht auszuschließen (Valinluck et al. 2004; Tsukahara 2014). Bereits unter physiologischen Bedingungen erfolgt ein kontinuierlicher Angriff von ROS auf DNA als notwendige Konsequenz der metabolischen biologischen Reaktionen im Körper (Poulsen et al. 1996). Dabei produziert der Körper physiologischer Weise aber nur so viel ROS, wie auch vom umliegenden Gewebe katabolisiert werden kann (Aust und Eveleigh 1999).

Sowohl an allen vier Nukleinbasen als auch am Kohlenstoffring der Desoxyribose in DNA kann eine Oxidation erfolgen (Aust und Eveleigh 1999). Bei einer Analyse des Erbgutes mittels Gaschromatographie in Kombination mit einem Massenspektrometer konnten 17 verschiedene durch Oxidation modifizierte Basen identifiziert werden (von Sonntag 1991). 
Die Oxidation von DNA durch eine Reaktion mit radikalischen ROS, wie zum Beispiel mit dem Hydroxylradikal HO’, kann auf verschiedenen Wegen erfolgen, zum Beispiel durch Eliminierung oder Addition. Eine Reaktion von $\mathrm{HO}^{\circ}$ mit der Desoxyribose in DNA führt zur Bildung von Kohlenstoffradikalen, welche weniger reaktiv sind als das angreifende Hydroxylradikal. Eine Eliminierungsreaktion durch Abspaltung von einem Wasserstoffatom ist an allen fünf Kohlenstoffatomen der Ringstruktur möglich (von Sonntag 1987). Unter anaeroben Bedingungen führt eine Wasserstoffeliminierung am $\mathrm{C}^{4}$-Atom zu einem Bruch der beta-Bindung und in Folge dieses Bindungsbruches kommt es zur Freigabe einer intakten Base und eines durch Oxidation modifizierten Kohlenhydratgerüsts (Dizdaroglu et al. 1975; Beesk et al. 1979). Eine Oxidation am C1'-Kohlenstoff führt dagegen zu einer Umlagerung des Kohlenhydrats zu einem Lacton und durch einen darauffolgenden Bindungsbruch zur Abgabe der intakten Base (Dizdaroglu et al. 1977). Unter aeroben Bedingungen kann eine Addition von Sauerstoffmolekülen an Kohlenstoffradikale erfolgen, die zur Bildung von Peroxylradikalen führen, welche ebenfalls den Bruch einer C-C-Bindung nach sich ziehen. Aufgrund der Bildung eines C5'-Peroxylradikals wird entweder ein modifizierter Zucker und eine intakte Base abgegeben oder es folgt eine Aldehydbildung am $\mathrm{C}^{`}{ }^{`}$ und damit der Bruch der Bindung zum nächsten Nukleotid (Dizdaroglu et al. 1977).

Neben der Oxidation des Zuckers erfolgt durch eine Reaktion mit ROS auch die Oxidation von Nukleinbasen durch eine Addition des Hydroxylradikals $\mathrm{HO}^{\bullet}$ an die Doppelbindung in den Heterozyklen (Lovell et al. 1999). Durch eine Oxidation des C8` in Guanin entsteht mit 8-Oxo-2‘-Desoxyguanin ein sehr häufig untersuchter DNA-Oxidationsmarker (Valavanidis et al. 2009). Über eine Keto-Enol-Tautomerie stehen 8-Oxo-2'-Desoxyguanosin (8-oxodG) und 8-Hydroxy-2'-Desoxyguanosin (8-OHdG) im Gleichgewicht, weshalb bei quantitativen Analysen eine Unterscheidung beider Formen nicht möglich ist (Abb. 6).

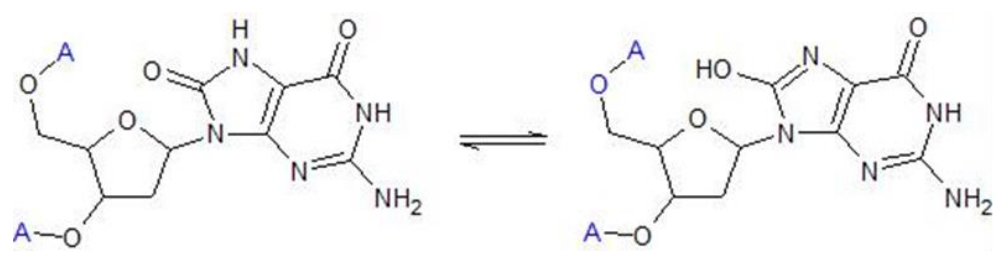

8-Oxo-2'-Desoxyguanosin 8-Hydroxy-2'-Desoxyguanosin

Abbildung 6: Keto-Enol-Tautomerie von am C8 oxidiertem Guanosin.

Durch die Oxidation von Guanosin am C8 innerhalb der Nukleinbase entsteht 8-Oxo-2‘Desoxyguanosin, welches über eine Keto-Enol-Tautomerie zu 8-Hydroxy-2'-Desoxyguanosin reagieren kann. 
Diese Modifizierung des Erbgutes durch Oxidation spielt sowohl in verschiedenen Krankheitsbildern als auch beim Alterungsprozess eine entscheidende Rolle (Aust und Eveleigh 1999). So korreliert die Konzentration von 8-OHdG stark mit dem Auftreten von Krebs, da dessen Vorhandensein im DNA-Strang die Funktion der alpha-Polymerase bei der DNA-Replikation stört. Diese kann die oxidierte Guaninform nicht korrekt ablesen, wodurch Fehler im replizierten Strang durch Miskodierung und den Austausch von Aminosäuren entstehen (Kuchino et al. 1987; Floyd et al. 1990). Die Konzentration von 8-OHdG steigt im DNA-Strang mit zunehmendem Alter an, wodurch ein Zusammenhang mit dem Alterungsprozess gezogen werden kann (Mecocci et al. 1994).

Oxidative Schäden an DNA sind aber nicht vollends irreversibel, da diesen ein Reparaturmechanismus entgegensteht, wodurch sich ein Gleichgewicht zwischen Schädigung und Reparatur einstellt. Dies geschieht mit Hilfe der Basenexzisionsreparatur (BER), bei welcher die Aktivität von vier Enzymen zur Extraktion der defekten Base aus dem DNA-Strang führen (Kubota et al. 1996). Zuerst erkennen spezifische DNAGlykosylasen beschädigte Basen und katalysieren die Öffnung der N-glykosidischen Bindung (Chung et al. 1991; Tchou et al. 1991). Zurück bleibt nach dem Herausschneiden der Base eine apurinische oder apyrimidinische Stelle im Strang. Diese Stellen werden von der APEndonuklease 1 (APE1) erkannt, welche die Öffnung der Phosphodiesterbindung katalysiert, wodurch ein Einzelstrangbruch erzielt wird. Anschließend wird die Nukleotidlücke durch die DNA-Polymerase $\beta$ aufgefüllt und durch eine Ligase verknüpft. Diese Art der Basenexzisionsreparatur wird als short patch bezeichnet, da lediglich eine Base ausgetauscht wird - das „Pflaster“ erstreckt sich also nur über die Länge einer Base. Bei einer anderen Variante der Basenexzisionsreparatur, dem long patch, wird zunächst auch nur eine von der Glykosylase als defekt erkannte Base herausgeschnitten, anschließend erwirkt die APE1 auch hier einen Einzelstrangbruch. Im Gegensatz zum short patch fügen die DNAPolymerasen $\beta$ (POB) und $\delta$ (POD) mehrere Nukleotide hinzu, wobei der ursprünglich dort gebundene Teil des DNA-Stranges noch nicht entfernt wurde. Dies geschieht erst durch die Aktivität der Flap-Endonukelase 1 (FEN1), bevor eine Ligase alle Nukleotide verknüpft (Robertson et al. 2009).

Bei den DNA-Glykosylasen handelt es sich um eine Enzymgruppe, welche jeweils spezifisch verschiedene Schäden an Nukleobasen erkennen können. Dazu gehört zum Beispiel die Oxoguaninglykosylase 1 (OGG1), welche spezifisch am C`8 oxidiertes Guanin erkennt und entfernt (Robertson et al. 2009). Die nach der Basenexzisionsreparatur nun freien oxidierten Basen werden über zerebrospinale Flüssigkeit (CSF), Blut und Urin abtransportiert und ausgeschieden (O'Neill 1983; Vieira und Steenken 1987; Vieira und Steenken 1990). Schon 1996 wurde festgestellt, dass die Konzentration von 8-OHdG im Urin mit Zunahme des Lebensalters sank (Poulsen et al. 1996). Dies bestätigte die Annahme, dass die Aktivität der Reparaturmechanismen im Alter abnimmt. 


\subsection{Eisen-Metabolismus}

Das Element Eisen ist für den Körper zwar essenziell, birgt aber auch eine gewisse Toxizität. Aufgrund der hohen Redoxaktivität des Eisens kann dessen Analyse Aufschluss über das Vorhandensein und das Ausmaß der Redoximbalance geben, welche eine wichtige Säule in der Pathogenese des Rett-Syndroms darstellt (Gotz et al. 1994; Eisenstein 2000).

\subsubsection{Redoxaktivität des Eisens}

In seiner proteingebundenen Form geht von Eisen keine Gefahr hinsichtlich potenzieller Reaktionen aus. Freies Eisen in Form von $\mathrm{Fe}^{2+}$-Ionen ist aufgrund seiner Labilität sehr reaktiv und entwickelt darüber sein toxisches Potential (Kakhlon und Cabantchik 2002; Kruszewski 2003; Kurz et al. 2004). Über eine Reaktion mit Wasserstoffperoxid, welches wie bereits erwähnt vor allem bei der mitochondrialen Atmungskette entsteht, entstehen Hydroxylradikale, welche zur oxidativen Schädigung von Zellbestandteilen führen. Diese Reaktion wird als Fenton-Reaktion bezeichnet (Fenton 1894). Dabei werden bis zu 2\% des verwendeten Sauerstoffs für die unerwünschte ROS-Synthese verwendet (Kehrer 2000).

$$
\mathrm{Fe}^{2+}+\mathrm{H}_{2} \mathrm{O}_{2} \rightleftharpoons \mathrm{Fe}^{3+}+\mathrm{OH}^{-}+\mathbf{O H}^{\bullet}
$$

[Formel 1]

Bei einer gestörten Redoxbalance, wie sie im Rett-Syndrom beschrieben wird, würde sich bei oxidativer Last das chemische Gleichgewicht auf die Seite der Eisen-(III)-Ionen verlagern. Darüber hinaus besitzt Eisen die Fähigkeit molekularen Sauerstoff zu Superoxidradikalen zu reduzieren, wobei diese Reaktion aber langsam abläuft und reversibel ist (Ambroz et al. 2001; Valko et al. 2005). Die Rückreaktion dazu ist als Superoxidanion-vermittelte FentonReaktion bekannt (Halliwell und Gutteridge 1990).

$$
\mathrm{Fe}^{3+}+\mathrm{O}_{2}^{-\bullet} \rightleftharpoons \mathrm{Fe}^{2+}+\mathrm{O}_{2}
$$

[Formel 2]

Diese Radikale sind in der Lage Eisen aus seiner proteingebundenen Form, zum Beispiel aus Ferritin, zu lösen, wodurch dieses als freies Eisen wiederum die Synthese von weiteren ROS fördert (Paul 2000). Dabei spielt besonders das Hydroxylradikal eine zentrale Rolle, da dessen Hauptentstehungsquelle die Fenton-Reaktion ist (Meneghini 1997). Im Gegensatz zu Wasserstoffperoxid und Superoxid können Hydroxylradikale nicht über enzymatisch katalysierte Reaktionen unschädlich gemacht werden, sodass die einzige Möglichkeit dazu in einer Reaktion mit Radikalfängern wie Glutathion oder Vitamin E liegt. Da es sich hierbei um die aggressivste Form aller reaktiven Sauerstoffstoffspezies handelt, führt die Entstehung dieser Radikale immer zu einer oxidativen Schädigung von Zellbestandteilen, solange keine Reaktion mit einem Radikalfänger erfolgt (Yu 1994). Allerdings sind Hydroxylradikale auch äußerst instabil, weshalb die Reaktion mit Zellbestandteilen nur in der Nähe des Entstehungsortes erfolgen kann (Pryor 1986). Sofern nicht ausreichend Radikalfänger in nächster Nähe zur Verfügung stehen, gilt es die Entstehung von Hydroxylradikalen zu verhindern, indem zum Beispiel freies Eisen zunehmend an Proteine gebunden wird (Sies 1993). 


\subsubsection{Funktion von Eisen}

Die Funktionen von Eisen sind vielseitig. Es dient als Kofaktor vieler Enzyme, aber ist in seiner komplexierten Form auch Bestandteil einiger Proteine. So fungiert es als Kofaktor für die Succinatdehydrogenase und Aconitase im Citratzyklus und ist über Zytochrom B, die Zytochromoxidase und die FeS-Komplexe an der Atmungskette in Mitochondrien beteiligt (Thompson et al. 2001; Atamna 2004). Außerdem wird es für die Myelinisierung der Axone von Oligodendrozyten im Gehirn benötigt (Qian und Wang 1998). Weiterhin wirkt es als Kofaktor bei der Synthese von Neurotransmittern wie Dopamin, Serotonin und Noradrenalin (Thompson et al. 2001). In komplexierter Form als zweiwertiges Fe(II) oder dreiwertiges Fe(III) findet es Verwendung in Häm-Proteinen oder FeS-Clustern. In HämProteinen ist es in einem Porphyrin-Ring komplexiert und ermöglicht die Bindung von molekularem Sauerstoff an Hämoglobin und Myoglobin (Peters 1912).

\subsubsection{Transport und Speicherung von Eisen im Gehirn}

Um der Toxizität freier Eisenionen entgegen zu wirken, werden diese im Blut an das Protein Transferrin ( $\mathrm{Tf}$ ) gebunden. Als Apotransferrin besitzt es eine sehr hohe Bindungsaffinität zu $\mathrm{Fe}^{3+}$. Nach der Bindung zweier $\mathrm{Fe}^{3+}$ - Ionen wird der Komplex als Holotransferrin bezeichnet (Osborne und Campbell 1900; Schade und Caroline 1944). Der in Membranen vorkommende Transferrin-Rezeptor (TfR) ist in der Lage, Holotransferrin zu erkennen und zu binden, bevor der Tf-TfR-Komplex durch Clathrin-vermittelte Endozytose in die Zelle aufgenommen wird (Jandl und Katz 1963; Goldstein et al. 1979). Die Lösung der Eisenionen vom Tranferrin-Molekül erfolgt erst in Endosomen, welche durch eine Fusion des endozytierten Komplexes mit weiteren Vesikeln entstehen. Dort wird der pH-Wert durch ATP-abhängige Protonenpumpen in der Membran soweit abgesenkt, dass die Bindung zwischen $\mathrm{Fe}^{3+}$ und Transferrin gelöst wird. Die nun freien Eisenionen werden nach einer Reduktion zu Fe ${ }^{2+}$ durch eine Ferrireduktase über den divalenten Metallionentransporter 1 (DMT1) in der Endosommembran in das Zytosol der Zelle transportiert und stehen dort verschiedenen Reaktionen zur Verfügung (Cheng et al. 2004). Zuletzt wird der mittlerweile eisenfreie Tf-TfR-Komplex exozytotisch aus dem Zellinneren entfernt und erneut in die Plasmamembran eingebaut, bevor Apotransferrin wieder an das Blut abgegeben werden kann (Dautry-Varsat et al. 1983; Aisen et al. 2001).

Innerhalb der Zelle wird ein Großteil des Eisens zur Speicherung an Ferritin gebunden (Bradbury 1997). Bei Ferritin handelt es sich um ein globuläres Eisenspeicherprotein, welches aus 24 Untereinheiten besteht. Diese Untereinheiten können aus zwei verschiedenen Polypeptidketten bestehen; Ferritin H besitzt ein hohes Molekulargewicht, Ferritin L dagegen nur ein niedriges. Ferritin $\mathrm{H}$ weist eine Ferroxidase-Aktivität auf und ermöglicht dadurch die schnelle Aufnahme von Eisenionen in das Molekül, wohingegen Ferritin L als Langzeitspeicher dient, indem es an der Bildung des Proteinkerns beteiligt ist (Eisenstein 2000; Thompson et al. 2001). Dies ermöglicht die Speicherung von bis zu 4500 Eisenatome 
in Ferritin, wobei im Durchschnitt nur 2000 bis 3000 Atome gespeichert werden (Andrews et al. 1992; Bradbury 1997; Chasteen und Harrison 1999). Eine weitere Speichermöglichkeit erfolgt über das Molekül Hämosiderin, welches unter eisenreichen Bedingungen seine Funktion ausübt (Harrison und Arosio 1996).

Als einziges bekanntes Eisenexport-Protein fungiert das Metalltransportprotein 1 (MTP1), welches auch als Ferroportin 1 bekannt ist. Dieses in Neuronen, Astrozyten und Oligodendrozyten vorkommende Molekül transportiert $\mathrm{Fe}^{2+}$ über die Plasmamembran ins Blut, wonach die Eisenionen von einer membranverankerten Ferroxidase wieder zu $\mathrm{Fe}^{3+}$ oxidiert werden, sodass eine Bindung an Tf wieder möglich ist (Abboud und Haile 2000; Burdo et al. 2001; Garrick et al. 2003; Wu et al. 2004). Eine schematische Übersicht dieser Prozesse ist Abbildung 7 zu entnehmen.

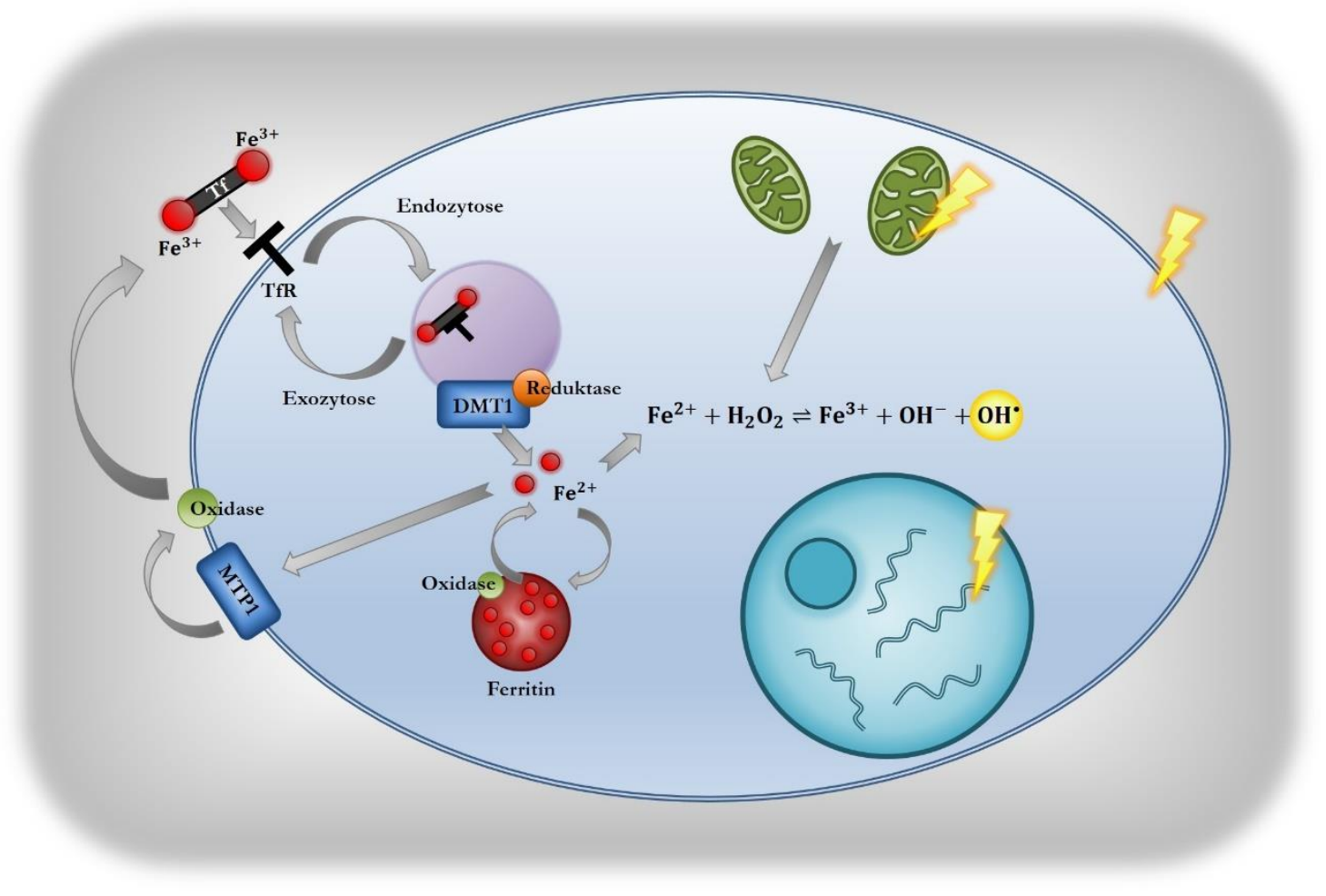

\section{Abbildung 7: Schematische Darstellung von Transport, Speicherung und Reaktivität von Eisen in Zellen.}

Eisen wird in Form von dreiwertigen Ionen in die Zelle aufgenommen, indem es an Transferrin ( $\mathrm{Tf}$ ) gebunden wird und nach Bindung dieses Komplexes an den Transferrin-Rezeptor (TfR) endozytotisch in das Endosom geschleust wird. Dort werden die Eisen-Ionen von Transferrin gelöst, zu zweiwertigem Eisen reduziert und über den DMT1-Transporter in das Zytosol transportiert, während der Tf-TfR-Komplex zur Wiederverwendung durch Exozytose aus der Zelle heraus bzw. in die Plasmamembran hinein transportiert wird. Vom Zytosol aus bestehen mehrere verschiedene Verwendungsmöglichkeiten für Eisen: Speicherung als dreiwertiges Eisen in Ferritin, Export über MTP1 und erneute Bindung an Transferrin oder Reaktion mit verschiedenen Stoffen. Eine mögliche Reaktion ist die Fenton-Reaktion, in der zweiwertige Eisen-Ionen mit ROS in einer Redoxreaktion zu freien Hydroxylradikalen reagieren. Diese sind in der Lage Proteine, Lipide und DNA oxidativ zu schädigen. 


\subsubsection{Eisen im Zusammenhang mit neuronalen Erkrankungen}

Aufgrund des breiten Spektrums an Funktionen, die Eisenionen in biologischen Systemen erfüllen, und der besonders hervorzuhebenden Redox-Sensibilität ist es nicht überraschend, dass Störungen des Eisen-Metabolismus eine wichtige Rolle in einer Vielzahl neuronaler und neurodegenerativer Erkrankungen einnehmen.

Besonders anfällig für Oxidation und Reduktion sind Bereiche des Gehirnes, welche ohnehin hohe Eisenkonzentrationen aufweisen, da dort das Ausmaß einer veränderten RedoxSituation folglich am größten ist. Zu diesen Hirnarealen zählen die Substantia nigra, das Putamen und der Globus pallidus (Hill und Switzer III 1984; Riederer et al. 1992; Benkovic und Connor 1993).

Aus einer Myelindefizienz resultiert die Akkumulation von Eisen besonders in Astrozyten und Mikroglia und weniger in Oligodendrozyten (Connor et al. 1987; Connor und Menzies 1990; Connor und Menzies 1996). Erfolgt eine Myelinisierung von Oligodendrozyten ohne Einschränkungen, sind nur wenige ruhende Mikroglia mit Eisenionen angereichert, sofern keine Erkrankung wie AIDS, Multiple Sklerose oder Alzheimer vorliegt. Ist dies der Fall, folgt eine Eisenakkumulation in Form von Plaques in der Umgebung von Neuronen (Jefferies et al. 1996; LeVine 1997).

Obwohl es sich beim Rett-Syndrom nicht um einen degenerativen Prozess zu handeln scheint, weisen sowohl das Rett-Syndrom als auch die Alzheimersche Erkrankung einen progressiven Verlauf und einen Verlust kognitiver Fähigkeiten auf. In einigen Regionen, wie zum Beispiel dem Hippocampus, weisen Gehirne von an Alzheimer erkrankten Individuen eine erhöhte Eisenakkumulation auf (Good et al. 1992; Connor et al. 1992b; LeVine 1997). Außerdem werden mit den für Alzheimer typischen Plaques auch Transferrin und Ferritin assoziiert (Connor et al. 1992a).

Über den Eisenmetabolismus von Rett-Patienten ist bisher nahezu nichts bekannt. Es konnte gezeigt werden, dass die Konzentration von nicht-proteingebundenem Eisen (NPBI) aus Erythrozyten bei Rett-Patienten signifikant erhöht ist (De Felice et al. 2009). Der NPBIWert steht für die Menge an freiem Eisen und dient als Marker für eine Redoximbalance. Außerhalb des klassischen Rett-Syndroms wurde durch eine MRT-Analyse von Patienten Eisenakkumulationen in einigen Hirnregionen nachgewiesen, welche eine Mutation im WDR45-Gen aufwiesen. Diese Patienten erfüllten mehrere Leitsymptome des klinischen Rett-Syndroms und könnten für eine weitere Gruppe von Mutationen stehen, welche mit dem Rett-Syndrom assoziiert sind (Ohba et al. 2014). 


\subsection{Ziel der Dissertation}

Das gestörte Redoxgleichgewicht und die oxidative Last sowie eine morphologische und funktionelle Abnormalität der Mitochondrien konnten wie bereits erwähnt bisher in diversen Arbeiten bewiesen werden. Auch die daraus resultierende oxidative Schädigung von Proteinen und Lipiden wurde von mehreren Forschungsgruppen untersucht und bestätigt (Sierra et al. 2001; De Felice et al. 2009; Janc et al. 2016). Eine oxidative Schädigung von DNA wurde zwar aufgrund des oxidativen Milieus vermutet, aber bisher noch nicht im Detail untersucht. So wurde angenommen, dass eine Oxidation von CpG-Motiven in der DNA die MeCP2-Bindung erschweren würde, wodurch die ohnehin gestörte Genregulation zusätzlich behindert würde (Valinluck et al. 2004). Dies könnte im Zusammenhang mit der Depression des Phänotyps im Krankheitsverlauf stehen. In einer weiteren Arbeit wurde eine mögliche Oxidation von Nukleinsäuren ebenfalls vermutet, aber nicht belegt (Tsukahara 2014). Da es sich bei 8-OHdG um eine Base handelt, die im Zusammenhang mit anderen neuronalen Erkrankungen bereits häufig untersucht wurde und da sowohl die Oxidation als auch die Reparatur von Oxidationsschäden an Guanin oft Gegenstand der Forschung waren, wurde auch in dieser Arbeit 8-OHdG als Marker für das Ausmaß der DNA-Oxidation im Rett-Syndrom verwendet. Eine progressive Oxidation von DNA im Rett-Syndrom könnte zu einer Akkumulation von Fehlern in der Proteinbiosynthese führen und die Dysfunktion dieser Zellbestandteile verstärken und damit ebenfalls im Zusammenhang mit dem progressiven Krankheitsverlauf stehen. Außerdem kann das Ausmaß der DNA-Oxidation als Marker für die Folgen einer erhöhten ROS-Synthese angesehen werden. Daher wurde im experimentellen Teil dieser Arbeit die DNA aus dem Cortex-Gewebe verschiedener Mäuse extrahiert, aufgereinigt und mit einem ELISA-Assay auf oxidierte Guaninspezies hin analysiert. Somit konnte der Anteil dieser Spezies an der gesamten DNA bestimmt und zwischen unterschiedlichen Mausgruppen verglichen werden.

Im Zusammenhang mit der Redoximbalance im Rett-Syndrom könnte auch ein verändertes Gleichgewicht des Eisenstoffwechsels stehen, da eine erhöhte ROS-Konzentration das chemische Gleichgewicht der Fenton-Reaktion auf die Seite der Produkte verlagern könnte. Eine etablierte Methode zur ortsaufgelösten Analyse von Eisenkonzentrationen in Gewebe ist die Färbung von Eisenionen in Hirnschnitten aus PFA-fixierten (Paraformaldehyd) Gehirnen, welche an MeCP2-defizienten Mäusen und Wildtyp-Mäusen erfolgen soll. Nicht nur die Untersuchung von Eisen-Konzentrationen ist in Hirnschnitten durch eine Färbung gut zu erzielen, es existiert auch eine Vielzahl von Methoden zur Darstellung weiterer Marker. Da im Rett-Syndrom auch Aberrationen bezüglich glialer Zellen von einigen Arbeitsgruppen festgestellt wurden, sollen in dieser Arbeit PFA-fixierte Hirnschnitte nicht nur in Hinsicht auf Eisenionen, sondern auch hinsichtlich verschiedener inflammatorischer und struktureller Zellmarker (immun-)histochemisch gefärbt werden, um Aufschlüsse über mögliche Veränderungen der Redox-Balance, synaptischen Verknüpfungen und der zerebralen Strukturen sowie über mögliche inflammatorische Prozesse im Rett-Syndrom zu geben und den Einfluss der zerebralen Zellen auf die Erkrankung weiter zu definieren. 


\section{$2 \quad$ Material und Methoden}

Die für die experimentelle Umsetzung der Analyse der mitochondrialen $\mathrm{H}_{2} \mathrm{O}_{2}$-Freisetzung und der Quantifizierung der DNA-Oxidation benötigten Chemikalien und Gerät sind in den nachfolgenden Tabellen gelistet.

Tabelle 1: Übersicht der verwendeten Chemikalien zur Bestimmung der mitochondrialen $\mathrm{H}_{2} \mathrm{O}_{2}$-Freisetzung.

\begin{tabular}{|c|c|c|}
\hline Substanz & Konzentration & Hersteller \\
\hline \multirow{2}{*}{$\begin{array}{c}20 \mathrm{mM} \text { HEPES } \\
220 \mathrm{mM} \text { Mannitol } \\
70 \mathrm{mM} \text { Sucrose } \\
1 \mathrm{mM} \text { EDTA } \\
0,5 \mathrm{mM} \text { PMSF }\end{array}$} & Sigma-Aldrich \\
\hline Coomassie-Brilliant-Blau & - & Bio-Rad \\
\hline Standard-Proben für & Bovines Serumalbumin & Sigma-Aldrich \\
\hline Bradford-Assay & $\begin{array}{c}1 \mathrm{M} \text { Pyruvat } \\
0,4 \mathrm{M} \mathrm{Malat} \\
\text { Substrate }\end{array}$ & Sigma-Aldrich \\
\hline Morseradish Peroxidase HRP & $500 \mathrm{U} / \mathrm{ml}$ & Sigma-Aldrich \\
\hline Amplex Ultra Red Lösung & $5 \mathrm{mM}$ & Thermo Fisher Scientific \\
\hline
\end{tabular}

Tabelle 2: Zur experimentellen Umsetzung verwendeten Geräte.

\begin{tabular}{|c|c|c|}
\hline Gerät & Gerätebezeichnung & Hersteller \\
\hline \hline UV-Vis-Photospektrometer & DU 800 Spectrophtometer & Beckman Coulter \\
\hline Photospektrometer & Flx-Xenius & SAFAS \\
\hline Spektralphotometer & NanoDrop 2000c & Thermo Scientific \\
\hline Thermomixer & $\begin{array}{c}\text { HLC-Heating- } \\
\text { Thermomixer MHR 23 }\end{array}$ & DITABIS \\
\hline Zentrifuge & Centrifuge 5418 & Eppendorf \\
\hline Heizblock & Rotilabo-Block-Heater & Carl Roth \\
\hline Orbital Shaker & MS 3 digital & IKA \\
\hline Digitales Mikroskop & Coolscope & Nikon \\
\hline Trinokular-Mikroskop & PZMTIV & $\begin{array}{c}\text { World Precision } \\
\text { Instruments }\end{array}$ \\
\hline
\end{tabular}


Tabelle 3: Benötigte Chemikalien zur Quantifizierung der oxidativen DNASchädigung.

\begin{tabular}{|c|c|c|}
\hline Substanz & Konzentration & Hersteller \\
\hline \hline Lyse-Puffer & $\begin{array}{c}43 \mathrm{mM} \text { Tris(hydroxymethyl)- } \\
\text { aminomethan } \\
85 \mathrm{mM} \mathrm{NaCl-Lösung} \\
0,03 \mathrm{mM} \text { Natriumlaurylsulfat } \\
\text { (SDS) } \\
0,85 \mathrm{mM} \text { EDTA } \\
\mathrm{H}_{2} \mathrm{O} \text { dest. }\end{array}$ & Carl Roth \\
\hline Proteinase K & $10 \mathrm{mg} / \mathrm{ml}$ & \\
\hline Isopropanol & $99,8 \%$ & Carl Roth \\
\hline Ethanol & $70 \%$ & Carl Roth \\
\hline UltraPure-Wasser & $100 \%$ & Honeywell \\
\hline Nuklease P1 & $5 \mu \mathrm{g} / \mathrm{ml}$ & Carl Roth \\
\hline Ammoniumacetat & $0,1 \mathrm{M}$ & Sigma-Aldrich \\
\hline Alkalische Phosphatase & $0,002 \mu \mathrm{g} / \mu \mathrm{l}$ & Sigma-Aldrich \\
\hline DNA/RNA Oxidative & - & Cayman Chemical \\
\hline Damage ELISA-Kit & - & Qiagen \\
\hline QIAmp Fast DNA Tissue & & \begin{tabular}{c} 
Kit \\
\hline
\end{tabular}
\end{tabular}




\subsection{Die Mecp2-Knockout-Maus als Modell für das Rett-Syndrom}

Um das Ausmaß der Oxidationsschäden an DNA unter Einfluss des Rett-Syndroms zu untersuchen, wurden Gewebeproben von Mäusen aus dem Tiermodell Mecp2 $2^{\text {tm1.1Bird }}$ verwendet (Guy et al. 2001). Für die histochemischen und immunhistochemischen Färbungen von Gewebeschnitten wurden ebenfalls Gehirne dieses Mausmodells verwendet.

Bei den zur Untersuchung der DNA-Oxidation verwendeten Gewebeproben handelte es sich um Cortex-Gewebe, welches in Abhängigkeit vom Alter, Geschlecht, Genotyp und Fütterungsart auf DNA-Oxidation hin untersucht wurde. Die Mäuse wurden entweder im Alter von 50 oder 400 Tagen analysiert (p50, p400) und waren entweder männlich oder weiblich. Genotypisch ließen sich Wildtyp-Mäuse (WTT) als $M e c p 2^{+/+}$bzw. Mecp2 ${ }^{+/ y}$ und RettMäuse (RTT) als Mecp2 $2^{+/-}$bzw. Mecp2 $2^{-/ y}$ unterscheiden.

Außerdem wurde der Einfluss der Fütterung auf die DNA-Oxidation untersucht, indem Mäuse verwendet wurden, die normales Nagetierfutter ohne besondere Zusätze (NF) erhielten, sowie Mäuse, die mit einem speziellen, auf Antioxidation ausgerichteten Futter (AOF) versorgt wurden. Die antioxidative Wirkung dieses Futters beruht vor allem auf einer Supplementierung von alpha-Liponsäure $(0,2 \%)$, N-Acetyl-L-Cystein $(0,25 \%)$ und Vitamin E $(0,025 \%)$.

Für die Zucht und Fütterung dieser Tiere liegt der Tierschutzkommission der Universitätsmedizin Göttingen und dem Niedersächsischen Landesamt für Verbraucherschutz und Lebensmittelsicherheit (LAVES) eine Genehmigung unter dem Aktenzeichen G17/2544 vor.

\subsection{Grundlagen der Photospektrometrie}

Da im experimentellen Ablauf Photospektrometer verwendet wurden, werden im Folgenden einige physikalische Grundlagen erläutert.

Die qualitative und quantitative Analyse verschiedener Stoffe wird durch die Tatsache ermöglicht, dass Elektronen in der Lage sind, Energie zu absorbieren und zu emittieren. Durch die Absorption der Energie von Photonen aus Licht werden sie in einen höheren Energiezustand angehoben, indem sie von ihrem ursprünglichen Orbital um den Atomkern in ein energetisch höher gelegenes Orbital wechseln. Dieser Vorgang kann auch umgekehrt ablaufen, indem ein Elektron die zuvor absorbierte Energie wieder emittiert. Die Energiemenge $\Delta \mathrm{E}$, die benötigt wird, um ein Elektron von seinem ursprünglichen Energiezustand $\mathrm{E}_{1}$ in einen höher gelegenen Energiezustand $\mathrm{E}_{2}$ zu befördern, richtet sich nach der Energie der Photonen, die absorbiert werden. Da nur ganze Photonen absorbiert werden können, beträgt $\Delta \mathrm{E}$ stets ein Vielfaches der Photonenenergie $\mathrm{E}_{\text {Photon }}$ und kann damit nur diskrete Werte annehmen. Sie ist also abhängig von der Frequenz und damit von der Wellenlänge des zu absorbierenden Lichtes (Abb. 8). 


$$
\mathbf{E}_{\text {Photon }}=\mathbf{h v}
$$

[Formel 3]

$$
\Delta \mathbf{E}=\mathbf{n} \mathbf{E}_{\text {Photon }}=\mathbf{n h v}
$$

[Formel 4]

Bei der UV-VIS-Absorptionsspektrometrie mit ultraviolettem und sichtbarem Licht wird ein Analyt Strahlung mit einer Wellenlänge zwischen $400 \mathrm{~nm}$ und $700 \mathrm{~nm}$ ausgesetzt. Die Frequenz, bei der der Analyt Licht absorbiert, ist für ihn spezifisch und gibt Aufschluss über seine Zusammensetzung; das Verhältnis der Intensitäten zwischen Emission und Absorption gibt Aufschluss über die Konzentration der Probe.

$$
\log \left(\frac{I_{0}}{I_{1}}\right)=\varepsilon c d
$$

Dabei bezeichnet $I_{0}$ nach dem Gesetz von Lambert-Beer die Intensität der einfallenden Strahlung, $I_{1}$ die Intensität der emittierten Strahlung, $\varepsilon$ den Extinktionskoeffizienten, c die Konzentration der Probe und d die Schichtdicke des durchstrahlten Körpers. Über diese Methoden werden in dieser Arbeit sowohl die DNA-Konzentration der verwendeten Standards als auch die Konzentration oxidierter Guaninspezies in den Proben bestimmt.

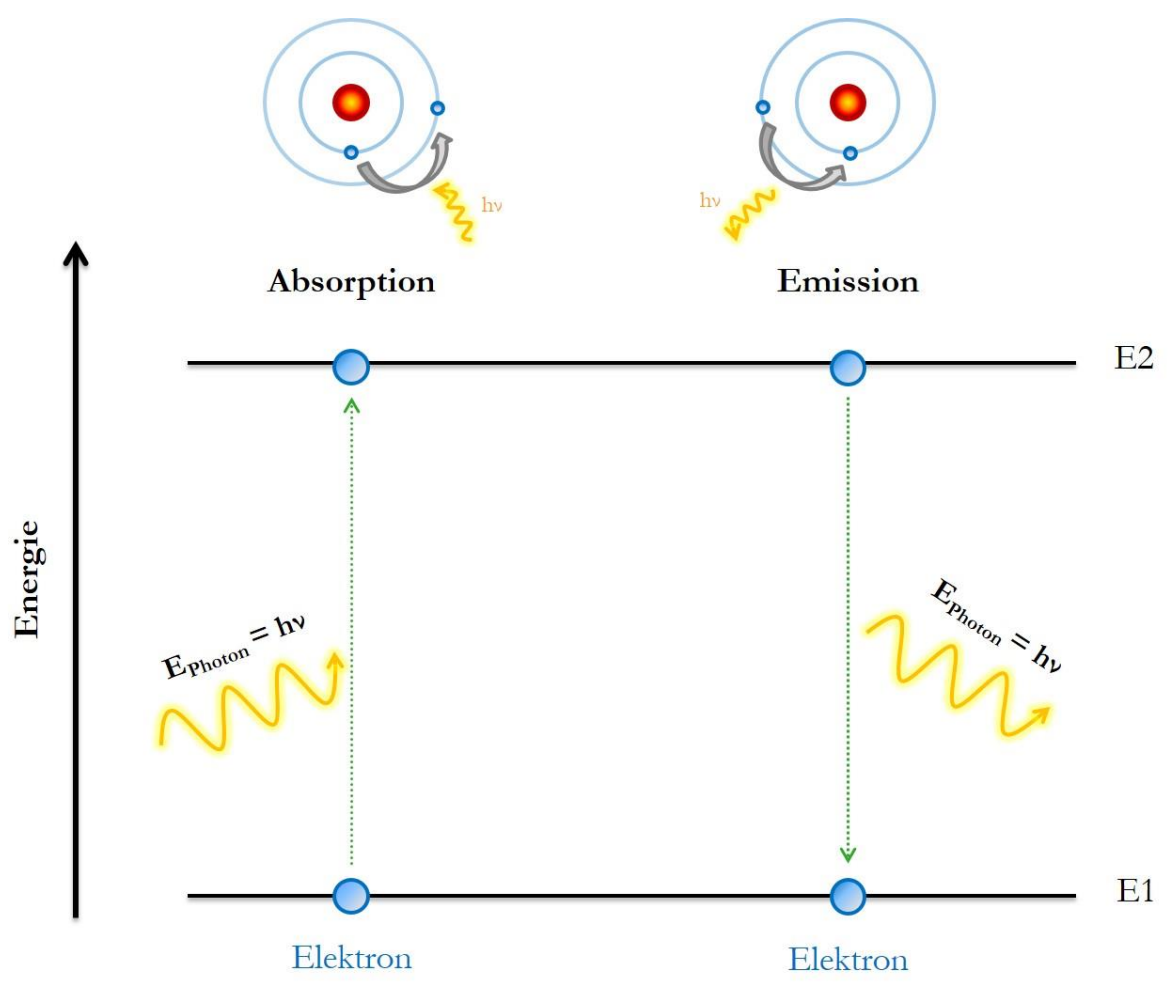

Abbildung 8: Physikalischer Mechanismus von Absorption und Emission.

Durch die Absorption der Energie von Photonen, können Elektronen von einem niedrigeren Energiezustand E1 in einen höheren Energiezustand E2 angehoben werden. Auch der entgegen gerichtete Übergang von E2 zu E1 ist durch eine Abgabe von Energie in Form von Strahlung möglich und wird als Emission bezeichnet. Die Energie der absorbierten und emittierten Photonen ist proportional zur Frequenz der Strahlung und kann zur Analyse von Agenzien genutzt werden. 


\subsection{Untersuchungen zur DNA-Oxidation}

\subsubsection{Probenentnahme}

Untersuchungsgegenstand dieser Arbeit war Hirngewebe aus Mecp2-Knockout-Mäusen. Um diese Proben $\mathrm{zu}$ entnehmen, wurden die Mäuse in Ethernarkose versetzt und durch dementsprechend autorisierte Mitglieder der Arbeitsgruppe durch zervikale Dislokation euthanasiert, das Gehirn entnommen und so präpariert, dass der Hirnstamm, das Kleinhirn, das Mittelhirn, das Großhirn und der Hippocampus voneinander separiert wurden. Die Gewebeproben, die für die Analyse der DNA-Oxidation vorgesehen waren, wurden bis zu ihrer Verwendung bei $-80{ }^{\circ} \mathrm{C}$ kryokonserviert, nachdem sie in flüssigem Stickstoff schockgefroren wurden. Gewebeproben für die Mitochondrien-Isolation wurden direkt nach ihrer Gewinnung für den Versuch verwendet.

\subsubsection{Regionsspezifische Bewertung der Analyse der mitochondrialen $\mathrm{H}_{2} \mathrm{O}_{2-}$ Freisetzung}

Um die Analyse der DNA-Oxidation auf die Hirnregion zu beschränken, in welcher die höchste Oxidationsschädigung zu erwarten wäre, wurden verschiedene Hirnregionen einer 200 Tage alten, weiblichen Mecp2-Wildtyp-Maus hinsichtlich ihrer mitochondrialen $\mathrm{H}_{2} \mathrm{O}_{2}$-Freisetzung untersucht, wobei diese als Marker für das Ausmaß der Redoximbalance fungierte. Die Durchführung dieser Messung erfolgte in Zusammenarbeit mit der Doktorandin Ina Dewenter (Studienfach Zahnmedizin, Arbeitsgruppe Prof. Michael Müller).

Dazu wurden Mitochondrien aus den Regionen Kortex, Mittelhirn, Hippocampus, Hirnstamm und Cerebellum isoliert, indem das bei der Präparation unter 2.3.1 gewonnene Gewebe mit $700 \mu \mathrm{l}$ Isolationspuffer versetzt und in einem Glasgefäß gemörsert wurde. Die dadurch homogenisierte Lösung wurde dreifach zentrifugiert und jeweils der Überstand übernommen. Daraus wurde ein Pellet gewonnen, das ausschließlich aus Mitochondrien bestand, welches anschließend in $100 \mu \mathrm{l}$ Isolationspuffer wieder gelöst wurde.

Damit die zu analysierende $\mathrm{H}_{2} \mathrm{O}_{2}$-Freisetzung einer jeden Probe auch mit den anderen Proben vergleichbar war, musste sichergestellt werden, dass jede Probe gleich viele Mitochondrien enthielt. Dies erfolgte mit Hilfe eines Bradford-Assays, in welchem über eine Proteinfärbung mit Coomassie-Brilliant-Blau die Mitochondrienkonzentration jeder Probe ermittelt wurde.

Um die $\mathrm{H}_{2} \mathrm{O}_{2}$-Freisetzung in den verschiedenen Hirnregionen zu analysieren, wurde die Mitochondrien-Lösung mit einer Pufferlösung und Substraten versetzt, um den weiteren Ablauf der Atmungskette zu ermöglichen, bei der als Nebenprodukt Wasserstoffperoxid abfiel. Dieses reagierte mit der anschließend beigefügten Horseradish Peroxidase (HRP) und dem Farbstoff Amplex Ultra Red zu Resorufin, dessen Fluoreszenzintensität mit dem FlxXenius Photospektrometer analysiert wurde (581 nm). 
Obwohl mit dieser Versuchsdurchführung keine exakte Wasserstoffperoxid-Konzentration bestimmt werden konnte, konnte trotzdem die Hirnregion mit der relativ höchsten $\mathrm{H}_{2} \mathrm{O}_{2}$-Freisetzung bestimmt werden. Das Ergebnis dieses Versuches wird unter 3.1 dargelegt. Da dieses aber für die weitere Versuchsdurchführung grundlegend ist, sei vorweggenommen, dass es sich bei der Hirnregion mit der höchsten mitochondrialen $\mathrm{H}_{2} \mathrm{O}_{2}$-Freisetzung um den Cortex handelt, weshalb Proben aus diesem Gewebe auch zur weiteren Untersuchung bezüglich der DNA-Oxidation verwendet wurden.

\subsubsection{Gewebelysierung zur Quantifizierung der DNA-Oxidation}

Das Ziel der Probenaufbereitung war die Gewinnung möglichst reiner DNA. Dazu wurden die Proben aufgetaut und je nach Verfügbarkeit 20 bis $100 \mathrm{mg}$ des Gewebes eingewogen. Nach Zugabe von $300 \mu$ l Lyse-Puffer und $20 \mu$ einer Lösung von Proteinase K wurden die Proben gesammelt in einem Thermomixer 5 Stunden lang bei $55^{\circ} \mathrm{C}$ und einer Stärke von $300 \mathrm{U} / \mathrm{min}$ lysiert.

In der so entstandenen Lösung blieben Zelltrümmer ungelöst, die durch eine Zentrifuge von der gelösten Phase getrennt wurden, in welcher die DNA enthalten war. Wenn nicht anders beschrieben, wurden die Proben immer $10 \mathrm{~min}$ lang bei $13500 \mathrm{rpm}$ zentrifugiert. Der Überstand wurde aufgefangen und mit $300 \mu \mathrm{l}$ Isopropanol alkoholisch gefällt. Die gefällte DNA wurde durch Zentrifugation in einem Pellet gesammelt und der Überstand verworfen. Das Pellet wurde mit $250 \mu \mathrm{l}$ Ethanol (70\%) versetzt und erneut zentrifugiert. Abschließend wurde das Pellet mit $100 \mu \mathrm{l}$ UltraPure-Wasser versetzt und 30 bis $60 \mathrm{~min}$ bei $37^{\circ} \mathrm{C}$ in einem Heizblock inkubiert, um den Alkohol durch Verdampfung zu entfernen und danach ungefähr vier Stunden bei $4^{\circ} \mathrm{C}$ inkubiert, damit sich die DNA wieder in der wässrigen Phase löste.

\subsubsection{Säulenchromatographie}

Um aus der DNA-Lösung Nebenbestandteile wie Proteine zu entfernen, wurden die Proben mittels Säulenchromatographie gereinigt. Dabei wird die Probelösung auf eine Silikatmembran gegeben, an welche DNA adsorbiert. Andere Bestandteile durchlaufen diese Membran ohne Bindung. Die gebundene DNA wird durch verschiedene Lösungen gewaschen, um möglichst alle Verunreinigungen zu entfernen und anschließend mit einer anderen Lösung eluiert.

In dieser Arbeit wurde dazu das QLAmp Fast DNA Tissue Kit verwendet. Dazu wurde die gelöste DNA jeder Probe mit $265 \mu$ l MVL-Puffer gemischt und in eine Säule überführt. Die Zentrifugation in Rahmen der Aufreinigung erfolgte immer eine Minute lang bei $14000 \mathrm{rpm}$. Die Säule wurde dementsprechend zentrifugiert und das Filtrat verworfen. Die DNA, die sich nun im Filter der Säule befand, wurde mit $500 \mu$ l eines Waschpuffers AW1 gespült und erneut zentrifugiert. Das Filtrat wurde ebenfalls verworfen und dieser Vorgang wurde mit einem zweiten Waschpuffer AW2 wiederholt. Im letzten Schritt wurden $100 \mu$ ATE auf den 
Filter aufgetragen, um die DNA zu lösen, eine Minute inkubiert und die Säulen zentrifugiert. Dieser Vorgang wurde einmal mit $150 \mu \mathrm{l}$ ATE wiederholt, um eine Gesamtvolumen von $250 \mu \mathrm{zu}$ erhalten. Die DNA befand sich abschließend in dem Filtrat und konnte nun auf ihren DNA-Gehalt hin analysiert werden. Die Bestandteile der verwendeten Lösungen aus dem QIAmp Fast DNA Tissue Kit wurden vom Hersteller nicht veröffentlicht. Es war lediglich bekannt, dass die ATE-Lösung EDTA enthielt.

\subsubsection{Spektralphotometrische Bestimmung der DNA-Konzentration}

Zur Bestimmung der DNA-Konzentration wurden je 1,3 $\mu$ l jeder Probe sowie des ATEPuffers in einem Spektralphotometer analysiert. Das Ergebnis dieser Analyse war die DNAKonzentration sowie ein Maß für den Reinheitsgrad der Lösung.

Verwendet wurde dazu das Spektralphotometer NanoDrop, welches mit Wellenlängen im sichtbaren Bereich und im UV-Bereich arbeitet. Mit diesem wird die DNA-Konzentration einer Probe bestimmt, indem die Extinktion $\mathrm{E}_{\lambda}$ von Licht im Bereich zwischen $220 \mathrm{~nm}$ und $350 \mathrm{~nm}$ gemessen wird. Über das Gesetz von Lambert-Beer wird aus dem Verhältnis der Lichtintensität der Probe $\mathrm{I}_{\text {Probe }}$ und des Lösungsmittels $\mathrm{I}_{\mathrm{LM}}$ die Konzentration c ermittelt.

$$
E_{\lambda}=-\log \left(\frac{I_{\text {Probe }}}{I_{L M}}\right)=\varepsilon_{\lambda} \cdot \mathbf{c} \cdot \mathbf{d}
$$

[Formel 6]

Dabei liegt die Schichtdicke d des durchstrahlten Körpers bei $0.05 \mathrm{~mm}$ bis $1 \mathrm{~mm}$ und der Extinktionskoeffizient $\varepsilon$ bei $50 \mathrm{ng} \mathrm{cm} \mu l^{-1}$ für doppelsträngige DNA und bei $33 \mathrm{ng} \mathrm{cm} \mu l^{-1}$ für einsträngige DNA. Die DNA-Konzentration wird also wie folgt mit einer Genauigkeit von $2 \mathrm{ng} \mathrm{\mu l}^{-1}$ bestimmt:

$$
\mathbf{c}=\frac{E_{\lambda}}{\varepsilon_{\lambda} \mathbf{d}}
$$

[Formel 7]

Das Ergebnis dieser Messung ist ein Absorptionsspektrum, in welchem die Absorption gegen die Wellenlänge aufgetragen war. Typischerweise absorbieren die Heterozyklen der Nukleinbasen in DNA und RNA bei $260 \mathrm{~nm}$, wohingegen Proteine ein Absorptionsmaximum bei $280 \mathrm{~nm}$ und organische Lösungsmittel wie Ethanol oder EDTA bei $230 \mathrm{~nm}$ aufweisen. Anhand der Absorptionsintensitäten der Signale bei $230 \mathrm{~nm}, 260 \mathrm{~nm}$ und $280 \mathrm{~nm}$ lässt sich auf die Reinheit der Probe schließend. Die Konzentrationsbestimmung für DNA erfolgte anschließend über das Gesetz von Lambert-Beer. Das Verhältnis der Absorption bei $260 \mathrm{~nm} z u 280 \mathrm{~nm}$ sollte mindestens 1,8 betragen, damit die Probe als rein bezeichnet werden kann. Ein weiteres Maß ist das Verhältnis der Absorption bei $260 \mathrm{~nm}$ zu $230 \mathrm{~nm}$. Dieser sollte ebenfalls bei mindestens 1,8 liegen. Sind diese Werte zu klein, ist die Absorption bei $280 \mathrm{~nm}$ beziehungsweise $230 \mathrm{~nm}$ erhöht, was auf eine Verunreinigung der Probe mit Proteinen oder verschiedenen Lösungsmitteln schließen lässt. 


\subsubsection{Digestierung}

Um die extrahierte DNA weiter aufzuspalten, wurden jeder Probe $1 \mu \mathrm{l}$ pro $\mu \mathrm{g}$ DNA einer Nukleaselösung in Ammoniumacetat und $0,81 \mu \mathrm{l}$ pro $\mu \mathrm{g}$ DNA einer Lösung von alkalischer Phosphatase zugefügt. Die Angaben zu den benötigten Mengen an Enzymen entsprechen den Herstellervorschlägen von Cayman Chemicals (s. 2.3.7). Zur Digestierung der DNA durch diese beiden Enzyme wurden die Proben 30 Minuten lang bei $37{ }^{\circ} \mathrm{C}$ in einem Heizblock inkubiert und zusätzlich 10 min gekocht. Bei einigen Proben kam es während des Kochens zu Volumenverlusten, sodass ihr Volumen mit UltraPure-Wasser auf ca. $200 \mu \mathrm{l}$ aufgefüllt werden musste. Anschließend wurden die Proben mit dem NanoDrop wie bereits beschrieben erneut auf ihren DNA-Gehalt hin analysiert und bis zu ihrer Verwendung am nächsten Tag bei $4{ }^{\circ} \mathrm{C}$ konserviert.

\subsubsection{ELISA-Kit zur Analyse der oxidativen DNA-Schädigung}

Um die Oxidationsschäden an DNA zu quantifizieren, wurde in dieser Arbeit ein ELISAAssay verwendet. Dieser Assay war in der Lage, die Konzentrationen von mehreren oxidierten Guaninformen zu messen, wodurch eine größere Bandbreite abgedeckt wird als bei anderen Assays, die häufig nur eine Spezies analysieren. Die detektierbaren Stoffe sind 8Hydroxy-2'-desoxyguanosin aus DNA, 8-Hydroxyguanosin aus RNA und 8-Hydroxyguanin, welches sowohl in DNA als auch in RNA vorkommt. Diese sollen im Folgenden als oxidierte Guaninspezies (oxG) zusammengefasst werden. Bei diesem Assay liegt der Messbereich zwischen 10 und 3000 pg pro $\mathrm{ml}$ oxG.

\subsubsection{Funktionsweise des ELISA-Kits für oxidative DNA-Schädigung}

Die Funktionsweise des Assays beruht auf der Grundlage, dass oxG und 8-OHdGAcetylcholinesterasen um die Bindung an spezielle monoklonale Antikörper konkurrieren. Als Tracer fungiert dabei die Acetylcholinesterase, welche zuvor kovalent an 8-Hydroxy-2'Desoxyguanosin gebunden wurde. So bindet entweder der Tracer oder oxG an einen monoklonalen Antikörper, anschließend bindet dieser Komplex an polyklonale Ziegen-AntiMaus-IgG-Antikörper, welche an der Platte des Assays gebunden sind. Die Konzentration des Tracers ist aufgrund dieser Konkurrenz antiproportional zur Konzentration der oxG (Abb. 9). 


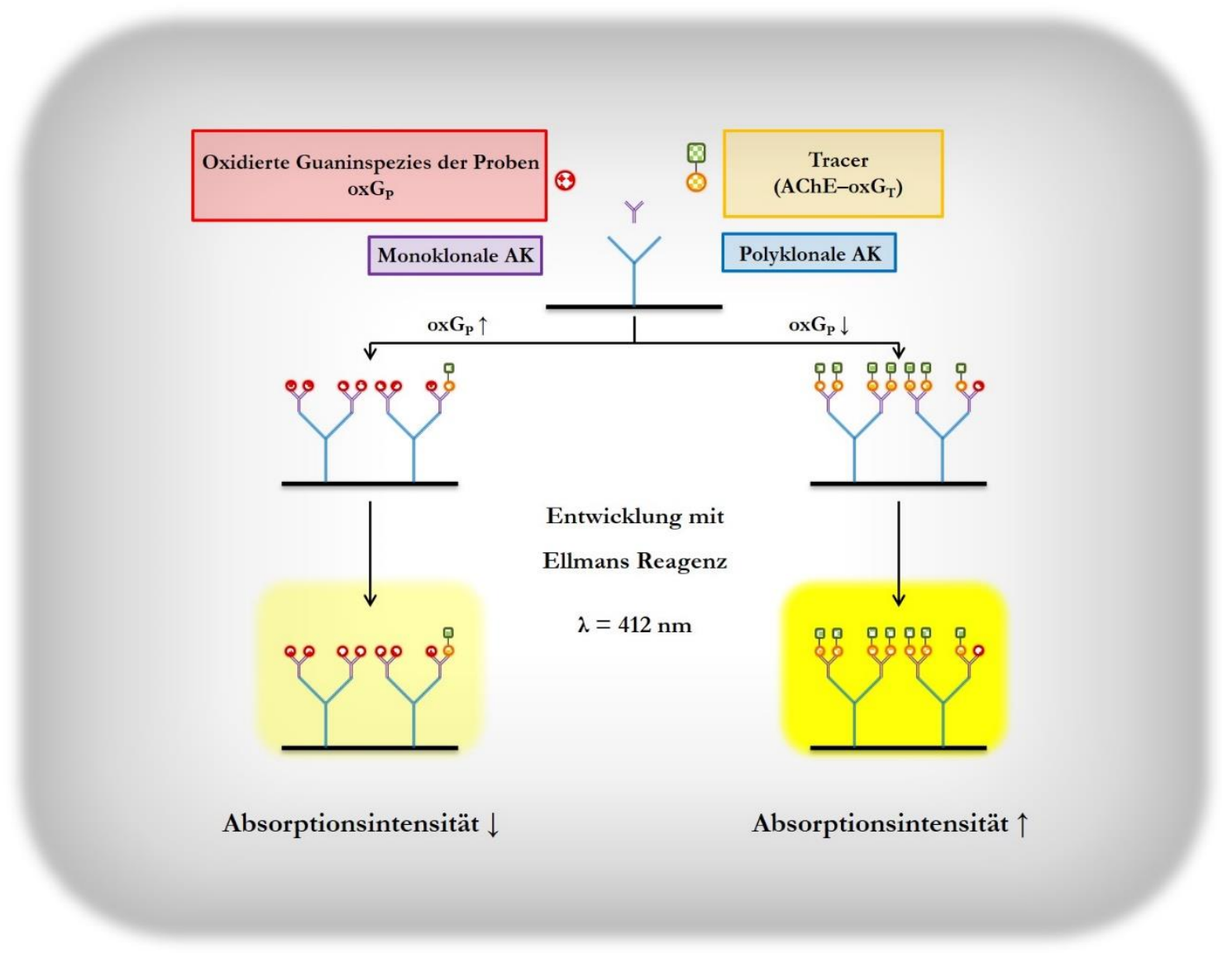

\section{Abbildung 9: Funktionsweise des ELISA-Kits zur Quantifizierung der oxidativen DNA-Schädigung.}

Es besteht eine Bindungskonkurrenz zwischen oxG aus den Proben (ox $\mathrm{G}_{\mathrm{P}}$ ) und dem Tracer, welcher aus einer Acetylcholinesterase (AChE) gebunden an 8-Hydroxy-2'-Desoxyguanosin (oxG ${ }_{\mathrm{T}}$ ) besteht, um einen monoklonalen Antikörper (AK). Dieser wiederum bindet an polyklonale Antikörper, die an der Wand der Reaktionsgefäße in der Mikrotiterplatte befinden. Über die Entwicklung des Analyten mittels Ellmans Reagenz, welches das Substrat für die AChE enthält, kann anhand der Absorptionsintensität auf die oxG-Konzentration der Proben geschlossen werden. Aufgrund der Bindungskonkurrenz und der Farbintensität der Lösung in Abhängigkeit von der TracerKonzentration, ergibt sich ein antiproportionaler Zusammenhang zwischen oxG $G_{p}$ und der Absorptionsintensität.

Anschließend wird Ellmans Reagenz zugegeben, welches Acetylthiocholin und 5,5'-dithiobis-2-Nitrobenzoesäure enthält und damit das Substrat für das Enzym des Tracers darstellt. Die Acetylcholinesterase katalysiert die Spaltung von Acetylthiocholin, dessen Reaktionsprodukt mit dem Benzoesäurederivat zu 5-thio-2-Nitrobenzoesäure reagiert. Dieses Produkt absorbiert Licht mit einer Wellenlänge von $412 \mathrm{~nm}$ und kann so mit einem Absorptionsspektrometer nachgewiesen werden. Die Absorptionsintensität $I_{1}$ ist damit proportional zur konstanten Konzentration des Tracers $\mathrm{c}_{\mathrm{T}}$ und antiproportional zur variablen Konzentration der oxidierten Guaninspezies $c_{o x G}$.

$$
\mathrm{I}_{1} \sim \mathrm{C}_{\mathrm{T}} \sim \frac{1}{\mathrm{coxG}_{\mathrm{oxG}}}
$$


Die chemischen Reaktionen, die der Entwicklung der Proben mit Ellmans Reagenz zugrunde liegen, wurden in Abbildung 10 veranschaulicht. Die Versuchsdurchführung zur Verwendung des Assays gliedert sich in die Teile Standardpräparation, Vorbereitung des Assays, Entwicklung und Auslesen der Platte.

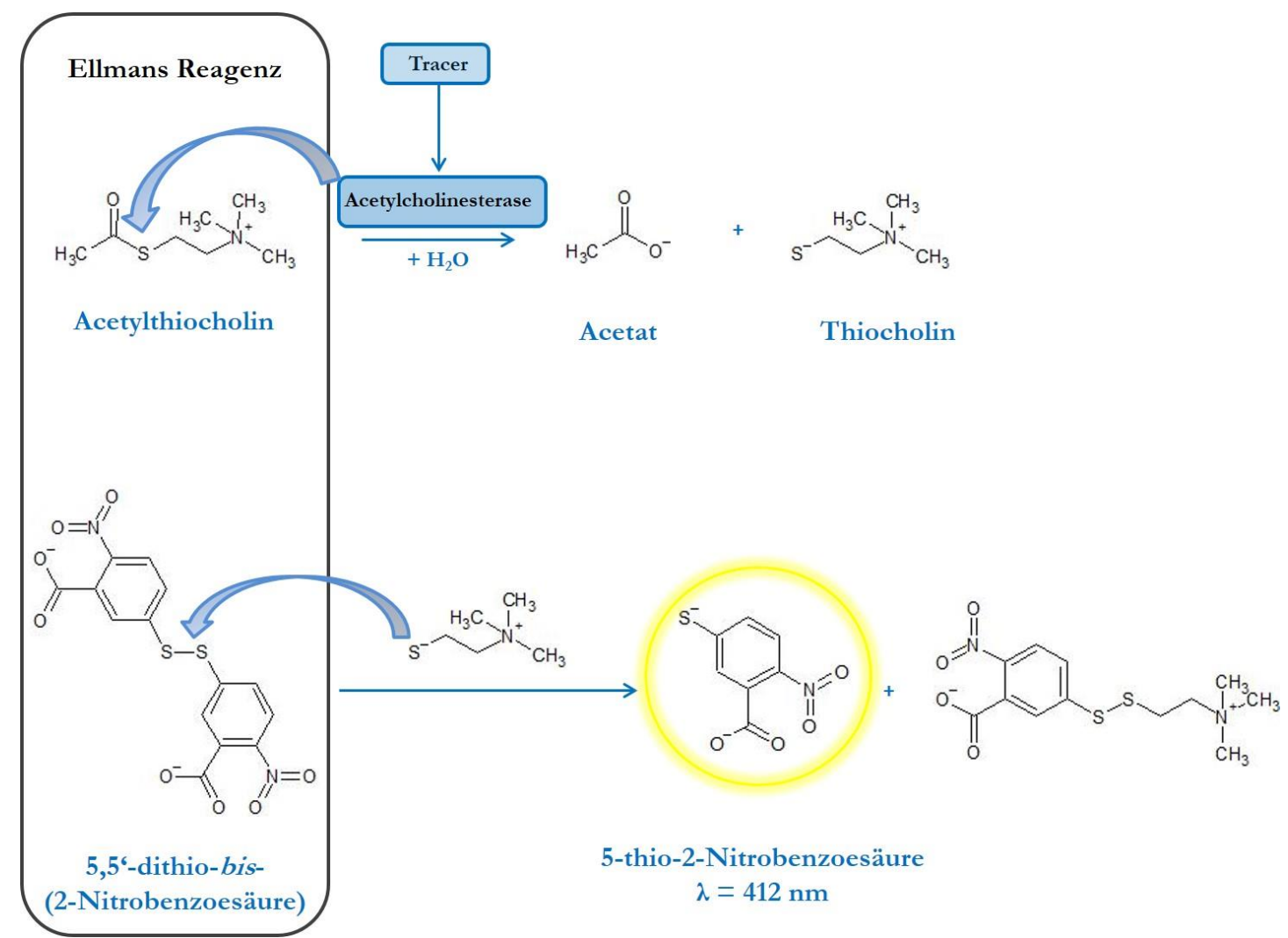

Abbildung 10: Chemische Reaktionen im Rahmen der Probenentwicklung.

Durch Zugabe von Ellmans Reagenz zu den Proben, wird der AChE aus dem Tracer auch mit Acetylthiocholin sein Substrat zugeführt. Die AChE katalysiert eine hydrolytische Spaltung des Substrats, aus der sowohl Acetat als auch Thiocholin entstehen. Letzteres reagiert mit einem weiteren Inhaltsstoff, 5,5'dithio-bis-(2-Nitrobenzoesäure), unter Abgabe eines Nebenproduktes weiter zu 5thio-2-Nitrobenzoesäure. Dieser Stoff absorbiert Strahlung mit einer Wellenlänge von $412 \mathrm{~nm}$, wobei dieser Vorgang mit einem Photospektrometer quantifiziert werden kann. 


\subsubsection{Präparation der Standards}

Um den später festgestellten Absorptionsintensitäten der Proben eindeutig eine spezifische oxG-Konzentration zuordnen zu können, wurden zunächst Standards mit bekannten 8OHdG-Konzentrationen hergestellt und diese später zusammen mit den Proben analysiert (Tab. 4). Zur Standardpräparation wurden $100 \mu$ aus dem mitgelieferten Standard mit 900 $\mu \mathrm{l}$ UltraPure-Wasser verdünnt. Anhand dieser Lösung, die als Bulk Standard bezeichnet wird, wurde eine Verdünnungsreihe durch Zugabe von ELISA-Puffer durchgeführt, deren Ergebnis acht Standards mit verschiedenen 8-OHdG-Konzentrationen sind. Außerdem wurden die monoklonalen Antikörper sowie der Tracer entsprechend der Herstelleranleitung mit je $6 \mathrm{ml}$ ELISA-Puffer verdünnt.

Tabelle 4: Konzentrationen von oxidiertem Guanin der Standardlösungen.

\begin{tabular}{|c|c|c|c|}
\hline $\begin{array}{c}\text { Standard } \\
\text { Nummer }\end{array}$ & $\begin{array}{c}\text { Entnahme aus dem } \\
\text { vorherigen Standard } \\
{[\mu \mathrm{l}]}\end{array}$ & $\begin{array}{c}\text { Zugabe } \\
\text { Lösungsmittel }[\mu \mathrm{l}]\end{array}$ & $\begin{array}{c}\text { OxG-Konzentration } \\
{[\mathrm{pg} / \mathrm{ml}]}\end{array}$ \\
\hline \hline Standard & - & - & 300000 \\
\hline Bulk-Standard & 100 & 900 & 30000 \\
\hline Standard 1 & 100 & 900 & 3000 \\
\hline Standard 2 & 400 & 500 & 1333 \\
\hline Standard 3 & 400 & 500 & 592,6 \\
\hline Standard 4 & 400 & 500 & 263,4 \\
\hline Standard 5 & 400 & 500 & 117,1 \\
\hline Standard 6 & 400 & 500 & 52,0 \\
\hline Standard 7 & 400 & 500 & 23,1 \\
\hline Standard 8 & 400 & 500 & 10,3 \\
\hline
\end{tabular}




\subsubsection{Vorbereitung und Beladung der Mikrotiterplatte}

Zur Vorbereitung des Assays wurde die Mikrotiterplatte, welche 96 Plätze enthielt, in verschiedene Bereiche aufgegliedert (Abb. 11). Zwei Plätze wurden für die Messung der Hintergrundabsorption verwendet, welche mit Blank betitelt wurden. Weitere zwei Plätze waren für die Messung der nicht-spezifischen Bindung NSB (non-specific-binding) vorgesehen, da der Tracer auch an andere Plattenbestandteile als die Antikörper binden könnte. Auf drei Plätzen wurde Messung der maximalen Absorption $\mathrm{B}_{0}$ vorbereitet, die der Absorption der maximalen Menge an reaktionsfähigem Tracer entsprach. Ein weiterer Platz galt der Messung der totalen Enzymaktivität des Tracers. Auf 16 Plätzen wurden alle acht Standards doppelt gemessen und auf den übrigen 72 Plätzen wurden 24 verschiedene Proben dreifach gemessen, um Messunsicherheiten zu reduzieren.

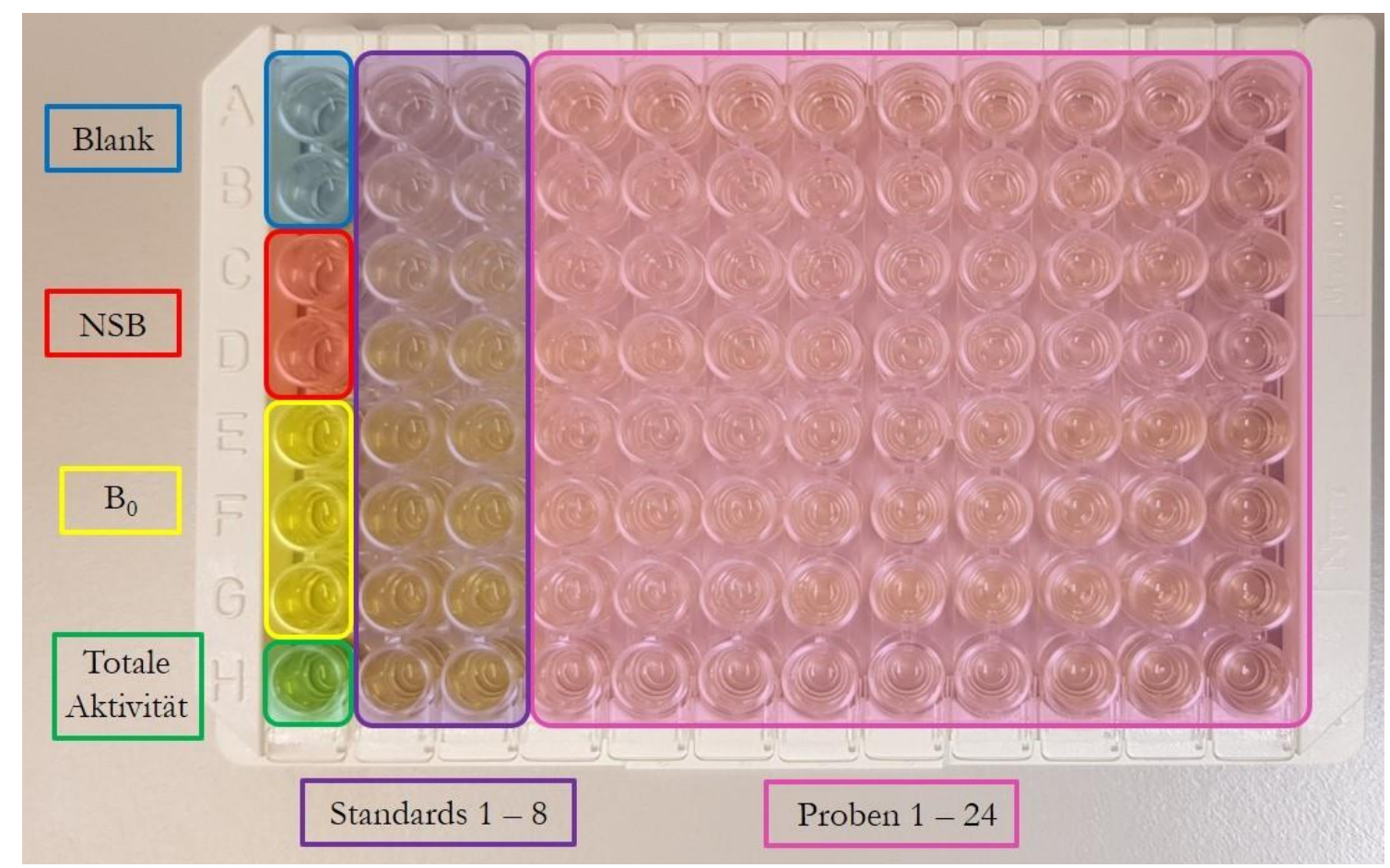

Abbildung 11: Probenaufteilung auf der Mikrotiterplatte.

Bei der Aufteilung der Mikrotiterplatte waren für die Bestimmung der Hintergrundabsorption (Blank.) zwei Plätze vorgesehen, wodurch später ein Mittelwert bestimmt werden konnte. Dasselbe gilt für die Plätze zur Bestimmung der nicht-spezifischen Bindungskapazität NSB. Die Messung der maximalen Absorption $\mathrm{B}_{0}$ erfolgte über die Vergabe von drei Plätzen, wohingegen zur Bestimmung der totalen Aktivität des Enzyms nur ein Platz vorgesehen war. Die Proben der Standardlösungen wurden daneben doppelt aufgetragen, um die Varianz zu verringern. Alle 24 Proben wurden dreifach nebeneinander aufgetragen, um mögliche Messunsicherheiten zu reduzieren. 
Die Vorbereitung jedes Platzes in der Platte erfolgte anhand eines Pipettierschemas und endete mit deren Inkubation für 18 Stunden bei $4{ }^{\circ} \mathrm{C}$ (Tab. 5).

Tabelle 5: Pipettierschema des ELISA-Kits zur Quantifizierung der DNA-Oxidation.

\begin{tabular}{|c|c|c|c|c|}
\hline Platz & ELISA-Puffer $[\mu \mathrm{l}]$ & Standard / Probe $[\mu \mathrm{l}]$ & Tracer $[\mu \mathrm{l}]$ & Antikörper $[\mu l]$ \\
\hline Blank & - & - & - & - \\
\hline $\begin{array}{c}\text { Totale } \\
\text { Aktivität }\end{array}$ & - & - & 5 (später) & - \\
\hline NSB & 100 & - & 50 & - \\
\hline$B_{0}$ & 50 & - & 50 & 50 \\
\hline $\begin{array}{c}\text { Standard/ } \\
\text { Probe }\end{array}$ & - & 50 & 50 & 50 \\
\hline \hline
\end{tabular}

\subsubsection{Entwicklung der Mikrotiterplatte}

An die Vorbereitung schloss sich die Entwicklung der Platte an. Dazu wurde Ellmans Reagenz zunächst mit $20 \mathrm{ml}$ UltraPure-Wasser verdünnt, die Platte entleert und fünffach mit Waschpuffer gespült, um nicht gebundene Stoffe zu entfernen. Danach wurden $200 \mu \mathrm{l}$ der Ellmans-Lösung zu jedem Platz zugegeben, zusätzlich wurde der Platz zur Messung der totalen Enzymaktivität mit $5 \mu \mathrm{l}$ Tracer versetzt. Zuletzt wurde die Platte mit Folie bedeckt und zur Entwicklung abgedunkelt unter leichtem Schwenken inkubiert. Nach ungefähr 90 Minuten bei der minimal einstellbaren Rüttlerstärke konnte die Platte im Photospektrometer ausgelesen werden.

\subsubsection{Auslesen der Mikrotiterplatte}

Zur Analyse der Mikrotiterplatte aus dem ELISA-Assay wurde das Photospektrometer FlxXenius verwendet. Zur Messung der Absorptionsintensität aller Proben wurde die Wellenlänge des Gerätes auf $412 \pm 8$ nm eingestellt, um einen möglichst optimalen Bereich abzudecken. Die photospektrometrische Analyse der Proben erfolgte konsekutiv, wobei jede Platte 3-fach ausgelesen wurde (technisches Duplikat).

\subsubsection{Datenauswertung}

Da jede Mikrotiterplatte dreifach ausgelesen wurde und alle Plätze auf der Platte mehrfach belegt waren, wurden zur Auswertung der Daten die Mittelwerte aller betreffenden Größen herangezogen. Um einen Zusammenhang zwischen der Konzentration an oxidierten Guaninspezies und der Absorptionsintensität herstellen zu können, musste die Absorptionsintensität der Standards und der Proben zunächst um einige Faktoren korrigiert 
werden. Dazu wurde das Verhältnis der Bindung von Tracer und Antikörper im Analyten B zur maximal möglichen Bindungskapazität $\mathrm{B}_{0}$ herangezogen:

$$
\frac{B}{B_{0}}=\frac{S-N S B}{B_{0}^{\text {corr }}}
$$

Dazu wurde die gemessene Gesamtabsorption S um die Absorption durch nicht-spezifische Bindung des Tracers an andere Plattenbestandteile NSB korrigiert und mit der maximalen Bindungskapazität des Tracers für die spezifischen Antikörper $\mathrm{B}_{0}{ }^{\text {corr }}$ ins Verhältnis gesetzt. Letztere musste ebenfalls um die Absorption der NSB korrigiert werden:

$$
\mathbf{B}_{0}^{\text {corr }}=\mathbf{B}_{0}-\mathrm{NSB}
$$

[Formel 10]

Im Anschluss wurden die prozentualen Werte von $\mathrm{B} / \mathrm{B}_{0}$ als $\mathrm{y}$-Achse gegen den Logarithmus der bekannten 8-OHdG-Konzentrationen der Standards als x-Achse in Excel graphisch aufgetragen. Daraus ergab sich ein polynominaler Funktionsverlauf, der im relevanten Bereich von 23 bis $1333 \mathrm{pg} \mathrm{ml}^{-1}$ linear approximiert werden konnte. Anhand der Funktionsparameter dieser linearen Regression konnte eine Gleichung erstellt werden, mit der die oxG-Konzentration in den Proben anhand ihrer Absorption bestimmt werden konnte.

$$
\begin{gathered}
\frac{B}{B_{0}} \cdot 100 \%=m x+b \\
x=\frac{\frac{B}{B_{0}} \cdot 100 \%-b}{m}
\end{gathered}
$$

Dabei stellte b die Größe des y-Achsen-Abschnittes und $\mathrm{m}$ die Größe der Steigung der linearen Regressionsgerade dar, während die logarithmische Konzentration als x bezeichnet wurde. Aufgrund der logarithmischen Auftragung gilt für die tatsächliche oxGKonzentration:

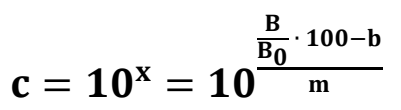

Im letzten Schritt wurde die so bestimmte oxG-Konzentration der Proben mit den zuvor im spektralphotometrisch bestimmten DNA-Konzentrationen verglichen, um den Anteil der oxidierten Guaninspezies an der gesamten DNA (DNA ox) zu bestimmen.

$$
\mathrm{DNA}_{\mathrm{OX}}=\frac{\mathrm{c}_{\mathrm{OXG}}}{\mathrm{c}_{\mathrm{DNA}}}
$$

Dieser Wert DNA Ox $_{\text {w }}$ wrde im Folgenden zum Vergleich der oxidativen DNA-Schädigung der verschiedenen Mausgruppen und der Bestimmung der Signifikanz der Ergebnisse verwendet. 


\subsection{Färbung PFA-fixierter Hirngewebeschnitte}

Zur Untersuchung verschiedener zellulärer Marker des Nervengewebes auf mögliche Auffälligkeiten im Rett-Syndrom wurden transversale Schnitte aus dem Hirngewebe von je zwei weiblichen Wildtyp-Mäusen $\left(M e c p 2^{+/+}\right)$und zwei heterozygoten Weibchen $\left(M e c p 2^{+/-}\right)$ mit einem Entnahmealter von 50 Tagen bei normaler Fütterung für verschiedene histochemische und immunhistochemische Marker gefärbt.

Die Herstellung der Gewebeschnitte erfolgte aus Gehirnen, welche durch vorherige transkardiale Perfusion mit Paraformaldehyd (PFA) unter Ethernarkose fixiert wurden. Dieser Vorgang wurde aufgrund der Tierschutzbestimmungen durch dementsprechend autorisierte Mitarbeiter vorgenommen. Danach wurden die fixierten Gehirne entnommen und anschließend für 24 Stunden in einer 4\% Lösung von PFA in phosphatgepufferter Salzlösung (PBS) nachfixiert und anschließend bis zur weiteren Verwendung in reiner PBS gelagert. Die weitere Verarbeitung der Proben, darunter die Herstellung und Färbung der Schnitte, erfolgte im Institut für Neuropathologie der Universitätsmedizin Göttingen.

\subsubsection{Herstellung von Hirnschnitten mit immunhistochemischer Färbung}

Da die Herstellung von PFA-fixierten Hirnschnitten mit maßgeblicher Unterstützung des Instituts für Neuropathologie erfolgte, soll diese hier nur kurz erläutert werden.

Für alle folgenden Färbungen wurden Schnitte von $1 \mu \mathrm{m}$ Dicke der PFA-fixierten Gehirne mit Hilfe eines Vibratoms erstellt. Es wurden immunhistochemische Färbungen für das Amyloid-Precursor-Protein APP, das saure Gliafaserprotein GFAP, das makrophagenspezifische aktivierte Antigen der Mikroglia Mac3 und für Synaptophysin durch Bindung spezieller Antikörper angefertigt.

Um aus diesen Schnitten das PFA zu lösen und diese zu rehydrieren, wurden sie mit einer abnehmend starken alkoholischen Reihe versetzt und mit destilliertem Wasser gewaschen. Zur weiteren Vorbehandlung wurden die Schnitte mit einer $10 \mathrm{mM}$ Citrat-Lösung auf einen $\mathrm{pH}$-Wert von $\mathrm{pH} 6$ gepuffert und mehrfach gekocht und wieder mit Citrat-Puffer und destilliertem Wasser versetzt. Danach wurden die Schnitte wieder in PBS überführt. Zur Blockierung der endogenen Peroxidase wurden die Gewebeproben $10 \mathrm{~min}$ in einer 3\% Lösung von $\mathrm{H}_{2} \mathrm{O}_{2}$ in PBS inkubiert und anschließend mehrfach mit reinem PBS gespült. Um eine spätere Bindung unspezifischer Proteine an die verschiedenen Antikörper zu verhindern, wurden die Schnitte 30 min lang mit 10\% PBS versetzt.

Nach dieser Probenvorbehandlung wurden die primären Antikörper eingebracht und die Schnitte über Nacht bei $4{ }^{\circ} \mathrm{C}$ inkubiert. Nach einer erneuten Spülung mit PBS wurden die Gewebeproben mit biotinylierten sekundären Antikörpern versetzt und $60 \mathrm{~min}$ bei Raumtemperatur inkubiert. Anschließend wurde nach erneuter PBS-Spülung AvidinPeroxidase zugefügt, die Proben erneut 60 min bei Raumtemperatur inkubiert und wieder mit PBS gespült. Es erfolgte eine Weiterentwicklung mit Diaminobenzidin (DAB), wodurch 
die anzufärbenden Proteine braun erschienen. Die Schnitte wurden mit entionisiertem Wasser gespült, auf die Objektträger gebracht und zur Gegenfärbung mit Hämalaun 30 Sekunden versetzt, bevor sie erneut mit destilliertem Wasser gespült wurden. Zum Abschluss wurde die alkoholische Reihe in umgekehrter Reihenfolge durchgeführt und die Schnitte endgültig auf den Objektträgern konserviert.

Mit spezifischen Antikörpern wurden durch dieses Verfahren verschiedene Proteine angefärbt, welche unterschiedliche Funktionen im zerebralen Gewebe erfüllen (Tab. 6). Alle Präparate wurden zur Verbesserung des Kontrastes mit Hämatoxylin gegengefärbt.

Tabelle 6: Zusammenfassung der immunhistochemisch gefärbten Proteine.

\begin{tabular}{|c|c|c|c|}
\hline Angefärbtes Protein & Abkürzung & Lokalisation & Gegenfärbung \\
\hline \hline $\begin{array}{c}\text { Amyloid-Precursor- } \\
\text { Protein }\end{array}$ & APP & $\begin{array}{c}\text { Peripher um neuronale } \\
\text { Perykarien }\end{array}$ & Hämatoxylin \\
\hline Saures Gliafaserprotein & GFAP & Astrozyten & Hämatoxylin \\
\hline $\begin{array}{c}\text { Makrophagenspezifisches } \\
\text { aktiviertes Antigen 3 }\end{array}$ & Mac3 & Mikroglia & Hämatoxylin \\
\hline Synaptophysin & - & Präsynaptische Vesikel & Hämatoxylin \\
\hline
\end{tabular}

\subsubsection{Herstellung von Hirnschnitten mit histochemischer Färbung}

Zusätzlich wurden histochemische Färbungen durchgeführt, darunter die Standardfärbung Hämatoxylin-Eosin (HE) sowie die Färbung mit Luxol-fast-blue/periodsaurem SchiffReagenz (LFB/PAS) und Färbungen für dreiwertige (Berliner Blau) und zweiwertige Eisenionen (Turnbulls Blau) (Tab. 7). Zur Erstellung dieser histochemisch gefärbten Präparate wurden den PFA-fixierten Gehirnen ebenfalls Schnitte von $1 \mu \mathrm{m}$ Dicke mit einem Vibratom entnommen und diese anschließend entparaffiniert. 
Tabelle 7: Zusammenfassung der histochemisch gefärbten Strukturen.

\begin{tabular}{|c|c|c|c|c|}
\hline Färbung & Abkürzung & Chemikalien & $\begin{array}{l}\text { Angefärbte } \\
\text { Strukturen }\end{array}$ & Gegenfärbung \\
\hline $\begin{array}{l}\text { Hämatoxylin- } \\
\text { Eosin }\end{array}$ & $\mathrm{HE}$ & $\begin{array}{c}\text { Hämatoxylin } \\
\text { Eosin Y }\end{array}$ & $\begin{array}{c}\text { Saure } \\
\text { Strukturen } \\
\text { (blau) } \\
\text { basische } \\
\text { Strukturen (rot) }\end{array}$ & - \\
\hline Berliner Blau & - & $\begin{array}{c}\text { Kaliumhexacyanoferrat- } \\
\text { (II) }\end{array}$ & $\begin{array}{l}\text { Dreiwertiges } \\
\text { Eisen (blau) }\end{array}$ & Kernechtrot \\
\hline $\begin{array}{l}\text { Turnbulls } \\
\text { Blau }\end{array}$ & - & $\begin{array}{c}\text { Kaliumhexacyanoferrat- } \\
\text { (III) }\end{array}$ & $\begin{array}{l}\text { Zweiwertiges } \\
\text { Eisen (braun) }\end{array}$ & Hämatoxylin \\
\hline Luxol-fast-blue & LFB-PAS & $\begin{array}{c}\text { Luxol-fast-blue } \\
\text { Periodsaures Schiff- } \\
\text { Reagenz }\end{array}$ & $\begin{array}{c}\text { Myelin (blau) } \\
\text { Kohlenhydrate } \\
\text { (rot) }\end{array}$ & - \\
\hline
\end{tabular}

Durch die separate Darstellung zweiwertiger und dreiwertiger Eisenionen konnte eine akkurate Beurteilung möglicher Auffälligkeiten in der Redox-Balance des Rett-Syndroms ermöglicht werden, da nicht nur eine mögliche Akkumulation freier Eisenionen, sondern auch die Verschiebung des Redox-Gleichgewichtes erfasst werden konnte. Dabei wurden dreiwertige Eisenionen durch die Zugabe von Kaliumhexacyanoferrat-(II) zu dem Komplex Eisen(III)-hexacyanidoferrat(II) umgesetzt, welches im Rahmen dieser Reaktion als Berliner Blau bezeichnet wird.

$$
4 \mathrm{Fe}^{3+}+3 \mathrm{~K}_{4}\left[\mathrm{Fe}(\mathrm{CN})_{6}\right] \rightarrow 12 \mathrm{~K}^{+}+\mathrm{Fe}_{4}\left[\mathrm{Fe}(\mathrm{CN})_{6}\right]_{3}
$$

[Formel 15]

Davon abzugrenzen ist der Nachweis zweiwertiger Eisenionen durch Zugabe von Kaliumhexacyanoferrat-(III), durch die ebenfalls Eisen(III)-hexacyanidoferrat(II) entstand, welches im Rahmen dieser Reaktion aber als Turnbulls Blau bezeichnet wird.

$$
\left.4 \mathrm{Fe}^{2+}+3 \mathrm{~K}_{3}\left[\mathrm{Fe}(\mathrm{CN})_{6}\right] \rightarrow 9 \mathrm{~K}^{+}+\mathrm{Fe}_{4}\left[\mathrm{Fe}(\mathrm{CN})_{6}\right)\right]_{3}
$$

[Formel 16]

Zur Verbesserung der Sensitivität wurde eine Verstärkung dieser Färbung mit Diaminobenzidin (DAB) durchgeführt. Diese Substanz färbte das blaue Eisen(III)hexacyanidoferrat(II) braun bis schwarz. Zur Verbesserung des Kontrastes wurden die Schnitte mit Hämatoxylin gegengefärbt. 


\subsection{Statistik}

Zur statistischen Auswertung der experimentell erhobenen Daten zur DNA-Oxidation wurde zunächst eine Normierung der Daten auf die entsprechenden Kontrollgruppen durchgeführt. Anschließend wurden diese mit einem one-sample T-Test statistisch bewertet. Normiert wurden jeweils die Messergebnisse aller Individuen einer Gruppe auf den Mittelwert der Messwerte einer anderen Kontrollgruppe. Aus diesen normierten Werten wurden dann der Mittelwert und die Standardabweichung bestimmt. Der t-Wert des Einstichproben-t-Tests wurde wie folgt für jede normierte Gruppe bestimmt:

$$
\mathbf{t}=\frac{\overline{\mathbf{x}}-\mu}{\frac{s}{\sqrt{\mathbf{n}}}}
$$

[Formel 17]

Der t-Wert hängt also vom Mittelwert der normierten Ergebnisse $\overline{\mathrm{x}}$, von deren Standardabweichung $\mu$, vom Standardwert s und der Anzahl der verwendeten Mäuse pro Gruppe n ab. Der t-Wert der einzelnen Gruppen wurde für eine Bewertung der Signifikanz mit t-Werten verglichen, welche von den Freiheitsgraden df der untersuchten Gruppe abhingen. Für alle Gruppen galt:

$$
\begin{gathered}
\mathbf{s}=\mathbf{1} \\
\mathbf{d f}=\mathbf{n}-\mathbf{1}
\end{gathered}
$$

[Formel 18]

[Formel 19]

Die Bewertung der statistischen Signifikanz erfolgte wie folgt:

$$
\begin{aligned}
& t \geq t(0,05) \text { für s*_Signifikanz } \\
& t \geq t(0,01) \text { für s**_Signifikanz } \\
& t \geq t(0,001) \text { für s***_Signifikanz }
\end{aligned}
$$

[Formel 20]

Normiert und statistisch bewertet wurden jeweils Gruppen, welche sich nur in einem Merkmal unterschieden. Somit konnte der Einfluss des Genotyps, des Geschlechts, des Futters und des Alters statistisch bewertet werden.

Die (immun-)histochemisch gefärbten Hirnschnitte wurden durch eine Analyse von Bildausschnitten mithilfe des Programmes ImageJ analysiert und anschließend mit einem T-Test statistisch bewertet. 


\section{Ergebnisse}

\subsection{Auswahl des Hirngewebes anhand der $\mathrm{H}_{2} \mathrm{O}_{2}$-Freisetzung}

Das Ausmaß oxidativer Gewebeschäden ist proportional zur ROS-Freisetzung in den Zellen, jedoch sind dabei je nach Hirnregion deutliche Unterschiede zu erwarten. Um vorab eine Auswahl der idealen Hirnregion für eine Analyse der DNA-Oxidation zu treffen, wurden mit Hilfe eines Küvetten-Assays und der Verwendung des Farbstoffes Amplex Ultra Red die zeitaufgelöste mitochondriale Wasserstoffperoxid-Freisetzung in verschiedenen Hirnregionen einer exemplarischen Wildtypmaus analysiert.

Die Daten, die sich aus der Analyse der $\mathrm{H}_{2} \mathrm{O}_{2}$-Produktion von isolierten MitochondrienProben aus verschiedenen Hirngeweben ergeben, zeigen deutlich, dass diese im Bereich Cortex verglichen mit den Bereichen Hippocampus, Cerebellum, Mittelhirn und Hirnstamm am höchsten ist (Abb. 12). Die relative Fluoreszenzintensität ist direkt proportional zur von den Mitochondrien synthetisierten Menge an Wasserstoffperoxid, da durch die Katalyse von HRP bei einer Reaktion von Amplex Ultra Red und Wasserstoffperoxid ein fluoreszierendes Produkt entsteht.

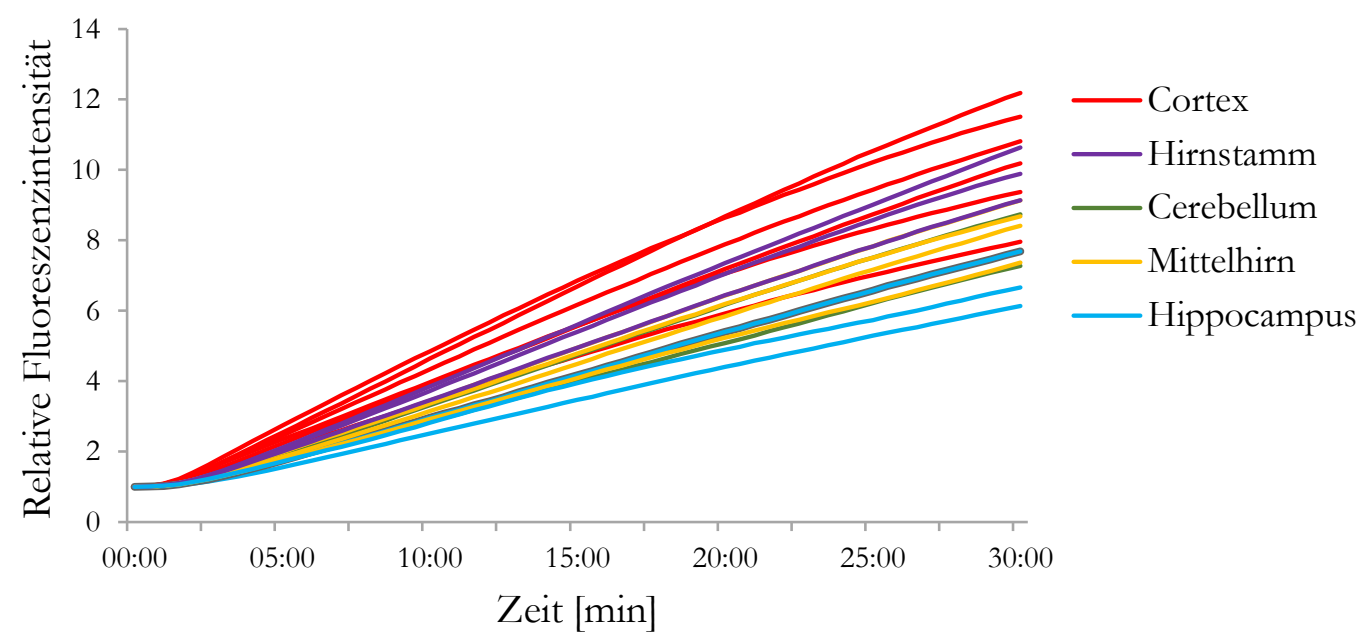

Abbildung 12: Mitochondriale Produktion von Wasserstoffperoxid in verschiedenen Hirngeweben.

Dargestellt ist der Zeitverlauf der relativen Fluoreszenzintensität des Produktes von $\mathrm{H}_{2} \mathrm{O}_{2}$ und Amplex Ultra Red in Mitochondrien aus verschiedenen Hirngeweben in Abhängigkeit von der Zeit aus einer weiblichen Mecp2-Wildtyp-Maus im Alter von 200 Tagen (Normalfutter). Da die Fluoreszenzintensität proportional zur $\mathrm{H}_{2} \mathrm{O}_{2}$-Menge ist, die von den lebenden Mitochondrien bei der Atmungskette synthetisiert werden, kann durch einen Vergleich der Messwerte der verschiedenen Gewebe eindeutig der Cortex als das Gewebe mit der höchsten $\mathrm{H}_{2} \mathrm{O}_{2}$-Freisetzung ermittelt werden. 
Da bereits bei einer Mecp2-Wildtyp-Maus die $\mathrm{H}_{2} \mathrm{O}_{2}$-Freisetzung im Cortex am höchsten ist, sollte sich dieses Gewebe am besten zur Analyse der DNA-Oxidation bei MeCP2-defizienten Mäusen eignen. Hier ist verglichen mit anderen Hirngeweben vermutlich auch die höchste DNA-Oxidation zu erwarten. Aufgrund dieser Schlussfolgerung wurden für die folgenden Versuche zur Ermittlung der DNA-Oxidation verschiedener Mausgruppen Cortex-Gewebe verwendet.

\subsection{Untersuchung auf Oxidationsschäden an DNA}

In diesem Abschnitt werden die Ergebnisse der Analyse der Oxidationsschäden an DNA veranschaulicht, indem der Parameter DNA Individuen, als auch dessen Mittelwerte zum Vergleich der untersuchten Gruppen untereinander im Folgenden verwendet wird. Die Mittelwerte und Standardabweichungen für die einzelnen Gruppen sind Tabelle 8 zu entnehmen.

Tabelle 8: Gruppenübersicht der durchschnittlichen DNA-Oxidation.

\begin{tabular}{|c|c|c|c|c|c|}
\hline Genotyp & $\begin{array}{l}\text { Alter } \\
{[\text { Tage] }}\end{array}$ & Futter & $\begin{array}{c}\text { Mittelwert } \\
\text { DNA }_{\text {ox }} \\
{[\mathrm{ppm}]}\end{array}$ & $\begin{array}{c}\text { Standardabweichung } \\
\text { [ppm] }\end{array}$ & Anzahl $n$ \\
\hline$M e c p 2^{+/ y}$ & 50 & $\mathrm{NF}$ & 4,3 & 2,2 & 6 \\
\hline$M e c p 2^{+/ y}$ & 400 & $\mathrm{NF}$ & 11,5 & 6,2 & 9 \\
\hline$M e c p 2^{+/+}$ & 50 & $\mathrm{NF}$ & 5,6 & 1,6 & 6 \\
\hline$M e c p 2^{+/+}$ & 400 & $\mathrm{NF}$ & 6,8 & 3,9 & 10 \\
\hline$M e c p 2^{-/ y}$ & 50 & $\mathrm{NF}$ & 9,7 & 6,4 & 11 \\
\hline$M e c p 2^{+/-}$ & 50 & $\mathrm{NF}$ & 12,5 & 8,5 & 13 \\
\hline$M e c p 2^{+/-}$ & 400 & $\mathrm{NF}$ & 10,0 & 3,3 & 19 \\
\hline$M e c p 2^{+/ y}$ & 50 & $\mathrm{AOF}$ & 3,4 & 1,2 & 6 \\
\hline$M e c p 2^{+/ y}$ & 400 & $\mathrm{AOF}$ & 13,5 & 1,5 & 6 \\
\hline$M e c p 2^{+/+}$ & 50 & $\mathrm{AOF}$ & 3,5 & 0,9 & 6 \\
\hline$M e c p 2^{+/+}$ & 400 & $\mathrm{AOF}$ & 9,8 & 3,3 & 6 \\
\hline$M e c p 2^{-/ y}$ & 50 & $\mathrm{AOF}$ & 10,2 & 9,2 & 10 \\
\hline$M e c p 2^{+/-}$ & 50 & $\mathrm{AOF}$ & 13,9 & 8,4 & 15 \\
\hline$M e c p 2^{+/-}$ & 400 & $\mathrm{AOF}$ & 14,5 & 3,6 & 5 \\
\hline
\end{tabular}




\subsubsection{Ergebnisse der DNAox-Bestimmung bei normal gefütterten Wildtyp-Tieren}

Das ermittelte Ausmaß der DNA-Oxidation der einzelnen Individuen der normal gefütterten Wildtyp-Männchen und Wildtyp-Weibchen wird im Folgenden veranschaulicht (Abb. 13). Die DNA ${ }_{O x}$-Werte, die ein Maß für die oxidative DNA-Schädigung darstellen, schwankten bei 50 Tage alten Wildtyp-Männchen zwischen 2 und 9 ppm um einen Mittelwert von 4,3 \pm 2,2 $\mathrm{ppm}(\mathrm{n}=6)$. Dagegen lagen die Werte 400 Tage alter Männchen mit einem Mittelwert von 11,5 \pm 6,2 ppm $(\mathrm{n}=9)$ deutlich höher. Auch die Datenanalyse bei WildtypWeibchen ergab im Alter von 50 Tagen eine eher niedrige DNA-Oxidation zwischen 3 und 11 ppm (Mittelwert 5,6 \pm 1,6 ppm, $\mathrm{n}=6$ ). Dagegen wiesen 400 Tage alte WildtypWeibchen im Gegensatz zu den Männchen eine nur geringfügig erhöhte oxidative DNASchädigung von mittelwertig $6,9 \pm 3,9 \mathrm{ppm}(\mathrm{n}=10)$ auf.

A)

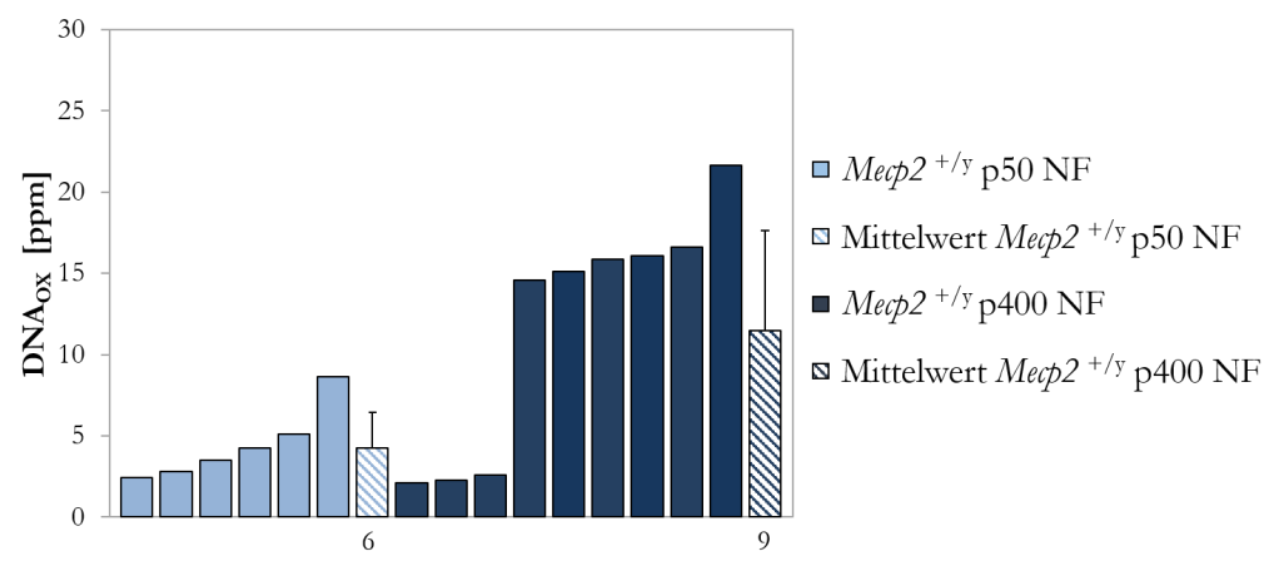

B)

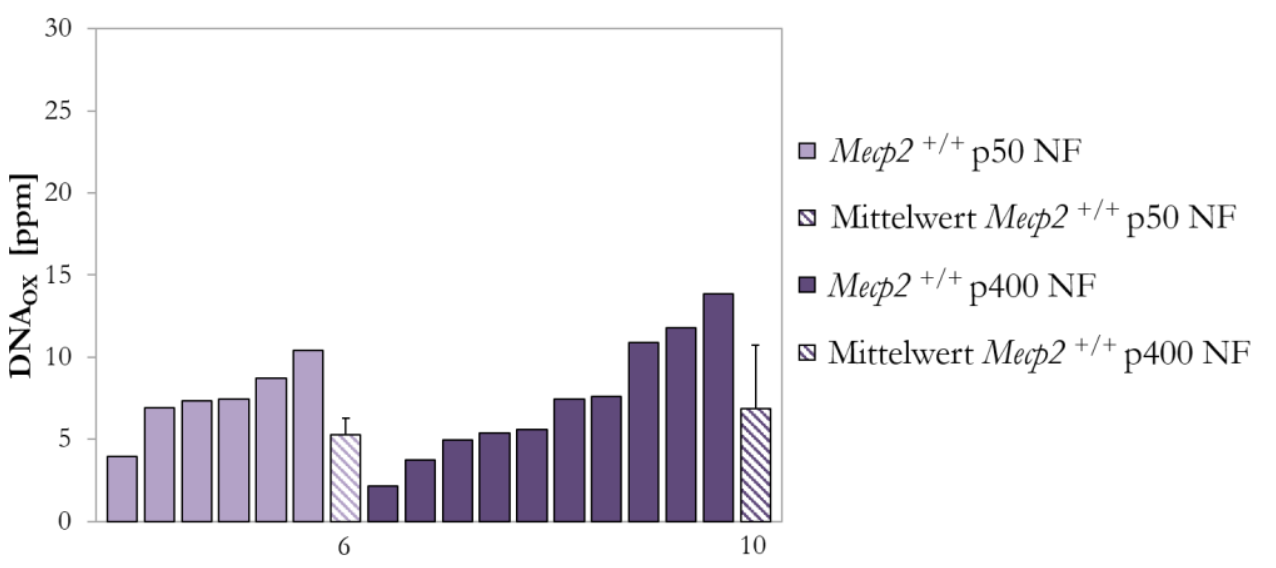

\section{Abbildung 13: Ausmaß der DNA-Oxidation bei männlichen und weiblichen Wildtyp-Tieren, welche normales Futter erhielten.}

Dargestellt ist hier das Ausmaß der DNA-Oxidation in Form der Einzelwerte DNAox für jedes analysierte Individuum der Gruppe männlicher Wildtypen (A) und weiblicher Wildtypen (B), wobei die Individuen beider Gruppen normales Futter (NF) erhielten. Zusätzlich wurden diese DNAoxWerte der Individuen einer Gruppe gemittelt und zusammen mit der Standardabweichung ebenfalls dargestellt, wobei jeder Gruppe gehörten zwischen sechs und elf einzelne Tiere angehörten. Dabei zeigte sich, dass die DNA-Oxidation von 50 Tage alten männlichen Wildtypen deutlich niedriger war als die von 400 Tage alten Wildtyp-Männchen. Dasselbe konnte auch bei weiblichen Wildtypen beobachtet werden, wobei hier der Unterschied in der DNA-Oxidation zwischen 400 und 50 Tage alten Tieren nicht ganz so ausgeprägt war. 


\subsubsection{Datenübersicht der oxidativen DNA-Schädigung bei normal gefütterten Rett-Mäusen}

Die Ergebnisse der Analyse oxidativen DNA-Schädigung in Form der Größe DNA ox sind für normal gefütterte RTT-Männchen der folgenden Abbildung zu entnehmen (Abb. 14). Dieser ist zu entnehmen, dass männliche Rett-Mäuse mit 50 Tagen mittelwertig eine DNAOxidation von 9,7 $\pm 6,4 \mathrm{ppm}(\mathrm{n}=11)$ aufwiesen, wobei die Einzelwerte zwischen 2 und 24 ppm variierten. Eine vergleichbare Gruppe 400 Tage alter Mäuse stand nicht zur Verfügung, da sie krankheitsbedingt bereits nach ca. 8 Wochen verstarben. Ein ähnliches Ergebnis ergab die Analyse der oxidativen DNA-Schädigung bei jungen Rett-Weibchen, deren DNAoxWerte von 2 bis 29 ppm reichten, wobei sich ein Mittelwert von 12,5 \pm 8,5 ppm ( $\mathrm{n}=13)$ ergab. Dagegen lagen bei 400 Tage alten Rett-Weibchen sowohl die Streuung mit 2 bis 19 ppm als auch der Mittelwert mit 10,0 $\pm 3,3$ ppm ( $=19)$ leicht unter denen jüngerer Tiere. 
A)

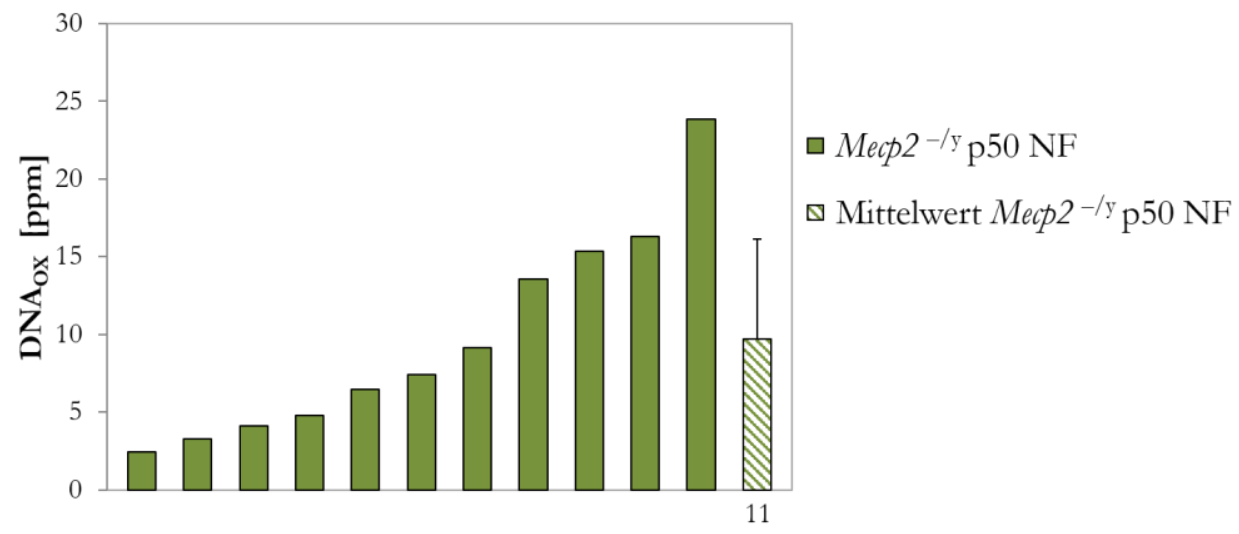

B)

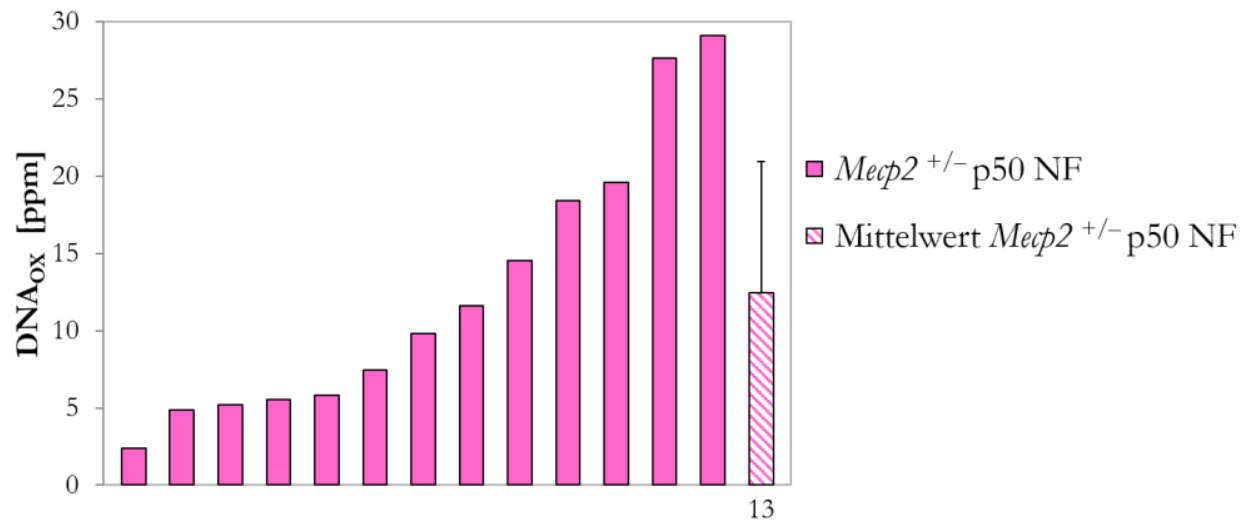

C)

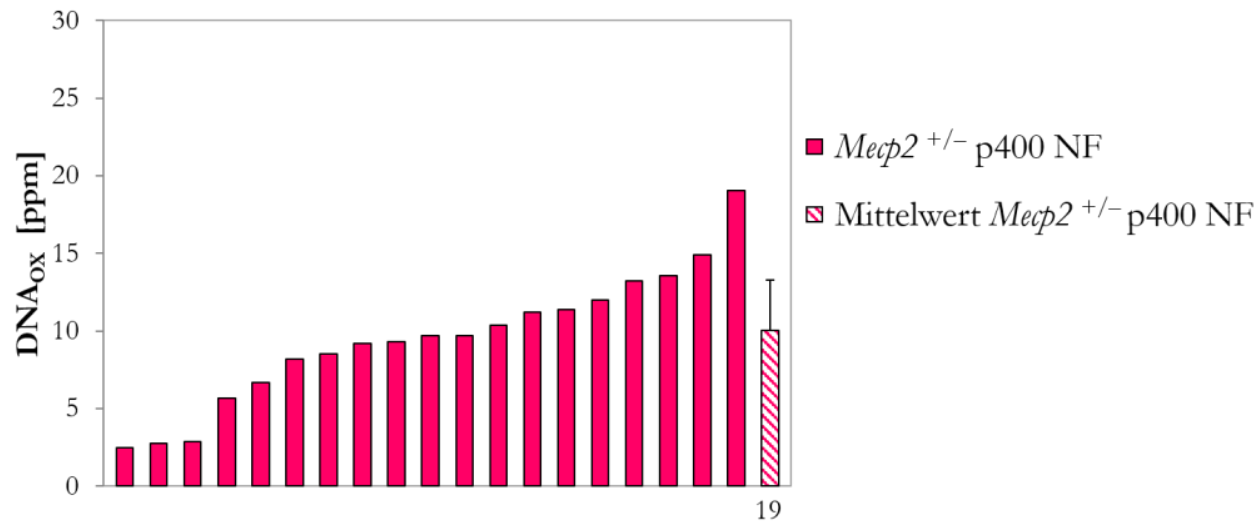

Abbildung 14: Übersicht der Daten der DNAox-Messwerte von normal gefütterten 50 Tage alten Rett-Männchen und Rett-Weibchen im Alter von 50 und 400 Tagen.

Die DNA-Oxidation einzelner Tiere sowie die dazugehörigen Mittelwerte und Standardabweichungen sind hier für männliche Rett-Mäuse mit 50 Tagen (A), weibliche Rett-Mäuse mit 50 Tagen (B) und weibliche Rett-Mäuse mit 400 Tagen (C) aufgeführt, welche allesamt normales Futter erhielten. Dem ist zu entnehmen, dass 50 Tage alte Rett-Tiere beider Geschlechter eine überaus hohe DNA-Oxidation in Form von DNA Ox aufweisen, welche Spitzenwerte von bis zu 25 ppm bzw. 30 ppm erreicht. Das Ausmaß der DNA-Oxidation 400 Tage alter Rett-Weibchen ist ebenfalls relativ hoch, liegt aber mit Maximalwerten von ca. 20 ppm leicht unter dem Niveau jüngerer Rett-Weibchen. 


\subsection{3 Übersicht der ermittelten oxG-Anteile bei antioxidativ gefütterten Wildtypen}

Die analysierten Daten zur DNA-Oxidation bei männlichen und weiblichen Wildtypmäusen, welche mit Antioxidantien angereichertes Futter erhielten, verdeutlichen, dass sowohl männliche als auch weibliche 50 Tage alte Wildtyp-Tiere eine vergleichsweise geringe oxidative DNA-Schädigung aufwiesen, welche mittelwertig bei 3,4 $\pm 1,1 \mathrm{ppm}(\mathrm{n}=6)$ bei den Männchen und 3,5 0,9 ppm ( $\mathrm{n}=6$ ) bei den Weibchen lag (Abb. 15). Bei 400 Tage alten Wildtyp-Männchen wurde dagegen deutlich höhere DNAox-Werte von mittelwertig $13,5 \pm 1,5 \mathrm{ppm}(\mathrm{n}=6)$ ermittelt. Bei diesen drei Gruppen fiel die Standardabweichung besonders gering aus. Die gemittelten Messwerte älterer Weibchen lagen mit 9,8 \pm 3,3 ppm ( $\mathrm{n}=6$ ) nur leicht unter dem Niveau der 400 Tage alten Männchen.

A)

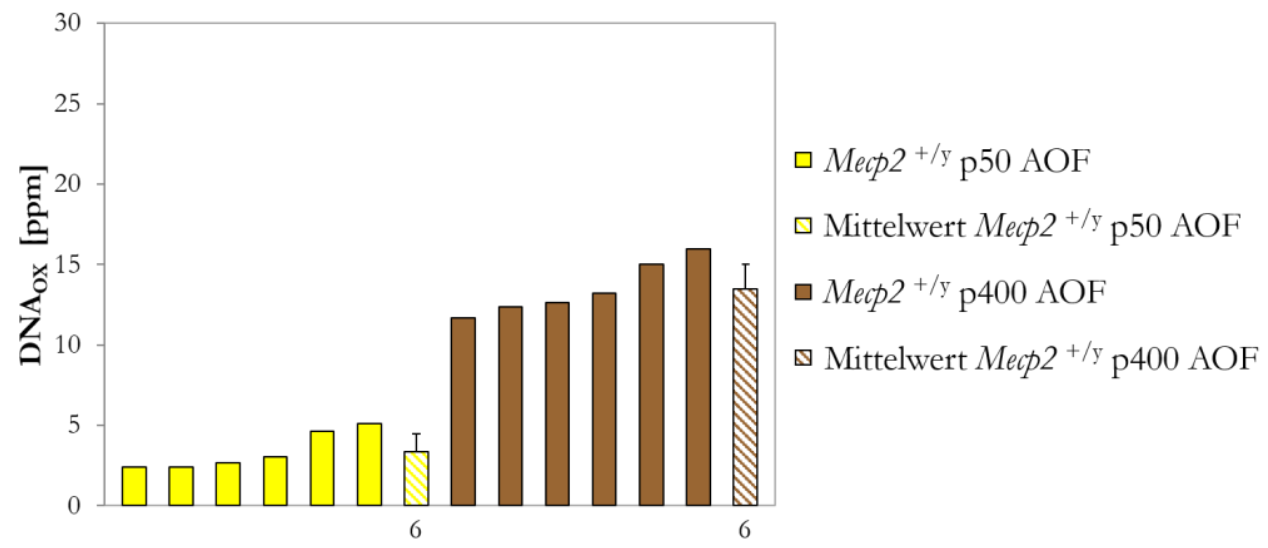

B)

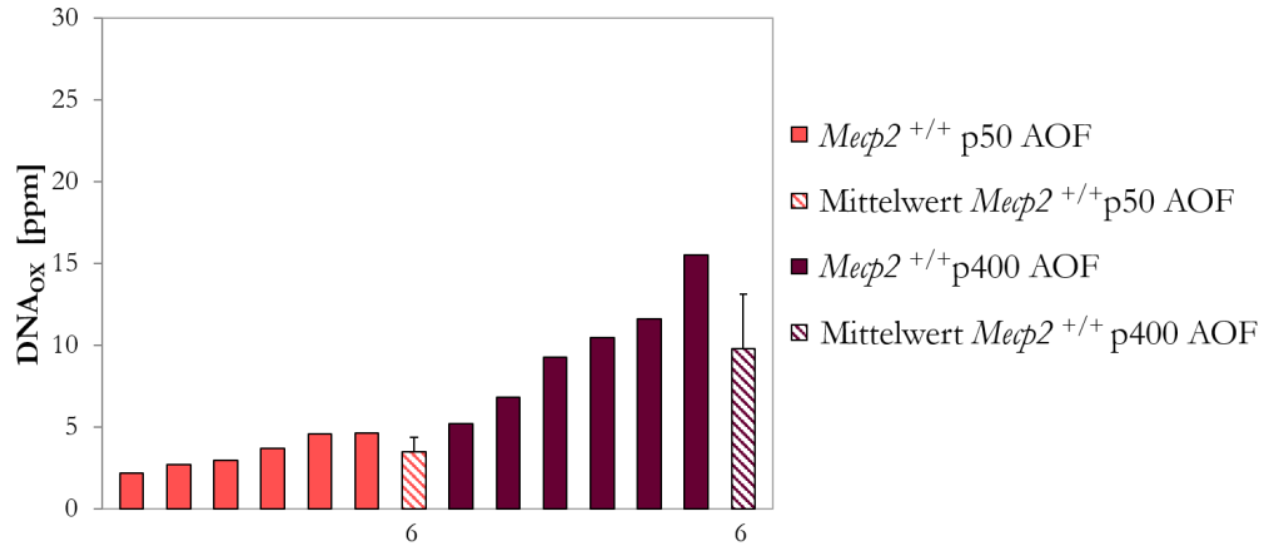

Abbildung 15: Gegenüberstellung der ermittelten Werte der oxidativen DNA-

Schädigung bei antioxidativ gefütterten Wildtyp-Tieren beider Geschlechter.

Bei Mäusen, welche mit Antioxidantien angereichertes Futter erhielten, lag das Ausmaß der DNAOxidation bei Wildtyp-Männchen (A) und -Weibchen (B) bei 50 Tage alten Tieren auf einem generell sehr niedrigen Niveau. Die DNA ${ }_{O X}$-Werte bei älteren Wildtyp-Mäusen lagen auf einem höheren Niveau von bis zu 15 ppm. Die Gruppen bestanden aus jeweils sechs Individuen, aus denen die mittelwertige DNA-Oxidation samt Standardabweichung bestimmt wurde. 


\subsubsection{Analyse der oxidativen DNA-Schädigung bei Rett-Tieren nach Fütterung von mit Antioxidantien angereichertem Futter}

Die Daten der DNAox-Analyse für antioxidativ gefütterte Rett-Individuen beider Geschlechter zeigen, dass männliche Rett-Mäuse nach antioxidativer Fütterung anteilige oxG-Werte im Bereich von 1 bis $30 \mathrm{ppm}$ aufwiesen, woraus sich ein Mittelwert von 10,2 \pm 9,2 ppm ( $\mathrm{n}=10)$ ergab (Abb. 16). Aufgrund des schweren Krankheitsverlaufes und der kurzen Lebenserwartung männlicher Rett-Mäuse, standen auch hier keine 400 Tage Alten Tiere zur Verfügung. Auch die Messwerte heterozygoter Weibchen im Alter von 50 Tagen variierten mit Werten zwischen 1 und 26 ppm bei einem Mittelwert von 13,9 \pm 8,4 ppm $(\mathrm{n}=15)$ stark. Im Gegensatz dazu fiel die Streubreite der Einzelwerte bei älteren,

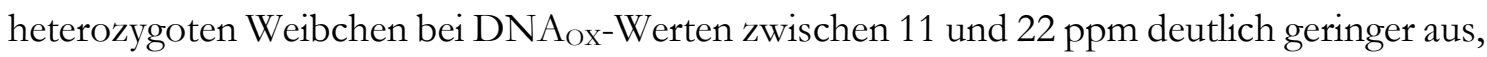
wobei der Mittelwert mit 14,5 \pm 3,6 ppm $(n=5)$ nur leicht über dem Mittelwert jüngerer Tiere lag.

A)

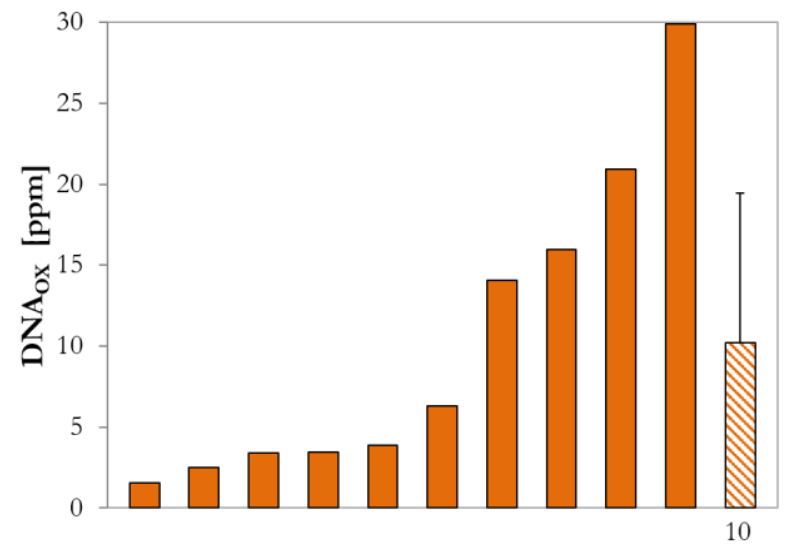

$\square \mathrm{Mecp} 2^{-/ \mathrm{y}} \mathrm{p} 50 \mathrm{AOF}$

ه Mittelwert $M e c 2^{-1 y}$ p50 AOF

B)

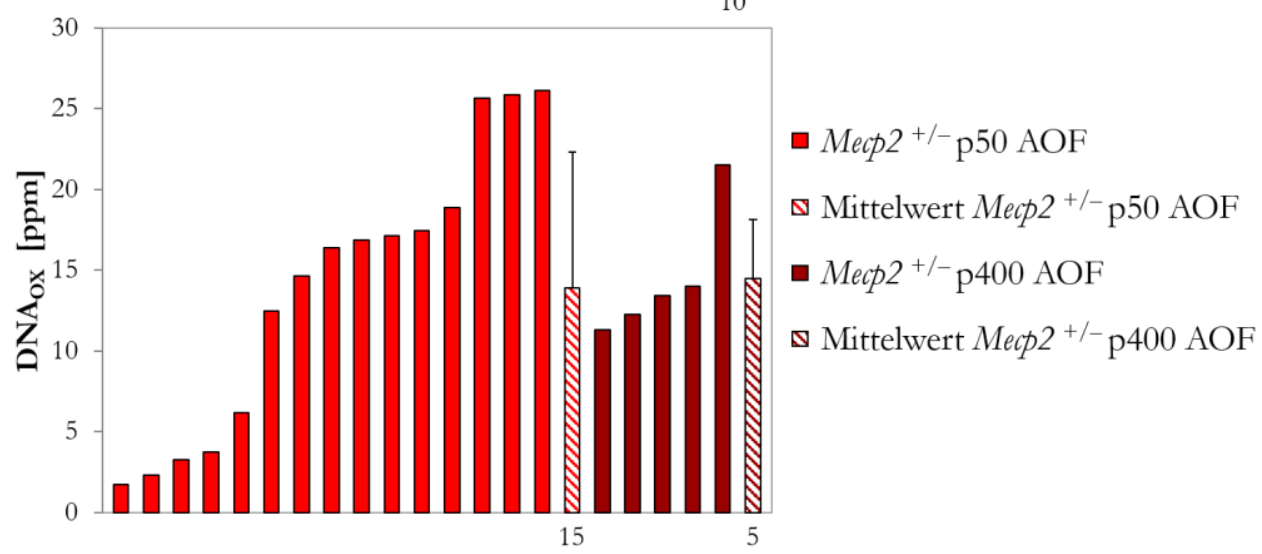

\section{Abbildung 16: DNA-Oxidation von antioxidativ gefütterten, männlichen und} weiblichen Rett-Mäusen.

Die DNA-Oxidation, die hier in Form der Größe DNA $0 x$ dargestellt wird, wird durch Einzelwerte und Mittelwerte mit Standardabweichung für AO-gefütterte, männliche (A) und weibliche (B) RettMäuse repräsentiert. Diese Auftragung zeigt, dass trotz der Gabe von Futter, welches mit Antioxidantien angereichert war, die DNA-Oxidation bei männlichen Rett-Mäusen mit 50 Tagen sehr hohe DNA $A_{\mathrm{OX}}$-Werte von bis zu 30 ppm aufwies. Auch bei weiblichen Rett-Mäusen wurde trotz der Spezialfütterung bei 50 und 400 Tage alten Mäuse ein relativ hohes Ausmaß der DNA-Oxidation von bis zu 25 ppm nachgewiesen. 


\subsubsection{Ergebnisse unter statistischer Bewertung}

Um die Ergebnisse der gemessenen DNA-Oxidation der verschiedenen Gruppen aussagekräftiger vergleichen zu können, wurden diese jeweils auf den Mittelwert einer Referenzgruppe normiert. So konnte der Einfluss des Genotyps, des Geschlechts, des Alters und der Fütterungsart der Mäuse auf die DNA-Oxidation verdeutlicht werden und die Signifikanz der jeweiligen Unterschiede mit einer höheren Trennschärfe bewertet werden.

\subsubsection{Abhängigkeit vom Genotyp}

Zur Beurteilung der Abhängigkeit der DNA-Oxidation vom Genotyp bezüglich des Mecp2Gens wurde jede Gruppe mit dem Genotyp der Rett-Erkrankung auf den Mittelwert der DNA-Oxidation der entsprechenden Kontrollgruppe mit dem Genotyp „Wildtyp“ normiert (Abb. 17). Daraus wird deutlich, dass nicht nur 50 Tage alte männliche Rett-Mäuse gegenüber den Wildtyp-Mäusen eine signifikant erhöhte DNA-Oxidation aufwiesen (Faktor 2,3), sondern dass dies auch für 50 Tage alte weibliche Rett-Mäuse galt (Faktor 2,2). Auch bei 400 Tage alten Rett-Weibchen konnte eine signifikante Zunahme der DNA-Oxidation gegenüber dem Wildtyp festgestellt werden, wobei diese deutlich geringer ausfiel als bei jüngeren Tieren (Faktor 1,3).

Bei Individuen, welche mit Antioxidantien-angereichertem Futter ernährt wurden, konnte ebenfalls eine Zunahme der DNA-Oxidation von Rett-Mäusen gegenüber dem Wildtyp verzeichnet werden. Bei 50 Tage alten männlichen Mäusen kam es zu einer signifikanten Steigerung (Faktor 3,0), bei weiblichen 50 Tage alten Individuen war eine noch deutlichere Zunahme der DNA-Oxidation um den Faktor 4,0 zu verzeichnen. Auch bei 400 Tage alten Weibchen war der Anteil oxidierten Guanins an der Gesamt-DNA um 50\% signifikant erhöht. Ein Vergleich beider Genotypen bei männlichen, 400 Tage alten Tieren war nicht möglich, da Individuen mit dem Genotyp $M e c p 2^{-/ y}$ kein so hohes Lebensalter erreichten. 


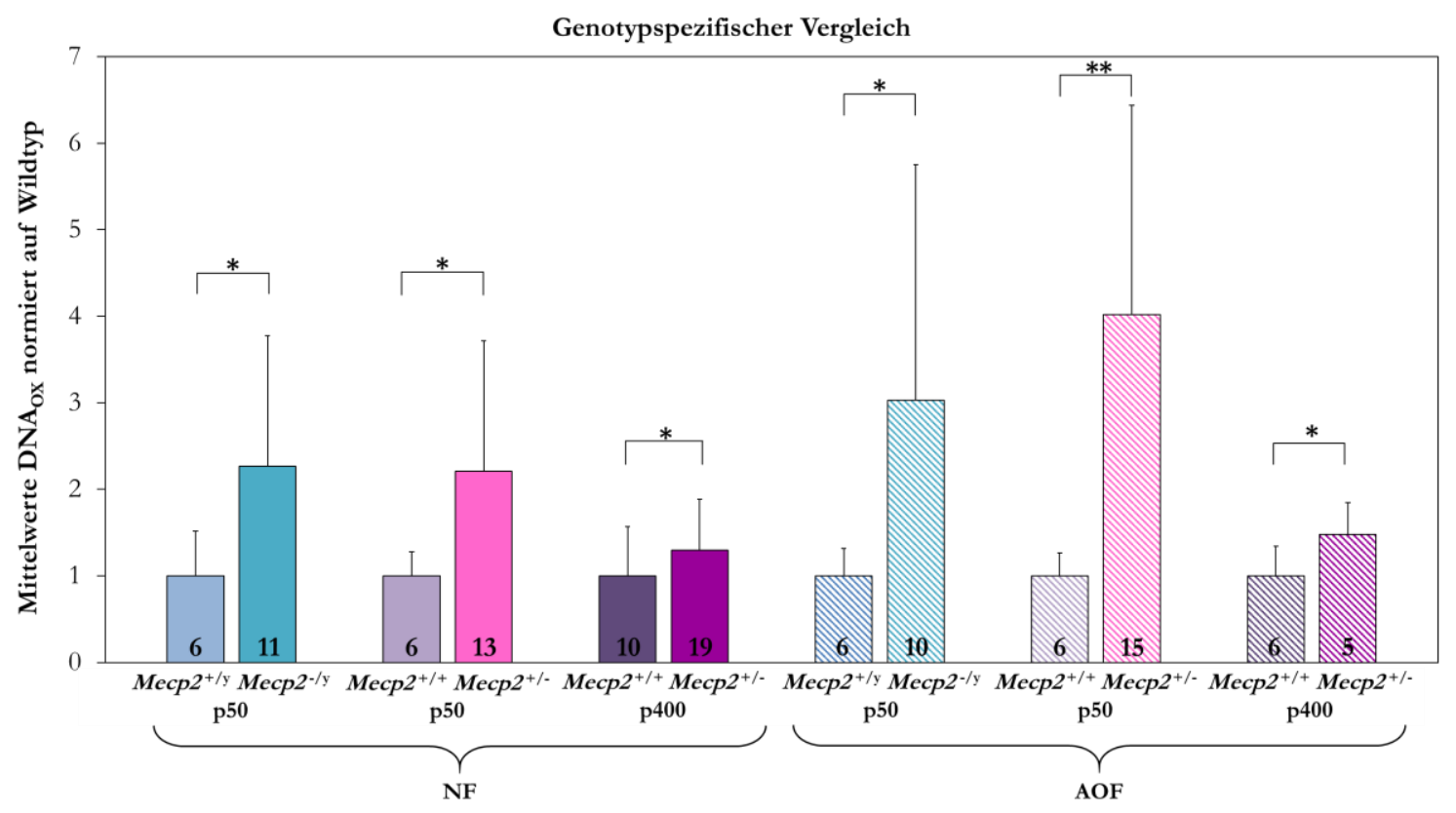

\begin{abstract}
Abbildung 17: DNA-Oxidation im Vergleich unter Normierung auf die entsprechende Kontrollgruppe mit dem Genotyp "Wildtyp".
\end{abstract}

In dieser Abbildung sind die Mittelwerte der DNA-Oxidation der verschiedenen Gruppen mit der zugehörigen Standardabweichung dargestellt. Dabei wurde jede Gruppe mit dem Genotyp Mecp2+/oder Mecp2-/y auf den entsprechenden Wildtyp mit dem Genotyp Mecp2+/+ oder Mecp2+/y normiert. Dabei zeigt sich, dass die DNA-Oxidation nicht nur bei 50 Tage alten Rett-Tieren beider Geschlechter und sowohl nach normaler Fütterung als auch nach antioxidantienreicher Fütterung signifikant gegenüber dem Wildtyp stark erhöht sind. Auch bei 400 Tage alten heterozygoten Weibchen zeigt sich bei beiden Fütterungsvarianten eine signifikant erhöhte DNA-Oxidation gegenüber den 400 Tage alten Wildtyp-Weibchen.

\title{
3.2.5.2 Abhängigkeit vom Geschlecht
}

Um sicherzustellen, dass die Erhöhung der DNA-Oxidation aufgrund des Genotyps nur aus Einflüssen aus dem Mecp2-Gen und nicht aus anderen geschlechtsspezifischen oder hormonellen Einflüssen resultierte, wurden die Messwerte für die DNA-Oxidation aller Gruppen auf die jeweilige Kontrollgruppe männlichen Geschlechts normiert (Abb. 18). Diese Daten zeigten, dass bei fast allen zu vergleichenden Gruppen - unabhängig von Alter und Fütterung - keine signifikante Abweichung der DNA-Oxidation zwischen den Geschlechtern festzustellen war. Lediglich bei 400 Tage alten Wildtyp-Mäusen wiesen die Weibchen bei normaler Fütterung sehr signifikant geringere Messwerte (Faktor 0,6) auf. Bei antioxidativer Fütterung wiesen Weibchen rund 30\% geringere Werte für die DNAOxidation auf als die Männchen (Faktor 0,7). 


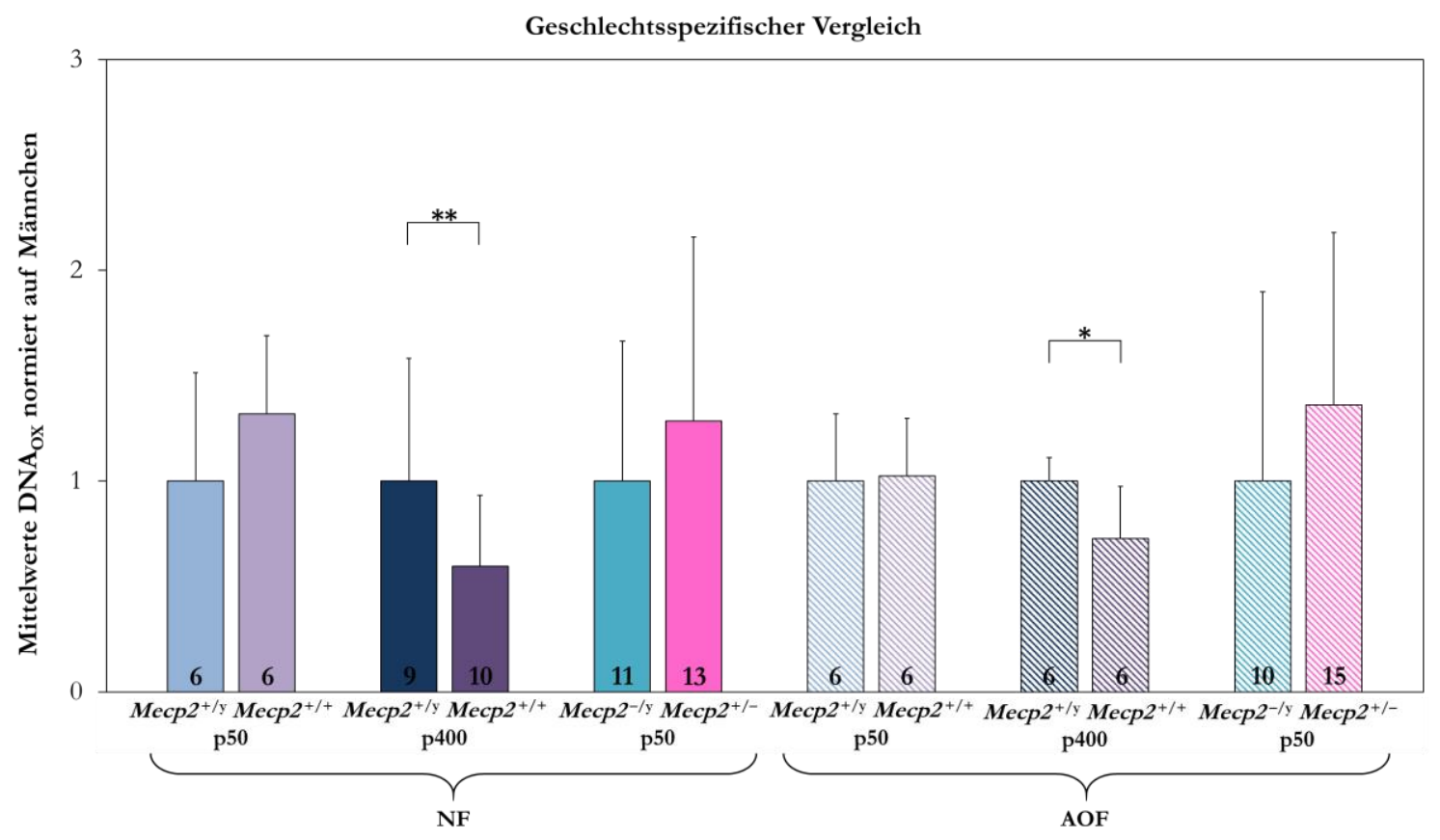

\section{Abbildung 18: Vergleich der oxidativen DNA-Schädigung unter Normierung auf die entsprechende Kontrollgruppe mit männlichem Geschlecht.}

Um den Einfluss des Geschlechtes auf die DNA-Oxidation deutlicher abzugrenzen, wurden die Mittelwerte der DNA-Oxidation zusammen mit der entsprechenden Standardabweichung aller untersuchten weiblichen Mäuse auf das Ausmaß der DNA-Oxidation entsprechender Männchen normiert. Diesem Vergleich ist zu entnehmen, dass lediglich bei 400 Tage alten Wildtypen die DNAOxidation bei Weibchen auf einem signifikant niedrigeren Niveau liegt als die der Männchen. Bei allen 50 Tage alten Tieren konnten keine signifikanten Unterschiede in der DNA-Oxidation zwischen Männchen und Weibchen festgestellt werden.

\subsubsection{Abhängigkeit von der Fütterung}

Da als mögliches Therapeutikum eine Fütterung von antioxidativem Futter bei allen zuvor unter Normalfutter verwendeten Gruppen durchgeführt wurde, wurde neben dem Einfluss des Genotyps und des Geschlechts auch der Einfluss der Fütterung auf die DNA-Oxidation bewertet. Dazu wurden die Messwerte aller Gruppen jeweils auf den Mittelwert der Kontrollgruppe unter Normalfütterung normiert (Abb. 19). Auffällig waren hier die Unterschiede der Futterwirkung zwischen Individuen der Wildtypen und der Rett-Mäuse. Bei männlichen, 50 Tage alten Wildtyp-Mäusen konnte eine Abnahme der DNA-Oxidation um ca. 20\% in Form eines Trends verzeichnet werden. Bei 50 Tage alten Wildtyp-Weibchen konnte ebenfalls eine sehr signifikante Abnahme der Messwerte beobachtet werden (Faktor 0,6). Dagegen schien bei männlichen und weiblichen 400 Tage alten Wildtypen die DNA-Oxidation durch AO-Fütterung tendenziell zuzunehmen (Männchen Faktor 1,2, Weibchen Faktor 1,4). Bei 50 Tage alten weiblichen und männlichen Rett-Mäusen konnte dagegen keine signifikante Veränderung bei der DNA-Oxidation durch eine solche Fütterung festgestellt werden. Bei 400 Tage alten Rett-Weibchen kam es dabei sogar zu einer signifikanten Zunahme des oxG-Anteils (Faktor 1,6). 


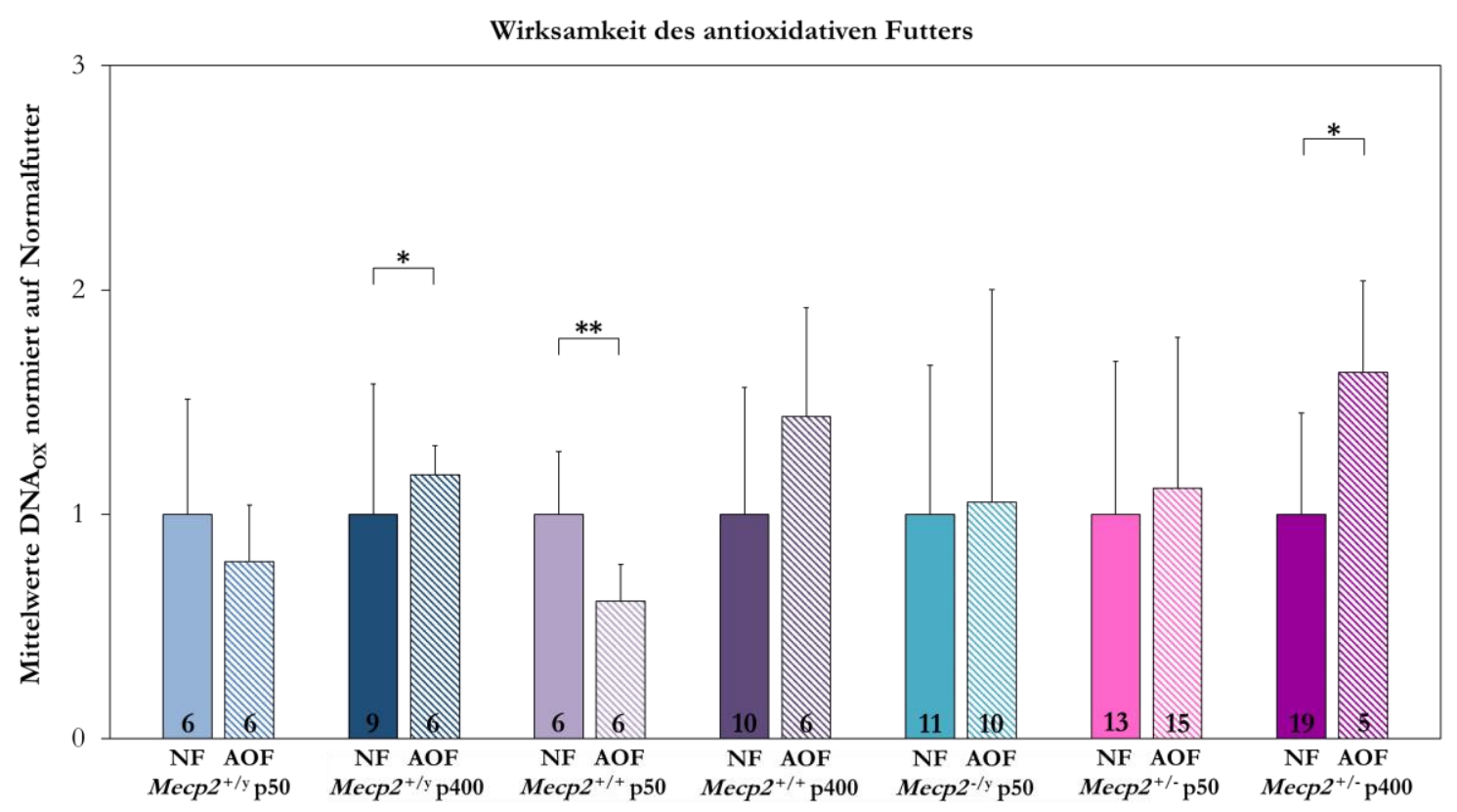

\section{Abbildung 19: Ausmaß DNA-Oxidation unter Normierung auf die entsprechende Kontrollgruppe unter Normalfutter.}

Die Wirkung einer antioxidantienreichen Fütterung auf die DNA-Oxidation wurde überprüft, indem

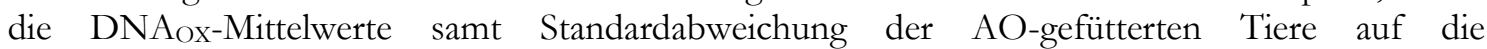
$\mathrm{DNA}_{\mathrm{OX}}$-Mittelwerte der normalgefütterten Tiere normiert wurden. Daran war zu erkennen, dass die DNA-Oxidation durch AO-Fütterung lediglich bei 50 Tage alten Wildtypen zur gewünschten Reduktion der DNAox-Werte führte, bei 400 Tage alten Wildtypen und heterozygoten Weibchen aber einen weiteren Anstieg der DNA-Oxidation herbeiführte. Bei 50 Tage alten Rett-Tieren beider Geschlechter, welche die höchsten $\mathrm{DNA}_{\mathrm{OX}}$-Werte aller Gruppen aufwiesen, führte die antioxidantienreiche Fütterung auch zu keinerlei Verbesserung des Ausmaßes der DNA-Oxidation.

\subsubsection{Abhängigkeit vom Alter}

Das Ausmaß der DNA-Oxidation wurde auch bezüglich der Altersabhängigkeit analysiert, indem die Messwerte der Gruppen auf den Mittelwert der Kontrollgruppe 50 Tage alter Tiere normiert wurden (Abb. 20). Die Untersuchung dieser Altersabhängigkeit diente unter anderem der Qualitätskontrolle der Messwerte, da die DNA-Oxidation bekannter Weise mit zunehmendem Alter ebenfalls ansteigen sollte. Dieser Gegenüberstellung war zu entnehmen, dass die oxidative DNA-Schädigung bei männlichen Wildtyp-Mäusen mit zunehmendem Alter bei normaler Fütterung (Faktor 2,7) und antioxidativer Fütterung (Faktor 4,0) ebenfalls anstieg. Bei entsprechenden Weibchen konnte ebenfalls eine solche Zunahme verzeichnet werden, wobei diese nur bei Tieren mit AO-Futter als sehr signifikant einzustufen war (Faktor 2,8). Bei normal gefütterten Rett-Weibchen war dagegen eine sehr signifikante Abnahme der DNA-Oxidation mit zunehmendem Alter festzustellen (Faktor 0,7). 


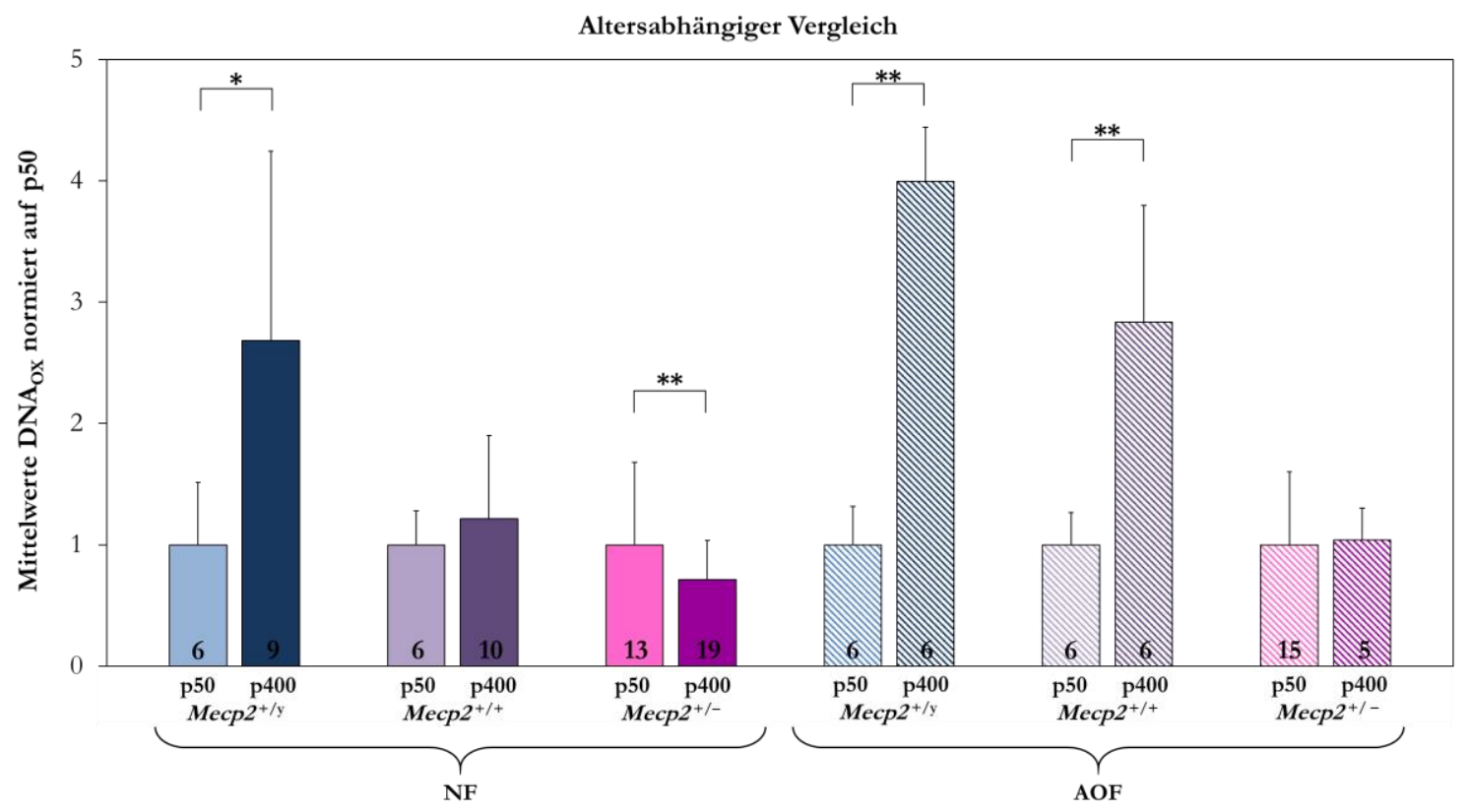

\section{Abbildung 20: Gruppenvergleich der Oxidation in DNA unter Normierung auf die entsprechende Kontrollgruppe im Alter von 50 Tagen.}

Eine Überprüfung der Altersabhängigkeit der DNA-Oxidation wurde durchgeführt, um die Qualität der Ergebnisse zu sichern, da diese bekannterweise mit dem Alter zunimmt. Die erfolgte durch eine Normierung der DNAox-Werte von 400 Tage alten Tieren auf die von 50 Tage alten Mäusen. Dabei zeigte sich, dass die DNA-Oxidation bei fast allen Vergleichspaaren mit dem Alter zunahm. Die einzige Ausnahme bildeten die heterozygoten Weibchen, bei welchen die DNA-Oxidation 400 Tage alter Weibchen auf einem niedrigeren Niveau liegt als die DNA-Oxidation jüngerer Mecp2+/--Weibchen.

\subsection{Auswertung verschiedener Färbungen an PFA-fixierten Hirnschnitten}

Bei den verwendeten histologischen Präparaten handelt es sich um späte transversale Hirnschnitte, da Teile der perfundierten Gehirne der Mäuse zuvor für anderweitige Untersuchungen verwendet wurden. Die Identifikation der anatomischen und funktionellen Einheiten innerhalb eines solchen Hirnschnittes ist der untenstehenden beispielhaften Abbildung zu entnehmen. Wie bereits bei der Analyse der DNA-Oxidation wurde auch bei der Auswertung der gefärbten Hirnschnitte schwerpunktmäßig der Cortex auf Unterschiede zwischen Rett- und Wildtyp-Weibchen hin untersucht, weshalb dieser dazu in funktionell ähnliche Areale differenziert wurde (Abb. 21). 


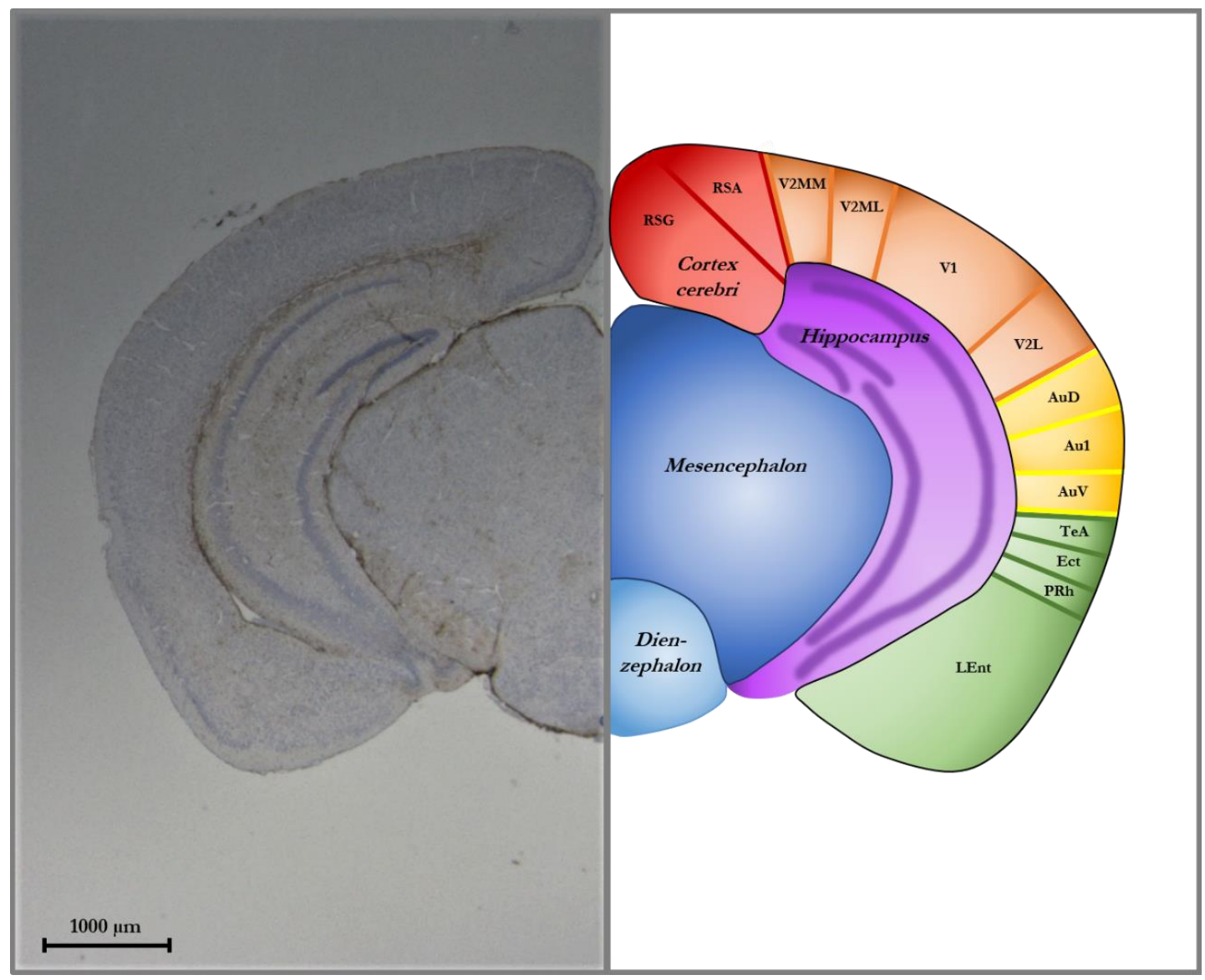

Abbildung 21: Einteilung der Hirnareale im transversalen Schnitt.

Strukturell konnten bei den verwendeten Hirnschnitten das Dienzephalon, das Mesenzephalon sowie der Hippocampus und der Cortex cerebri des Telencephalons unterschieden werden. Eine funktionelle Einteilung wurde für den Cortex vorgenommen. Dabei wurden der retrospleniale Cortex (RSA, RSG), der visuelle Kortex (V1, V2MM, V2ML, V2L), der auditive Cortex (Au1, AuD, AuV), der temporale Assoziationscortex (TeA) sowie der ectorhinale (Ect), der perirhinale (PRh) und der laterale entorhinale Cortex (LEnt) identifiziert (Paxinos und Franklin 2001).

Bei einem solchen späten, transversalen Hirnschnitt konnten im Cortex diverse funktionelle Bereiche identifiziert werden. Dazu gehörten der granuläre (RSG) und agranuläre (RSA) retrospleniale Cortex, welchen kognitive Funktionen zugesprochen werden, darunter zum Beispiel das Kurzzeitgedächtnis. Ein weiterer Abschnitt, bestehend aus der primären Sehrinde (V1) und den mediomedialen (V2MM), den mediolateralen (V2ML) und den lateralen (V2L) Anteilen der sekundären Sehrinde, dient der Erfassung und Verarbeitung von Objekten beim Sehvorgang. Im auditiven Cortex wird Gehörtes erfasst und interpretiert; er besteht aus der primären Hörrinde (Au1) und den dorsalen (AuD) und ventralen ( $\mathrm{AuV}$ ) Anteilen der sekundären Hörrinde. Bei den übrigen Cortexarealen dieses Schnittes handelt es sich um den temporalen Assoziationscortex (TeA) sowie um den ectorhinalen (Ect), den perirhinalen (PRh) und den lateralen entorhinalen Cortex (LEnt), deren Aufgaben in der Vermittlung höherer kognitiver Funktionen liegen. In den folgenden Abbildungen sind die Ausschnitte aus Hirnschnitten von Wildtyp-Weibchen mit $M e c p 2^{+/+}$und von Rett-Weibchen mit $M e c p 2^{+/-}$gekennzeichnet. 


\subsubsection{Analyse der Hämatoxylin-Eosin-gefärbten Präparate (HE)}

Bei der HE-Färbung wurde Hämatoxylin in seiner basischen Form dazu verwendet, sich in sauren (basophilen) Strukturen anzureichern und diese damit mikroskopisch sichtbar zu machen. Zu den wichtigsten aufgrund ihrer Basophilie blau angefärbten Strukturen gehörten der Zellkern mit der enthaltenen DNA und die Ribosomen. Die zusätzliche Färbung mit Eosin Y verschärfte den Kontrast, indem sich dieser saure Farbstoff in basischen (azidophilen) Strukturen ansammelt. Dazu gehörten Proteine des Zytoplasmas, Mitochondrien und Kollagen, welche rot erschienen. Die Färbung eines Präparates mit Hämatoxylin-Eosin erlaubte also eine Beurteilung der Strukturen aufgrund der kontrastreichen Darstellung sowie einen Vergleich der Basizität und Azidität der Präparate untereinander.

Ein Vergleich der Übersichtsaufnahmen der Hirnschnitte, welche aus den vier untersuchten Mäusen gewonnen wurden, zeigte keinerlei offensichtlichen Unterschiede zwischen Rettund Wildtyp-Weibchen bezüglich der Struktur - mit Ausnahme der Beobachtung, dass die Hirne von heterozygoten Weibchen kleiner waren als die der Wildtypen (Abb. 22).

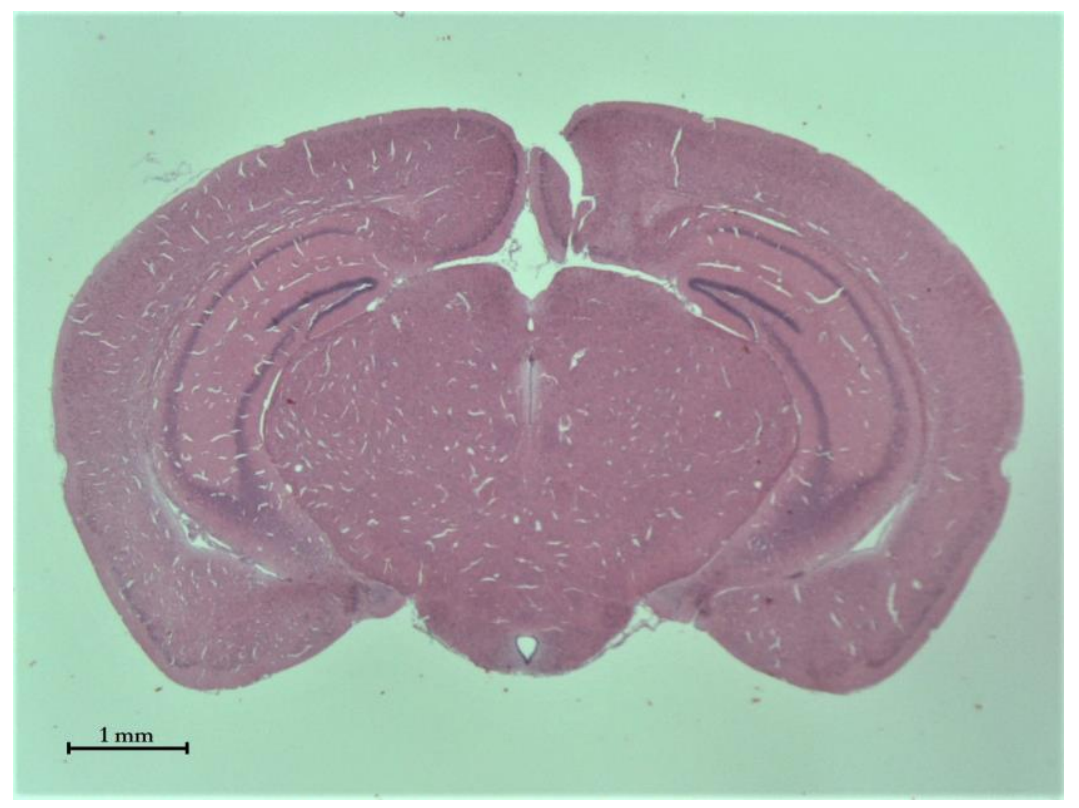

\section{Abbildung 22: Präparat eines heterozygoten Weibchens in der HE-Färbung.}

Diese Übersichtsaufnahme eines Hirnschnittes in der HE-Färbung stammt von einem heterozygoten Weibchen im Alter von 50 Tagen und zeigt gegenüber den Präparaten der anderen Individuen keinerlei offensichtliche strukturelle Veränderung auf. 
Den Gegenüberstellungen der Präparate aus dem Bereich Cortex bei 20-facher und 40-facher Vergrößerung ist zu entnehmen, dass die Körnerzellen der Rett-Mäuse etwas dichter gepackt sind und etwas kleiner scheinen als die der Wildtyp-Mäuse (Abb. 23). Zudem zeigt sich in den Präparaten der heterozygoten Weibchen sowohl eine intensivere Färbung der Extrazellulärmatrix durch Eosin also auch ein generell dunkleres Erscheinungsbild der Zellkörper. Auch in den Aufnahmen des Hippocampus wird bei 20-facher und 40-facher Vergrößerung deutlich, dass die Perykarien der Körnerzellen im Gyrus dentatus der RettWeibchen dunkler wirken und dass die Extrazellulärmatrix intensiver durch Eosin angefärbt wurde als bei den Präparaten der Wildtyp-Weibchen. Zusätzlich scheinen auch hier die Perykarien der Körnerzellen der Rett-Weibchen etwas kleiner und dichter gepackt als die der Wildtyp-Weibchen. Die Zählung der Pixel nach Applikation einer Farbintensitätsschwelle (Threshold) mit ImageJ ergab keine signifikanten Unterschiede zwischen Wildtyp und RettTyp im auditiven Cortex und im Gyrus dentatus, wobei anzumerken ist, dass es sich hier nur um eine Analyse der Fläche, nicht aber der Farbintensität handelte. 
A)
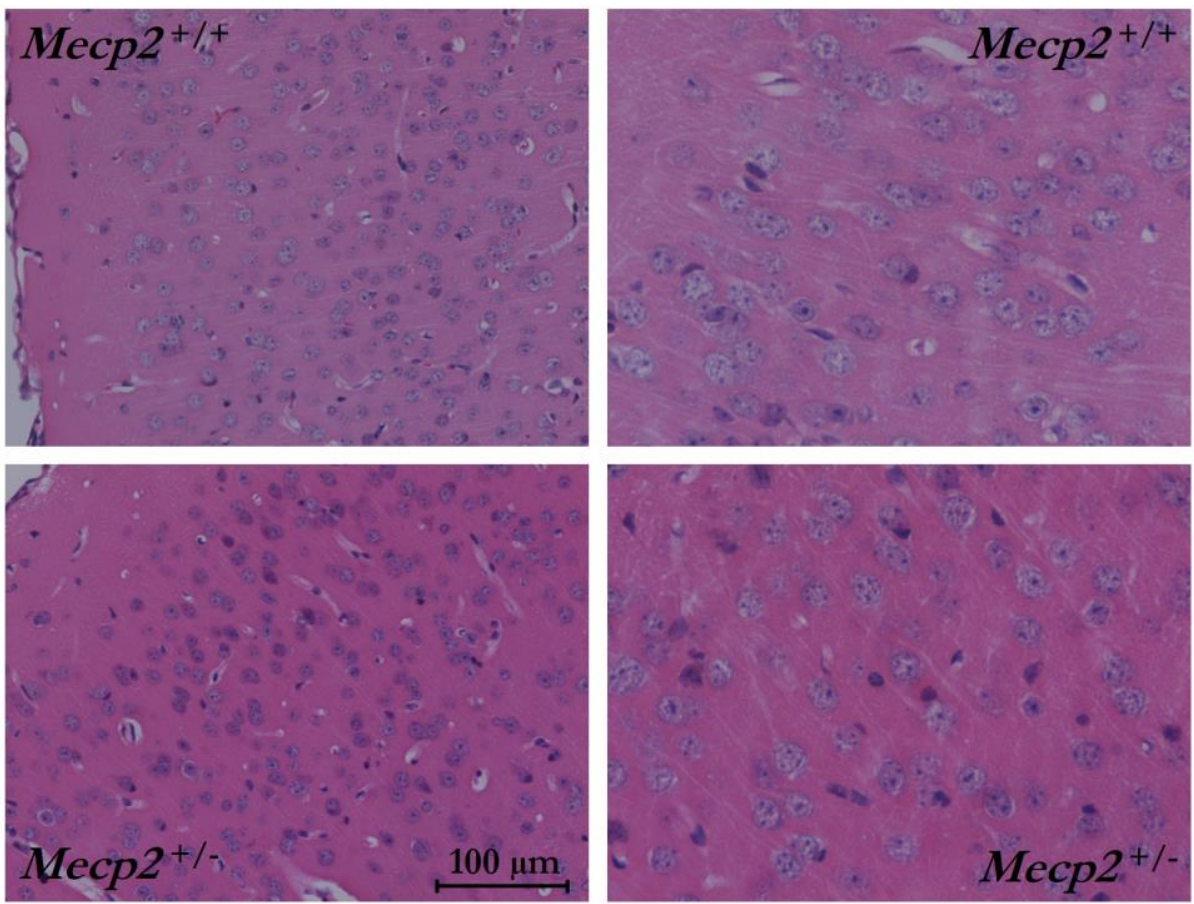

B)
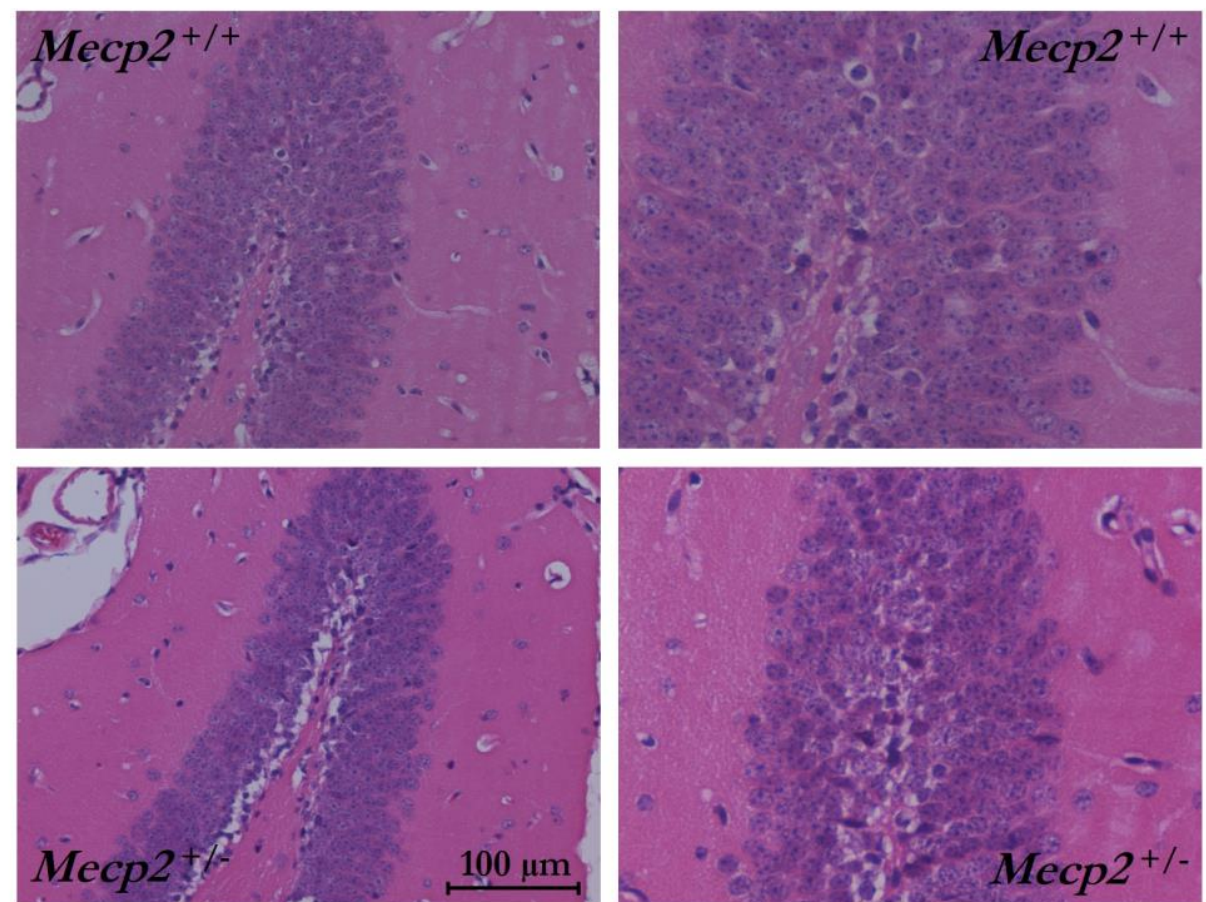

Abbildung 23: Präparate in der HE-Färbung von heterozygoten und WildtypWeibchen aus den Bereichen des auditiven Cortex (A) und des Gyrus dentatus des Hippocampus (B).

Hier wurden Ausschnitte aus dem Bereich des auditiven Cortex (A) und des Gyrus dentatus des Hippocampus (B) exemplarisch aufgezeigt. Auf der jeweils linken Seite sind Ausschnitte in 20-facher Vergrößerung, auf der rechten Seite in 40-facher Vergrößerung dargestellt. Dabei zeigt sich in beiden Hirnarealen, dass die Perykarien der Körnerzellen von Rett-Weibchen kleiner und dichter gepackt sind als die der Wildtypen. 


\subsubsection{Bestimmung der Verteilung dreiwertigen Eisens über die Färbung von Berliner Blau}

Um die Verteilung dreiwertiger Eisenionen in einem Gewebeschnitt zu visualisieren, wurde dieser mit gelbem Blutlaugensalz versetzt, welches präziser als Kaliumhexacyanoferrat-(II) bezeichnet wird. Durch die Aufnahme der dreiwertigen Eisenionen in die Komplexstruktur unter Abgabe von Kaliumionen entstand Eisen(III)-hexacyanidoferrat(II), welches als Berliner Blau bezeichnet wird. Bei der Gegenüberstellung von Hirnschnitten als Übersichtsaufnahmen konnten keine starken strukturellen Unterschiede zwischen heterozygoten und Wildtyp-Weibchen festgestellt werden (Abb. 24).

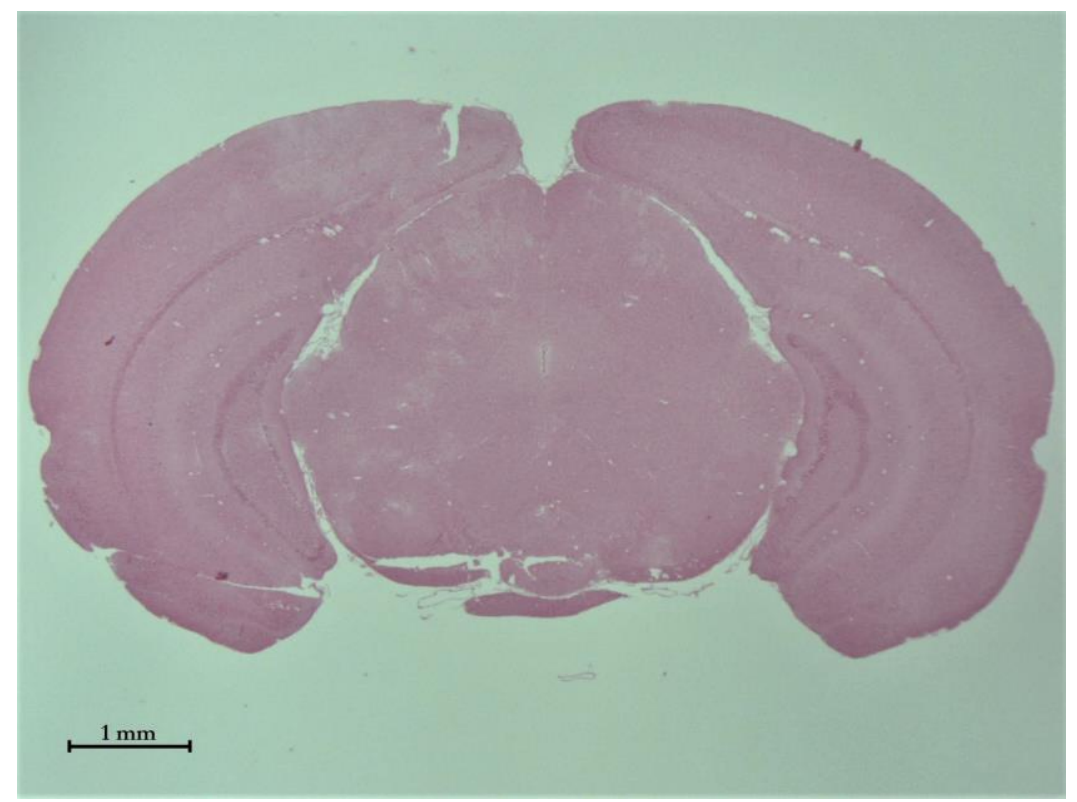

\section{Abbildung 24: Übersichtsaufnahme eines Präparates eines $M e c p 2^{+/+}$-Weibchens in der Färbung Berliner Blau.}

Der Abbildung ist die Übersichtsaufnahme eines Hirnschnittes in der Färbung Berliner Blau einer Mecp2+/+-Maus zu entnehmen. Ein Vergleich dieser Aufnahmen zwischen den verwendeten Individuen lies keine offensichtlichen strukturellen Unterschiede erkennen. Nur die Hirngröße war bei heterozygoten Weibchen gegenüber den Wildtyp-Weibchen reduziert.

Die Analyse Berliner Blau Färbung (Abb. 25) ergab für den Cortex ebenfalls, dass einige Perykarien der Körnerzellen in B deutlich dunkler erschienen als in A. Da die Präparate der Berliner Blau Färbung mit Kernechtrot gegengefärbt wurden, resultierte dies aus einer stärkeren Anfärbung der Zellkerne von Körnerzellen von $M e c p 2^{+/-}$-Mäusen gegenüber Wildtyp-Weibchen. Im Bereich des Gyrus dentatus des Hippocampus konnte dagegen keine eindeutige unterschiedliche Färbung der Perykarien der Körnerzellen zwischen $M e c p 2^{+/+}$ und $M e c p 2^{+/-}$-Weibchen festgestellt werden. 
Auch konnten in keinem der untersuchten Präparate Auffälligkeiten bei der Verteilung dreiwertiger Eisenionen, welche durch Berliner Blau angefärbt waren, oder eine Akkumulation dieser Ionen beobachtet werden. In allen vier Präparaten konnten vereinzelt Zellen identifiziert werden, welche mehr freie dreiwertige Eisenionen auswiesen als andere Zellen, dabei schienen besonders Oligodendrozyten reich an dreiwertigen Eisenionen gewesen zu sein. Die Analyse der in Berliner Blau angefärbten Flächen im visuellen Cortex mit ImageJ ergab bei den Wildtyp-Weibchen einen Mittelwert von $6780 \pm 1570$ Pixel $(n=2)$ und bei den Rett-Weibchen einen Mittelwert von $8450 \pm 2780$ Pixel $(n=2)$. Aufgrund der geringen Probenzahl ist dieser Unterschied zwar nicht signifikant, in Form eines Trends kann aber eine Zunahme der in Berliner Blau gefärbte Fläche um ca. 30\% bei Rett-Weibchen gegenüber Wildtyp-Weibchen beobachtet werden. Am Gyrus dentatus betrug die Fläche der markierten dreiwertigen Eisenionen bei weiblichen Wildtyp-Tieren $600 \pm 130$ Pixel $(\mathrm{n}=2)$ und bei weiblichen Rett-Tieren $540 \pm 10$ Pixel $(\mathrm{n}=2)$, sodass die Verteilung von dreiwertigem Eisen im Gyrus dentatus in Wildtyp- und Rett-Weibchen als gleich hoch betrachtet werden kann. 
A)
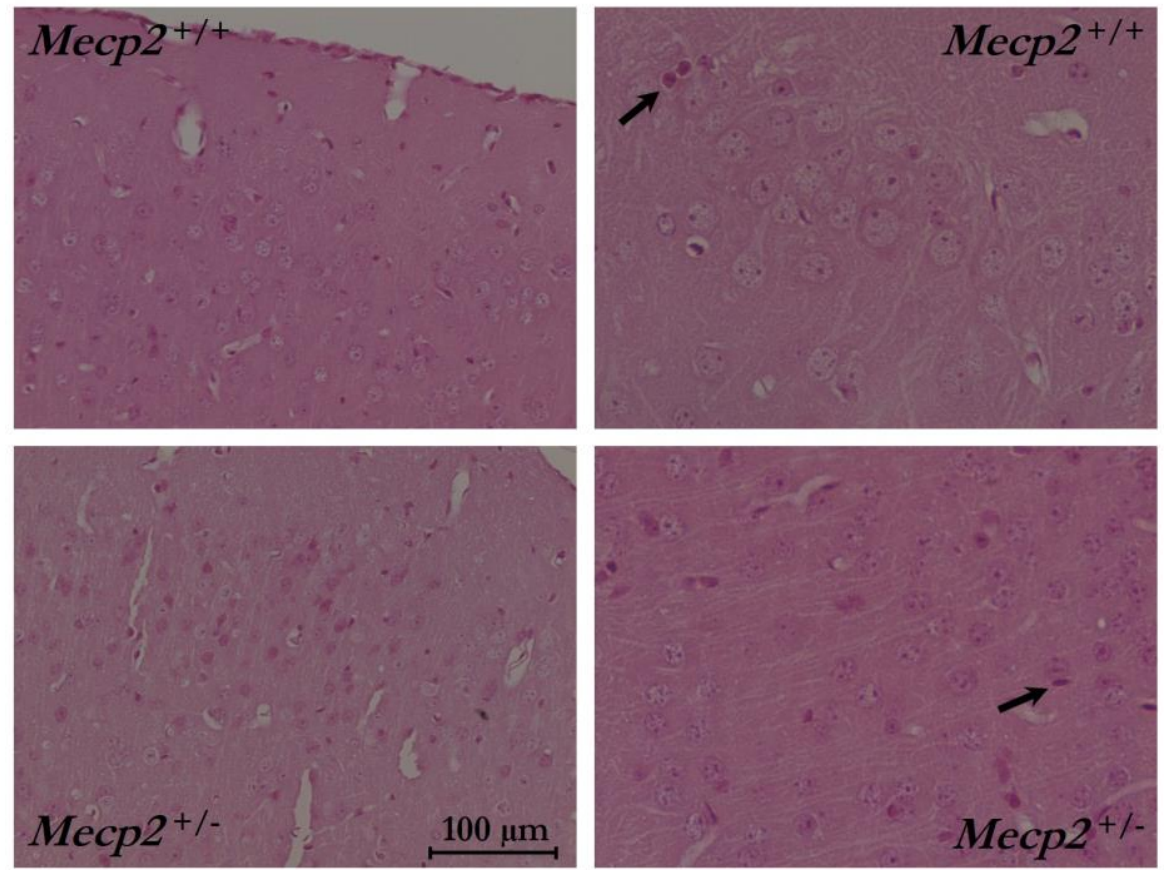

B)
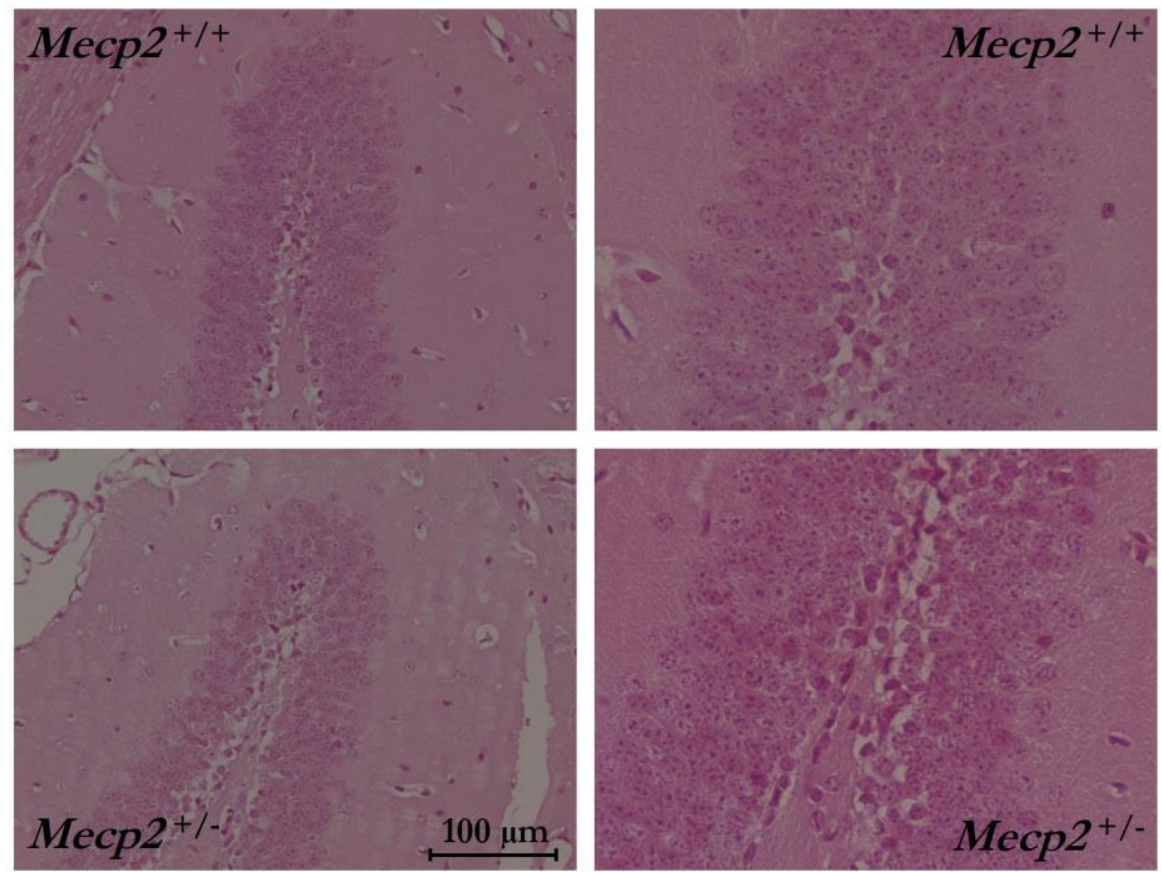

Abbildung 25: Exemplarische Ausschnitte aus den Präparaten in der Färbung

Berliner Blau aus den Bereichen des visuellen Cortex (A) und des Gyrus dentatus des Hippocampus (B).

Der exemplarischen Gegenüberstellung der Präparate aus dem visuellen Cortex (A) und dem Gyrus dentatus des Hippocampus (B) ist zu entnehmen, dass zwar in einzelnen Zellen vermehrt dreiwertiges Eisen markiert wurde, jedoch finden sich aufgrund der geringen Probenzahl keine statistisch validierbaren Unterschiede in der Verteilung dreiwertiger Eisenionen zwischen Mecp2+/+-Weibchen und Mecp2+/--Weibchen. Auf der jeweils linken Seite finden sich Ausschnitte in 20-facher Vergrößerung, in den Präparaten auf der rechten Seite wurden in 40-facher Vergrößerung durch Pfeile einzelne eisenreichere Zellen markiert. 


\subsubsection{Verteilungsanalyse von zweiwertigem Eisen durch die Färbung von Turnbulls Blau}

Vom Nachweis dreiwertiger Eisenionen (Berliner Blau) ist der Nachweis von zweiwertigen Eisenionen durch die Visualisierung mit Turnbulls Blau zu unterschieden. Diese Ionen wurden durch eine Weiterentwicklung der Präparate braun statt blau gefärbt. Auch bei dieser Färbung konnte keine offensichtlichen Strukturunterschiede zwischen den verschiedenen Hirnschnitten nachgewiesen werden (Abb. 26).

In allen Ausschnitten der in Turnbulls Blau gefärbten Präparate ließ sich bei den RTT-Tieren eine dichtere Packung der neuronalen Zellen im Hirngewebe gegenüber den WT-Weibchen gut erkennen (Abb. 27). Die generell in den Schnitten angefärbten neuronalen Zellen sind aufgrund ihrer Form und Lage als Körnerzellen und Pyramidenzellen zu identifizieren. Sichtbare Unterschiede zwischen den beiden Genotypen bezüglich der Anfärbung zweiwertiger Eisenionen hinsichtlich Menge oder Intensität war in keiner der untersuchten Hirnregionen zu erkennen. In allen Schnitten existierten neuronale Zellen mit kleinen, braun gefärbten Eisen-Granula, jedoch konnte keine Systematik in der Verteilung dieser Granula zwischen den Hirnschnitten der untersuchten weiblichen Rett- und Wildtyp-Mäuse erkannt werden. Die Flächenanalyse der markierten zweiwertigen Eisenionen ergab für den visuellen Cortex bei weiblichen Wildtypen eine Fläche von $1210 \pm 210$ Pixel $(\mathrm{n}=2)$ und bei RettWeibchen eine Fläche von $1000 \pm 10$ Pixel $(n=2)$. Die Tendenz zur Abnahme der markierten Fläche von ca. 15\% bei Rett-Weibchen gegenüber Wildtyp-Weibchen im visuellen Cortex ist als nicht signifikant zu bewerten. Auch im Gyrus dentatus des Hippocampus lagen die angefärbten Flächen mit $1360 \pm 290$ Pixel $(n=2)$ bei WildtypWeibchen und $1310 \pm 30$ Pixel $(n=2)$ bei Rett-Weibchen auf einem gleichen Niveau. 


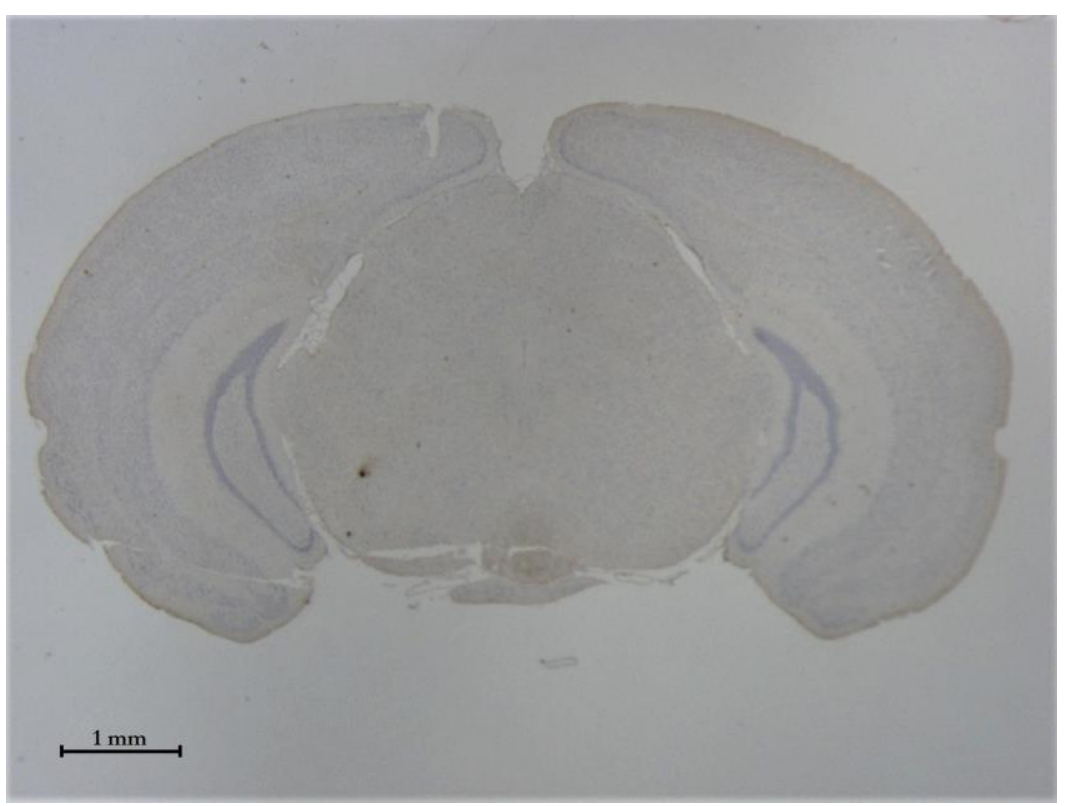

\section{Abbildung 26: Aufnahme eines exemplarischen Präparates in der Färbung} Turnbulls Blau aus dem Gehirn eines Wildtyp-Weibchens.

Gezeigt ist eine Übersichtsaufnahme eines Hirnschnittes eines Wildtyp-Weibchens in der Färbung Turnbulls Blau. Eine Gegenüberstellung dieser Aufnahmen aller verwendeten Individuen führte zu keiner Feststellung offensichtlicher struktureller Unterschiede zwischen Mecp $2^{+/+_{-}}$und Mecp2+/--Weibchen. 
A)
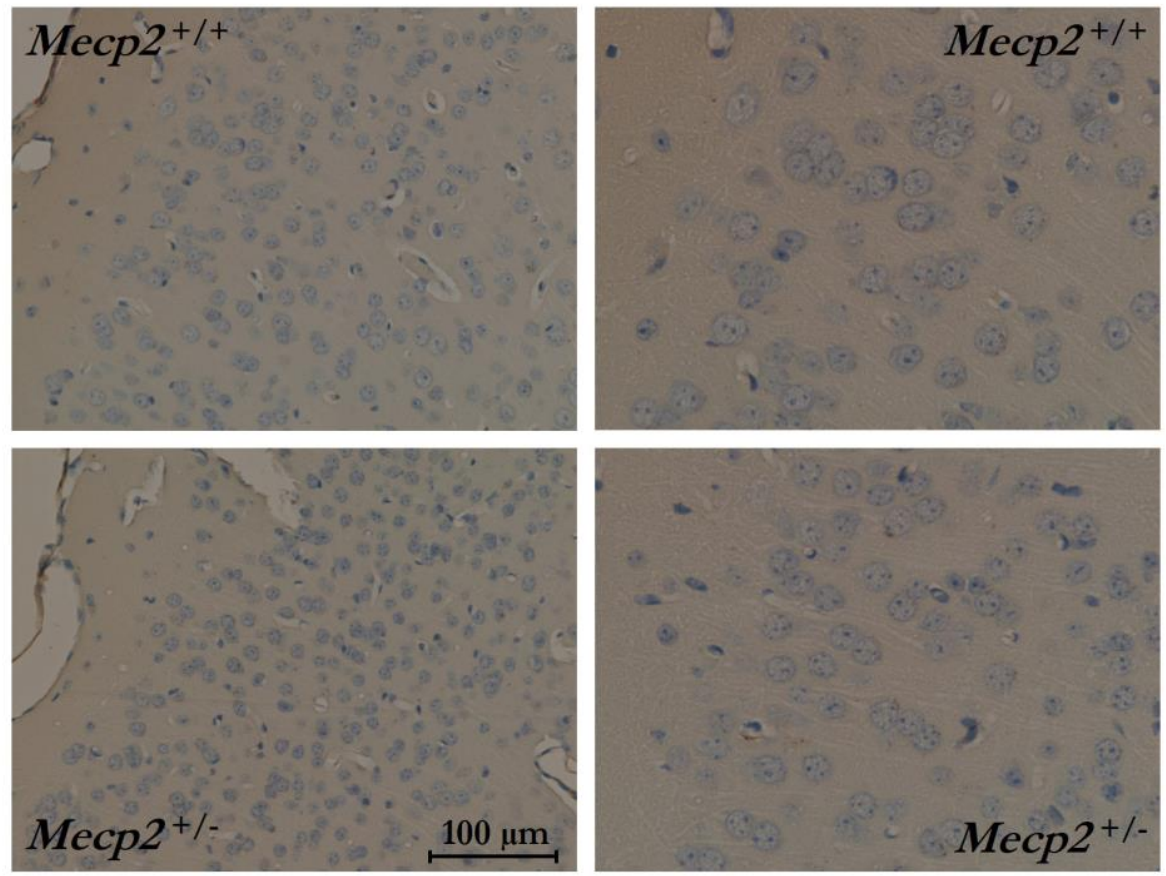

B)
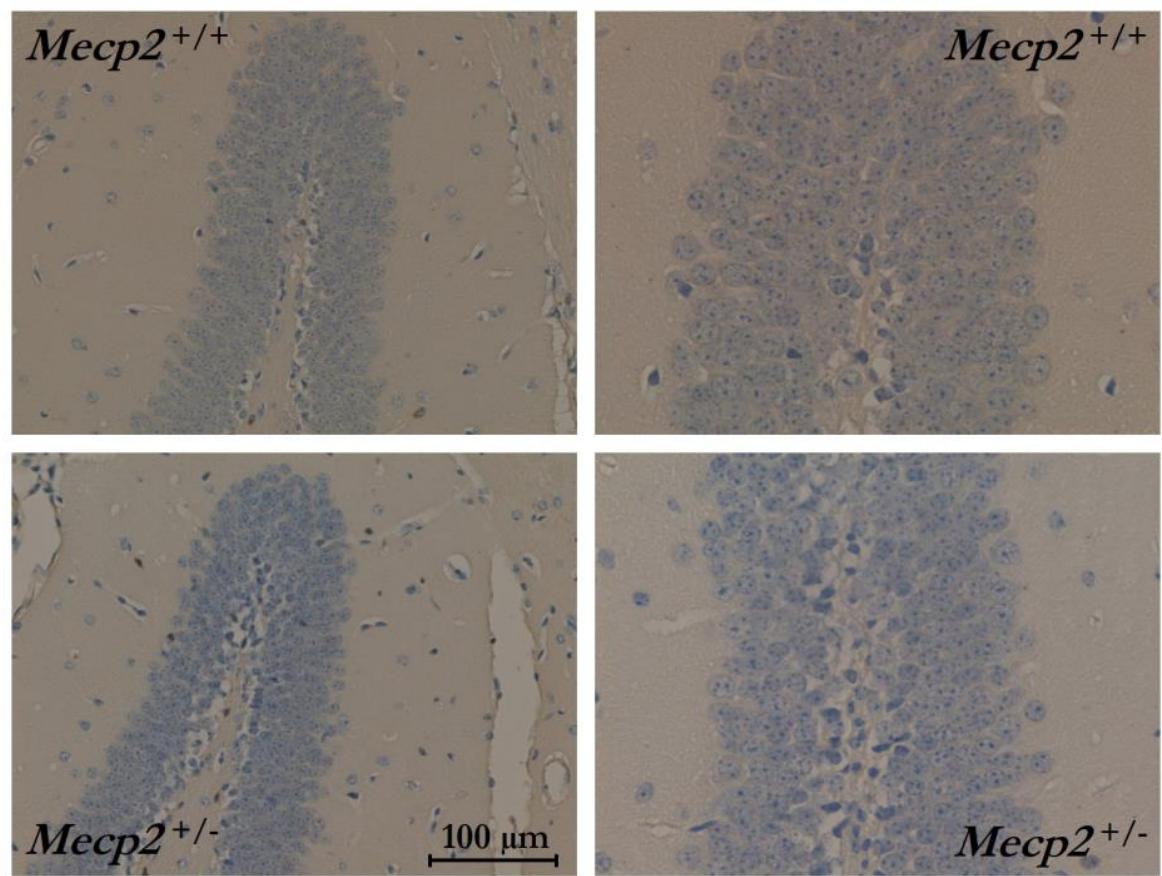

\section{Abbildung 27: Exemplarische Ausschnitte aus dem visuellen Cortex (A) und dem Gyrus dentatus des Hippocampus (B) in der Färbung Turnbulls Blau.}

Unter allen untersuchten Regionen des Cortex wurden hier beispielhaft Ausschnitte aus dem visuellen Cortex (A) verwendet, um das Ausbleiben von Verteilungsveränderungen von zweiwertigem Eisen zwischen Mecp 2+/-- und Mecp2 $2^{+/+}$-Weibchen aufzuzeigen. Dieselbe Feststellung war auch im Bereich des Hippocampus zu treffen, wobei hier exemplarisch der Gyrus dentatus gezeigt ist (B). Dies wird nicht nur in 20-facher Vergrößerung (links), sondern vor allem in 40-facher Vergrößerung (rechts) deutlich. 


\subsubsection{Analyse der immunhistochemischen Färbung für das Amyloid-Precursor- Protein APP}

Um die Verteilung des Amyloid-Precursor-Proteins APP darzustellen, wurde eine immunhistochemische Färbung mit Antikörpern durchgeführt, welche spezifisch an APP binden. Das Vorhandensein von APP um die Perykarien der Neurone war als physiologisch anzusehen, da es als Transmembranprotein fungierte. Dagegen handelte es sich bei axonaler Akkumulation von APP um eine Markierung akuter Schäden. Bei der Auswertung der APPgefärbten Hirnschnitte konnten bei einem Vergleich von Übersichtsaufnahmen keine offensichtlichen Unterschiede oder strukturelle Auffälligkeiten bei Rett-Weibchen gegenüber den Wildtypen festgestellt werden (Abb. 28).

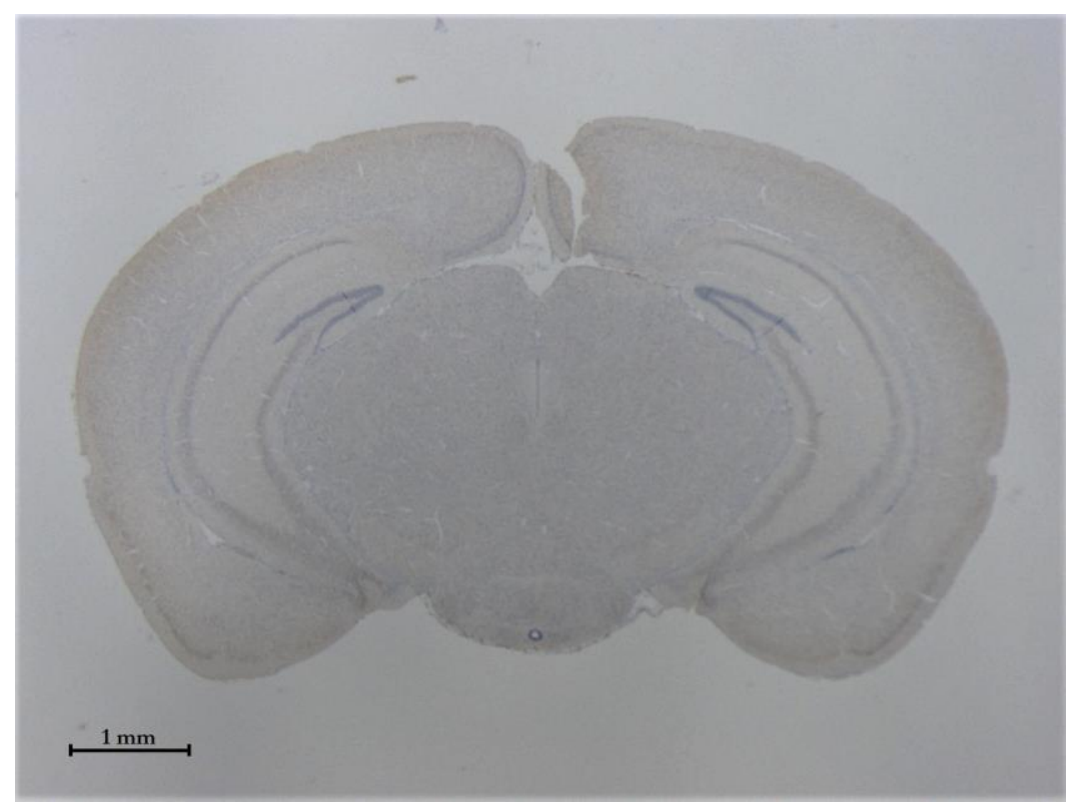

Abbildung 28: Gegen APP gefärbtes Präparat eines heterozygoten Weibchens.

Bei einem Vergleich der Übersichtsaufnahmen der Präparate in APP-Färbung aller untersuchten Mecp 2+/+- und Mecp 2+/--Weibchen konnten keine offensichtlichen strukturellen Auffälligkeiten festgestellt werden. 
Die Begutachtung der Gegenüberstellung der Präparate im Bereich Cortex (Abb. 29) ergab, dass keine axonale Akkumulation von APP bei heterozygoten Weibchen gegenüber den Wildtyp-Weibchen offensichtlich war. In allen Präparaten befand sich APP um die Perykarien der Neurone verteilt, welches als physiologisch zu werten ist. Da diese Feststellung in allen untersuchten Cortexregionen $\mathrm{zu}$ treffen war, wurde hier nur exemplarisch Ausschnitte aus dem visuellen Cortex aufgeführt. Dort ergab die Pixelzählung in den Ausschnitten nach Thresholding mit ImageJ eine angefärbte Fläche von $8850 \pm 610$ Pixel ( $\mathrm{n}=2$ ) bei Mecp $2^{+/+}$-Weibchen und $10390 \pm 440$ Pixel $(\mathrm{n}=2)$ bei Mecp $2^{+/-}$-Weibchen, woraus ein nicht signifikanter, tendenzieller Anstieg der markierten Fläche um ca. 15\% bei Rett-Weibchen gegenüber Wildtyp-Weibchen resultiert. Im Gyrus dentatus des Hippocampus fehlte APP in allen Präparaten nahezu vollständig, weshalb bei der Flächenanalyse mit ImageJ kein signifikanter Unterschied zwischen Rett-Weibchen und Wildtyp-Weibchen festgestellt werden konnte. 
A)
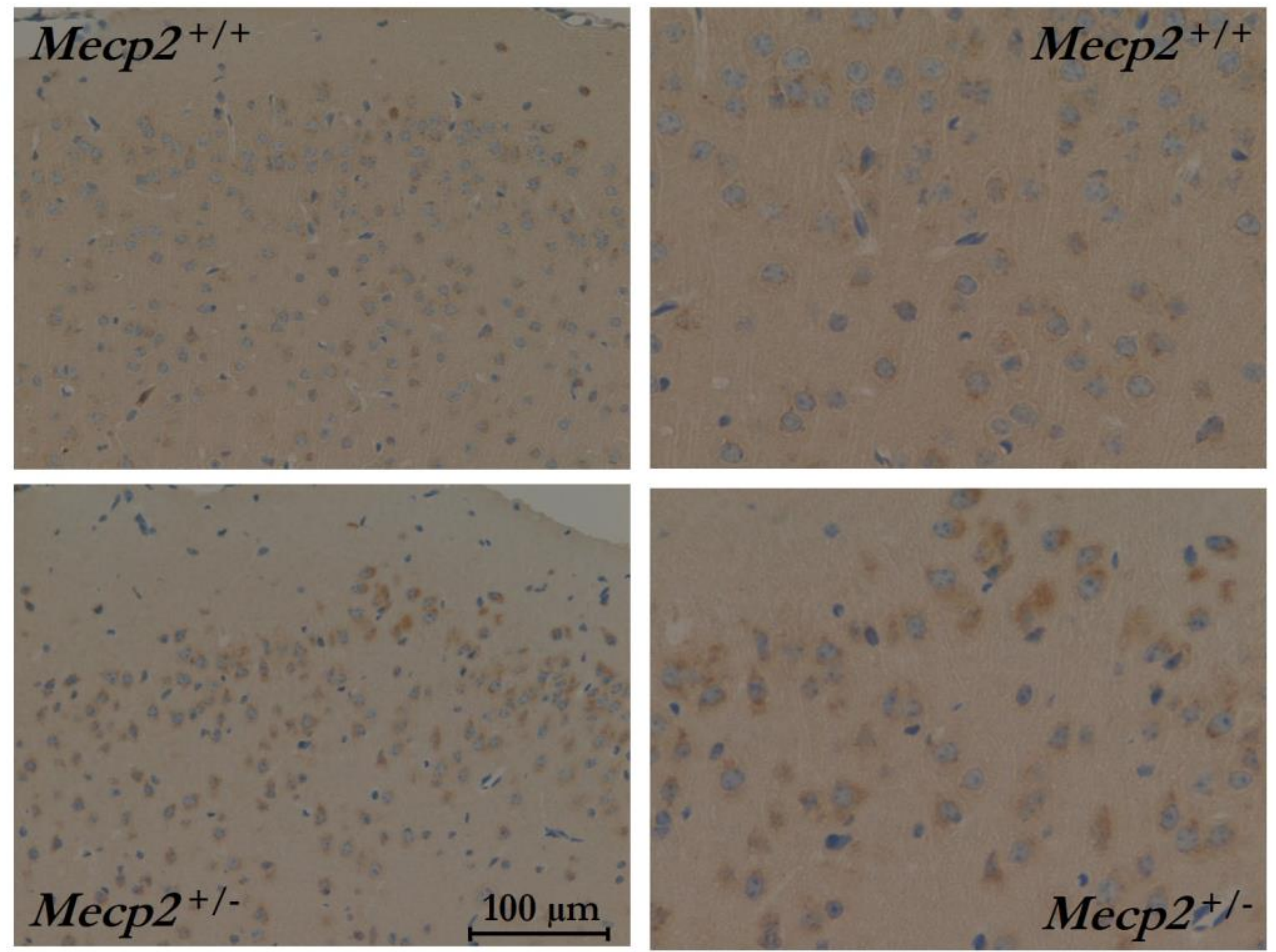

B)
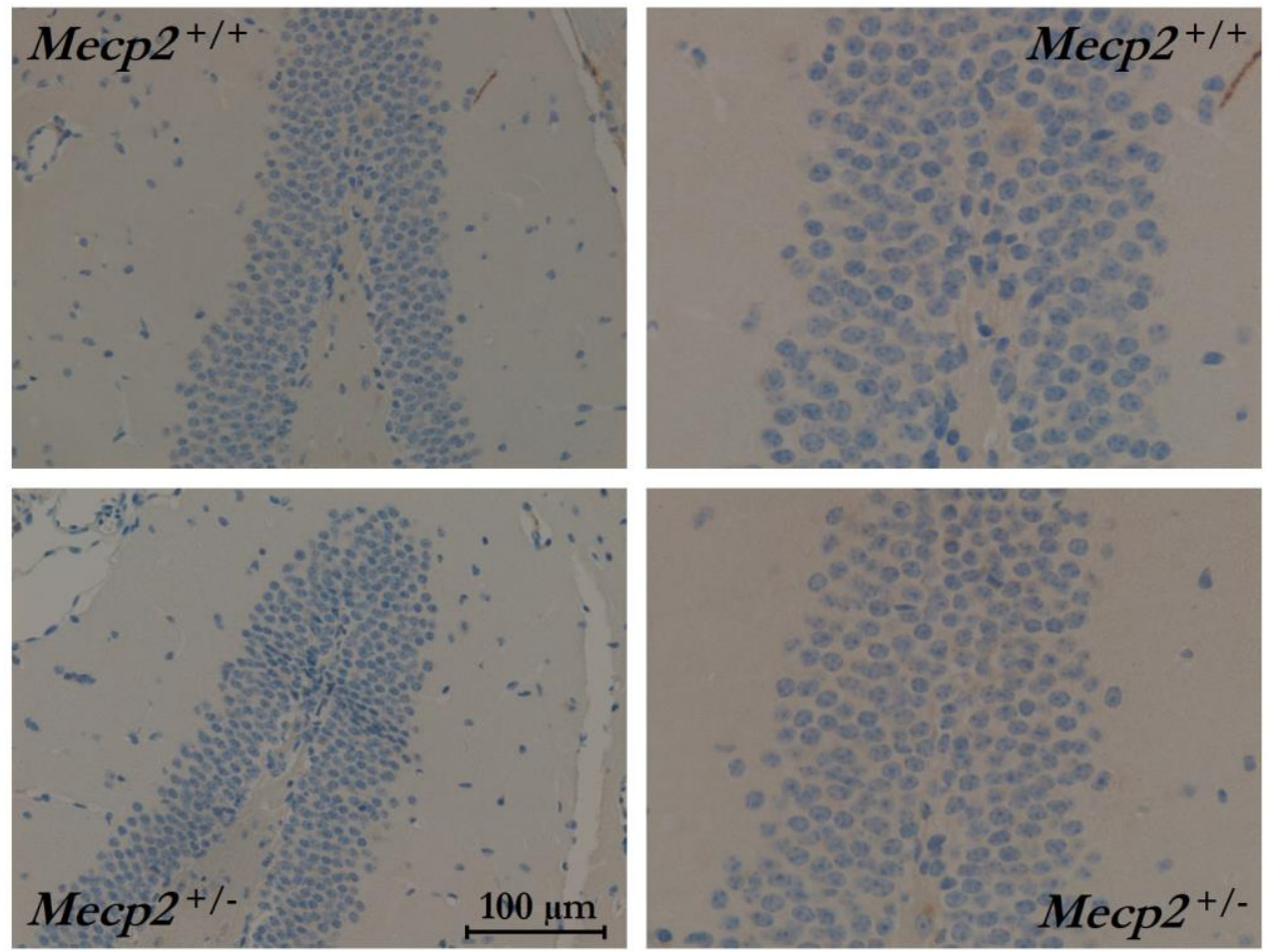

Abbildung 29: Präparatausschnitte aus dem visuellen Cortex (A) und dem Gyrus dentatus des Hippocampus (B) mit immunhistochemischer Färbung von APP.

Sowohl in den Ausschnitten in 20-facher Vergrößerung (links), also auch in denen in 40-facher Vergrößerung (rechts), findet sich im visuellen Cortex (A) Populationen von APP um neuronale Perykarien herum bei Mecp2+/+- und Mecp2+/-Weibchen, wohingegen im Gyrus dentatus des Hippocampus (B) APP in den Präparaten beider Genotypen völlig zu fehlen scheint. 


\subsubsection{Bewertung der histochemischen Färbung von Myelin und Kohlenhydraten in der LFB/PAS-Färbung}

Die histochemische Färbung von Präparaten mit LFB/PAS erfolgte durch die Verwendung von essigsaurem Luxol-fast-blue (LFB) und periodsaurem Schiff-Reagenz (PAS). Bei LFB handelte es sich um einen blauen Farbstoff, der besonders an Lipoproteine des Myelins bindet. Dagegen bindet PAS an Aldehydgruppen von Kohlenhydraten und färbt diese magentarot. Somit wurde eine kontrastreiche Färbung erzielt, in welcher sich mögliche Demyelinisierungen durch einen Mangel an LFB darstellen ließen. Ein Vergleich von Übersichtsaufnahmen von Hirnschnitten der Wildtyp- und Rett-Weibchen zeigte keine offensichtlichen strukturellen Unterschiede (Abb. 30).

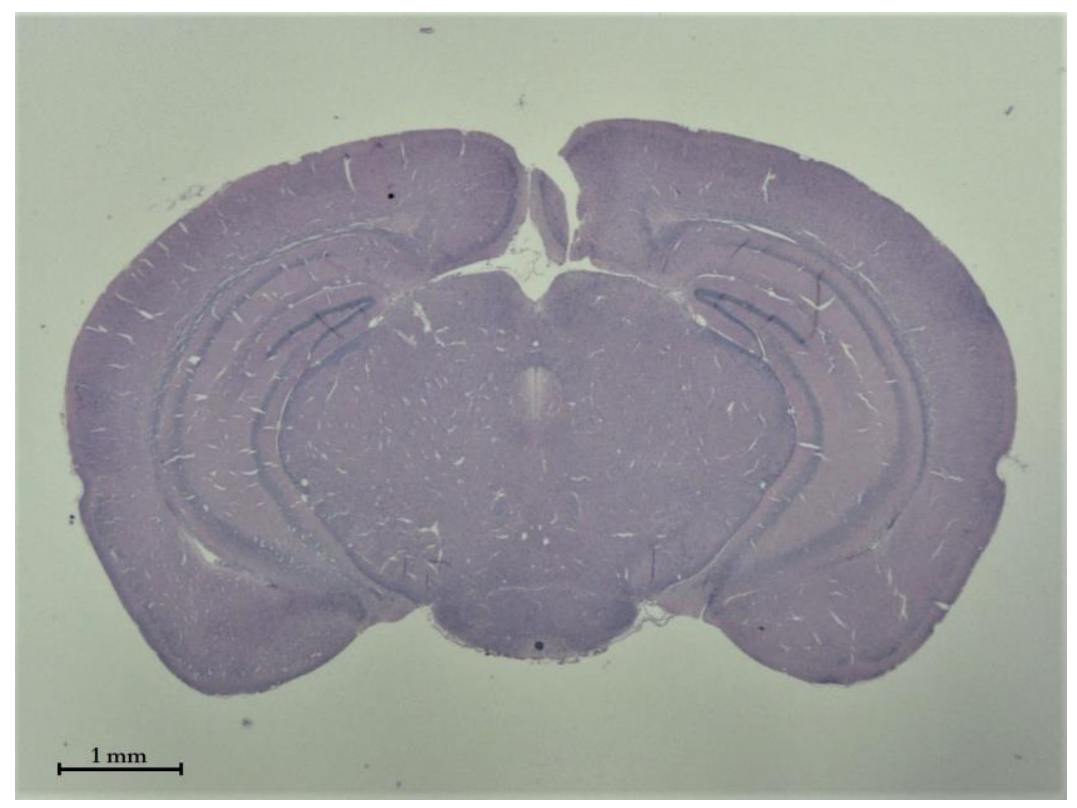

\section{Abbildung 30: LFB/PAS-gefärbtes, exemplarisches Präparat aus dem Gehirn eines heterozygoten Weibchens.}

Vergleicht man Übersichtsaufnahmen wie diese zwischen den beiden untersuchten Genotypen, so lassen sich keine offensichtlichen Strukturveränderungen in den Hirnschnitten in der LFB/PASFärbung finden. Strukturelle Auffälligkeiten, wie hier im Bereich des retrosplenialen Cortex, sind als Artefakte zu werten, da sie bei der Herstellung der gefärbten Hirnschnitte entstanden sind. 
Sowohl die Gegenüberstellung der Präparate im Bereich Cortex als auch im Bereich Hippocampus führte zu dem Ergebnis, das die Präparate bezüglich der LFB/PAS-Färbung keine Auffälligkeiten oder signifikante Unterschiede auswiesen (Abb. 31). Daher wurde hier nur exemplarisch jeweils ein Ausschnitt jedes Präparates aus dem auditiven Cortex (A) und aus dem Gyrus dentatus des Hippocampus (B) aufgezeigt. Lediglich der bereits erwähnte Befund, dass Körnerzellen in Rett-Mäusen tendenziell kleiner und dichter gepackt sind als in Wildtyp-Mäusen, konnte auch hier erhoben werden. Dies spiegelt auch die Flächenanalyse mit ImageJ wider, bei der im auditiven Cortex eine LFB-angefärbte Fläche von $405800 \pm 20440$ Pixel $(n=2)$ bei Wildtyp-Weibchen und von $422940 \pm 3860$ Pixel $(n=2)$ bei Rett-Weibchen bestimmt wurde. Damit sind bei einer nicht signifikanten, nur tendenziellen Zunahme von ca. 5\% die Ergebnisse im auditiven Cortex als gleich hoch zu werten. Auch im Gyrus dentatus ergab die Flächenanalyse keinen signifikanten Unterschied. 
A)
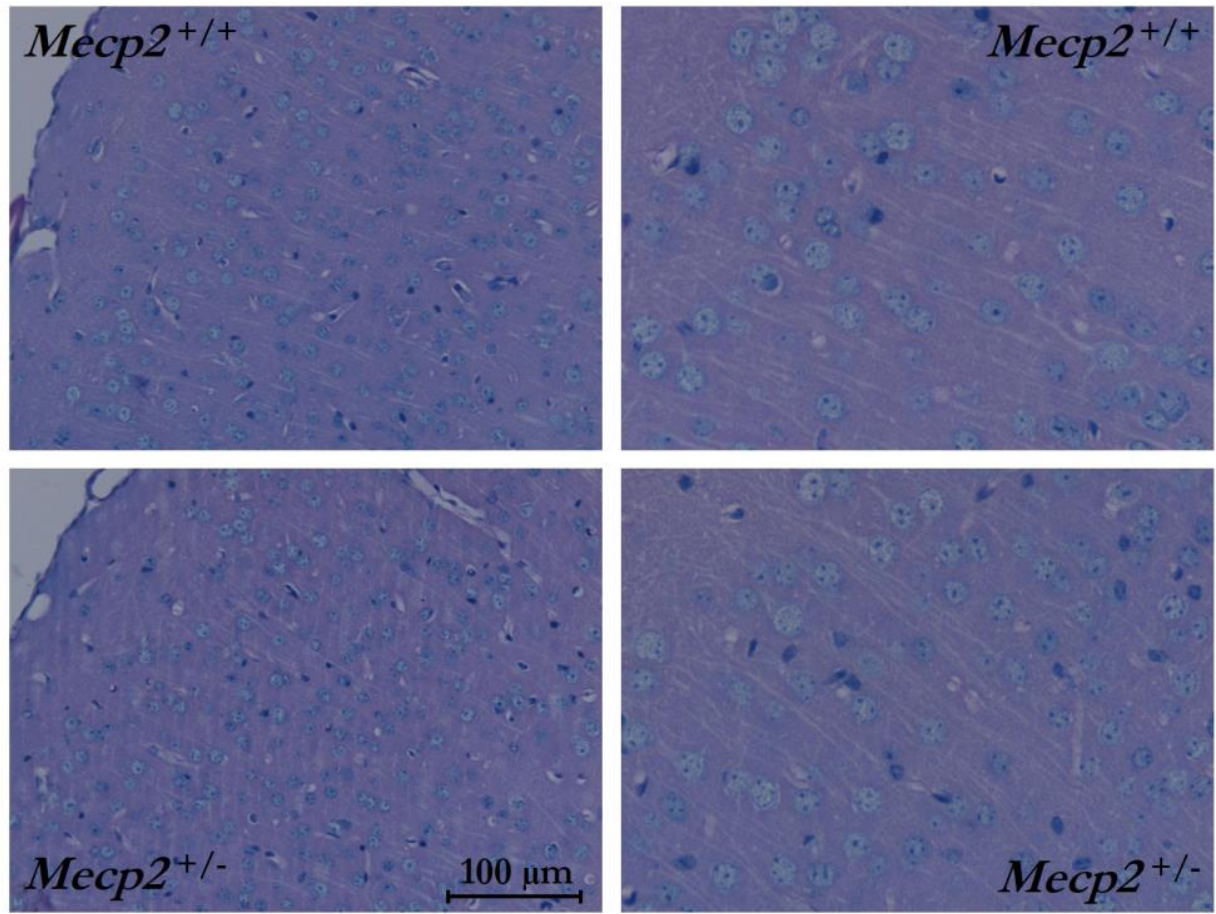

B)
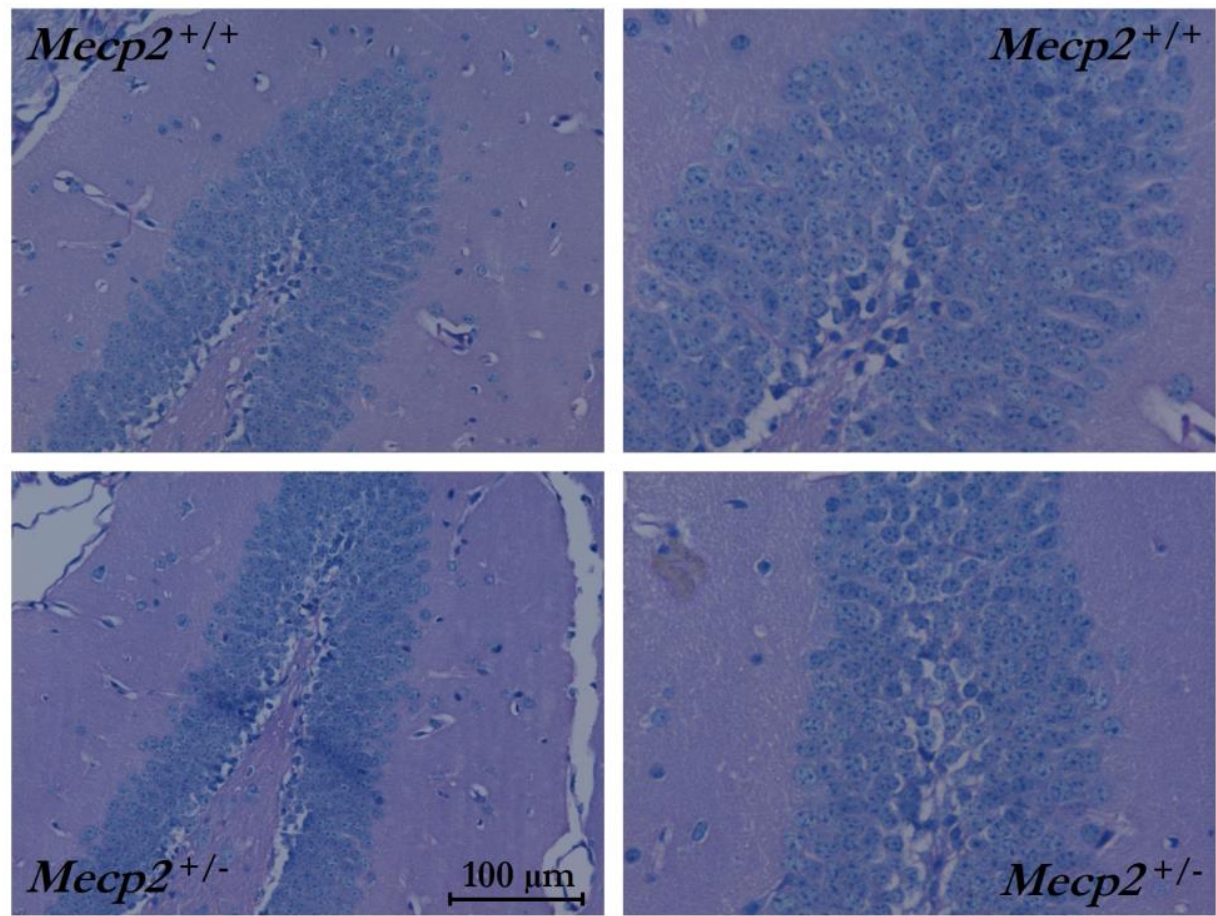

\section{Abbildung 31: Ausschnitte aus Präparaten in der LFB/PAS-Färbung aus dem} auditiven Cortex (A) und dem Gyrus dentatus des Hippocampus (B).

Gezeigt sind hier exemplarische Ausschnitte aus den Präparaten, in welchen mit LFB/PAS Myelin und Kohlenhydrate angefärbt wurden, aus dem auditiven Cortex (A) und dem Gyrus dentatus des Hippocampus (B), wobei die Ausschnitte auf der linken Seite 20-fach vergrößert und auf der rechten Seite 40-fach vergrößert wurden. Dabei konnten keine farblichen Unterschiede zwischen den Genotypen $M e c p 2^{+/+}$und $M e c p 2^{+/-}$festgestellt werden. 


\subsubsection{Analyse der immunhistochemischen Färbung von astrozytärem saurem Gliafaserprotein GFAP}

Auch für die immunhistochemische Darstellung von saurem Gliafaserprotein (GFAP) wurden spezifische Antikörper verwendet. Da GFAP überwiegend in Astrozyten vorkam, konnten diese strukturell mit dieser Methode von anderen Zellen abgegrenzt werden. Ein möglicher Mangel von GFAP hätte entweder das Fehlen von Astrozyten oder eine mangelnde GFAP-Synthese und damit eine reduzierte Astrozytenaktivität zur Folge. Ein GFAP-Überschuss dagegen würde auf einen entzündlichen Vorgang hindeuten.

Die Analyse der Übersichtsaufnahmen der Hirnschnitte, in denen GFAP markiert wurde, ergab keinerlei offensichtliche strukturelle Unterschiede zwischen Rett- und WildtypWeibchen, abgesehen von der reduzierten Hirngröße bei heterozygoten Weibchen (Abb. 32)

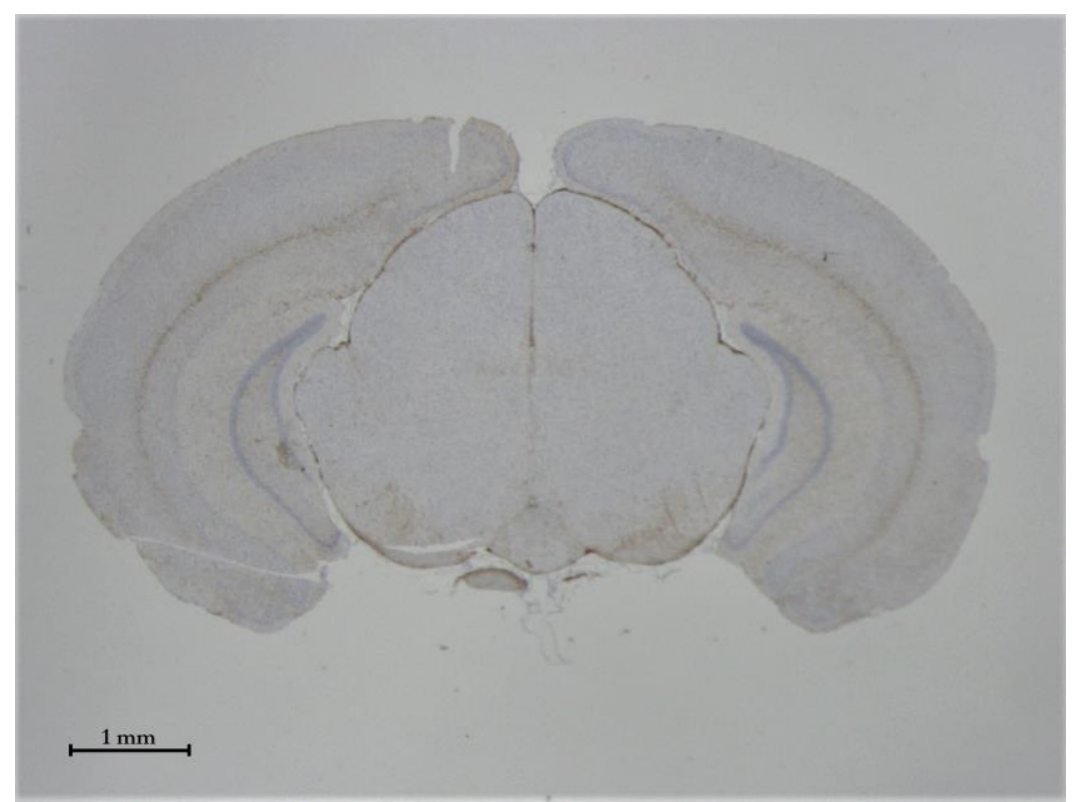

\section{Abbildung 32: Präparat aus dem Gehirn eines Wildtyp-Weibchens mit immunhistochemischer Markierung von GFAP.}

Gezeigt ist hier eine Übersichtsaufnahme eines Hirnschnittes einer weiblichen Wildtyp-Maus in GFAP-Färbung. Ein Vergleich dieser Ausschnitte von Mecp2+/+-Weibchen mit denen von $M e c p 2^{+/-}$Weibchen ergab keine offensichtlichen Strukturunterschiede - abgesehen von Artefakten, welche bei der Durchführung der Färbung entstanden sind. 
A)
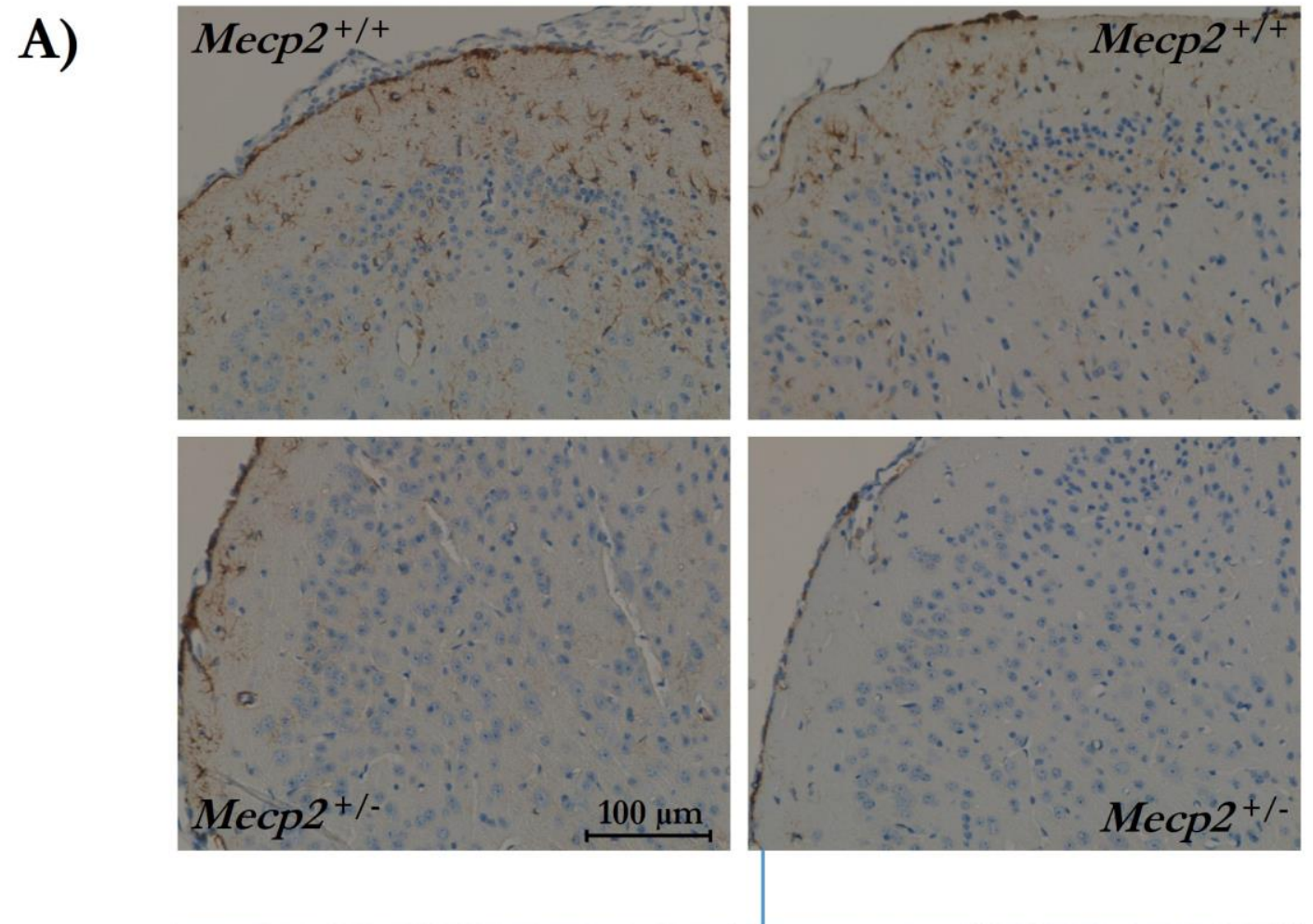

B)
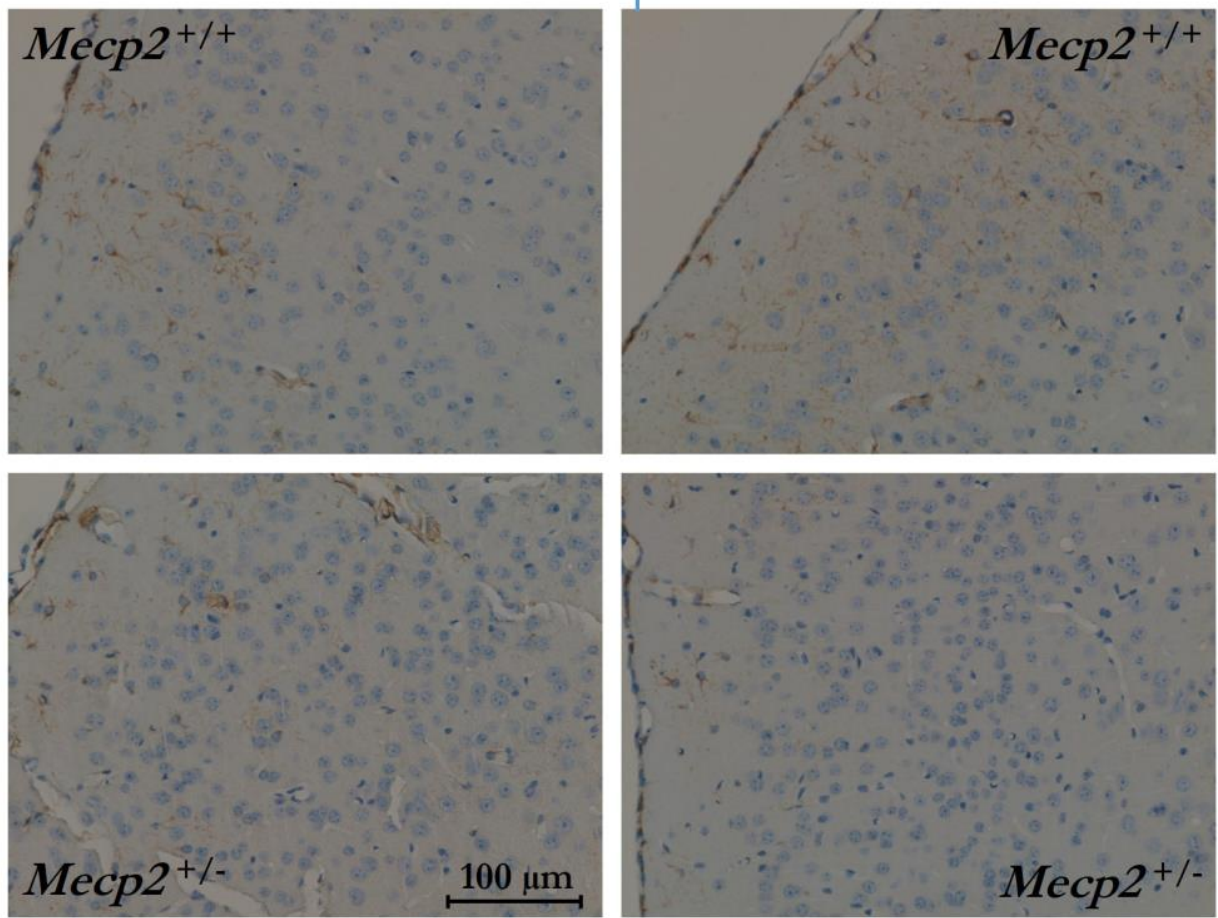

Abbildung 33: Ausschnitte aus den Bereichen des retrosplenialen Cortex (A) und aus dem visuellen Cortex (B) in GFAP-Färbung.

Dieser Abbildung sind Ausschnitte von GFAP-gefärbten Präparaten aus dem retrosplenialen Cortex (A) und dem visuellen Cortex (B) zu entnehmen, wobei diese 20-fach vergrößert wurden. In beiden Hirnarealen ist ein deutlicher GFAP-Mangel in Hirnschnitten heterozygoter Weibchen gegenüber weiblichen Wildtypen zu erkennen. 
A)
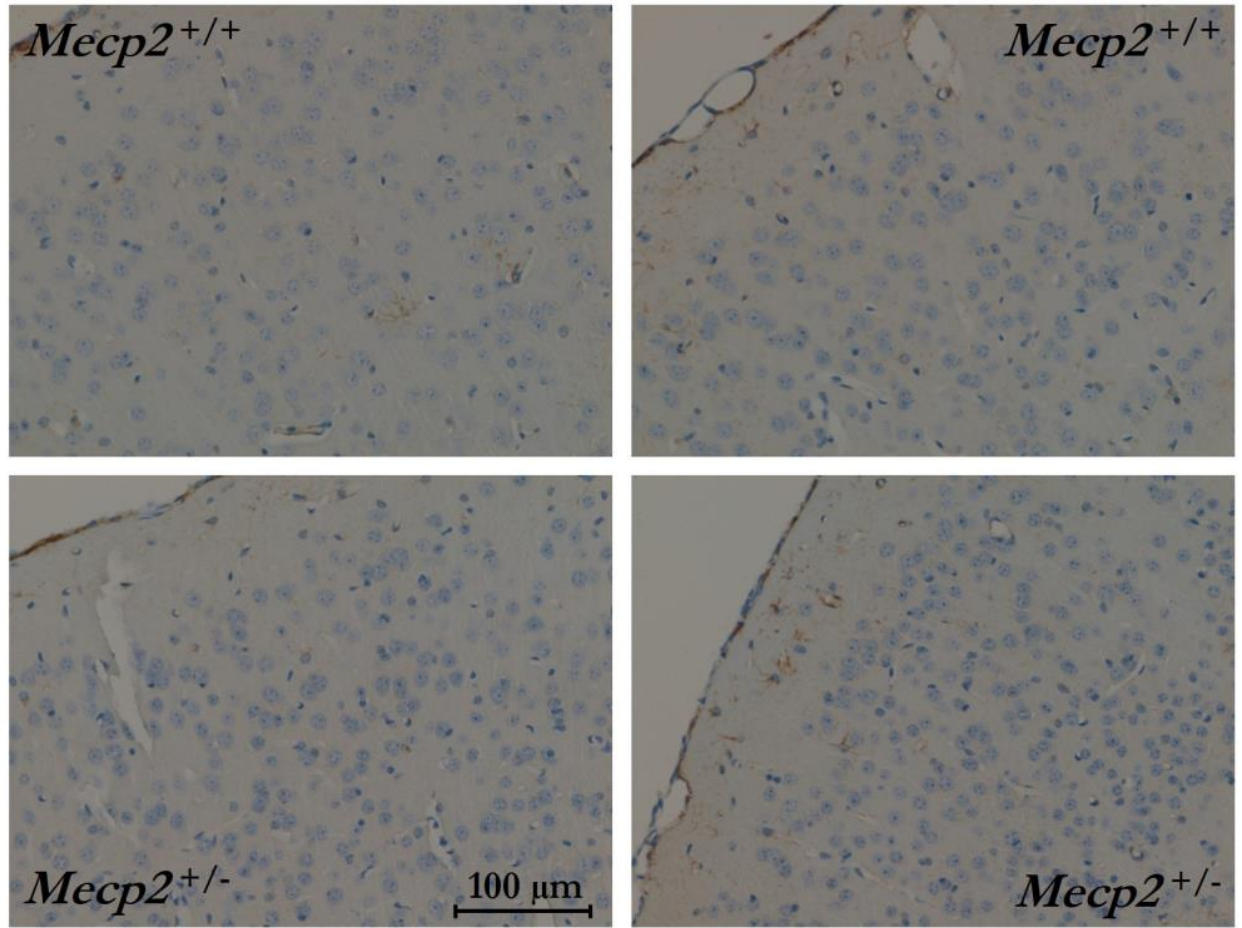

B)
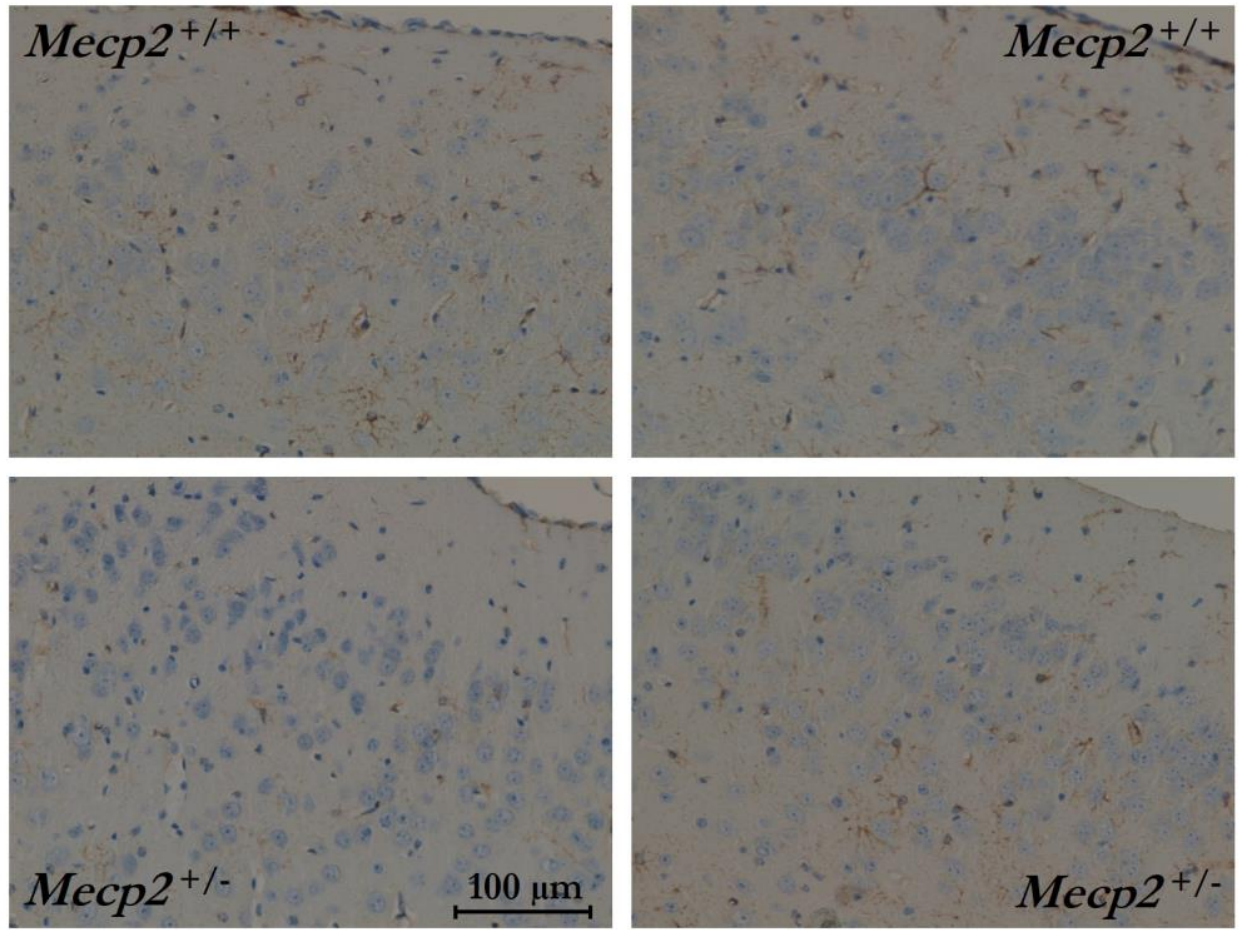

Abbildung 34: Ausschnitte aus den Bereichen des auditiven Cortex (A) und aus den Cortexregionen TeA, Ect und PRh (B) in GFAP-Färbung.

In der Hirnregion des auditiven Cortex (A) ist bei 20-facher Vergrößerung kein deutlicher Unterschied in der GFAP-Expression oder Verteilung zwischen Rett- und Wildtyp-Weibchen zu erkennen. Dagegen weisen die Ausschnitte aus den Cortexregionen TeA, Ect und PRh (B) einen GFAP-Mangel in heterozygoten Weibchen auf, wobei diese Ausschnitte ebenfalls 20 -fach vergrößert sind. 
A)
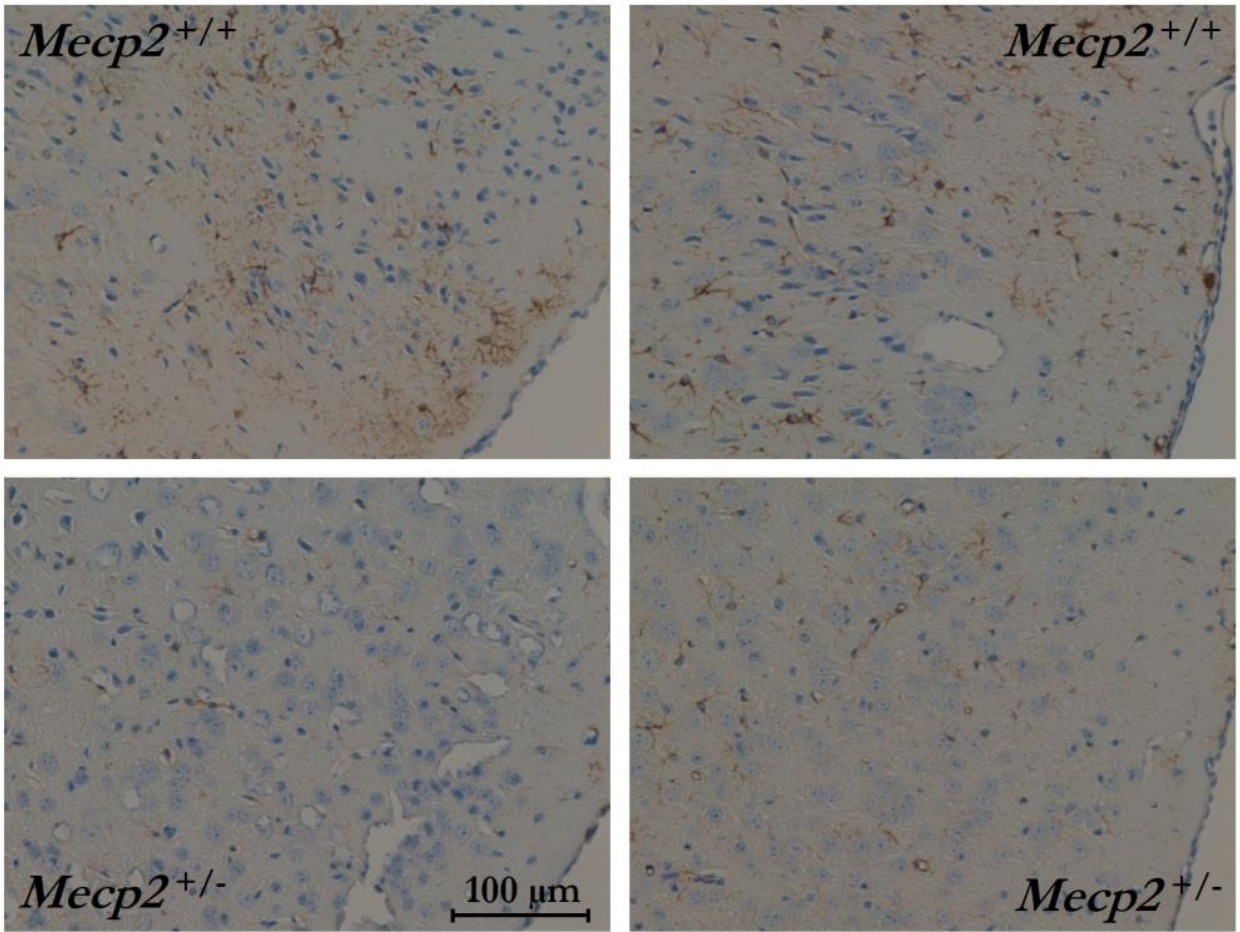

B)
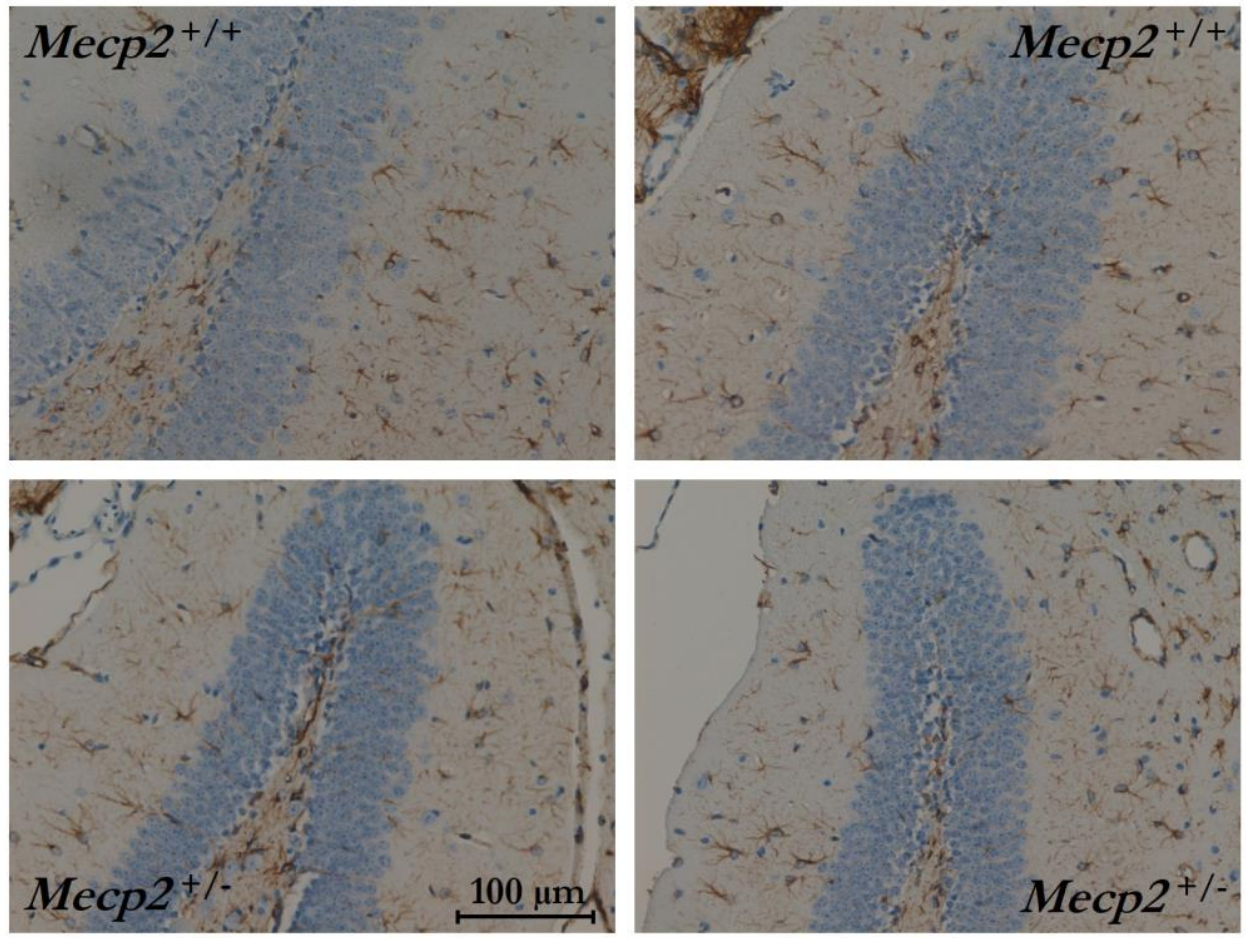

\section{Abbildung 35: Präparate aus den Bereichen des lateralen entorhinalen Cortex (A) und aus dem Gyrus dentatus des Hippocampus (B) in GFAP-Färbung.}

Die Ausschnitte in 20-facher Vergrößerung aus dem lateralen entorhinalen Cortex (A) zeigen besonders deutlich, dass in den Präparaten von Mecp $2^{+/-}$Weibchen hier viel weniger GFAP vorhanden ist als in Präparaten von Mecp2 $2^{++}-$Weibchen. Dagegen fehlt dieser Unterschied in der GFAP-Menge bei Ausschnitten aus dem Gyrus dentatus des Hippocampus (B) völlig, da hier das GFAP in den Präparaten beider Genotypen gleich verteilt ist. 
Zur Analyse der GFAP-gefärbten Schnitte wurde eher die Verteilung des GFAP in den Gewebestrukturen als in den Astrozyten auf zellulärer Ebene untersucht, weshalb Ausschnitte in 20-facher Vergrößerung verwendet wurden. Dabei konnte im Cortex das Stratum moleculare gut identifiziert und abgegrenzt werden, wohingegen eine Unterscheidung zwischen Stratum granulosum und pyramidale und zwischen externen und internen Strati bei den verwendeten Schnitten kaum möglich war. Daher wird im Folgenden von „Laminae“ die Rede sein, wobei damit zusammenfassend die Lamina II, III, IV und V gemeint sind.

In den Präparaten im Bereich des retrosplenialen Cortex (Abb. 33) wurde eine unterschiedliche Konzentration von GFAP beim Vergleich der Präparate deutlich. Im Gewebe von Wildtyp-Weibchen fand sich im Stratum moleculare eine Anfärbung von besonders viel GFAP, wohingegen bei den Rett-Weibchen dort nahezu kein angefärbtes GFAP zu finden war. Im den Laminae der Wildtyp-Mäuse konnte ebenfalls eine deutliche Färbung von GFAP beobachtet werden, wohingegen diese Anfärbung den Laminae der RettMäuse im retrosplenialen Cortex fast vollständig fehlt. Für beide Schichten ergibt sich damit eine GFAP-markierte Fläche von $32440 \pm 5950$ Pixel $(n=2)$ bei Wildtyp-Weibchen und von $4840 \pm 3080$ Pixel $(n=2)$ bei Rett-Weibchen, woraus sich ein statistisch signifikanter Mangel von ca. 80\% bei Rett-Weibchen gegenüber Wildtyp-Weibchen ergibt.

Im Bereich des visuellen Cortex (Abb. 33) fand sich bei allen Präparaten im Stratum moleculare generell wenig angefärbtes GFAP. Dagegen konnte in den tieferen Schichten bei den Wildtyp-Mäusen viel GFAP festgestellt werden (13640 \pm 4420 Pixel, $n=2)$, welches dort bei den Rett-Mäusen fast vollständig fehlte $(5570 \pm 1000$ Pixel, $n=2)$. Daraus resultiert ein GFAP-Mangel von ca. $60 \%$ bei $M e c p 2^{+/-}$-Weibchen gegenüber $M e c p 2^{+/+}$-Weibchen, welcher aber aufgrund der geringen Probenzahl nur als Tendenz festzustellen war.

Weiterhin konnte im auditiven Cortex (Abb. 34) in allen Präparaten nur sehr wenig GFAP dargestellt werden. Im Stratum moleculare fanden sich nur vereinzelte Ansammlungen von GFAP; im den Laminae fehlte GFAP in allen Präparaten nahezu vollständig. Hier konnte kein eindeutiger Unterschied in der GFAP-Färbung zwischen Mecp $2^{+/+}$-Weibchen $(4310 \pm 1770$ Pixel, $n=2)$ und Mecp $2^{+/-}$-Weibchen $(3930 \pm 1920$ Pixel, $n=2)$ festgestellt werden.

In den Cortexregionen TeA, Ect und PRh (Abb. 34) war der Unterschied in der Menge des angefärbtes GFAP wiederum deutlich zu sehen. Im Stratum moleculare und in den Laminae der Präparate war bei den Wildtypen relativ viel GFAP dargestellt (15880 \pm 690 Pixel, $n=2)$, wohingegen bei den heterozygoten Weibchen besonders in den tieferen histologischen Schichten viel weniger GFAP nachweisbar war $(8380 \pm 450$ Pixel, $n=2)$. Dieser GFAPMangel in diesen Cortexregionen bei Rett-Weibchen gegenüber Wildtyp-Weibchen ist mit einer Reduktion von ca. 50\% statistisch signifikant. 
Im lateralen entorhinalen Cortex (Abb. 35) war der Unterschied der GFAP-Menge ebenfalls besonders stark sichtbar. Im Stratum moleculare und in den Laminae der Präparate der Mecp $2^{+/+}$-Weibchen befand sich deutlich mehr GFAP $(32210 \pm 3890$ Pixel, $\mathrm{n}=2)$ als in den Präparaten der $M e c p 2^{+/-}$-Weibchen, in einigen Bereichen des entorhinalen Cortex fehlte GFAP hier sogar ganz (12700 \pm 1120 Pixel, $n=2)$. Daraus resultiert ein signifikanter Mangel von ca. $60 \%$ bei Rett-Weibchen gegenüber den weiblichen Wildtyp-Tieren.

Im Gegensatz zu diesen zum Teil sehr deutlichen Unterschieden in der Verteilung und Menge von GFAP den untersuchten Cortexregionen, konnte im Hippocampus (Abb. 35) am Gyrus dentatus diesbezüglich kein Unterschied zwischen Wildtyp-Weibchen $(30520 \pm 3210$ Pixel, $n=2)$ und Rett-Weibchen (33500 \pm 9320 Pixel, $n=2)$ festgestellt werden.

\subsubsection{Verteilungsbestimmung von makrophagenspezifischem aktiviertem Antigen 3 durch immunhistochemische Färbung (Mac 3)}

Ebenso wurden bei der immunhistochemischen Färbung des makrophagenspezifischen aktivierten Antigens 3 (Mac 3), welches von Mikroglia exprimiert wird, spezifische Antikörper verwendet und eine Gegenfärbung mit Hämatoxylin durchgeführt. Somit diente diese Methode zur Beurteilung einer möglichen übermäßigen Aktivierung von Mikroglia, da diese physiologisch nur wenig aktiv sind. Eine Beurteilung von Übersichtsaufnahmen der Mac3-gefärbten Hirnschnitte in der Übersichtsaufnahme führte zu der Feststellung, dass die Hirne der heterozygoten Weibchen zwar kleiner als die der Wildtypen waren, jedoch ansonsten keine offensichtlichen Auffälligkeiten aufwiesen (Abb. 36).

Die Gegenüberstellung der Präparate des Cortex in Mac3-Färbung (Abb. 37) ergab keinerlei signifikante Unterschiede zwischen den Individuen. In allen Präparaten fanden sich vereinzelt Makrophagen mit gefärbtem Mac 3, welche durch Pfeile markiert wurden. Die Menge des markierten Mac3 wurde durch eine Flächenanalyse mit ImageJ bestimmt und beträgt bei Wildtyp-Weibchen $1620 \pm 320$ Pixel $(n=2)$ und bei Rett-Weibchen $1750 \pm 660$ Pixel $(\mathrm{n}=2)$. Demnach ist die Menge von Mac3 zwischen den untersuchten Genotypen als gleich hoch anzusehen. Auch im Gyrus dentatus des Hippocampus (Abb. 37) konnten einzelne aktivierte Makrophagen bei Wildtyp-Weibchen (1110 \pm 140 Pixel, $n=2)$ und Rett-Weibchen (1310 \pm 110 Pixel, $\mathrm{n}=2)$ beobachten werden, wobei der Unterschied in der Mac3-angefärbten Fläche zwischen den beiden Genotypen mit ca. 15\% sehr gering ausfällt und als nicht signifikant $\mathrm{zu}$ bewerten ist. $\mathrm{Da}$ in keinem der untersuchten Hirnregionen signifikante Unterschiede in der Mikroglia-Aktivierung gefunden wurde, sind hier nur exemplarische Ausschnitte gezeigt. 


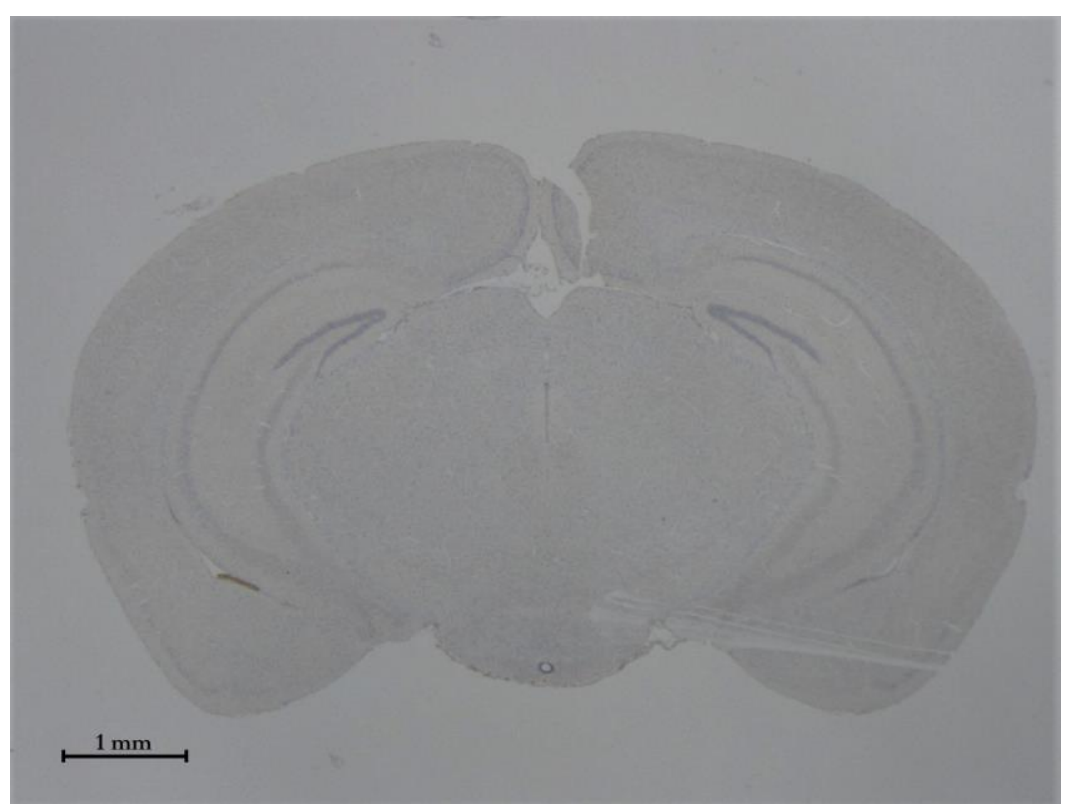

\section{Abbildung 36: Gegen Mac3-gefärbte Übersichtsaufnahme eines Präparates eines heterozygoten Weibchens.}

Hier ist die Übersichtsaufnahme eines Hirnschnittes eines heterozygoten Weibchens im Alter von 50 Tagen gezeigt, in welchem durch eine Anfärbung von Mac3 das Ausmaß der Mikroglia-Aktivierung wiedergegeben wird. Auch konnten keine Strukturveränderungen in den Hirnen von heterozygoten Weibchen gegenüber Wildtyp-Weibchen gefunden werden. 
A)
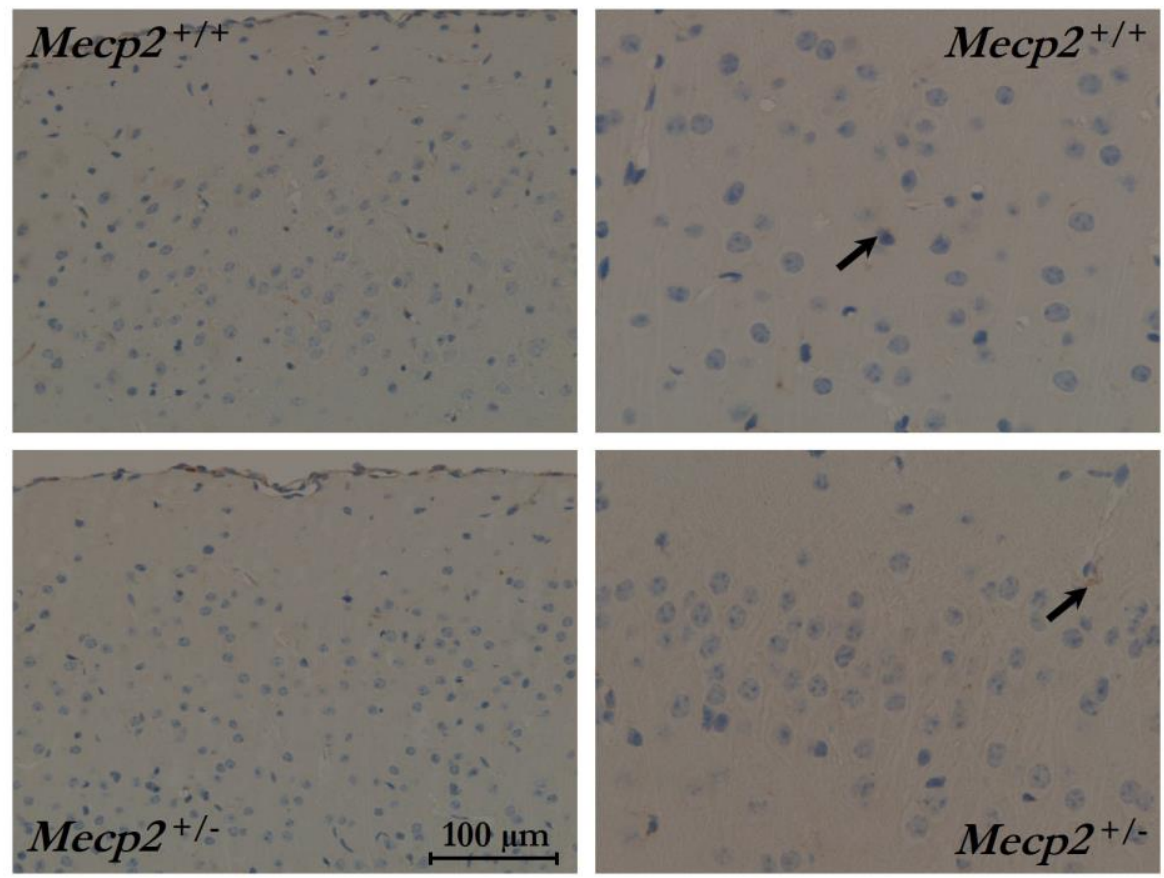

B)
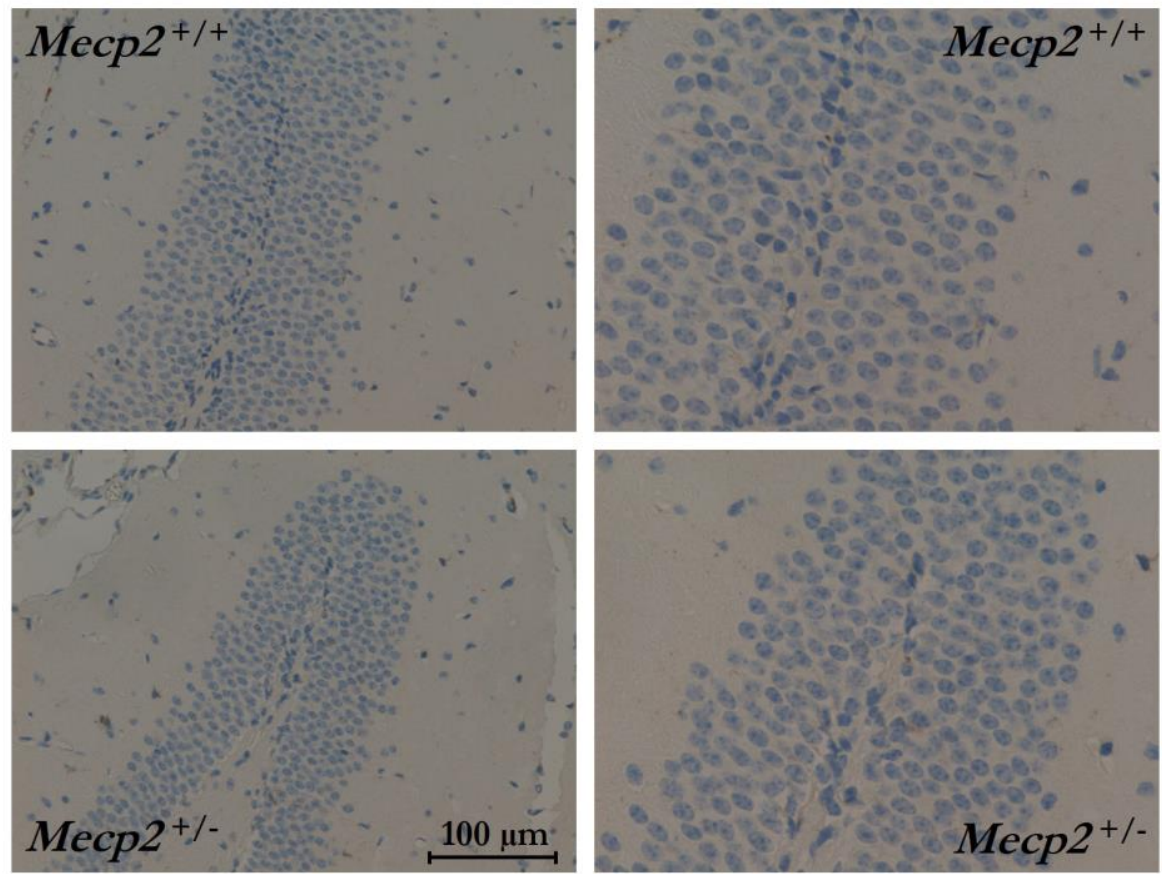

\section{Abbildung 37: Präparate in Mac3-Färbung im Bereich des retrosplenialen Cortex \\ (A) und des Gyrus dentatus des Hippocampus (B) mit markierten aktivierten Makrophagen (Pfeil).}

Die bei 20-facher Vergrößerung (links) eher schlecht zu erkennenden aktivierten Mikroglia wurden durch die immunhistochemische Färbung von Mac3 markiert. Bei 40-facher Vergrößerung (rechts) sind diese etwas besser im Cortex - hier exemplarisch im retrosplenialen Cortex (A) - zu erkennen, wobei einzelne aktivierte Makrophagen mit Pfeilen gekennzeichnet wurden. Dabei konnten keine Unterschiede in der Mac3-Markierung zwischen Mecp2+/+- Weibchen und Mecp2+/--Weibchen aufgezeigt werden. Im Gyrus dentatus des Hippocampus (B) sind dagegen in Hirnschnitter der beiden Genotypen so gut wie keine Mikroglia durch Mac3 markiert worden. 


\subsubsection{Bewertung der immunhistochemisch gegen Synaptophysin gefärbten Hirnschnitte}

Die immunhistochemische Färbung von Synaptophysin erfolgte durch eine Behandlung mit für dieses Protein spezifischen Antikörpern im Rahmen der unter 2.4.1 erläuterten Durchführung. Dieses Membranprotein befindet sich hauptsächlich in synaptischen Vesikeln neuronaler Zellen. Obwohl dessen Funktion noch nicht vollständig geklärt ist, wird vermutet, dass es die Aufnahme von Neurotransmittern aus dem Zytosol ermöglicht und damit eine wesentliche Rolle bei der Informationsübertragung zwischen Neuronen spielt (Wiedenmann und Franke 1985; Janz et al. 1999). Daher könnten Veränderungen in der Synaptophysin-Konzentration in zerebralem Gewebe mit der im Rett-Syndrom beobachteten gestörten synaptischen Plastizität zusammenhängen.

Ein Vergleich der Übersichtsaufnahmen brachte keinerlei offensichtliche Unterschiede in der Hirnstruktur zwischen Rett- und Wildtyp-Weibchen hervor, nur die Hirne von heterozygoten Weibchen waren gegenüber den Wildtypen in ihrer Größe reduziert (Abb. 38).

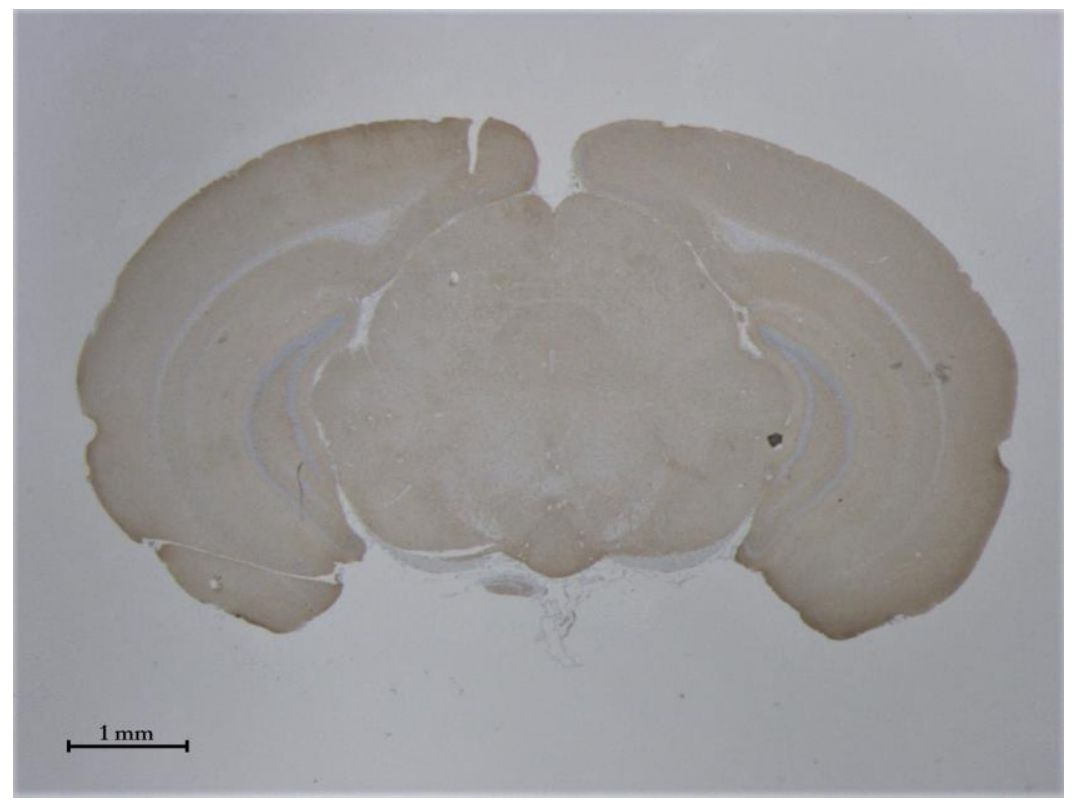

\section{Abbildung 38: Exemplarisches, gegen Synaptophysin gefärbtes Präparat eines} Mecp $2^{+/+}$-Weibchens.

$\mathrm{Zu}$ sehen ist hier eine Übersichtsdarstellung eines Hirnschnittes aus einer weiblichen Wildtyp-Maus, in welchem Synaptophysin immunhistochemisch gefärbt wurde. Ein Vergleich dieser Übersichten aller untersuchten Präparate ergab keine offensichtlichen strukturellen Veränderungen zwischen Rett- und Wildtyp-Weibchen. 
Bei der Begutachtung der Präparatgegenüberstellungen für die Hirnareale des auditiven Cortex und der Bereiche TeA, Ect und PRh (Abb. 40), des lateralen entorhinalen Cortex (Abb. 41) konnten durch die Analyse der Bildausschnitte mit ImageJ bei den weiblichen RettMäusen jeweils ein Synaptophysin-Mangel von ca. 50\% im Gegensatz zu den WildtypWeibchen beobachtet werden. Aufgrund der geringen Probenzahl war dieser Unterschied aber nicht statistisch zu validieren und kann daher nur als Trend angesehen werden.

Dagegen war der Gegenüberstellung der Präparate aus den Hirnareal des visuellen Cortex (Abb. 39) eine vermindert intensive Färbung von Synaptophysin bei Mecp $2^{+/-}$-Mäusen gegenüber weiblichen $M e c p 2^{+/+}$-Tieren zu entnehmen. Dieser dezente Unterschied wird auch durch eine Analyse der Bildausschnitte mit ImageJ wiedergegeben. Dabei ergab sich, dass bei heterozygoten Weibchen im visuellen Cortex ca. 60\% weniger Synaptophysin immunhistochemisch markiert wurde als bei Wildtyp-Weibchen, wobei auch dieses Ergebnis aufgrund der geringen Probenzahl nur als Trend einzustufen ist.

In den Cortexregionen des retrosplenialen Cortex (Abb. 39), des auditiven Cortex (Abb. 40) und des Gyrus dentatus des Hippocampus (Abb. 41) konnte dagegen kein Unterschied in der immunhistochemisch gefärbten Synaptophysinmenge beobachtet werden. 

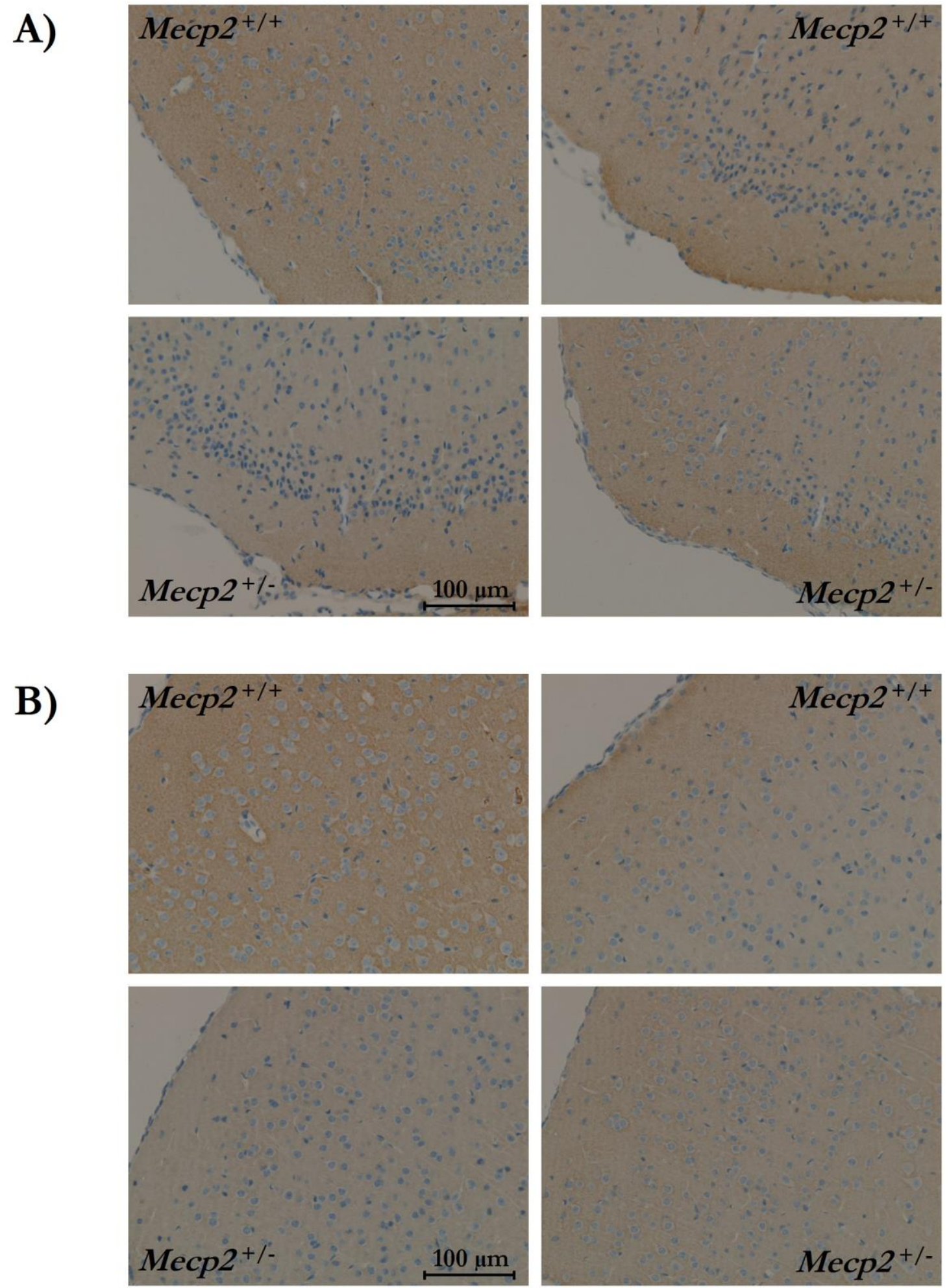

Abbildung 39: Präparate in Synaptophysin-Färbung im Bereich des retrosplenialen Cortex (A) und des visuellen Cortex (B).

Bei 20-facher Vergrößerung erkennt man in den Ausschnitten aus Präparaten von heterozygoten Weibchen sowohl im retrosplenialen Cortex (A), also auch im visuellen Cortex (B) einen leichten Synaptophysin-Mangel gegenüber Wildtyp-Weibchen, welcher durch die reduzierte Farbintensität dargestellt wird. 
A)
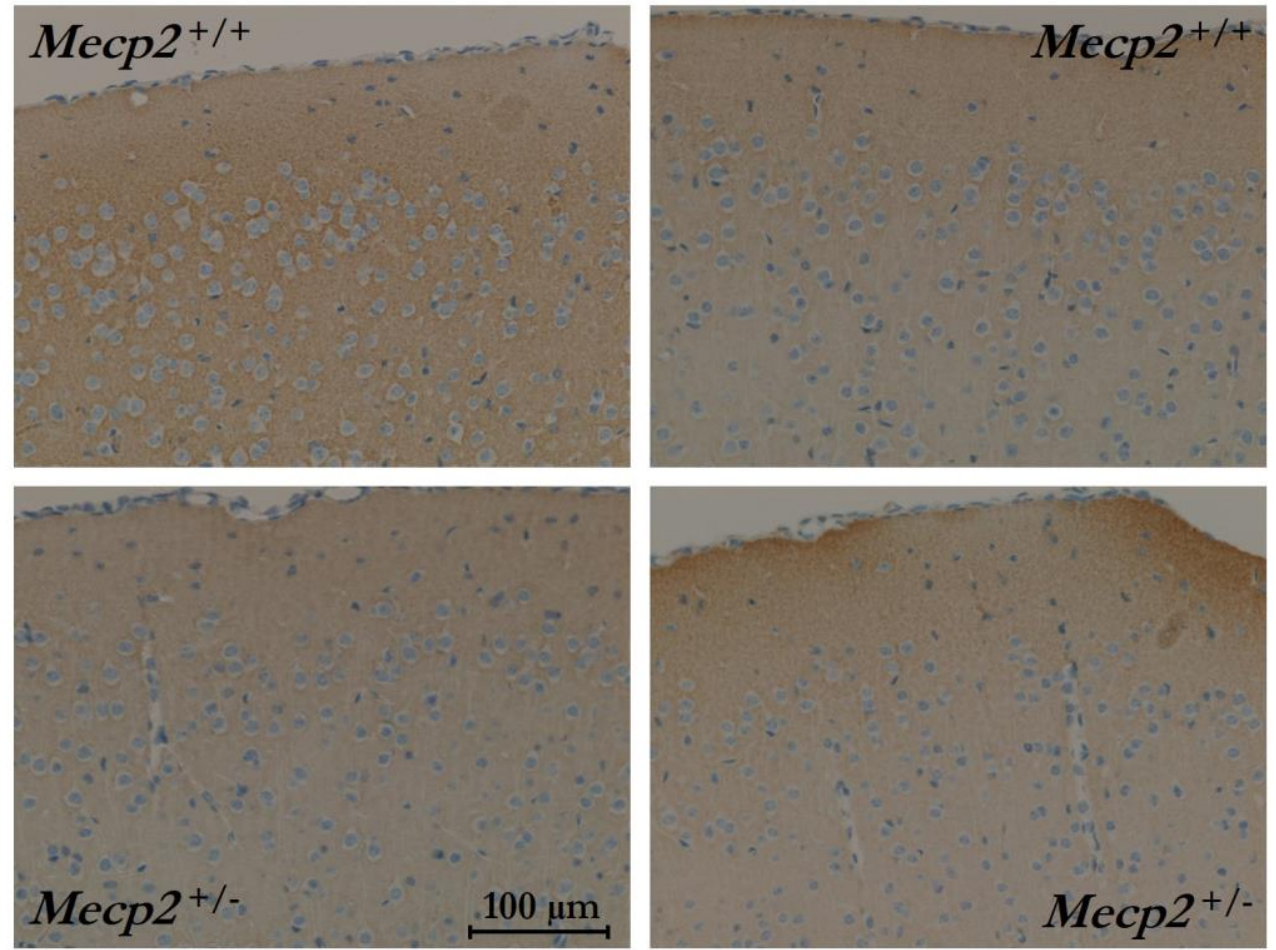

B)
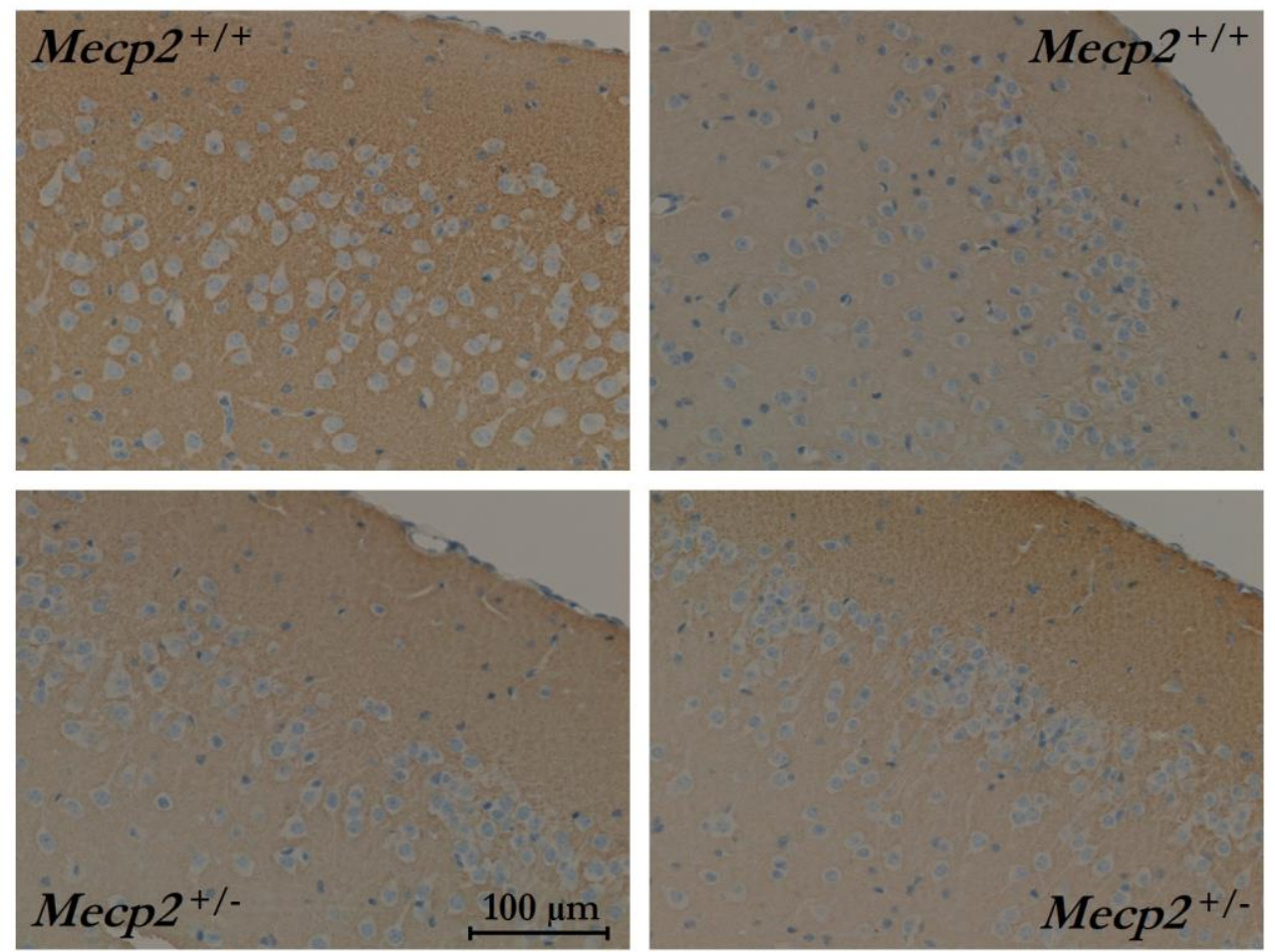

Abbildung 40: Ausschnitte in Synaptophysin-Färbung im Bereich des auditiven

Cortex (A) und der Regionen TeA, Ect und PRh (B).

In den Bereichen des auditiven Cortex (A) und der Cortexregionen TeA, Ect und PRh (B) ist in den Ausschnitten in 20-facher Vergrößerung zu erkennen, dass generell relativ viel Synaptophysin immunhistochemisch angefärbt wurde. In keiner dieser Region konnte aber ein Unterschied in der Farbintensität zwischen Rett- und Wildtyp-Weibchen festgemacht werden. 
A)
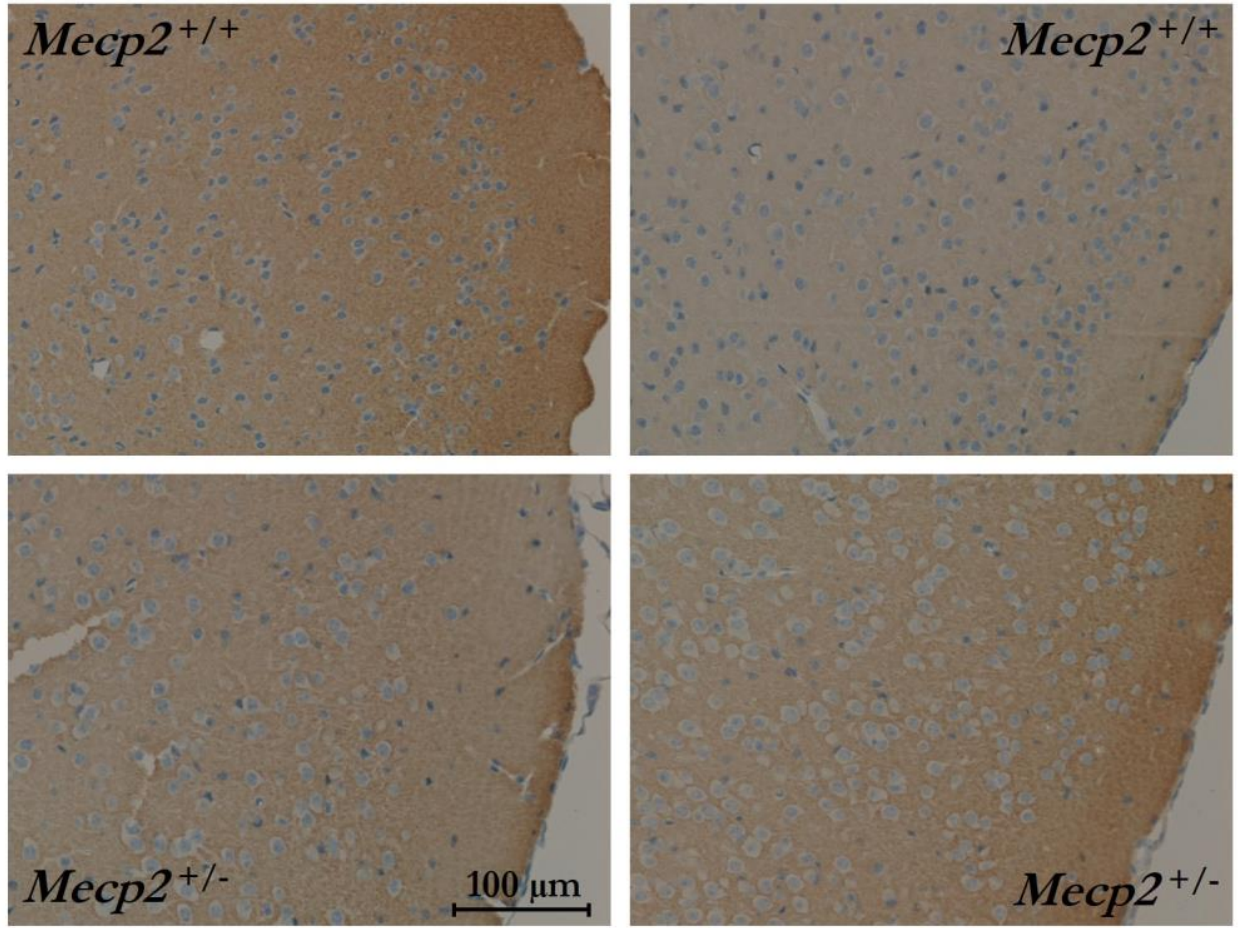

B)
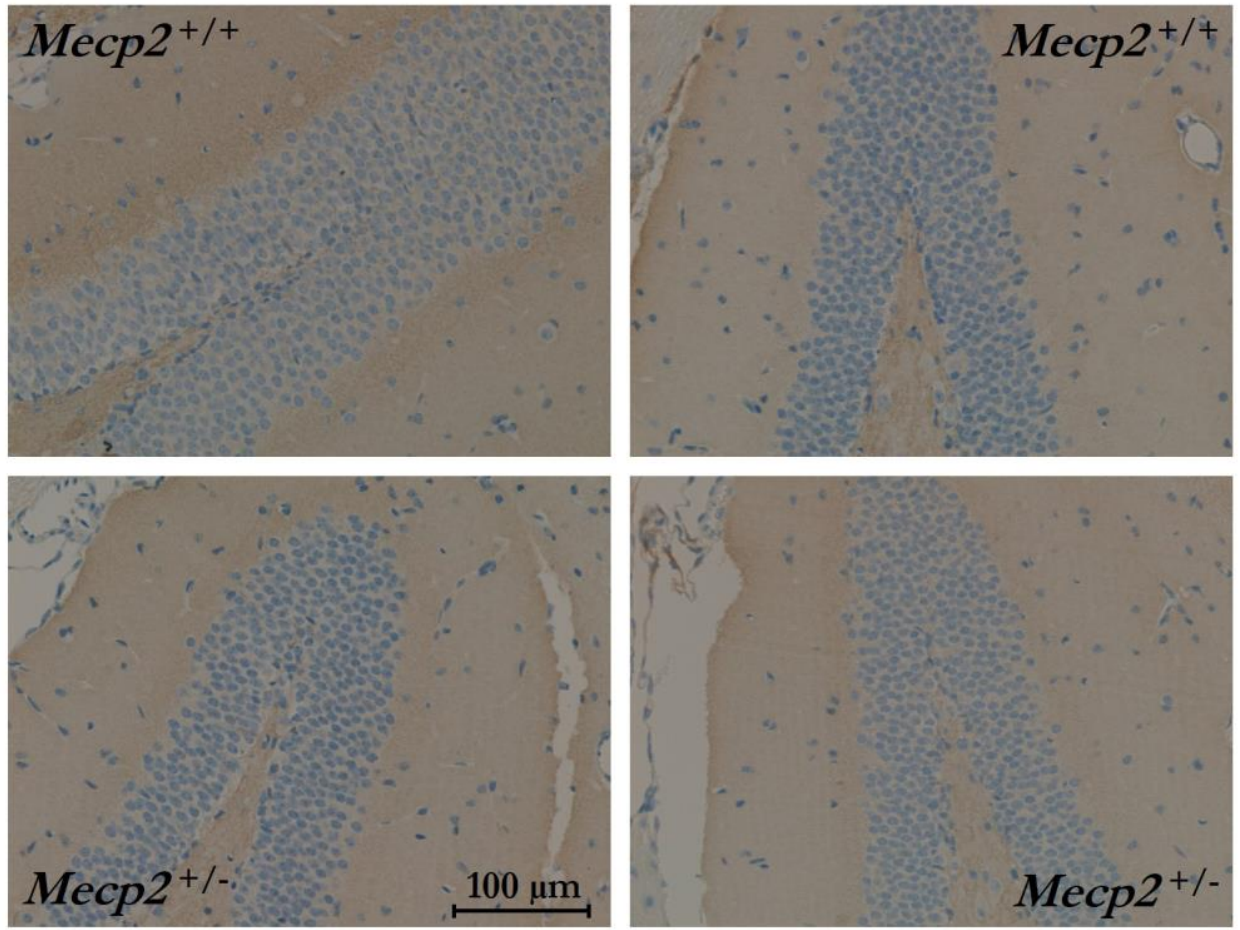

Abbildung 41: Präparatausschnitte in Synaptophysin-Färbung im Bereich lateraler entorhinaler Cortex (A) und des Gyrus dentatus des Hippocampus (B).

Auch im lateralen entorhinalen Cortex (A) ist zwar generell recht viel Synaptophysin markiert worden, jedoch zeigen sich keine deutlichen Unterschiede zwischen den Präparaten der beiden Genotypen. Im Gyrus dentatus des Hippocampus (B) ist dagegen weniger Synaptophysin angefärbt worden, wobei auch hier keine genotypspezifischen Unterschiede in der Farbintensität festgestellt werden konnten. 


\section{Diskussion}

Da es im Rett-Syndrom als Folge einer Redoximbalance zu einer erhöhten mitochondrialen ROS-Freisetzung kommt, führt der daraus resultierende oxidative Stress zu einer Gewebeschädigung, indem Zellbestandteile durch Oxidation in ihrer Funktion beeinträchtigt werden. Obwohl die oxidative Schädigung durch ein gestörtes Redoxgleichgewicht und durch die dabei entstehenden ROS an Proteinen und Lipiden bereits vor Jahren bestätigt wurden, konnte eine mögliche oxidative DNA-Schädigung nur vermutet werden (Sierra et al. 2001; Valinluck et al. 2004; De Felice et al. 2009; Tsukahara 2014; Janc et al. 2016). Der Untersuchung dieser Vermutung war der Kernpunkt des experimentellen Teils dieser Arbeit gewidmet, deren Ergebnisse im Abschnitt 3.2 veranschaulicht wurden. Bei der extrahierten DNA handelte es sich um ein Gemisch aus nukleärer und mitochondrialer DNA, wobei die Analyse der DNA-Oxidation mit dem ELISA-Kit keine Unterscheidung zwischen nukleärer und mitochondrialer DNA bezüglich ihrer Oxidation erlaubt.

Diese Vermutung konnte nun bestätigt werden, da bei Mäusen mit Rett-assoziierten Mutationen im Mecp2-Gen gegenüber entsprechenden Wildtyp-Tieren eine signifikant erhöhte DNA-Oxidation in Form des Anteils von oxidiertem Guanin (oxG) an der gesamten DNA (DNA ${ }_{\text {ox }}$ ) festzustellen war. Besonders ausgeprägt war dieser Zuwachs der oxidativen DNA-Schädigung bei erst 50 Tage alten Tieren; bei männlichen Individuen konnte ein Anstieg um ca. 130\% und bei weiblichen Individuen ein Anstieg um ca. 120\% verzeichnet werden. Auch ältere heterozygote Weibchen (400 Tage) wiesen eine signifikante Zunahme um ca. 30\% gegenüber dem Wildtyp auf.

Da die DNA-Oxidation auch geschlechtsspezifischen Einflüssen, zum Beispiel durch Geschlechtshormone, unterliegen könnte, musste dies als Ursache für die bei Rett-Mäusen erhöhte oxidative DNA-Schädigung ausgeschlossen werden. Dies konnte durch einen geschlechtsspezifischen Gruppenvergleich erzielt werden, da die jeweiligen geschlechtsabhängigen Unterschiede in der DNA-Oxidation nicht signifikant waren. Lediglich bei älteren Wildtyp-Mäusen lag bei weiblichen Tieren ein signifikant reduzierter

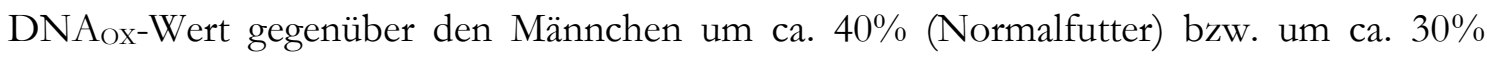
(antioxidatives Futter) vor. Dies ist damit zu begründen, dass laut einigen Studien sowohl in männlichen Nagetieren als auch Menschen die Menge an oxidierten Guaninspezies gegenüber entsprechenden weiblichen Individuen signifikant erhöht ist, da letztere durch den Einfluss von Östrogen besser davor geschützt sind (Proteggente et al. 2002; Çakatay et al. 2010). Zusätzlich ist die mitochondriale Wasserstoffperoxid-Freisetzung bei männlichen Rett-Tieren höher als in Rett-Weibchen. Da aber bei allen anderen Gruppen keine signifikanten geschlechtsabhängigen Unterschiede in der oxidativen DNA-Schädigung festzustellen war, konnte die bei Rett-Mäusen erhöhten DNA ${ }_{O x}$-Werte auf Mutationen im Mecp2-Gen zurückgeführt werden. 
Eine Zunahme der Konzentration oxidierter Guaninspezies erfolgt auch bei gesunden Individuen stets mit zunehmendem Alter (Ames 1988). Auf Grundlage dieser Erkenntnis wurde das Ausmaß der gemessenen DNA-Oxidation auch bezüglich ihrer Altersabhängigkeit überprüft. Bei Wildtyp-Tieren konnte eine signifikante Zunahme der DNA-Oxidation mit zunehmendem Alter um ca. $170 \%$ bei Männchen mit Normalfutter, um ca. 300\% bei Männchen mit antioxidativem Futter und um ca. 180\% bei Weibchen mit Normalfutter festgestellt werden. Lediglich bei Weibchen, die normales Futter erhielten, konnte dieser Anstieg der DNA-Oxidation nur in Form eines Trends beobachtet werden, wobei dies wohl auch auf den zusätzlichen Schutz durch Östrogen zurückzuführen ist.

Für Wildtyp-Tiere konnte also die physiologische Zunahme der DNAox-Werte mit steigendem Lebensalter bestätigt werden. Dagegen nimmt bei heterozygoten Weibchen die oxidative DNA-Schädigung scheinbar mit zunehmendem Alter weniger stark zu, sodass das Ausmaß der DNA-Oxidation um rund 30\% unter dem Niveau der Wildtyp-Weibchen liegt. Eine tatsächliche Abnahme der DNA-Oxidation wäre nur damit zu begründen, dass mit zunehmendem Alter auch die ROS-Produktion sinken oder der zelleigene Abbau von ROS hochreguliert werden würde. Dies konnte in einer anderen Arbeit in der Arbeitsgruppe für die mitochondriale $\mathrm{H}_{2} \mathrm{O}_{2}$-Freisetzung bewiesen werden.

Eine andere Ursache für diese Beobachtung liegt aber wahrscheinlich im X-chromosomalen Mosaik heterozygoter Tiere. Humane Patientinnen mit dem Rett-Syndrom weisen stark variierende Schweregrade der Erkrankung auf, dies trifft auch für die Mäuse des verwendeten Mausmodells zu (Guy et al. 2001). Heterozygote Mäuse, welche an einem eher schweren Phänotyp leiden, versterben nicht selten, bevor ihr Cortexgewebe mit 400 Tagen analysiert werden kann. Da die DNA-Oxidation im Gewebe dieser Tiere aufgrund ihres natürlichen Todes nicht bestimmt werden kann, fließen somit in die Statistik der 400 Tage alten Tiere nur Individuen mit einem milderen Phänotyp ein, was dazu beitragen könnte, dass die DNAOxidation scheinbar mit zunehmendem Alter sinkt. Dagegen werden bei den 50 Tage alten Tieren Individuen aller Ausprägungsgrade des Krankheitsbildes erfasst. Ob ein verfrühtes Versterben von heterozygoten Weibchen die alleinige Ursache für die scheinbar im Alter abnehmende DNA-Oxidation ist, ist jedoch unklar. Dies bedarf einer Analyse der zellulären ROS-Freisetzung sowie der tatsächlichen Redoxbedingungen und einem Vergleich dieser zwischen den hier untersuchten Gruppen. Weiterhin könnte eine Auswertung der Überlebenszeiten aller untersuchten Tiergruppen Aufschluss darüber geben, ob und in welchem Ausmaß heterozygote Weibchen signifikant eher versterben als die Individuen der anderen Gruppen. In diesem X-chromosomalen Mosaik und den daraus resultierenden diversen Phänotypen könnte außerdem eine Ursache für die gegenüber anderen Gruppen besonders hohe Standardabweichung bei allen Gruppen mit dem Genotyp Mecp2 ${ }^{+/-}$liegen. 
Eine Akkumulation von Oxidationsschäden an DNA im Rett-Syndrom wurde zuvor als mögliche Ursache für den progressiven Krankheitsverlauf vermutet, da dies eine Anhäufung von Fehlern in der Proteinbiosynthese bewirken und die Dysfunktion der dabei entstehenden Zellbestandteile verstärken könnte (Tsukahara 2014). Dies konnte aber anhand der vorliegenden Ergebnisse weder bestätigt noch ausgeschlossen werden, da für 50 Tage alte Mecp2-1y-Tiere keine ältere Vergleichsgruppe existiert und da die Ursache für die scheinbare Abnahme des oxG-Anteils bei heterozygoten Weibchen noch nicht geklärt wurde. Eine Möglichkeit, diese These zu stützen, wäre die Analyse einer zweiten Population von Rett-Männchen in einem Alter über 50 Tagen, wobei es dazu eines weniger stark beeinträchtigten Mausmodells bedarf, bei dem männliche Rett-Tiere nicht so früh versterben.

Interessant ist, dass männliche Rett-Mäuse zwar den am schwersten betroffenen Phänotyp und erwartungsgemäß eine signifikant erhöhte DNA-Oxidation aufweisen, heterozygote Weibchen aber trotz der durch das X-chromosomale Mosaik verursachten Variabilität im Phänotyp ebenfalls in der oxidativen DNA-Schädigung signifikant um einen nahezu gleichen Prozentsatz erhöht sind. Dies ist besonders hervorzuheben, da sich Rett-Weibchen mit 50 Tagen phänotypisch in einem präsymptomatischen Zustand befinden und erst im Alter von mehreren Monaten sichtbare Symptome aufzeigen (Guy et al. 2001; Lawson-Yuen et al. 2007). Dabei liegt die Vermutung nahe, dass Tiere mit einer ausgeprägt hohen DNAOxidation aufgrund gehäufter Fehler in der Proteinbiosynthese auch einen schwerer betroffenen Phänotyp aufweisen.

Für weibliche Rett-Mäuse im Alter von 50 Tagen könnte diese These zutreffen, da hier eine besonders hohe Streubreite der ermittelten DNAox-Werte vorlag und diese mit der äußerst heterogenen phänotypischen Ausprägung, welche dem Krankheitsbild inhärent sind, übereinstimmt. Bei Rett-Männchen liegt aber ebenfalls eine relativ große Varianz in der DNA-Oxidation der einzelnen Individuen vor, welche aufgrund des hemizygotischen Genotyps nicht auf die genetischen Bedingungen zurückzuführen ist.

Ein Anhaltspunkt für die Abhängigkeit der DNA-Oxidation vom Phänotyp der Erkrankung liefert eine Untersuchung der Atmung der Mäuse. Diese wurde bei einigen der verwendeten Mäuse durchgeführt, wobei dieser Aspekt Teil einer anderen Dissertation sein wird. Diese Daten zeigen aber, dass Individuen, die einer sehr unregelmäßigen Atmung mit vielen Atemaussetzern unterlagen, auch eine deutlich höhere DNA-Oxidation aufwiesen als Mäuse mit einer regelmäßigen Atmung. Diese Korrelation scheint logisch, da eine unregelmäßige Atmung eine intermittierende systemische Hypoxie begünstigt oder verstärkt, wodurch die ROS-Freisetzung erhöht würde, welche wiederum somit stärker die DNA schädigen könnte. Allerdings trifft dies für junge Mäuse beider Geschlechter zu, obwohl der MeCP2-Mangel bei männlichen Tieren maximal und bei weiblichen Tieren stark variabel sein sollte. Obwohl es nur wenige Individuen gab, bei denen Daten sowohl aus der Atmungsanalyse als auch aus der Bestimmung der DNA-Oxidation vorlagen, sollte diese Beobachtung nicht 
vernachlässigt werden. Eine sich verschlechternde Atmung scheint im Rett-Syndrom nicht ausschließlich von einem X-chromosomalen Mosaik abzuhängen, da beide Geschlechter davon betroffen sind. Um diese bisher undurchsichtige Verbindung zwischen gestörter Atmung, Phänotyp und DNA-Oxidation genauer zu untersuchen, könnte die Kontrolle der Atmung für alle Individuen durchgeführt werden, die zu einem späteren Zeitpunkt zur Bestimmung der oxidativen DNA-Schädigung entnommen werden. Außerdem scheint der Zeitpunkt, an welchem eine zunehmende Verschlechterung der Atmung einsetzt auch einer relativ großen Schwankung zu unterliegen. Das gilt vor allem für heterozygote Weibchen, welche ohnehin ein deutlich höheres Lebensalter erreichen als die entsprechenden hemizygoten Rett-Männchen.

Die Analyse der DNA-Oxidation erfolgte aufgrund der Ergebnisse aus Abschnitt 3.1 nur in Cortex-Gewebe. Daher sollte auch zukünftig die Möglichkeit, die Analyse der DNAOxidation mit dem verwendeten Assay auch an Hirngewebe aus den Regionen Hippocampus, Mittelhirn, Hirnstamm und Kleinhirn durchzuführen, nicht außer Acht gelassen werden, um mögliche regionsspezifische Effekte zu erfassen.

Als mögliches therapeutisches Konzept wurden einige Mäuse mit speziellem Futter ernährt, welches aufgrund der hohen Konzentration an Antioxidantien die oxidative Schädigung an Zellbestandteilen durch ROS mindern sollte. Bei Wildtyp-Tieren waren die Ergebnisse widersprüchlich; bei jungen Männchen und älteren Weibchen führte eine solche antioxidantienreiche Fütterung zu einer Reduktion der DNA-Oxidation, wohingegen diese bei älteren Männchen jedoch anstieg. Die erwünschte Wirkung blieb aber bei jungen RTTIndividuen beider Geschlechter aus - es konnte an den Rett-Mäusen keine signifikante Veränderung des oxG-Anteils durch antioxidative Fütterung beobachtet werden. Bei älteren, heterozygoten Weibchen führte diese antioxidantienreiche Fütterung sogar zu einem weiteren signifikanten Anstieg der oxidativen DNA-Schädigung um ca. 60\% und damit nicht zu der erhofften Verbesserung, sondern sogar zur offensichtlichen Verschlechterung der Redox-Situation. Die ausbleibende Wirkung der antioxidativen Fütterung in diesem Langzeitversuch könnte viele Ursachen haben. Ein Beispiel dafür wäre, dass die antioxidativen Bestandteile in zu geringer Konzentration gefüttert wurden - eine Gabe von Mengen, die die DNA-Oxidation signifikant senken würden, könnte aber möglicherweise deren $\mathrm{LD}_{50}$-Dosis bei Mäusen überschreiten. Außerdem müssten Radikalfänger nach ihrer Aufnahme in den Organismus auch an den Ort ihrer erwünschten Wirkung gelangen, da Hydroxylradikale, welche besonders für die oxidative Schädigung von Zellbestandteilen verantwortlich sind, aufgrund ihrer mangelnden Stabilität nur in der Nähe ihres Entstehungsortes wirken und auch nur dort erfolgreich durch Radikalfänger unschädlich gemacht werden können (Sies 1993). Ob die erwünschte Akkumulation von Radikalfängern in zerebralem Gewebe nach erfolgter Fütterung auch eintritt, ist unklar und könnte ein Grund für die ausbleibende Wirkung bezüglich der DNA-Oxidation sein. Jedoch konnte in parallel durchgeführten Studien gezeigt werden, dass durch eine antioxidantienreiche 
Fütterung die Hirngröße und die kortikale Schichtdicke bei Rett-Mäusen wieder zunimmt und somit nur eine Wirkung auf das Ausmaß der DNA-Oxidation entbehrt.

Dass bei erst 50 Tage alten Tieren antioxidatives Futter nur bei Wildtyp-Mäusen eine Reduktion der DNA-Oxidation erzielt werden konnte, wohingegen bei Rett-Mäusen diese erwünschte Wirkung ausblieb, könne ursächlich im Ablauf der Basenexzisionsreparatur (BER) liegen. Dazu ist anzumerken, dass die Beziehung zwischen der Konzentration an DNA-schädigenden Substanzen und deren Wirkung auf die DNA nicht linear ist; erst ab einem Dosis-Schwellenwert kommt es zu einer erheblichen DNA-Schädigung (Jenkins et al. 2010). Unterhalb dieses Schwellenwertes kann die DNA-Schädigung durch die BER nahezu komplett kompensiert werden - die Funktion der BER versagt erst bei höheren Dosen und wird durch eine Apoptose oder Nekrose der Zelle abgelöst (Doak et al. 2008). Eine Reduktion der DNA-Oxidation durch die Aktivität der BER-Enzyme erfolgt also am effizientesten bei einer geringen ROS-Belastung. Die hohe Menge an Antioxidantien, die den Zellen durch spezielle Fütterung zur Verfügung stehen, fangen bei Wildtyp-Mäusen vermutlich so viele Sauerstoffradikale ab, dass nicht nur die direkte oxidative Schädigung der DNA reduziert, sondern auch die DNA-Reparatur optimiert wird. Dagegen ist die ROSBelastung bei Rett-Mäusen beider Geschlechter signifikant erhöht - die erhöhte Konzentration an Antioxidantien durch Spezialfütterung reichte also nicht aus, um diese zusätzliche oxidative Belastung im Rett-Syndrom abzufangen und die ROS-Dosis gering genug für eine effiziente BER zu halten, wodurch die erwünschte Wirkung des Futters bei MeCP2-reduzierten Mäusen ausblieb.

Der beobachtete Effekt, dass eine antioxidative Fütterung bei 400 Tage alten Tieren zu einer deutlich erhöhten DNA-Oxidation führte, tritt wohl unabhängig vom Mecp2-Genotyp auf, da dies auch bei Wildtyp-Tieren beobachtet wurde. Dies könnte auf eine Kombination aus zwei Ursachen zurückzuführen sein: Bei einer dauerhaften antioxidativen Fütterung könnte es zu einem Gewöhnungseffekt kommen, durch welchen die Radikalfänger-Konzentration in den Zellen nicht mehr signifikant erhöht wäre. Durch die ausbleibende Kompensation der ROS-Konzentration würde auch zusätzlich die oxidative Belastung für eine effiziente BER zu groß werden. Offenbar bewegt sich die oxidative DNA-Schädigung unter antioxidativer Fütterung bei älteren Individuen in einem Bereich, in dem die BER der oxidativen Belastung nicht mehr standhält, in dem aber der Zellschaden für eine Apoptose oder Nekrose noch nicht ausreichend ausgeprägt ist. Da eine lebenslange Gabe zusätzlicher Antioxidantien offenbar nicht zum gewünschten Erfolg führte, könnte eine periodische Gabe mit Phasen ohne Nahrungsergänzung bessere Aussichten aufweisen. Dazu müssten aber zunächst besonders Redox-vulnerable Phasen des Krankheitsverlaufes identifiziert werden. Zur abschließenden Bewertung der antioxidantienreichen Fütterung als mögliches Therapiemittel im Rett-Syndrom sind aber neben der DNA-Oxidation noch diverse andere Parameter aus den Antioxidantien-behandelten Mäusen heranzuziehen. 
Um diese These zu stützen, müsste die Aktivität der BER-Enzyme bei denselben Individuen ermittelt werden, für die eine Analyse der DNA-Oxidation und der ROS-Konzentration durchgeführt wird. Außerdem wäre es wie bereits erwähnt sinnvoll, zusätzliche diese Messungen an besonders jungen (z.B. 10 Tage) und 200 Tage alten Tieren durchzuführen, um das Dosis-Wirkungsmodell in Kombination mit der Effizienz der DNA-Reparatur im Rett-Syndrom detaillierter zu untersuchen und die Altersabhängigkeit dieser Parameter besser zu verstehen.

Ein weiterer Teil dieser Dissertation behandelt neben der Untersuchung des Eisenstoffwechsels von neuronalen und glialen Zellen auch eine Überprüfung auf Unterschiede zwischen Wildtyp-Weibchen und Rett-Weibchen bezüglich verschiedener histochemischer und immunhistochemischer Marker.

Mit der Redoximbalance im Rett-Syndrom könnte auch ein verändertes Gleichgewicht im Eisenstoffwechsel im Zusammenhang stehen, weshalb diese These durch die Färbung von zwei- und dreiwertigen Eisenionen in PFA-fixierten Hirnschnitten überprüft wurde. Da im Rett-Syndrom auch Aberrationen bezüglich glialer und neuronaler Zellen von einigen Arbeitsgruppen festgestellt wurden, wurden in dieser Arbeit PFA-fixierte Hirnschnitte nicht nur in Hinsicht auf Eisenionen, sondern auch hinsichtlich verschiedener struktureller und inflammatorischer Zellmarker histochemisch bzw. immunhistochemisch gefärbt, um Aufschlüsse über mögliche Veränderungen im Rett-Syndrom zu geben und den Einfluss dieser Zellen auf die Erkrankung weiter zu definieren (Jellinger et al. 1988; Ballas et al. 2009; Maezawa und Jin 2010).

Zunächst wurde als Routineverfahren zur Überprüfung der Hirnstrukturen eine HEFärbung durchgeführt, bei welcher basische und saure Strukturen unterschiedlich gefärbt wurden. Aus der Gegenüberstellung der HE-Präparate ging hervor, dass die Neurone bei heterozygoten Weibchen im Gegensatz zu Wildtypen kleiner und dichter gepackt waren, was den Erwartungen entspricht (Kaufmann und Moser 2000; Armstrong 2005; Belichenko et al. 2008). Auffällig war, dass die Perykarien der Neurone bei Rett-Tieren dunkler bzw. intensiver gefärbt waren. Um die Frage zu klären, ob diese Beobachtung auf Eosin oder Hämatoxylin zurückzuführen ist, wurden die Präparate der Färbungen Berliner Blau und Turnbulls Blau herangezogen. Die in Berliner Blau gefärbten Hirnschnitte waren zur Kontrastverbesserung mit Kernechtrot gegengefärbt worden; das Phänomen der dunkleren Zellkörper konnte hier ebenfalls festgestellt werden. Die in Turnbulls Blau gefärbten Präparate wurden dagegen mit Hämatoxylin gegengefärbt; hier konnte keine Veränderung in den Perykarien der Neurone bei heterozygoten Weibchen gegenüber den Wildtypen festgestellt werden. Dies führt zu dem Schluss, dass die Beobachtung der dunkleren Zellkerne aus einer intensiveren Färbung mit Eosin (HE-Färbung) und Kernechtrot (Berliner Blau) resultierte. Als mögliche Ursachen für dieses Phänomen kommt eine nicht exakt gleiche Behandlung aller Präparate bei der Durchführung dieser Färbungen in Frage. 
Bei der Analyse der Präparate, welche für Berliner Blau und Turnbulls Blau gefärbt wurden, konnten zwischen Wildtypen und Rett-Mäusen keine signifikanten Unterschiede bezüglich der Menge und Verteilung von dreiwertigem und zweiwertigem Eisen festgestellt werden. Jedoch konnte über eine Analyse der Pixelanzahl nach Thresholding mit ImageJ in einigen Cortexregionen eine erhöhte Menge an histochemisch markierten dreiwertigen Eisenionen von bis zu 30\% bei Mecp2 $2^{+/-}$-Mäusen im Gegensatz zu Mecp2 $2^{+/+}$-Weibchen festgestellt werden. Die Auswertung der Präparate, welche in Turnbulls Blau gefärbt wurden, ergab dagegen einen nicht signifikanten Mangel von bis zu 15\% in Teilen der untersuchten Cortexregionen bei Rett-Weibchen gegenüber den weiblichen Wildtypen. Das Ausmaß der Verschiebung des Gleichgewichtes der Fenton-Reaktion aufgrund der im Rett-Syndrom erhöhten mitochondrialen $\mathrm{H}_{2} \mathrm{O}_{2}$-Freisetzung ist bei einem Probenumfang von zwei Individuen je Genotyp zwar nicht groß genug, um als statistisch signifikant bewertet zu werden, jedoch weisen die hier getroffenen Beobachtungen auf eine redoxabhängige Beeinflussung des Eisenmetabolismus hin.

Auch die Auswertung von Präparaten, die gegen das Amyloid-Precursor-Protein APP immunhistochemisch gefärbt wurden, ergab keine signifikanten Unterschiede zwischen Wildtyp- und Rett-Weibchen. Das Vorhandensein von APP, welches um die Perykarien in allen vier Präparaten festgestellt wurde, gilt als physiologisch. Anzeichen für einen akuten axonalen Schaden durch Akkumulation an Axonen gab es ebenfalls nicht. Dasselbe gilt für die Präparate, welche bezüglich möglicher Demyelinisierungen in LFB/PAS gefärbt wurde - auch hier konnten keine signifikanten Unterschiede zwischen den Präparaten festgestellt werden. Diese Befunde stehen mit der Tatsache im Einklang, dass es sich beim RettSyndrom im Gegensatz zu anderen neuronalen Erkrankungen nicht um einen degenerativen Prozess handelt und belegen dies nun auch auf zellulärer Ebene (Armstrong et al. 1995).

Besonders interessant sind die Ergebnisse der Präparatvergleiche der für Mac3- und GFAPgefärbten Hirnschnitte. Obwohl in einzelnen Arbeiten pro-inflammatorische Prozesse und eine „subklinische Oxinflammation“ postuliert wurden (Cortelazzo et al. 2014; Pecorelli et al. 2016), konnte dies für den Cortex unserer Tiere nicht bestätigt werden Die Analyse der gegen das makrophagenspezifische aktivierte Antigen Mac 3 gefärbten Präparate ergab keine signifikant erhöhte Makrophagenaktivierung bei heterozygoten Weibchen gegenüber deren Wildtypen, wie sie bei einem entzündlichen Prozess zu erwarten wären (Stoll et al. 1998). In Präparaten, in denen das saure Gliafaserprotein GFAP visualisiert wurde, waren in den meisten funktionellen Cortexregionen ein deutlicher GFAP-Mangel bei heterozygoten Weibchen von bis zu 80\% festzustellen. Lediglich im auditiven Cortex und im Hippocampus konnte dieser Effekt nicht beobachtet werden. Dies steht ebenfalls im Konflikt mit den zuvor vermuteten „subklinischen Inflammationen“, da eine Entzündung oder ein Trauma eine Zunahme der GFAP-Menge über eine verstärkte Astrozyten-Aktivierung zur Folge hätte (Stephenson und Byers 1995; Sweitzer et al. 1999; Winkelstein und DeLeo 2002; Valacchi et al. 2018). Ein entzündlicher Prozess kann damit nicht nur nicht bestätigt, sondern auf glialer Ebene auch widerlegt werden. Diese reduzierte GFAP-Menge in heterozygoten 
Weibchen ist weiterhin hervorzuheben, da in einer Jahrzehnte zurückliegenden Arbeit von einer unveränderten GFAP-Expression gesprochen wurde (Jellinger et al. 1988). Der festgestellte GFAP-Mangel in heterozygoten Weibchen ist wahrscheinlich auf die eingeschränkte Funktion der Astrozyten zurückzuführen. Ein Untergang oder eine unzureichende Reifung dieser Zellen ist als unwahrscheinlich einzustufen, da bei der Untersuchung von Astrozyten hinsichtlich einer Astrozytose ein Mangel dieser Zellen ebenfalls aufgefallen wäre (Jellinger et al. 1988). Da aber offenbar ein GFAP-Mangel bei MeCP2-defizienten Astrozyten vorliegt, kann entweder die GFAP-Expression oder die Astrozytenanzahl doch nicht unverändert sein - eine dieser beiden Feststellungen kann also revidiert werden. Die Ursache des GFAP-Mangels sollte ermittelt werden; die kann zum Beispiel über die Bestimmung der Astrozytenanzahl in histologischen Präparaten oder über eine Analyse der GFAP-mRNA erfolgen.

Unabhängig von der eigentlichen Ursache des GFAP-Mangels bei heterozygoten RettWeibchen, fügt sich dieser gut in das Bild einer gestörten synaptischen und dendritischen Plastizität im Rett-Syndrom ein (Maragakis und Rothstein 2001; Ullian et al. 2001). Der Verlust von MeCP2 im Rett-Syndrom, der auch bei glialen Zellen festgestellt wurde, schränkt also die Astrozyten in ihrer Funktion ein, die extrazelluläre Matrix um die Neurone herum zu stabilisieren und stellt damit eine Ursache für die gestörte Zell-Zell-Kommunikation dar (Ballas et al. 2009). Generell ist bei einem hohen Verlust von GFAP mit einer verlangsamten Regeneration des Hirngewebes nach Schädigungen zu rechnen, welche bei GFAP-NullMäusen nachgewiesen wurde (Pekny et al. 1999; Triolo et al. 2006). Dies könnte auch für oxidative Schäden zutreffen, welche durch das im Rett-Syndrom gestörte RedoxGleichgewicht entstehen.

Zusätzlich konnte bei der Auswertung der gegen Synaptophysin gefärbten Präparate festgestellt werden, dass in einigen Cortexarealen bei heterozygoten Weibchen ein leichter Synaptophysin-Mangel vorlag. Da die Funktion dieses Membranproteins im Bereich der Informationsübertragung zwischen den Neuronen spielt, passt ein Mangel dieses Proteins ebenfalls zur gestörten Zell-Zell-Kommunikation im Rett-Syndrom (Janz et al. 1999). Im Gegensatz zu den Ergebnissen der GFAP-Präparate fallen die beobachteten Unterschiede in der Synaptophysin-Konzentration aber nur dezent aus, ihnen konnte keine Signifikanz nachgewiesen werden. Weiterhin ist die Funktion dieses Membranproteins noch nicht vollständig geklärt, daher sollte dieses Ergebnis lediglich als weiterer Hinweis auf die bekannterweise im Rett-Syndrom gestörte synaptische Plastizität bewertet werden. Da es sich beim Rett-Syndrom aber um eine Synaptopathie handelt, bei welcher dendritische Verzweigungen weniger komplex ausgebildet sind und Synapsen in ihrer Funktion und unter Umständen auch in ihrer Anzahl reduziert sind, fügt sich ein Synaptophysin-Mangel in heterozygoten Weibchen gut in dieses Bild ein und sollte weiterführend untersucht werden (Belichenko et al. 1994; Schüle et al. 2008; Belichenko et al. 2009). 
Die funktionellen Cortex-Regionen, in welchen ein GFAP-Mangel bei heterozygoten Weibchen festgestellt wurde, erfüllen verschiedene Funktionen bei der Aufnahme und Interpretation verschiedener Sinneseindrücke, beim Erkennen und Identifizieren von Umwelteindrücken und bei der Funktion des Gedächtnisses (Kelly und Van Essen 1974; Suzuki 1996; Canto et al. 2008; Vann et al. 2009; Dalmay et al. 2019). Dass besonders diese Funktionen durch einen GFAP-Mangel reduziert sind, würde mit den klinischen Symptomen des Rett-Syndroms übereinstimmen, zu denen wie in Abschnitt 1.1 erörtert Probleme beim Lernvorgang, Gedächtnisprobleme, diverse kognitive Störungen und aufgrund eines häufig diagnostizierten Autismus auch eine gestörte Wahrnehmung und Interaktion mit der Umwelt gehören. Auch der milde Synaptophysin-Mangel in den Bereichen des retrosplenialen und des visuellen Cortex würde diese These stützen.

Die verschiedenen Färbungen wurden zunächst nur an jeweils zwei Wildtyp-Weibchen und zwei Rett-Weibchen im Alter von 50 Tagen durchgeführt. Um die Signifikanz der Ergebnisse der Berliner Blau und Turnbulls Blau Färbung, der GFAP-Färbung, der Mac3-Färbung und der Synaptophysin-Färbung zu verbessern, könnte zum einen die Probenzahl erhöht werden. Zum anderen sollte diese Färbung auch an Hirnschnitten anderer Tiere durchgeführt werden - so zum Beispiel nicht nur von weiblichen, sondern auch von männlichen Wildtypund Rett-Mäusen sowie nicht nur von 50 Tage alten, sondern auch von 400 Tage alten Mäusen beider Geschlechter und Genotypen. Dazu wären besonders PFA-fixierte Gehirne geeignet, welche Einblicke in andere Schnittebenen zulassen. Dies würde die gezielte Auswahl bestimmter funktioneller Hirnareale erlauben, in denen eine gestörte Funktion im Rett-Syndrom zu erwarten wäre, zum Beispiel im medullärem Atemzentrum. Ein Vergleich dieser Areale in gefärbten Präparaten zwischen den verschiedenen Mausgruppen würde möglicherweise fundiertere Rückschlüsse auf die Entstehung der typischen klinischen Symptome zulassen. 


\section{$5 \quad$ Zusammenfassung}

Aufgrund verschiedener Mitochondriendysfunktionen und einer systemischen intermittierenden Hypoxie erfolgt im Rett-Syndrom eine erhöhte mitochondriale Freisetzung von reaktiven Sauerstoffspezies (ROS) in zerebralem Gewebe, welche die Redoxbalance stört und die Oxidation diverser Zellbestandteile fördert. Weiterhin liegen auch auf zellulärer Ebene Veränderungen in der synaptischen und dendritischen Plastizität vor, wobei das RettSyndrom aber nicht als neurodegenerative Erkrankung einzustufen ist.

Um zunächst diejenige Hirnregion zu ermitteln, in welchem aufgrund der relativ höchsten $\mathrm{H}_{2} \mathrm{O}_{2}$-Freisetzung auch das höchste Ausmaß der DNA-Oxidation zu erwarten wäre, wurden Mitochondrien aus den verschiedenen Hirnregionen isoliert und die mitochondriale $\mathrm{H}_{2} \mathrm{O}_{2-}$ Freisetzung photospektrometrisch bestimmt. Dies identifizierte den Cortex als am besten für die Analyse der DNA-Oxidation geeignetes Hirngewebe. Für die entsprechenden experimentellen Untersuchungen wurde das Mausmodell Mecp $2^{\text {tm1.1Bird }}$ verwendet. Dazu wurde aus dem Cortex von männlichen und weiblichen, 50 und 400 Tage alten Wildtyp- und Rett-Mäusen, welche normales oder mit Antioxidantien angereichertes Futter erhielten, DNA isoliert und mit einem ELISA-Kit die Konzentration oxidierter Guaninspezies photospektrometrisch quantifiziert.

Die Quantifizierung der oxidierten Guaninspezies ergab, dass die DNA-Oxidation bei RettMäusen aller untersuchten Gruppen signifikant gegenüber den entsprechenden WildtypMäusen erhöht war. Besonders ausgeprägt war die DNA-Oxidation bei 50 Tage alten RettMäusen beider Geschlechter, bei welchen sich diese gegenüber 50 Tage alten, männlichen und weiblichen Wildtyp-Mäusen mehr als verdoppelte. Dies ist bemerkenswert, da weibliche Rett-Mäuse im Alter von 50 Tagen im Gegensatz zu den Männchen präsymptomatisch sind. Neben der Mutation im Mecp2-Gen ist wahrscheinlich auch eine sich verschlechternde Atmung mit zunehmenden Apnoen für diese Beobachtungen verantwortlich. Außerdem wurde als mögliches Therapeutikum im Rett-Syndrom die Auswirkung einer antioxidantienreichen Fütterung (Vitamin E, alpha-Liponsäure, N-Acetyl-L-Cystein) auf die DNA-Oxidation in Wildtyp- und Rett-Mäusen untersucht. In 50 Tage alten Wildtyp-Mäusen senkte dies die DNA-Oxidation, jedoch blieb dieser Effekt bei 50 Tage alten Rett-Mäusen gegenüber normal gefütterten Rett-Mäusen bei beiden Geschlechtern aus. Weiterhin zeigte sich, dass die antioxidantienreiche Fütterung sowohl bei 400 Tage alten Wildtyp-Weibchen und -Männchen, aber auch bei 400 Tage alten heterozygoten Weibchen, zu einem signifikant erhöhten Ausmaß der DNA-Oxidation gegenüber den normal gefütterten Tieren führte.

Um die Auswirkung der Mutationen im Mecp2-Gen auf zellulärer Ebene in zerebralem Gewebe zu überprüfen, wurden (immun-)histochemisch gefärbte Hirnschnitte von 50 Tage alten Wildtyp-Weibchen und heterozygoten Weibchen ausgewertet. Da die erhöhte ROSFreisetzung über die Fenton-Reaktion mit dem Eisenmetabolismus im Zusammenhang stehen könnte, wurden mit Berliner Blau dreiwertige und mit Turnbulls Blau zweiwertige Eisenionen gefärbt. Dies ergab eine tendenzielle Zunahme der $\mathrm{Fe}^{3+}$-Menge im Cortex bei 
weiblichen Rett-Tieren gegenüber weiblichen Wildtypen, welche aber aufgrund der geringen Probenzahl statistisch nicht signifikant ist. Da es sich beim Rett-Syndrom um eine Synaptopathie handelt, wurde das präsynaptische Vesikelprotein Synaptophysin immunhistochemisch gefärbt. Dabei zeigte sich ein Trend zum Synaptophysin-Mangel im Cortex von heterozygoten Weibchen von bis zu 60\%, welcher im Einklang mit den neuronalen Störungen auf zellulärer Ebene steht. Jedoch konnten diese Veränderungen aufgrund der geringen Probenzahl ebenfalls nicht als signifikant bewertet werden.

Entsprechend der Tatsache, dass es sich beim Rett-Syndrom nicht um einen neurodegenerativen Prozess handelt, konnte eine mögliche akute axonale Schädigung mit Hilfe der Markierung des Amyloid-Precursor-Proteins (APP) im Cortex und im Hippocampus ausgeschlossen werden konnte. Auch mögliche Demyelinisierungen mittels LFB-PASFärbung konten in Cortex und Hippocampus ebenfalls nicht nachgewiesen werden.

Um auch auf zellulärer Ebene einen entzündlichen Prozess auszuschließen, wurde die Aktivierung von Mikrogliazellen durch eine Färbung des makrophagenspezifischen aktivierten Antigens 3 (Mac3) durchgeführt. Hierbei konnte in Cortex und Hippocampus keine gesteigerte Zellaktivierung in Rett-Weibchen gegenüber den Wildtyp-Weibchen festgestellt werden, was eine Entzündungsreaktion wiederum sehr unwahrscheinlich macht. Die immunhistochemische Färbung des sauren Gliafaserproteins GFAP, welches von Astrozyten exprimiert wird, sollte diese These unterstützen. Es zeigte sich, dass in nahezu allen Cortexregionen ein signifikanter GFAP-Mangel bei Mecp $2^{+/-}$-Mäusen im Vergleich zu Mecp $2^{+/+}$-Mäusen von bis zu $80 \%$ vorlag. Bei einer entzündlichen Reaktion wäre die Expression von GFAP dagegen hochreguliert, weshalb dieses Ergebnis im Widerspruch mit den von einigen Autoren postulierten „subklinischen Oxinflammation“ steht und diese auf zellulärer Ebene ausschließt.

Schlussfolgernd kann demnach festgehalten werden, dass in dieser Arbeit zum ersten Mal die oxidative Schädigung von DNA im Rett-Syndrom eingehend untersucht und eindeutig nachgewiesen werden konnte. Dabei ist besonders hervorzuheben, dass dieser Nachweis bereits bei 50 Tage alten Rett-Weibchen erbracht werden konnte, die klinisch als präsymptomatisch einzustufen sind. Somit manifestiert sich neben mitochondrialen Veränderungen auch die oxidative DNA-Schädigung bereits lange vor dem Eintritt manifester klinischer Symptome. Da zurzeit keine kausalen Therapien für diese genetisch bedingte Krankheit zur Verfügung stehen, liegt ein verbreiteter Therapieansatz in einer mit Antioxidantien angereicherten Ernährung zur potenziellen Reduktion oxidativer Zellschäden. In dieser Arbeit konnte bezüglich der DNA-Oxidation jedoch eine nutzenbringende Wirkung an den entsprechend behandelten Mäusen nicht nachgewiesen werden - dies sollte bei der umfassenden Beurteilung solcher Therapieansätze berücksichtigt werden. Der hier nachgewiesene GFAP-Mangel in jungen, weiblichen Rett-Tieren aktualisiert außerdem die Rolle der Astrozyten im Rett-Syndrom, da diesen Zellen zuvor eine Beteiligung abgesprochen wurde (Jellinger et al. 1988). Der Einfluss einer veränderten 
GFAP-Menge im Cortex kann nun vor dem Hintergrund der neurologischen klinischen Symptome von Rett-Patienten eingestuft werden. Zusätzlich erzeugt dieser GFAP-Mangel einen Konflikt mit einer vermuteten „subklinischen Oxinflammation“, da sich diese offenbar auf glialer Ebene nicht widerspiegeln lässt. Summa summarum konnte mit dieser Arbeit das Bild des Rett-Syndroms vor allem auf metabolischer sowie zellulärer Ebene ergänzt und aktualisiert werden. So wurden weitere Detaileinblicke zum Verständnis der komplexen Pathogenese beigesteuert, was auch für die noch ausstehende Entwicklung adäquater Therapielösungen von Interesse sein dürfte. 


\section{$6 \quad$ Literaturverzeichnis}

Abboud S, Haile DJ (2000): A novel mammalian iron-regulated protein involved in intracellular iron metabolism. J Biol Chem 275, 19906-19912

Aisen P, Enns C, Wessling-Resnick M (2001): Chemistry and biology of eukaryotic iron metabolism. Int J Biochem Cell Biol 33, 940-959

Aizenman E, Lipton SA, Loring RH (1989): Selective modulation of NMDA responses by reduction and oxidation. Neuron $\underline{2}, 1257-1263$

Ambroz HB, Bradshaw TK, Kemp TJ, Kornacka EM, Przybytniak GK (2001): Role of iron ions in damage to DNA: influence of ionising radiation, UV light and $\mathrm{H}_{2} \mathrm{O}_{2}$. J Photochem Photobiol A $\underline{142}, 9-18$

Ames B (1988): Measuring oxidative damage in humans: relation to cancer and ageing. IARC Sci Publ $\underline{89}, 407-416$

Amir RE, Van den Veyver IB, Wan M, Tran CQ, Francke U, Zoghbi HY (1999): Rett syndrome is caused by mutations in $\mathrm{X}$-linked MECP2, encoding methyl-CpG-binding protein 2. Nat Genet $\underline{23}, 185-188$

Andrews SC, Arosio P, Bottke W, Briat JF, von Darl M, Harrison PM, Laulhere JP, Levi S, Lobreaux S, Yewdall SJ (1992): Structure, function, and evolution of ferritins. J Inorg Biochem 47, 161-174

Ariani F, Hayek G, Rondinella D, Artuso R, Mencarelli MA, Spanhol-Rosseto A, Pollazzon M, Buoni S, Spiga O, Ricciardi S et al. (2008): FOXG1 is responsible for the congenital variant of Rett syndrome. Am J Hum Genet $\underline{83}$, 89-93

Armstrong D, Dunn JK, Antalffy B, Trivedi R (1995): Selective dendritic alterations in the cortex of Rett syndrome. J Neuropathol Exp Neurol 54, 195-201

Armstrong DD (2005): Neuropathology of Rett syndrome. J Child Neurol 20, 747-753

Asaka Y, Jugloff DG, Zhang L, Eubanks JH, Fitzsimonds RM (2006): Hippocampal synaptic plasticity is impaired in the Mecp2-null mouse model of Rett syndrome. Neurobiol Dis $\underline{21}$, $217-227$

Atamna H (2004): Heme, iron, and the mitochondrial decay of ageing. Ageing Res Rev $\underline{3}$, 303-318 
Aust AE, Eveleigh JF (1999): Mechanisms of DNA oxidation. Proc Soc Exp Biol Med 222, 246-252

Ballas N, Lioy DT, Grunseich C, Mandel G (2009): Non-cell autonomous influence of MeCP2-deficient glia on neuronal dendritic morphology. Nat Neurosci $\underline{12}$, 311-317

Balmer D, Goldstine J, Rao YM, LaSalle JM (2003): Elevated methyl-CpG-binding protein 2 expression is acquired during postnatal human brain development and is correlated with alternative polyadenylation. J Mol Med $\underline{81}, 61-68$

Bass NH, Hess HH, Pope A, Thalheimer C (1971): Quantitative cytoarchitectonic distribution of neurons, glia, and DNA in rat cerebral cortex. J Comp Neurol $\underline{143}, 481-490$

Beesk F, Dizdaroglu M, Schulte-Frohlinde D, von Sonntag C (1979): Radiation-induced DNA strand breaks in deoxygenated aqueous solutions. The formation of altered sugars as end groups. Int J Radiat Biol Relat Stud Phys Chem Med 36, 565-576

Belichenko NP, Belichenko PV, Li HH, Mobley WC, Francke U (2008): Comparative study of brain morphology in Mecp2 mutant mouse models of Rett syndrome. J Comp Neurol $\underline{508}$, 184-195

Belichenko PV, Oldfors A, Hagberg B, Dahlstrom A (1994): Rett syndrome: 3-D confocal microscopy of cortical pyramidal dendrites and afferents. Neuroreport $\underline{5}, 1509-1513$

Belichenko PV, Wright EE, Belichenko NP, Masliah E, Li HH, Mobley WC, Francke U (2009): Widespread changes in dendritic and axonal morphology in Mecp2-mutant mouse models of Rett syndrome: evidence for disruption of neuronal networks. J Comp Neurol $\underline{514}, 240-258$

Benkovic SA, Connor JR (1993): Ferritin, transferrin, and iron in selected regions of the adult and aged rat brain. J Comp Neurol $\underline{338}, 97-113$

Bertani I, Rusconi L, Bolognese F, Forlani G, Conca B, De Monte L, Badaracco G, Landsberger N, Kilstrup-Nielsen C (2006): Functional consequences of mutations in CDKL 5, an X-linked gene involved in infantile spasms and mental retardation. J Biol Chem $\underline{281}, 32048-32056$

Bodda C, Tantra M, Mollajew R, Arunachalam JP, Laccone FA, Can K, Rosenberger A, Mironov SL, Ehrenreich H, Mannan AU (2013): Mild overexpression of Mecp2 in mice causes a higher susceptibility toward seizures. Am J Pathol 183, 195-210

Boveris A, Chance B (1973): The mitochondrial generation of hydrogen peroxide: General properties and effect of hyperbaric oxygen. Biochem J 134, 707-716 
Bradbury MW (1997): Transport of iron in the blood-brain-cerebrospinal fluid system. J Neurochem $\underline{69}, 443-454$

Bramlett HM, Kraydieh S, Green EJ, Dietrich WD (1997): Temporal and regional patterns of axonal damage following traumatic brain injury: a beta-amyloid precursor protein immunocytochemical study in rats. J Neuropathol Exp Neurol $\underline{56}, 1132-1141$

Burdo J, Menzies S, Simpson I, Garrick L, Garrick M, Dolan K, Haile D, Beard J, Connor J (2001): Distribution of divalent metal transporter 1 and metal transport protein 1 in the normal and Belgrade rat. J Neurosci Res $\underline{66}, 1198-1207$

Çakatay U, Aydin S, Yanar K, Uzun H (2010): Gender-dependent variations in systemic biomarkers of oxidative protein, DNA, and lipid damage in aged rats. Aging Male $\underline{13}, 51-58$

Calfa G, Percy AK, Pozzo-Miller L (2011): Experimental models of Rett syndrome based on MeCP2 dysfunction. Exp Biol Med 236, 3-19

Can K, Menzfeld C, Rinne L, Rehling P, Kügler S, Golubiani G, Dudek J, Müller M (2019): Neuronal redox-imbalance in Rett syndrome affects mitochondria as well as cytosol, and is accompanied by intensified mitochondrial $\mathrm{O}_{2}$ consumption and ROS release. Front Physiol $\underline{10}, 479$

Canto CB, Wouterlood FG, Witter MP (2008): What does anatomical organization of entorhinal cortex tell us? Neural Plast 2008, 1-18

Casanova MF, Buxhoeveden D, Switala A, Roy E (2003): Rett syndrome as a minicolumnopathy. Clin Neuropathol 22, 163-168

Chahrour M, Zoghbi HY (2007): The story of Rett syndrome: from clinic to neurobiology. Neuron $\underline{56}, 422-437$

Chang Q, Khare G, Dani V, Nelson S, Jaenisch R (2006): The disease progression of Mecp2 mutant mice is affected by the level of BDNF expression. Neuron 49, 341-348

Chao HT, Zoghbi HY (2012): MeCP2: only 100\% will do. Nat Neurosci 15, 176-177

Chasteen ND, Harrison PM (1999): Mineralization in ferritin: an efficient means of iron storage. J Struct Biol 126, 182-194

Chen Q, Vazquez EJ, Moghaddas S, Hoppel CL, Lesnefsky EJ (2003a): Production of reactive oxygen species by mitochondria: central role of complex III. J Biol Chem 278, 36027-36031 
Chen RZ, Akbarian S, Tudor M, Jaenisch R (2001): Deficiency of methyl-CpG binding protein-2 in CNS neurons results in a Rett-like phenotype in mice. Nat Genet 27, 327-331

Chen WG, Chang Q, Lin Y, Meissner A, West AE, Griffith EC, Jaenisch R, Greenberg ME (2003b): Derepression of BDNF transcription involves calcium-dependent phosphorylation of MeCP2. Science 302, 885-889

Cheng Y, Zak O, Aisen P, Harrison SC, Walz T (2004): Structure of the human transferrin receptor-transferrin complex. Cell $\underline{116}, 565-576$

Christodoulou J, Grimm A, Maher T, Bennetts B (2003): RettBASE: The IRSA MECP2 variation database - a new mutation database in evolution. Hum Mutat 21, 466-472

Chung MH, Kim HS, Ohtsuka E, Kasai H, Yamamoto F, Nishimura S (1991): An endonuclease activity in human polymorphonuclear neutrophils that removes 8hydroxyguanine residues from DNA. Biochem Biophys Res Commun $\underline{178}$, 1472-1478

Cohen DR, Matarazzo V, Palmer AM, Tu Y, Jeon OH, Pevsner J, Ronnett GV (2003): Expression of MeCP2 in olfactory receptor neurons is developmentally regulated and occurs before synaptogenesis. Mol Cell Neurosci 22, 417-429

Collins AL, Levenson JM, Vilaythong AP, Richman R, Armstrong DL, Noebels JL, David Sweatt J, Zoghbi HY (2004): Mild overexpression of MeCP2 causes a progressive neurological disorder in mice. Hum Mol Genet 13, 2679-2689

Connor J, Menzies S, St. Martin S, Mufson E (1992a): A histochemical study of iron, transferrin, and ferritin in Alzheimer's diseased brains. J Neurosci Res $\underline{31}, 75-83$

Connor J, Snyder B, Beard J, Fine R, Mufson E (1992b): Regional distribution of iron and iron-regulatory proteins in the brain in aging and Alzheimer's disease. J Neurosci Res $\underline{31}$, $327-335$

Connor JR, Menzies SL (1990): Altered cellular distribution of iron in the central nervous system of myelin deficient rats. Neuroscience $\underline{34}, 265-271$

Connor JR, Menzies SL (1996): Relationship of iron to oligodendrocytes and myelination. Glia 17, 83-93

Connor JR, Phillips TM, Lakshman MR, Barron KD, Fine RE, Csiza CK (1987): Regional variation in the levels of transferrin in the CNS of normal and myelin-deficient rats. J Neurochem $\underline{49}$, 1523-1529 
Cornford ME, Philippart M, Jacobs B, Scheibel AB, Vinters HV (1994): Neuropathology of Rett syndrome: case report with neuronal and mitochondrial abnormalities in the brain. J Child Neurol $\underline{9}, 424-431$

Cortelazzo A, De Felice C, Guerranti R, Signorini C, Leoncini S, Pecorelli A, Zollo G, Landi C, Valacchi G, Ciccoli L et al. (2014): Subclinical inflammatory status in Rett syndrome. Mediators Inflamm 2014, 480980

Croonenberghs J, Bosmans E, Deboutte D, Kenis G, Maes M (2002): Activation of the inflammatory response system in autism. Neuropsychobiology $\underline{45}, 1-6$

Dalmay T, Abs E, Poorthuis RB, Hartung J, Pu DL, Onasch S, Lozano YR, Signoret-Genest J, Tovote P, Gjorgjieva J et al. (2019): A critical role for neocortical processing of threat memory. Neuron 104, 1180-1194

Dani VS, Chang Q, Maffei A, Turrigiano GG, Jaenisch R, Nelson SB (2005): Reduced cortical activity due to a shift in the balance between excitation and inhibition in a mouse model of Rett syndrome. Proc Natl Acad Sci U S A 102, 12560-12565

Dautry-Varsat A, Ciechanover A, Lodish HF (1983): $\mathrm{pH}$ and the recycling of transferrin during receptor-mediated endocytosis. Proc Natl Acad Sci U S A $\underline{80}, 2258-2262$

De Felice C, Ciccoli L, Leoncini S, Signorini C, Rossi M, Vannuccini L, Guazzi G, Latini G, Comporti M, Valacchi G et al. (2009): Systemic oxidative stress in classic Rett syndrome. Free Radic Biol Med 47, 440-448

De Felice C, Signorini C, Durand T, Ciccoli L, Leoncini S, D'Esposito M, Filosa S, Oger C, Guy A, Bultel-Ponce V et al. (2012): Partial rescue of Rett syndrome by $\omega-3$ polyunsaturated fatty acids (PUFAs) oil. Genes Nutr $\underline{7}, 447-458$

De Filippis B, Valenti D, de Bari L, De Rasmo D, Musto M, Fabbri A, Ricceri L, Fiorentini C, Laviola G, Vacca RA (2015): Mitochondrial free radical overproduction due to respiratory chain impairment in the brain of a mouse model of Rett syndrome: protective effect of CNF1. Free Radic Biol Med $\underline{83}$, 167-177

Dizdaroglu M, Von Sonntag C, Schulte-Frohlinde D (1975): Strand breaks and sugar release by $\gamma$-irradiation of DNA in aqueous solution. J Am Chem Soc 97, 2277-2278

Dizdaroglu M, Schulte-Frohlinde D, von Sonntag C (1977): $\gamma$-radiolyses of DNA in oxygenated aqueous solution. Structure of an alkali-labile site. Z Naturforsch C $\underline{32}, 1021$ 1022 
Doak SH, Brüsehafer K, Dudley E, Quick E, Johnson G, Newton RP, Jenkins GJS (2008): No-observed effect levels are associated with up-regulation of MGMT following MMS exposure. Mutat Res $\underline{648}, 9-14$

Dragich JM, Kim YH, Arnold AP, Schanen NC (2007): Differential distribution of the MeCP2 splice variants in the postnatal mouse brain. J Comp Neurol 501, 526-542

Eeg-Olofsson O, Al-Zuhair AG, Teebi AS, Daoud AS, Zaki M, Besisso MS, Al-Essa MM (1990): Rett syndrome: a mitochondrial disease? J Child Neurol $\underline{5}, 210-214$

Eisenstein RS (2000): Iron regulatory proteins and the molecular control of mammalian iron metabolism. Annu Rev Nutr 20, 627-662

Elkabes S, DiCicco-Bloom EM, Black IB (1996): Brain microglia/macrophages express neurotrophins that selectively regulate microglial proliferation and function. J Neurosci 16 , $2508-2521$

Engineer CT, Rahebi KC, Borland MS, Buell EP, Centanni TM, Fink MK, Im KW, Wilson LG, Kilgard MP (2015): Degraded neural and behavioral processing of speech sounds in a rat model of Rett syndrome. Neurobiol Dis $\underline{83}, 26-34$

Fehr S, Wilson M, Downs J, Williams S, Murgia A, Sartori S, Vecchi M, Ho G, Polli R, Psoni $S$ et al. (2013): The CDKL5 disorder is an independent clinical entity associated with earlyonset encephalopathy. Eur J Hum Genet 21, 266-273

Fenton H (1894): LXXIII.-Oxidation of tartaric acid in presence of iron. J Chem Soc Trans $\underline{65}, 899-910$

Fischer M, Reuter J, Gerich FJ, Hildebrandt B, Hägele S, Katschinski D, Müller M (2009): Enhanced hypoxia susceptibility in hippocampal slices from a mouse model of Rett syndrome. J Neurophysiol 101, 1016-1032

Floyd RA, West MS, Eneff KL, Schneider JE, Wong PK, Tingey DT, Hogsett WE (1990): Conditions influencing yield and analysis of 8-hydroxy-2'-deoxyguanosine in oxidatively damaged DNA. Anal Biochem $\underline{188}, 155-158$

Formichi P, Battisti C, Dotti MT, Hayek G, Zappella M, Federico A (1998): Vitamin E serum levels in Rett syndrome. J Neurol Sci 156, 227-230

Fukuda T, Itoh M, Ichikawa T, Washiyama K, Goto YI (2005): Delayed maturation of neuronal architecture and synaptogenesis in cerebral cortex of Mecp2-deficient mice. J Neuropathol Exp 64, 537-544 
Garrick MD, Dolan KG, Horbinski C, Ghio AJ, Higgins D, Porubcin M, Moore EG, Hainsworth LN, Umbreit JN, Conrad ME et al. (2003): DMT1: A mammalian transporter for multiple metals. Biometals $\underline{16}, 41-54$

Gerich FJ, Funke F, Hildebrandt B, Faßhauer M, Müller M (2009): $\mathrm{H}_{2} \mathrm{O}_{2}$-mediated modulation of cytosolic signaling and organelle function in rat hippocampus. Pflügers Arch $\underline{458}, 937$

Giacometti E, Luikenhuis S, Beard C, Jaenisch R (2007): Partial rescue of MeCP2 deficiency by postnatal activation of MeCP2. Proc Natl Acad Sci U S A $\underline{104}$, 1931-1936

Giulian D, Baker TJ (1986): Characterization of ameboid microglia isolated from developing mammalian brain. J Neurosci $\underline{6}, 2163-2178$

Glaze DG (2005): Neurophysiology of Rett syndrome. J Child Neurol 20, 740-746

Goffin D, Allen M, Zhang L, Amorim M, Wang IT, Reyes AR, Mercado-Berton A, Ong C, Cohen S, Hu L et al. (2011): Rett syndrome mutation MeCP2 T158A disrupts DNA binding, protein stability and ERP responses. Nat Neurosci 15, 274-283

Goldstein JL, Anderson RGW, Brown MS (1979): Coated pits, coated vesicles, and receptormediated endocytosis. Nature $\underline{279}, 679-685$

Good PF, Perl DP, Bierer LM, Schmeidler J (1992): Selective accumulation of aluminum and iron in the neurofibrillary tangles of Alzheimer's disease: a laser microprobe (LAMMA) study. Ann Neurol 31, 286-292

Gotz ME, Kunig G, Riederer P, Youdim MB (1994): Oxidative stress: free radical production in neural degeneration. Pharmacol Ther $\underline{63}, 37-122$

Großer E, Hirt U, Janc OA, Menzfeld C, Fischer M, Kempkes B, Vogelgesang S, Manzke TU, Opitz L, Salinas-Riester G et al. (2012): Oxidative burden and mitochondrial dysfunction in a mouse model of Rett syndrome. Neurobiol Dis $\underline{48}, 102-114$

Grosso S, Brogna A, Bazzotti S, Renieri A, Morgese G, Balestri P (2007): Seizures and electroencephalographic findings in CDKL5 mutations: Case report and review. Brain Dev 29, 239-242

Guy J, Hendrich B, Holmes M, Martin JE, Bird A (2001): A mouse Mecp2-null mutation causes neurological symptoms that mimic Rett syndrome. Nat Genet 27, 322-326 
Guy J, Gan J, Selfridge J, Cobb S, Bird A (2007): Reversal of neurological defects in a mouse model of Rett syndrome. Science $\underline{315}, 1143-1147$

Haas RH, Rice MA, Trauner DA, Merritt TA, Opitz JM, Reynolds JF (1986): Therapeutic effects of a ketogenic diet in Rett syndrome. J Med Genet 25, 225-246

Hagberg B (2005): Rett syndrome: long-term clinical follow-up experiences over four decades. J Child Neurol 20, 722-727

Hagberg B, Berg M, Steffenburg U (2001): Three decades of sociomedical experiences from West Swedish Rett females 4-60 years of age. Brain Dev 23 Suppl 1, 28-31

Hagberg B, Aicardi J, Dias K, Ramos O (1983): A progressive syndrome of autism, dementia, ataxia, and loss of purposeful hand use in girls: Rett's syndrome: report of 35 cases. Ann Neurol 14, 471-479

Halliwell B, Gutteridge JMC: Role of free radicals and catalytic metal ions in human disease: An overview; In: Packer L and Glazer AN (Hrsg.): Methods in Enzymology. Academic Press, Cambridge 1990, 1-85

Hammarström AK, Gage PW (2000): Oxygen-sensing persistent sodium channels in rat hippocampus. J Physiol 르, 107-118

Hanks SB (1986): The role of therapy in Rett syndrome. Am J Med Genet Suppl 1, 247-252

Hardy J, Higgins G (1992): Alzheimer's disease: the amyloid cascade hypothesis. Science 256 , 184-185

Harman D (1956): Aging: a theory based on free radical and radiation chemistry. J Gerontol $\underline{11}, 298-300$

Harrison PM, Arosio P (1996): The ferritins: molecular properties, iron storage function and cellular regulation. Biochim Biophys Acta $\underline{1275}, 161-203$

Hendrich B, Bird A (1998): Identification and characterization of a family of mammalian methyl-CpG binding proteins. Mol Cell Biol $\underline{18}$, 6538-6547

Hidalgo C, Bull R, Behrens MI, Donoso P (2004): Redox regulation of RyR-mediated Ca ${ }^{2+}$ release in muscle and neurons. Biol Res $\underline{37}, 539-552$ 
Hill J, Switzer III R (1984): The regional distribution and cellular localization of iron in the rat brain. Neuroscience $\underline{11}, 595-603$

Horike SI, Cai S, Miyano M, Cheng JF, Kohwi-Shigematsu T (2005): Loss of silent-chromatin looping and impaired imprinting of DLX5 in Rett syndrome. Nat Genet $\underline{37}, 31-40$

Itoh M, Ide S, Takashima S, Kudo S, Nomura Y, Segawa M, Kubota T, Mori H, Tanaka S, Horie $\mathrm{H}$ et al. (2007): Methyl CpG-binding protein 2 (a mutation of which causes Rett syndrome) directly regulates insulin-like growth factor binding protein 3 in mouse and human brains. J Neuropathol Exp Neurol 66, 117-123

Jan MM, Dooley JM, Gordon KE (1999): Male Rett syndrome variant: application of diagnostic criteria. Pediatr Neurol 20, 238-240

Janc OA, Müller M (2014): The free radical scavenger Trolox dampens neuronal hyperexcitability, reinstates synaptic plasticity, and improves hypoxia tolerance in a mouse model of Rett syndrome. Front Cell Neurosci $\underline{8}, 56$

Janc OA, Hüser MA, Dietrich K, Kempkes B, Menzfeld C, Hülsmann S, Müller M (2016): Systemic radical scavenger treatment of a mouse model of Rett syndrome: merits and limitations of the vitamin E derivative Trolox. Front Cell Neurosci 10, 266

Jandl JH, Katz JH (1963): The plasma-to-cell cycle of transferrin. J Clin Invest 42, 314-326

Janz R, Südhof TC, Hammer RE, Unni V, Siegelbaum SA, Bolshakov VY (1999): Essential Roles in Synaptic Plasticity for Synaptogyrin I and Synaptophysin I. Neuron 24, 687-700

Jefferies WA, Food MR, Gabathuler R, Rothenberger S, Yamada T, Yasuhara O, McGeer PL (1996): Reactive microglia specifically associated with amyloid plaques in Alzheimer's disease brain tissue express melanotransferrin. Brain Res $\underline{712}$, 122-126

Jeffery L, Nakielny S (2004): Components of the DNA methylation system of chromatin control are RNA-binding proteins. J Biol Chem $\underline{279}$, 49479-49487

Jellinger K, Armstrong D, Zoghbi HY, Percy AK (1988): Neuropathology of Rett syndrome. Acta Neuropathol 므, 142-158

Jenkins GJS, Zaïr Z, Johnson GE, Doak SH (2010): Genotoxic thresholds, DNA repair, and susceptibility in human populations. Toxicology $\underline{278}, 305-310$ 
Jentarra GM, Olfers SL, Rice SG, Srivastava N, Homanics GE, Blue M, Naidu S, Narayanan $\mathrm{V}$ (2010): Abnormalities of cell packing density and dendritic complexity in the MeCP2 A140V mouse model of Rett syndrome/X-linked mental retardation. BMC Neurosci 11, 19

Jian L, Nagarajan L, De Klerk N, Ravine D, Bower C, Anderson A, Williamson S, Christodoulou J, Leonard H (2006): Predictors of seizure onset in Rett syndrome. J Pediatr $\underline{149}, 542-547$

Jones PL, Veenstra GJ, Wade PA, Vermaak D, Kass SU, Landsberger N, Strouboulis J, Wolffe AP (1998): Methylated DNA and MeCP2 recruit histone deacetylase to repress transcription. Nat Genet $\underline{19}, 187-191$

Julu PO, Kerr AM, Apartopoulos F, Al-Rawas S, Engerström IW, Engerström L, Jamal GA, Hansen S (2001): Characterisation of breathing and associated central autonomic dysfunction in the Rett disorder. Arch Dis Child $\underline{85}$, 29-37

Kakhlon O, Cabantchik ZI (2002): The labile iron pool: characterization, measurement, and participation in cellular processes. Free Radic Biol Med $\underline{33}$, 1037-1046

Katz DM, Dutschmann M, Ramirez JM, Hilaire G (2009): Breathing disorders in Rett syndrome: progressive neurochemical dysfunction in the respiratory network after birth. Respir Physiol Neurobiol 168, 101-108

Katz DM, Bird A, Coenraads M, Gray SJ, Menon DU, Philpot BD, Tarquinio DC (2016): Rett syndrome: Crossing the threshold to clinical translation. Trends Neurosci $\underline{39}, 100-113$

Katz DM, Berger-Sweeney JE, Eubanks JH, Justice MJ, Neul JL, Pozzo-Miller L, Blue ME, Christian D, Crawley JN, Giustetto M et al. (2012): Preclinical research in Rett syndrome: setting the foundation for translational success. Dis Model Mech $\underline{5}, 733-745$

Kaufmann WE, Moser HW (2000): Dendritic anomalies in disorders associated with mental retardation. Cereb Cortex 10, 981-991

Kehrer JP (2000): The Haber-Weiss reaction and mechanisms of toxicity. Toxicology 149, 43-50

Kelly JP, Van Essen DC (1974): Cell structure and function in the visual cortex of the cat. J Physiol 238, 515-547

Kerr AM, Armstrong DD, Prescott RJ, Doyle D, Kearney DL (1997): Rett syndrome: analysis of deaths in the British survey. Eur Child Adolesc Psychiatry 6 Suppl 1, 71-74 
Kishi N, Macklis JD (2004): MeCP2 is progressively expressed in post-migratory neurons and is involved in neuronal maturation rather than cell fate decisions. Mol Cell Neurosci 27 , 306-321

Kishi N, Sato K, Sasaki E, Okano H (2014): Common marmoset as a new model animal for neuroscience research and genome editing technology. Dev Growth Differ $\underline{56}$, 53-62

Kriaucionis S, Bird A (2004): The major form of MeCP2 has a novel N-terminus generated by alternative splicing. Nucleic Acids Res $\underline{32}, 1818-1823$

Kriaucionis S, Paterson A, Curtis J, Guy J, Macleod N, Bird A (2006): Gene expression analysis exposes mitochondrial abnormalities in a mouse model of Rett syndrome. Mol Cell Biol 26, 5033-5042

Kron M, Müller M (2010): Impaired hippocampal $\mathrm{Ca}^{2+}$ homeostasis and concomitant $\mathrm{K}^{+}$ channel dysfunction in a mouse model of Rett syndrome during anoxia. Neuroscience $\underline{171}$, 300-315

Kron M, Zimmermann JL, Dutschmann M, Funke F, Müller M (2011): Altered responses of MeCP2-deficient mouse brain stem to severe hypoxia. J Neurophysiol 105, 3067-3079

Kruszewski M (2003): Labile iron pool: the main determinant of cellular response to oxidative stress. Mutat Res $\underline{531}$, 81-92

Kubota T, Watanabe N, Kanai Y, Stollar BD (1996): Enhancement of oxidative cleavage of DNA by the binding sites of two anti-double-stranded DNA antibodies. J Biol Chem 271, 6555-6561

Kuchino Y, Mori F, Kasai H, Inoue H, Iwai S, Miura K, Ohtsuka E, Nishimura S (1987): Misreading of DNA templates containing 8-hydroxydeoxyguanosine at the modified base and at adjacent residues. Nature $\underline{327}, 77-79$

Kurz T, Leake A, Von Zglinicki T, Brunk UT (2004): Relocalized redox-active lysosomal iron is an important mediator of oxidative-stress-induced DNA damage. Biochem J $\underline{378}$, 1039-1045

Kushnareva Y, Murphy AN, Andreyev A (2002): Complex I-mediated reactive oxygen species generation: modulation by cytochrome $\mathrm{c}$ and $\mathrm{NAD}(\mathrm{P})^{+}$oxidation-reduction state. Biochem J $\underline{368}, 545-553$ 
Kuster GM, Lancel S, Zhang J, Communal C, Trucillo MP, Lim CC, Pfister O, Weinberg EO, Cohen RA, Liao R et al. (2010): Redox-mediated reciprocal regulation of SERCA and $\mathrm{Na}^{+}-\mathrm{Ca}^{2+}$ exchanger contributes to sarcoplasmic reticulum $\mathrm{Ca}^{2+}$ depletion in cardiac myocytes. Free Radic Biol Med $\underline{48}, 1182-1187$

Lawson-Yuen A, Liu D, Han L, Jiang ZI, Tsai GE, Basu AC, Picker J, Feng J, Coyle JT (2007): Ube3a mRNA and protein expression are not decreased in Mecp2 R168X mutant mice. Brain Res 1180, 1-6

Leoncini S, De Felice C, Signorini C, Zollo G, Cortelazzo A, Durand T, Galano JM, Guerranti R, Rossi M, Ciccoli L et al. (2015): Cytokine dysregulation in MECP2- and CDKL5-related Rett syndrome: Relationships with aberrant redox homeostasis, inflammation, and $\omega-3$ PUFAs. Oxid Med Cell Longev 2015, 421624

LeVine SM (1997): Iron deposits in multiple sclerosis and Alzheimer's disease brains. Brain Res $\underline{760}$, 298-303

Levitt P, Campbell DB (2009): The genetic and neurobiologic compass points toward common signaling dysfunctions in autism spectrum disorders. J Clin Invest $\underline{119}$, 747-754

Lewis JD, Meehan RR, Henzel WJ, Maurer-Fogy I, Jeppesen P, Klein F, Bird A (1992): Purification, sequence, and cellular localization of a novel chromosomal protein that binds to methylated DNA. Cell $\underline{69}, 905-914$

Li W, Pozzo-Miller L (2012): Beyond widespread Mecp2 deletions to model Rett syndrome: Conditional spatio-temporal knockout, single-point mutations and transgenic rescue mice. Autism Open Access 2012, 5

Liu Z, Zhou X, Zhu Y, Chen ZF, Yu B, Wang Y, Zhang CC, Nie YH, Sang X, Cai YJ (2014): Generation of a monkey with MECP2 mutations by TALEN-based gene targeting. Neurosci Bull $\underline{30}, 381-386$

Lovell MA, Gabbita SP, Markesbery WR (1999): Increased DNA oxidation and decreased levels of repair products in Alzheimer's disease ventricular CSF. J Neurochem $\underline{72}$, 771-776

Maezawa I, Jin LW (2010): Rett syndrome microglia damage dendrites and synapses by the elevated release of glutamate. J Neurosci $\underline{30}$, 5346-5356

Maffei S, De Felice C, Cannarile P, Leoncini S, Signorini C, Pecorelli A, Montomoli B, Lunghetti S, Ciccoli L, Durand T et al. (2014): Effects of $\omega-3$ PUFAs supplementation on myocardial function and oxidative stress markers in typical Rett syndrome. Mediators Inflamm 2014, 983178 
Maragakis NJ, Rothstein JD (2001): Glutamate transporters in neurologic disease. Arch Neurol $\underline{58}, 365-370$

Martinowich K, Hattori D, Wu H, Fouse S, He F, Hu Y, Fan G, Sun YE (2003): DNA methylation-related chromatin remodeling in activity-dependent $B d n f$ gene regulation. Science $\underline{302}, 890$

Mecocci P, MacGarvey U, Beal MF (1994): Oxidative damage to mitochondrial DNA is increased in Alzheimer's disease. Ann Neurol $\underline{36}$, 747-751

Meneghini R (1997): Iron homeostasis, oxidative stress, and DNA damage. Free Radic Biol Med 23, 783-792

Mironov SL, Skorova E, Hartelt N, Mironova LA, Hasan MT, Kügler S (2009): Remodelling of the respiratory network in a mouse model of Rett syndrome depends on brain-derived neurotrophic factor regulated slow calcium buffering. J Physiol 587, 2473-2485

Mnatzakanian GN, Lohi H, Munteanu I, Alfred SE, Yamada T, MacLeod PJM, Jones JR, Scherer SW, Schanen NC, Friez MJ et al. (2004): A previously unidentified MECP2 open reading frame defines a new protein isoform relevant to Rett syndrome. Nat Genet $\underline{36}$, 339341

Moretti P, Levenson JM, Battaglia F, Atkinson R, Teague R, Antalffy B, Armstrong D, Arancio O, Sweatt JD, Zoghbi HY (2006): Learning and memory and synaptic plasticity are impaired in a mouse model of Rett syndrome. J Neurosci 26, 319-327

Moser SJ, Weber P, Lutschg J (2007): Rett syndrome: clinical and electrophysiologic aspects. Pediatr Neurol $\underline{36}, 95-100$

Mount RH, Hastings RP, Reilly S, Cass H, Charman T (2001): Behavioural and emotional features in Rett syndrome. Disabil Rehabil 23, 129-138

Mullaney BC, Johnston MV, Blue ME (2004): Developmental expression of methyl-CpG binding protein 2 is dynamically regulated in the rodent brain. Neuroscience $\underline{123}$, 939-949

Müller M, Can K (2014): Aberrant redox homoeostasis and mitochondrial dysfunction in Rett syndrome. Biochem Soc Trans $\underline{42}$, 959-964

Nan X, Campoy FJ, Bird A (1997): MeCP2 is a transcriptional repressor with abundant binding sites in genomic chromatin. Cell $\underline{88}, 471-481$ 
Nan X, Ng HH, Johnson CA, Laherty CD, Turner BM, Eisenman RN, Bird A (1998): Transcriptional repression by the methyl-CpG-binding protein MeCP2 involves a histone deacetylase complex. Nature 393, 386-389

Neul JL, Kaufmann WE, Glaze DG, Christodoulou J, Clarke AJ, Bahi-Buisson N, Leonard H, Bailey ME, Schanen NC, Zappella M et al. (2010): Rett syndrome: revised diagnostic criteria and nomenclature. Ann Neurol $\underline{68}, 944-950$

Nomura Y (2005): Early behavior characteristics and sleep disturbance in Rett syndrome. Brain Dev 27, 35-42

Nuber UA, Kriaucionis S, Roloff TC, Guy J, Selfridge J, Steinhoff C, Schulz R, Lipkowitz B, Ropers HH, Holmes MC (2005): Up-regulation of glucocorticoid-regulated genes in a mouse model of Rett syndrome. Hum Mol Genet 14, 2247-2256

O'Neill P (1983): Pulse radiolytic study of the interaction of thiols and ascorbate with $\mathrm{OH}$ adducts of dGMP and dG: implications for DNA repair processes. Radiat Res $\underline{96}, 198-210$

Ohba C, Nabatame S, Iijima Y, Nishiyama K, Tsurusaki Y, Nakashima M, Miyake N, Tanaka F, Ozono K, Saitsu H (2014): De novo WDR45 mutation in a patient showing clinically Rett syndrome with childhood iron deposition in brain. J Hum Genet $\underline{59}$, 292-295

Osborne TB, Campbell GF (1900): The protein constituents of egg white. J Am Chem Soc $\underline{22}, 422-450$

Panighini A, Duranti E, Santini F, Maffei M, Pizzorusso T, Funel N, Taddei S, Bernardini N, Ippolito C, Virdis A et al. (2013): Vascular dysfunction in a mouse model of Rett syndrome and effects of curcumin treatment. PLoS One $\underline{8}$, e64863

Paul T (2000): Effect of a prolonged superoxide flux on transferrin and ferritin. Arch Biochem Biophys $\underline{382}$, 253-261

Paxinos G, Franklin KBJ: The Mouse Brain in Stereotaxic Coordinates; Academic Press, San Diego 2001

Pecorelli A, Cervellati C, Hayek J, Valacchi G (2016): OxInflammation in Rett syndrome. Int J Biochem Cell Biol 1ㅜ, 246-253

Pecorelli A, Leoni G, Cervellati F, Canali R, Signorini C, Leoncini S, Cortelazzo A, De Felice C, Ciccoli L, Hayek J et al. (2013): Genes related to mitochondrial functions, protein degradation, and chromatin folding are differentially expressed in lymphomonocytes of Rett syndrome patients. Mediators Inflamm 2013, 137629 
Peddada S, Yasui DH, LaSalle JM (2006): Inhibitors of differentiation (ID1, ID2, ID3 and ID4) genes are neuronal targets of MeCP2 that are elevated in Rett syndrome. Hum Mol Genet $\underline{15}$, 2003-2014

Pekny M, Johansson CB, Eliasson C, Stakeberg J, Wallén Å, Perlmann T, Lendahl U, Betsholtz C, Berthold C-H, Frisén J (1999): Abnormal reaction to central nervous system injury in mice lacking glial fibrillary acidic protein and vimentin. J Cell Biol 145, 503-514

Pelka GJ, Watson CM, Christodoulou J, Tam PPL (2005): Distinct expression profiles of Mecp2 transcripts with different lengths of 3'UTR in the brain and visceral organs during mouse development. Genomics $\underline{85}, 441-452$

Pelka GJ, Watson CM, Radziewic T, Hayward M, Lahooti H, Christodoulou J, Tam PP (2006): Mecp2 deficiency is associated with learning and cognitive deficits and altered gene activity in the hippocampal region of mice. Brain $\underline{129}$, 887-898

Peters RA (1912): Chemical nature of specific oxygen capacity in haemoglobin. J Physiol 44 , 131-149

Pitcher MR, Herrera JA, Buffington SA, Kochukov MY, Merritt JK, Fisher AR, Schanen NC, Costa-Mattioli M, Neul JL (2015): Rett syndrome like phenotypes in the R255X Mecp2 mutant mouse are rescued by MECP2 transgene. Hum Mol Genet $\underline{24}$, 2662-2672

Poulsen HE, Loft S, Vistisen K (1996): Extreme exercise and oxidative DNA modification. J Sports Sci 14, 343-346

Proteggente AR, England TG, Rehman A, Rice-Evans CA, Halliwell B (2002): Gender differences in steady-state levels of oxidative damage to DNA in healthy individuals. Free Radic Res $\underline{36}, 157-162$

Pryor WA (1986): Oxy-radicals and related species: their formation, lifetimes, and reactions. Annu Rev Physiol 48, 657-667

Qian ZM, Wang Q (1998): Expression of iron transport proteins and excessive iron accumulation in the brain in neurodegenerative disorders. Brain Res Brain Res Rev $\underline{27}$, 257267

Quaderi NA, Meehan RR, Tate PH, Cross SH, Bird AP, Chatterjee A, Herman GE, Brown SDM (1994): Genetic and physical mapping of a gene encoding a methyl CpG binding protein, Mecp2, to the mouse X chromosome. Genomics 22, 648-651

Reiss AL, Faruque F, Naidu S, Abrams M, Beaty T, Bryan RN, Moser H (1993): Neuroanatomy of Rett syndrome: a volumetric imaging study. Ann Neurol 34, 227-234 
Rett A (1966): Über ein eigenartiges hirnatrophisches Syndrom bei Hyperammonämie im Kindesalter. Wien Med Wochenschr 116, 723-726

Riederer P, Dirr A, Goetz M, Sofic E, Jellinger K, Youdim MB (1992): Distribution of iron in different brain regions and subcellular compartments in Parkinson's disease. Ann Neurol 32 Suppl, S101-104

Robertson AB, Klungland A, Rognes T, Leiros I (2009): DNA repair in mammalian cells: Base excision repair: the long and short of it. Cell Mol Life Sci $\underline{66}$, 981-993

Ruch A, Kurczynski TW, Velasco ME (1989): Mitochondrial alterations in Rett syndrome. Pediatr Neurol $\underline{5}, 320-323$

Sah R, Galeffi F, Ahrens R, Jordan G, Schwartz-Bloom RD (2002): Modulation of the $\mathrm{GABA}_{\mathrm{A}}$-gated chloride channel by reactive oxygen species. J Neurochem $\underline{80}, 383-391$

Samaco RC, Hogart A, LaSalle JM (2005): Epigenetic overlap in autism-spectrum neurodevelopmental disorders: $M E C P 2$ deficiency causes reduced expression of UBE3A and GABRB3. Hum Mol Genet 14, 483-492

Saywell V, Viola A, Confort-Gouny S, Le Fur Y, Villard L, Cozzone PJ (2006): Brain magnetic resonance study of Mecp2 deletion effects on anatomy and metabolism. Biochem Biophys Res Commun $\underline{340}$, 776-783

Schade AL, Caroline L (1944): Raw hen egg white and the role of iron in growth inhibition of Shigella dysenteriae, Staphylococcus aureus, Escherichia coli and Saccharomyces cerevisiae. Science $\underline{100}, 14-15$

Schubert D, Jin LW, Saitoh T, Cole G (1989): The regulation of amyloid $\beta$ protein precursor secretion and its modulatory role in cell adhesion. Neuron $\underline{3}$, 689-694

Schüle B, Armstrong DD, Vogel H, Oviedo A, Francke U (2008): Severe congenital encephalopathy caused by MECP2 null mutations in males: central hypoxia and reduced neuronal dendritic structure. Clin Genet $\underline{74}$, 116-126

Schwartzman JS, Bernardino A, Nishimura A, Gomes RR, Zatz M (2001): Rett syndrome in a boy with a 47,XXY karyotype confirmed by a rare mutation in the MECP2 gene. Neuropediatrics $\underline{32}, 162-164$

Shahbazian M, Young J, Yuva-Paylor L, Spencer C, Antalffy B, Noebels J, Armstrong D, Paylor R, Zoghbi H (2002): Mice with truncated MeCP2 recapitulate many Rett syndrome features and display hyperacetylation of histone H3. Neuron $\underline{35}$, 243-254 
Shahbazian MD, Antalffy B, Armstrong DL, Zoghbi HY (2002a): Insight into Rett syndrome: MeCP2 levels display tissue- and cell-specific differences and correlate with neuronal maturation. Hum Mol Genet 11, 115-124

Sierra C, Vilaseca MA, Brandi N, Artuch R, Mira A, Nieto M, Pineda M (2001): Oxidative stress in Rett syndrome. Brain Dev 23, S236-239

Sies H (1993): Strategies of antioxidant defense. Eur J Biochem 215, 213-219

Smeets E, Terhal P, Casaer P, Peters A, Midro A, Schollen E, van Roozendaal K, Moog U, Matthijs G, Herbergs J et al. (2005): Rett syndrome in females with CTS hot spot deletions: a disorder profile. Am J Med Genet A $\underline{132 a}, 117-120$

Steffenburg U, Hagberg G, Hagberg B (2001): Epilepsy in a representative series of Rett syndrome. Acta Paediatr 90, 34-39

Stephenson JL, Byers MR (1995): GFAP immunoreactivity in trigeminal ganglion satellite cells after tooth injury in rats. Exp Neurol 131, 11-22

Stettner GM, Huppke P, Gärtner J, Richter DW, Dutschmann M (2008): Disturbances of breathing in Rett syndrome: Results from patients and animal models. Adv Exp Biol Med $\underline{605}, 503-507$

Stoll G, Jander S, Schroeter M (1998): Inflammation and glial responses in ischemic brain lesions. Prog Neurobiol $\underline{56}, 149-171$

Suzuki WA (1996): The anatomy, physiology and functions of the perirhinal cortex. Curr Opin Neurobiol $\underline{6}, 179-186$

Sweitzer SM, Colburn RW, Rutkowski M, DeLeo JA (1999): Acute peripheral inflammation induces moderate glial activation and spinal IL-1 $\beta$ expression that correlates with pain behavior in the rat. Brain Res $\underline{829}$, 209-221

Tao J, Van Esch H, Hagedorn-Greiwe M, Hoffmann K, Moser B, Raynaud M, Sperner J, Fryns JP, Schwinger E, Gécz J et al. (2004): Mutations in the X-linked cyclin-dependent kinase-like 5 (CDKL5/STK9) gene are associated with severe neurodevelopmental retardation. Am J Hum Genet $\underline{75}, 1149-1154$

Tao X, Finkbeiner S, Arnold DB, Shaywitz AJ, Greenberg ME (1998): $\mathrm{Ca}^{2+}$ influx regulates BDNF transcription by a CREB family transcription factor-dependent mechanism. Neuron $\underline{20}, 709-726$ 
Tchou J, Kasai H, Shibutani S, Chung MH, Laval J, Grollman AP, Nishimura S (1991): 8oxoguanine (8-hydroxyguanine) DNA glycosylase and its substrate specificity. Proc Natl Acad Sci U S A $\underline{88}, 4690-4694$

Thompson KJ, Shoham S, Connor JR (2001): Iron and neurodegenerative disorders. Brain Res Bull $\underline{55}, 155-164$

Thrasher AJ, Keep NH, Wientjes F, Segal AW (1994): Chronic granulomatous disease. Biochim Biophys Acta 1227, 1-24

Todorovic SM, Jevtovic-Todorovic V, Meyenburg A, Mennerick S, Perez-Reyes E, Romano C, Olney JW, Zorumski CF (2001): Redox modulation of T-type calcium channels in rat peripheral nociceptors. Neuron $\underline{31}, 75-85$

Trappe R, Laccone F, Cobilanschi J, Meins M, Huppke P, Hanefeld F, Engel W (2001): MECP2 mutations in sporadic cases of Rett syndrome are almost exclusively of paternal origin. Am J Hum Genet $\underline{68}$, 1093-1101

Triolo D, Dina G, Lorenzetti I, Malaguti M, Morana P, Del Carro U, Comi G, Messing A, Quattrini A, Previtali SC (2006): Loss of glial fibrillary acidic protein (GFAP) impairs Schwann cell proliferation and delays nerve regeneration after damage. J Cell Sci $\underline{119}$, 3981 3993

Tsukahara H: Oxidative Stress Biomarkers: Current Status and Future Perspective; In: Tsukahara H and Kaneko K (Hrsg.): Studies on Pediatric Disorders. Springer, New York 2014, 87-113

Tudor M, Akbarian S, Chen RZ, Jaenisch R (2002): Transcriptional profiling of a mouse model for Rett syndrome reveals subtle transcriptional changes in the brain. Proc Natl Acad Sci U S A $\underline{99}$, 15536-15541

Ullian EM, Sapperstein SK, Christopherson KS, Barres BA (2001): Control of synapse number by glia. Science 291, 657-661

Valacchi G, Virgili F, Cervellati C, Pecorelli A (2018): OxInflammation: from subclinical condition to pathological biomarker. Front Physiol ㅁ, 858

Valavanidis A, Vlachogianni T, Fiotakis C (2009): 8-hydroxy-2' -deoxyguanosine (8-OHdG): A critical biomarker of oxidative stress and carcinogenesis. J Environ Sci Heal C 27, 120-139

Valenti D, de Bari L, Vigli D, Lacivita E, Leopoldo M, Laviola G, Vacca RA, De Filippis B (2017): Stimulation of the brain serotonin receptor 7 rescues mitochondrial dysfunction in female mice from two models of Rett syndrome. Neuropharmacology 121, 79-88 
Valinluck V, Tsai HH, Rogstad DK, Burdzy A, Bird A, Sowers LC (2004): Oxidative damage to methyl-CpG sequences inhibits the binding of the methyl-CpG binding domain (MBD) of methyl-CpG binding protein 2 (MeCP2). Nucleic Acids Res $\underline{32}$, 4100-4108

Valko M, Morris H, Cronin MT (2005): Metals, toxicity and oxidative stress. Curr Med Chem 12, 1161-1208

Vann SD, Aggleton JP, Maguire EA (2009): What does the retrosplenial cortex do? Nat Rev Neurosci $\underline{10}, 792-802$

Vieira A, Steenken S (1987): Pattern of OH radical reaction with N6, N6-dimethyladenosine. Production of three isomeric $\mathrm{OH}$ adducts and their dehydration and ring-opening reactions. J Am Chem Soc 109, 7441-7448

Vieira A, Steenken S (1990): Pattern of hydroxy radical reaction with adenine and its nucleosides and nucleotides. Characterization of two types of isomeric hydroxy adduct and their unimolecular transformation reactions. J Am Chem Soc 112, 6986-6994

Villard L, Lévy N, Xiang F, Kpebe A, Labelle V, Chevillard C, Zhang Z, Schwartz CE, Tardieu M, Chelly J et al. (2001): Segregation of a totally skewed pattern of X chromosome inactivation in four familial cases of Rett syndrome without MECP2 mutation: implications for the disease. J Med Genet $\underline{38}$, 435-442

von Sonntag C (1987): New aspects in the free-radical chemistry of pyrimidine nucleobases. Free Radic Res Commun $\underline{2}$, 217-224

von Sonntag C (1991): The chemistry of free-radical-mediated DNA damage. Basic Life Sci $\underline{58}, 287-317$

Wake H, Moorhouse AJ, Jinno S, Kohsaka S, Nabekura J (2009): Resting microglia directly monitor the functional state of synapses in vivo and determine the fate of ischemic terminals. J Neurosci 29, 3974-3980

Wan M, Lee SS, Zhang X, Houwink-Manville I, Song HR, Amir RE, Budden S, Naidu S, Pereira JL, Lo IF et al. (1999): Rett syndrome and beyond: recurrent spontaneous and familial MECP2 mutations at CpG hotspots. Am J Hum Genet 65, 1520-1529

Weaving LS, Christodoulou J, Williamson SL, Friend KL, McKenzie OL, Archer H, Evans J, Clarke A, Pelka GJ, Tam PP et al. (2004): Mutations of CDKL5 cause a severe neurodevelopmental disorder with infantile spasms and mental retardation. Am J Hum Genet $\underline{75}$, 1079-1093 
Wegener E, Brendel C, Fischer A, Hülsmann S, Gärtner J, Huppke P (2014): Characterization of the MeCP2 R168X knockin mouse model for Rett syndrome. PLoS One $\underline{9}, \mathrm{e} 115444$

Weidemann A, König G, Bunke D, Fischer P, Salbaum JM, Masters CL, Beyreuther K (1989): Identification, biogenesis, and localization of precursors of Alzheimer's disease A4 amyloid protein. Cell $\underline{57}, 115-126$

Wiedenmann B, Franke WW (1985): Identification and localization of synaptophysin, an integral membrane glycoprotein of Mr 38,000 characteristic of presynaptic vesicles. Cell $\underline{41}$, $1017-1028$

Winkelstein BA, DeLeo JA (2002): Nerve root injury severity differentially modulates spinal glial activation in a rat lumbar radiculopathy model: considerations for persistent pain. Brain Res 므, 294-301

Wu LJC, Leenders AGM, Cooperman S, Meyron-Holtz E, Smith S, Land W, Tsai RYL, Berger UV, Sheng ZH, Rouault TA (2004): Expression of the iron transporter ferroportin in synaptic vesicles and the blood-brain barrier. Brain Res 1001, 108-117

Young JI, Hong EP, Castle JC, Crespo-Barreto J, Bowman AB, Rose MF, Kang D, Richman R, Johnson JM, Berget S et al. (2005): Regulation of RNA splicing by the methylationdependent transcriptional repressor methyl-CpG binding protein 2. Proc Natl Acad Sci U S A $\underline{102}, 17551-17558$

Yu BP (1994): Cellular defenses against damage from reactive oxygen species. Physiol Rev 74, 139-162 


\section{Danksagung}

An dieser Stelle möchte ich besonders meinem Doktorvater Prof. Dr. Michael Müller nicht nur dafür danken, dass er mir das Thema überlassen hat, sondern auch für seine überragende Unterstützung und Betreuung. Er hatte jeder Zeit ein offenes Ohr bei Fragen und Problemen und hat sich dadurch nie aus der Ruhe bringen lassen. Eine solcher Einsatz als Doktorvater ist im Bereich der medizinischen Promotionsvorhaben wohl einzigartig.

Außerdem gilt mein Dank auch Frau Belinda Kempkes, deren fachliches Wissen als technische Assistentin und herzliche Art ich immer geschätzt habe.

Weiterhin möchte ich Prof. Dr. Christine Stadelmann-Nessler und ihrer Arbeitsgruppe für die Herstellung der (immun-)histochemisch gefärbten Gewebeschnitte und für die stete fachliche Beratung danken.

Ich bedanke mich auch bei Prof. Dr. Ivan Bogeski, der sich bereit erklärt hat als Zweitgutachter nicht nur die fertige Dissertation zu bewerten, sondern auch den beiden Fortschrittsberichten beizuwohnen.

Ein besonderer Dank geht an meine Co-Doktoranden, vor allem Ina Dewenter und Stefanie Auel, die nicht nur für eine heitere Arbeitsatmosphäre gesorgt haben, sondern auch bei fachbezogenen Diskussionen immer hilfreiche Beiträge geleistet haben. 